0

A TWO-STEP APPROACH TO

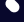

HYDROTHERMAL GASIFICATION

Varsha R. Paida

0

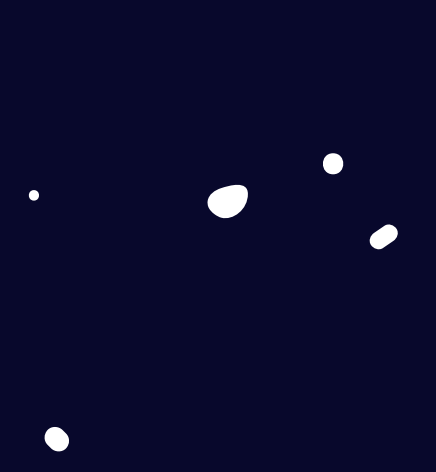

0 


\title{
A TWO-STEP APPROACH TO HYDROTHERMAL GASIFICATION
}

\author{
Varsha Reddy Paida
}





\title{
A TWO-STEP APPROACH TO HYDROTHERMAL GASIFICATION
}

\author{
DISSERTATION \\ to obtain \\ the degree of doctor at the University of Twente, \\ on the authority of the rector magnificus, \\ prof.dr. T.T.M. Palstra, \\ on account of the decision of the Doctorate Board, \\ to be publicly defended \\ on Friday, the $12^{\text {th }}$ of July 2019 at $16: 45$ hours
}

by

Varsha Reddy Paida

born on the $19^{\text {th }}$ of January 1989

in Chennai, India 


\section{This dissertation has been approved by:}

Supervisors: prof.dr. S.R.A. Kersten

dr. D.W.F. Brilman

This research has been carried out in the Sustainable Process Technology group at the University of Twente, the Netherlands. The work has been sponsored by ADEM Innovation Labs, a Green Deal in Innovative Energy Materials, under project number UT-P06.

Cover design: Tomas Olfos Vargas and Agostina Paola Alaniz Peña

Printed by: Gildeprint

Lay-out: Varsha R. Paida and Rens Veneman

ISBN: 978-90-365-4800-7

DOI: $10.3990 / 1.9789036548007$

(C) 2019 Enschede, the Netherlands. All rights reserved. No parts of this thesis may be reproduced, stored in a retrieval system or transmitted in any form or by any means without permission of the author. Alle rechten voorbehouden. Niets uit deze uitgave mag worden vermenigvuldigd, in enige vorm of op enige wijze, zonder voorafgaande schriftelijke toestemming van de auteur. 
GRADUATION COMMITTEE:

Chairman:

Secretary:

Supervisors:

Referee:

Members: prof.dr. J. L. Herek

prof.dr. J. L. Herek

prof.dr. S.R.A. Kersten

dr. D.W.F. Brilman

dr. A.G.J. van der Ham

prof.dr. H.W.J.P. Neomagus

prof.dr. W. de Jong

prof.dr. K. Seshan

prof.dr. G. Mul
University of Twente

University of Twente

University of Twente

University of Twente

University of Twente

North-West University

Delft University of Technology

University of Twente

University of Twente 


\section{Contents}

Samenvatting

viii

1

Introduction

1

2

Stabilisation of carbohydrates

11

Appendix A

35

3

Hydrothermal gasification of sorbitol 39

Appendix B

73 


\begin{tabular}{l|lr}
\hline 4 & $\begin{array}{l}\text { Sequential Pt-Ru catalysts for } \\
\text { increased productivity }\end{array}$ & 79 \\
Appendix C & 92 \\
5 & $\begin{array}{l}\text { Process design and Economic } \\
\text { evaluation }\end{array}$ & 95 \\
Appendix D & 124 \\
Conclusions & \\
& Nomenclature & 143
\end{tabular}




\section{Samenvatting}

Fossiele brandstoffen hebben niet alleen een eindig karakter, het gebruik er van heeft nog andere belangrijke nadelen waaronder de antropogene $\mathrm{CO}_{2}$-uitstoot en de daaraan gelinkte klimaatverandering, alsmede zorgen over energie zekerheid en mogelijk politieke spanningen. Dit heeft geleid tot een zoektocht naar hernieuwbare brandstoffen om zo onze de afhankelijkheid van fossiele brandstoffen te minimaliseren, of beter nog, te elimineren. Biomassa speelt, samen met andere bronnen van hernieuwbare energie, een belangrijke rol in de energie transitie van fossiele brandstoffen naar hernieuwbare brandstoffen en heeft de potentie om het gebruik van elektriciteit, warmte en transportbrandstoffen significant te verduurzamen en de $\mathrm{CO}_{2}$ concentratie in de atmosfeer te stabiliseren.

Dit proefschrift richt zich op het ontwerp en de ontwikkeling van een proces om "natte" biomassa stromen om te zetten in hernieuwbaar waterstofgas. Natte biomassa stromen, zoals afvalwaterstromen uit de voedselindustrie of de agrarische sector bevatten meer dan $80 \%$ water op gewichtsbasis. Om te voorkomen dat deze biomassastromen eerst gedroogd moet worden, zoals dat in traditionele processen het geval is, is er in dit proefschrift gekeken naar een relatief nieuw type proces waarin water gebruikt wordt als reactie medium. Hydrothermale processen kunnen biomassa omzetten in kool, bio olie en gas vormige producten, afhankelijk van de condities, naast in water opgeloste componenten. Het proces dat in dit proefschrift is onderzocht is een katalytisch tweestaps proces voor hydrothermale vergassing met simultane verwijdering van organisch materiaal uit de afvalwaterstromen.

In Hoofdstuk 1 is de relevante achtergrondinformatie over het omzetten van natte biomassastromen behandeld gevolgd door een beschouwing van de voornaamste uitdagingen in het veld van hydrothermale vergassing. Aan het eind van het hoofdstuk is de structuur van het proefschrift besproken.

Het eerste deel van dit proefschrift (Hoofdstuk 2 en 3) richt zich op het verkrijgen van meer fundamenteel inzicht op het gebied stabilisatie en vergassing, de twee hoofdstappen in het beoogde proces.

Stabilisatie, uitgevoerd met een $5 \mathrm{wt} \% \mathrm{Ru}-\mathrm{C}$ katalysator en besproken in Hoofdstuk 2, is toegepast om de hoog reactieve suikers en koolwaterstoffen om te zetten naar stabielere verbindingen om zo de teer- en kool formatie te minimaliseren of te voorkomen in de vervolg stappen van het proces. Hier is gebleken dat de hydrolyse is de snelheidsbepalende stap is onder de experimentele condities, ongeacht het type biomassa dat in de experimenten gebruikt is. 
Het vergassen van gestabiliseerde monsters resulteert in minimale hoeveelheden afgezet koolstof op de katalysator. De efficiëntie van koolstofvergassing en de $\mathrm{H}_{2}$ opbrengsten van de gestabiliseerde monsters zijn vergelijkbaar gebleken met die van gestabiliseerd sucrose en gestabiliseerd glucose. De afwezigheid van oligosachariden, zoals bepaald door middel van HPLC, toont het succes van de stabilisatie stap aan. De afwezigheid van kleurvorming in het product tijdens vergassing bevestigt dit verder. Er is een vereenvoudigd mathematisch model ontwikkeld, waarin temperatuur effecten zijn meegenomen, om de snelheid van het sucrose stabilisatieproces te beschrijven.

In Hoofdstuk 3 is de vergassingsstap besproken. Sorbitol, een C6 suikeralcohol afgeleid van glucose, is hiervoor als model component geselecteerd. De hydrothermale vergassing van sorbitol is onderzocht in de aanwezigheid van een katalysator bestaande uit $5 \mathrm{wt} \% \mathrm{Pt}$ op $\gamma-\mathrm{Al}_{2} \mathrm{O}_{3}$ met en zonder de aanwezigheid van stikstof gas als stripgas. Het hoofddoel van het proces is het optimaliseren van de $\mathrm{H}_{2}$-opbrengst bij een hoge koolstofvergassingsefficiency. Dit is een uitdaging omdat bij de vergassing van sorbitol de selectiviteit naar $\mathrm{H}_{2}$ laag is. Het gebruik van $\mathrm{N}_{2}$ als stripgas blijkt de $\mathrm{H}_{2}$ opbrengst te verbeteren, zonder dat dit de efficiëntie van de koolstofvergassing negatief beïnvloed.

Er is een reactor model ontwikkeld dat zowel het massa transport als de reactiekinetiek beschrijft. Het complexe reactiemechanisme is beschreven aan de hand van een vereenvoudigd kinetiek schema met geclusterde reacties. Dit reactor model, gevalideerd aan de hand van laboratorium experimenten, is vervolgens gebruikt om de technische haalbaarheid van het proces op een industriële schaal aan te tonen. Uit de studie blijkt dat verhoogde $\mathrm{H}_{2}$-opbrengsten haalbaar zijn in reactoren met goede gas-vloeistof stoftransport karakteristieken (hoge $k_{L} a$ ), in combinatie met de in-situ verwijdering van de gevormde $\mathrm{H}_{2}$ door middel van een stripgas of een membraan. Het tweede deel van dit proefschrift bevat werk gericht op verdere procesontwikkeling. Hierin is onderzocht of het proces haalbaar is voor implementatie op grote(re) schaal. Het gebruik van twee gekatalyseerde vergassingsstappen in serie, de eerste met Pt en de tweede met $\mathrm{Ru}$, heeft twee voordelen. De hoge selectiviteit naar $\mathrm{H}_{2}$ die Pt biedt, in combinatie met de hoge reactiviteit van Ru voor koolstof-vergassing blijkt veelbelovend, vooral bij hoge doorzetten (hoge WHSV). Op industriële schaal biedt een hogere WHSV namelijk de mogelijkheid om de procesapparatuur te verkleinen bij lagere katalysator beladingen, hetgeen tot lagere kosten leidt. De combinatie van Pt en Ru in serie, zoals beschreven in Hoofdstuk 4, resulteert in een attractief industrieel proces voor simultaan $\mathrm{H}_{2}$ productie en koolstofvergassing. Dit biedt mogelijkheden, niet alleen met het oog op waterstof productie maar ook met het oog op afvalwaterzuivering. 
De ontwikkelde stabilisatie- en vergassingsmodellen zijn vervolgens gebruikt om een ontwerp te genereren voor het proces op industriële schaal. Dit is besproken in hoofdstuk 5. De energiebalans van het proces laat zien dat het geproduceerde $\mathrm{H}_{2}$ gas en de restgassen beiden ongeveer $35 \%$ van de energie-inhoud van het afvalwater bevatten. De overige energie die geproduceerd wordt (35 $\%$ ) wordt gebruikt om het proces zelf te voorzien van elektriciteit, stoom en warmte. De totale energie efficiëntie van het proces is dus ca. $70 \%$.

Om de minimale $\mathrm{H}_{2}$ verkoopprijs te bepalen is er een economische analyse uitgevoerd. De minimale $\mathrm{H}_{2}$ verkoopprijs bleek vergelijkbaar met die voor andere hernieuwbare processen. Zowel de concentratie, de hoeveelheid als de kostprijs van de grondstof hebben echter een sterke invloed op deze minimale $\mathrm{H}_{2}$ verkoopprijs. Het is dus essentieel om voor een beoogde grondstof (natte biomassa) de ontwikkelde economische analyse te gebruiken om de toepasbaarheid van deze technologie voor het specifieke geval te evalueren.

De hoofdconclusies van dit proefschrift zijn in Hoofdstuk 6 besproken. Daarnaast bevat dit hoofdstuk een nadere beschouwing van de toekomstige toepasbaarheid van deze technologie. 


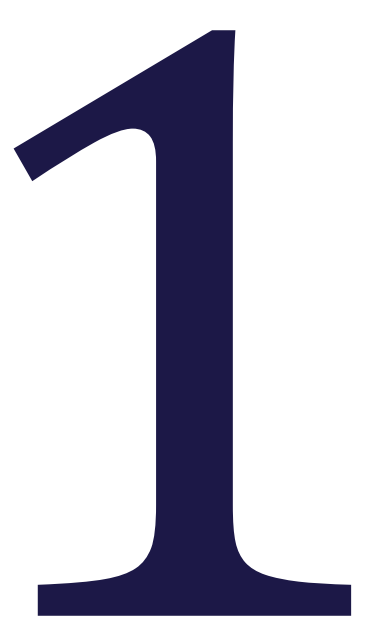

\section{Introduction}


2| Chapter 1 


\subsection{The current energy scenario}

In 2017, the world primary energy consumption reached 13,511 million tons of oil equivalent, growing at an average rate of $1.5 \%$ between 2007 and 2017 [1]. Of this, oil, natural gas and coal accounted for $34 \%, 23 \%$ and $28 \%$ respectively. Aside from fossil fuels being a finite source of energy, they present other significant disadvantages including anthropogenic $\mathrm{CO}_{2}$ emission concerns held responsible for global warming, as well as energy security concerns leading to political tensions. This has motivated the search for renewable sources of energy in order to minimise, and hopefully eliminate, society's dependence on fossil fuels. Short-term and longterm policies have been set by governments in order to reach this goal. For example, through the 'Energy Roadmap 2050', the EU aims to reduce greenhouse gas (GHG) emissions to 80-95 $\%$ below 1990 levels [2]. The key objective in achieving this target is the decarbonisation of the energy system. Gradual decarbonisation can be achieved by increasing the share of low-carbon energy sources, through the use of renewables, by increasing energy efficiency of existing systems leading to reduced growth in the energy demand, as well as by capping GHG emissions from fossil fuel power stations through carbon capture and storage (CCS).

\subsection{Biomass valorisation}

In addition to other renewable sources of energy, biomass plays a vital role as a renewable feedstock, with potential to replace fossils for the production of electricity, heat and transportation. Biomass, being a major source of carbon, is attractive specifically in the transport sector, where alternative fuels are needed to replace fossil based oils, and in the production of plant-based equivalents of important petro-chemicals. Additionally, replacement of fossil fuels by renewable biomass can contribute to stabilising atmospheric $\mathrm{CO}_{2}$ concentrations. The production of biofuels initially began with edible biomass resources, i.e., from sugars and oils in food crops, leading to a debate on 'food vs. fuel' [3]. Perennial crops that do not compete with food were therefore considered for the production of bioenergy, leading to the production of second-generation biofuels. Such crops (ligno-cellulosic biomasses) include plant materials such as trees and grass, as well as waste biomass residues from agriculture and forestry.

The production of bioenergy can also be achieved from processes based on wet biomasses (biomasses with over $80 \%$ moisture), such as bio-wastes from the food and agro-industries. Such biodegradable wastes present the potential to produce energy, while also increasing net GHG savings. 


\subsubsection{Ligno-cellulosic biomass}

Ligno-cellulosic biomass comprises of three main polymeric units; cellulose, hemi-cellulose and lignin. Depending on the type, species, and source of biomass, these polymers are present in varying compositions, and are associated with each other to different degrees in a matrix. In addition to these three polymers, ligno-cellulosic biomass also contains smaller quantities of pectin, protein, extractives and ash [4]. The complex nature of ligno-cellulosic biomass leads to higher processing costs in comparison to simpler and readily degradable edible biomass. The first step in the processing of ligno-cellulosic biomasses is therefore often a pre-treatment, in order to breakdown the matrix and make the cellulose and hemi-cellulose more accessible for further conversions.

\subsubsection{Renewable hydrogen from biomass}

Hydrogen is an industrially important chemical and feedstock. At present, over $95 \%$ of the world's hydrogen is produced from fossil fuels [5]. In the transition towards a decarbonised energy system, fossil hydrogen will be replaced by green hydrogen, produced sustainably from renewable sources. Currently, $4 \%$ of the world's hydrogen is produced by electrolysis, making it the only renewable route with a significant contribution. However, the electricity used for electrolysis is still largely fossil based, making the overall process carbon intensive. Although hydrogen from biomass currently accounts for less than $1 \%$ of the total hydrogen produced, biomass-derived hydrogen is sustainable as it leads to carbon-neutral (and potentially carbon-negative) emissions. There is therefore much opportunity for the production of renewable hydrogen from biomass, specifically biomass-derived wastes.

\subsection{Wet biomass processing}

Wet biomasses are renewable sources containing high moisture contents (80 - $90 \mathrm{wt} \%$ ). Typical biomass processing technologies such as gasification and pyrolysis are based on dry biomasses. Such technologies cannot be utilised for processing wet biomasses without an additional drying step prior to processing, in order to remove the moisture of the stream. This is energy intensive, and the process energy requirement exceeds that which is obtainable from the stream. A different approach is to utilise the water present in the stream for the conversion process. Such processes are hydrothermal in nature.

There are two main routes for the conversion of wet biomasses, as depicted in Figure 1.1; biological and thermo-chemical. In biological pathways, enzymes and micro-organisms are used to breakdown organic matter to produce valuable gases or fuels. 
Anaerobic digestion, for example, is typically used for the processing of wet biomass wastes including sewage sludge, cattle manure and food wastes. Both routes present advantages and pitfalls, and significant R\&D efforts need to be demonstrated before they can be compared accurately [6]. The focus of this research is on one of the thermo-chemical routes for the conversion of wet biomass.

Thermo-chemical routes for hydrothermal processing of biomasses fall into three main categories, based on the desired product to be obtained. Hydrothermal carbonisation is the conversion into solid carbon, referred to as hydrochar. Hydrochar, a rich source of carbon, has applications in the field of soil amendment, as a solid fuel and adsorbent [7]. Liquefaction refers to the conversion of biomass primarily to a liquid product, referred to as bio-crude. Bio-crude can be further upgraded to produce liquid fuels [8]. Gasification is the conversion of biomass to valuable gases, primarily $\mathrm{H}_{2}$, and $\mathrm{CH}_{4}$. Depending on the temperature range of operation, hydrothermal gasification can further be broken down into the technologies, briefly described below.

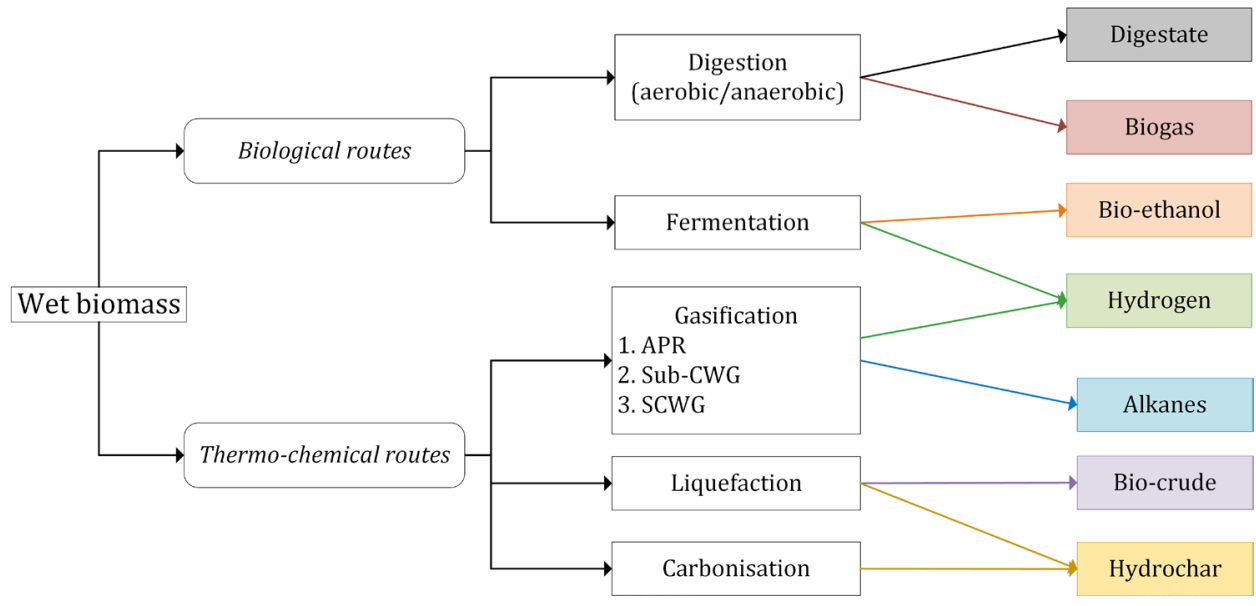

Figure 1.1: Processing routes for wet biomass conversion

\subsubsection{Aqueous phase reforming}

Aqueous phase reforming (APR) is a catalytic hydrothermal process that utilises low temperatures $\left(180-280^{\circ} \mathrm{C}\right)$ in order to convert biomass oxygenates to $\mathrm{H}_{2}$. APR is a young technology, introduced by Dumesic et al. in 2002 [9], with the primary objective to decrease the energy consumption of high temperature hydrothermal processes. Studies with biomass derived model compounds containing a stoichiometric ratio of C:0 of 1:1 (sugars and alcohols) showed that comparable to steam reforming, at low temperatures, $\mathrm{H}_{2}$ and $\mathrm{CO}$ can be produced over a suitable catalyst. By utilising pressures above the saturation pressure of water, water in liquid form participates 
in a low-temperature WGS shift reaction, to convert $\mathrm{CO}$ produced via reforming to $\mathrm{CO}_{2}$, thereby producing $\mathrm{H}_{2}$. The overall reaction can be expressed as follows:

$$
\mathrm{C}_{x} \mathrm{H}_{y} \mathrm{O}_{z}+(2 x-z) \mathrm{H}_{2} \mathrm{O} \rightarrow\left(2 x+\frac{y}{2}-z\right) \mathrm{H}_{2}+x \mathrm{CO}_{2}
$$

While APR had many advantages compared to traditional hydrothermal gasification processes, such as the absence of $\mathrm{CO}$ production, higher $\mathrm{H}_{2}$ selectivity and low energy requirements, studies have been limited to model compounds as feedstock and catalyst development to increase hydrothermal stability. Challenges hindering the commercial application of APR include low hydrolysis and reforming activity at low temperatures, low feed concentrations (1-2 wt \%) required for high $\mathrm{H}_{2}$ selectivity and increasing the catalyst affordability by moving from noble metal catalysts towards base metals [10].

\subsubsection{Supercritical water gasification}

The utilisation of the properties of water in its supercritical state for the gasification of biomass compounds to $\mathrm{H}_{2}$ was the pioneering work of Antal et al. [11]. While the formation of pyrolytic char and tar during steam reforming of biomass limited gasification efficiencies, supercritical conditions (temperatures $>600{ }^{\circ} \mathrm{C}$ ) were found to convert the char into combustible gases including $\mathrm{H}_{2}, \mathrm{CH}_{4}, \mathrm{CO}_{2}$ and CO. Higher temperatures $\left(600-800{ }^{\circ} \mathrm{C}\right)$ were found to favour the methane steam-reforming reaction, resulting in the production of a hydrogen-rich gas. Studies in the field of SCWG have been conducted for varying biomass components including cellulose, hemi-cellulose, lignin, proteins, lipids [12], and varying biomass such as sewage sludge, olive mill wastewater, wine distillery wastes, and algae [13]. Despite its advantages, SCWG has not yet been able to enter the market as a competitive technology for $\mathrm{H}_{2}$ production because it is an expensive technology. Extensive corrosion of material leads to the requirement of expensive materials for construction of reactors [14]. Additionally, the necessity for high temperatures makes the process less energy efficient. The use of catalysts at lower temperatures $\left(\sim 400^{\circ} \mathrm{C}\right)$ was found to enhance reaction rates. The use of bi-metallic and base metal catalysts to increase their affordability was also studied $[15,16]$. However, the catalysts were prone to deactivation problems [17] due to coking. Coke production was also found to cause plugging of reactor tubes.

\subsubsection{Sub-critical gasification}

The use of heterogeneous catalysts in wet biomass processing allowed effective operation at lower temperatures. Research conducted at the Pacific Northwest Laboratory (PNNL) in the early $1990^{\prime}$ 's [18] demonstrated that low-temperature $\left(\sim 350^{\circ} \mathrm{C}\right)$ high-pressure $(200 \mathrm{bar})$ systems using noble and base metal catalysts had the economic potential to convert wet biomasses to methane.

\section{6 | Chapter 1}


Studies focussed on the development of long-term stable catalysts found that Ni catalysts lost activity due to crystallite growth and loss of surface area, while noble metals such as $\mathrm{Ru}$ and $\mathrm{Rh}$ presented better stability. Further work in the next decade included process development from batch to continuous flow reactor tests as well as catalyst development for activity and support stability. Stable support materials tested in hydrothermal environments were found to be monoclinic zirconia, rutile titania and carbon. Carbon supported ruthenium was found to be a highly active and stable catalyst for the complete carbon gasification of $10 \mathrm{wt} \%$ phenol solutions to $\mathrm{CH}_{4}$ and $\mathrm{CO}_{2}[19]$.

\subsection{Challenges in hydrothermal gasification}

While the aforementioned technologies of hydrothermal gasification have all been utilised for different biomasses and present unique advantages, there are some key issues that they have in common. The challenges pertaining to the scope of the thesis are outlined here.

\subsubsection{Production of undesired solid by-products}

The production of undesired solid by-products has been inevitable in the processing of biomass. The production of char, coke and tar during gasification reduces potential gasification efficiencies. Char is formed by the direct conversion of a solid biomass particulate that is incompletely liquefied, thus partially retaining its original morphology [20]. Coke, on the other hand, is formed by dissolved intermediates that undergo further condensation and polymerisation reactions, producing porous microspheres [21]. Coke produced from conversion of sugars were found to be insoluble in water and organic solvents and very stable under hydrothermal conditions. Tar represents molecules with high molecular weight that are insoluble in water but soluble in organic solvents such as acetone.

Dedicated studies on the characterisation of these products formed during hydrothermal gasification of glucose [22], cellulose [23-25] and other compounds [26, 27] are present in literature. One of the key findings was that $5-\mathrm{HMF}$, an intermediate produced from the dehydration of C6 sugars, was a precursor to coke formation [28].

In the field of dry biomass gasification, tar removal could be accounted for in-situ (primary methods) through the use of additives/catalysts during operation, or by adequately controlling process operation parameters. Additionally, post-gasification methods (secondary methods) include physical cleaning, partial oxidation and thermal cracking [29].

Fewer studies have focussed on reducing or eliminating these unwanted solid by-products associated with hydrothermal gasification reactions. Under supercritical conditions, it was found that carbon gasification increased with faster heating rates, thereby reducing coke formation [30]. 
This finding led to the development of innovative solutions for rapid heating rates, or post-critical feed injection and mixing strategies $[12,31]$. However, additional challenges associated with the design of a post-critical mixing section, such as variation in mixing profiles, led to discrepancies in reaction rates. Reactor design considerations in order to remove solids from the gasification environment include a down-flow reactor, a feature of the VERENA plant [32], in which coke and salt precipitates accumulated at the bottom of the reactor, avoiding downstream plugging.

Tests were also conducted for particle separation in supercritical environment using a hydrocyclone with separation efficiencies ranging from 80-99 \% [33].

The use of active catalysts was also found to reduce coke formation in supercritical conditions [34]. Osada et al. [35] gasified organosolv lignin and cellulose at $400{ }^{\circ} \mathrm{C}$ using $\mathrm{Ru}-\mathrm{TiO}_{2}$ and no char was formed. $\mathrm{Ru}-\mathrm{TiO}_{2}$ also presented good stability under hydrothermal conditions, making it a potential catalyst for hydrothermal gasification. Waldner et al. [36] demonstrated in batch experiments that in order to avoid secondary reactions to form tars and coke, a catalyst active at low temperatures $\left(\sim 250^{\circ} \mathrm{C}\right)$ must be used.

\subsubsection{Hydrogen production vs carbon gasification}

The production of $\mathrm{H}_{2}$ from hydrothermal biomass gasification processes has been studied for both SCWG and APR. Under SCWG conditions, high temperatures $\left(>600{ }^{\circ} \mathrm{C}\right)$ are required for $\mathrm{H}_{2}$ production to be thermodynamically favourable. The requirement for less energy intensive processes led to the utilisation of catalysts at lower supercritical, sub-critical and APR conditions. The production and development of hydrothermally stable and affordable catalysts that show high selectivity towards $\mathrm{H}_{2}$ production has been a subject of numerous studies. In the field of APR, noble metal catalysts were used for studies on biomass-derived alcohols [37, 38]. Among noble metals, Pt consistently demonstrated higher $\mathrm{H}_{2}$ selectivity in comparison to other Group VIII metals including Pd, Ru, Rh, Ni and Ir. This led to the development of bi-metallic Pt catalysts [39] and Ni-based catalysts, such as a Sn-Raney-Ni catalyst [40], in search for more affordable catalysts that present high $\mathrm{H}_{2}$ selectivity.

A number of conditions were found to hinder the $\mathrm{H}_{2}$ selectivity from biomass oxygenates via APR. Some of these include feedstock considerations, such as the reduced $\mathrm{H}_{2}$ selectivity obtained with increasing feedstock concentrations, conversions, and increasing carbon number of the feed, as well as operating conditions, such as reduced $\mathrm{H}_{2}$ selectivity at higher system pressures and higher temperatures [37]. In spite of the application of catalysts aimed at high $\mathrm{H}_{2}$ selectivity, the use of low reforming temperatures led to low $\mathrm{H}_{2}$ productivities. 
Additionally, low conversions meant that unconverted carbon fractions with the potential for energy production were left unrecovered in the aqueous stream, making the prospects of APR for the production of $\mathrm{H}_{2}$ from wet biomass undesirable.

The utilisation of catalysts in hydrothermal gasification to achieve complete carbon gasification of aqueous waste streams is not a new field of study. At sub-critical temperatures $\left(\sim 350^{\circ} \mathrm{C}\right)$, over $98 \%$ carbon gasification was achieved using Ru catalysts with wet biomasses including manure and distillery wastes $[41,42]$, producing $\mathrm{CH}_{4}$ and $\mathrm{CO}_{2}$. The technology was found to be a means of recovering useful energy from aqueous organic streams.

\subsection{Scope and outline}

This thesis deals with the design and development of a two-step process for the conversion of aqueous biomass streams and/or carbohydrate-rich aqueous wastes and wastewaters, primarily to $\mathrm{H}_{2}$. The requirement for the two-step approach to hydrothermal gasification arose in order to tackle the coking tendencies of carbohydrates in hot water, as discussed previously. The formation of coke was associated with reduced energy efficiencies, since a large fraction of the carbon was lost to a solid phase that by itself, presented a low calorific value. The constant production of coke in biomass processing also led to deactivation of catalysts and plugging of reactor tubes. Unless solid coke was the desired product of the process, minimizing or eliminating its production is one of the biggest challenges faced in the field of biomass conversion processes.

The potential of biomass derived molecules to be converted to more stable molecules that do not experience such coking tendencies was first studied in the field of pyrolysis oil upgrading [43]. This process, termed stabilisation, was a catalytic hydrotreating step analogous to hydrotreating steps used in conventional fossil-based processes. Stabilisation involved the treatment of highly reactive molecules with $\mathrm{H}_{2}$ at low temperatures and sufficient pressures, converting them to more stable molecules via hydrolysis, hydrogenation and hydrogenolysis reactions. For example, sugars can easily be hydrogenated to sugar alcohols.

In this thesis, it is hypothesised that the application of stabilisation to wet biomasses and wastes rich in carbohydrates prior to hydrothermal gasification will increase gasification efficiencies by minimising, if not eliminating, coke formation typically associated with biomass derived monoand polysaccharides. The main research objective was to determine if stabilisation could only be utilised for the conversion of monosaccharides to stable alcohols, or if it could also be applied to polysaccharides derived from biomass. Therefore, the stabilisation of increasingly complex feedstock is investigated, the results of which are presented in Chapter 2. Additionally, a simple mathematic model is developed in order to describe the stabilisation of sucrose, one of the studied feeds. 
While high $\mathrm{H}_{2}$ yield under APR conditions and high carbon gasification under sub-critical conditions have both been achieved in the past, these results have been mutually exclusive. Optimising $\mathrm{H}_{2}$ production at high carbon gasification conditions was therefore the main research objective in this work. This investigation, described in Chapter 3, was conducted using sorbitol, a stabilised sugar derived from glucose, and included temperature ranges of both APR and subcritical conditions $\left(270-350{ }^{\circ} \mathrm{C}\right)$. $\mathrm{Pt}_{-} \mathrm{Al}_{2} \mathrm{O}_{3}$, a benchmark catalyst for $\mathrm{H}_{2}$ production, was utilised. $\mathrm{N}_{2}$ was used as a stripping agent to provide deeper insight into the influence of kinetics and mass transfer on the production of $\mathrm{H}_{2}$. In order to describe the experimental findings, a temperaturedependent, path-lumped kinetic and mass transfer model is developed.

One of the main challenges involved in taking the process from lab to industrial scale is to improve the productivity, of both $\mathrm{H}_{2}$ and carbon gasification. This is addressed by using a novel sequential combination of catalysts, Pt and $\mathrm{Ru}$. It is proposed that the collaboration between a Pt catalyst that presents a high selectivity to $\mathrm{H}_{2}$ production, and a $\mathrm{Ru}$ catalyst that presents high activity for carbon gasification would improve $\mathrm{H}_{2}$ productivity and carbon gasification at higher space velocities. These results, reported in Chapter 4, could open doors for potential applications of the two-step approach not only in the waste-to-energy sector, but also in the field of wastewater treatment.

Based on experimental results, the two-step approach is conceptually applied on industrial scale by conducting a process design and economic evaluation, described in Chapter $\mathbf{5}$. A basis of 200 tons $\mathrm{h}^{-1}$ of 10 wt \% carbohydrate-rich wastewater is considered. A minimum $\mathrm{H}_{2}$ selling price is calculated using a discounted cash flow analysis at zero NPV. Different cases are considered, including the use of dual Pt and Ru gasification catalysts on the minimum $\mathrm{H}_{2}$ selling price in comparison to a single Pt gasification reactor. The influence of key parameters is studied using a sensitivity analysis. The minimum $\mathrm{H}_{2}$ selling price is also compared to the price of $\mathrm{H}_{2}$ obtained from other renewable production technologies.

The main conclusions and implications from the thesis are summarised in Chapter 6. In addition, a perspective is presented, considering current industries wherein this technology could be incorporated, as well as potential applications for the future. 


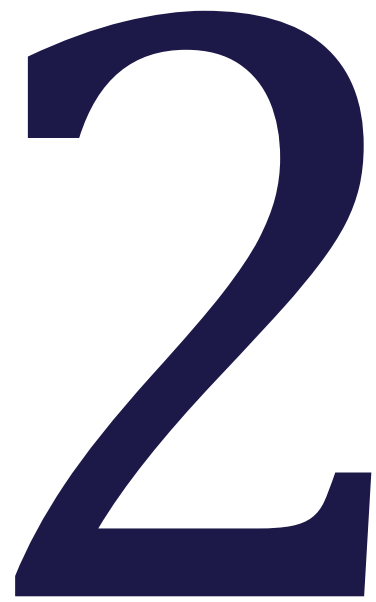

\section{Stabilisation of}

\section{carbohydrates}

This chapter has been adapted from the following publications:

V.R. Paida, S.R.A. Kersten, D.W.F. Brilman, Hydrothermal gasification of sucrose, Biomass and Bioenergy, 126

(2019) 130-141.

V.R. Paida, S.R.A. Kersten, A.G.J. van der Ham, D.W.F. Brilman, A two-step approach to hydrothermal gasification: Process design and Economic evaluation (submitted). 


\section{Abstract}

The concept of stabilisation as a hydrotreating step for biomass derived polysaccharides is studied using a 5 wt \% Ru-C catalyst and sucrose, starch and sugar beet pulp as feedstock. Complete conversion of sucrose was achieved at low temperatures $\left(100-140{ }^{\circ} \mathrm{C}\right)$ and WHSVs of $7-80 \mathrm{~h}^{-1}$. A mathematical model was developed to describe the reaction kinetics of sucrose stabilisation under the studied conditions. Higher temperatures $\left(200-240{ }^{\circ} \mathrm{C}\right)$ were required in order to completely breakdown starch and sugar beet pulp at WHSVs of $10-40 \mathrm{~h}^{-1}$. It was found that under sufficient $\mathrm{H}_{2}$ pressure, the hydrolysis of starch occurred orders of magnitude slower than the catalytic hydrogenation of glucose to sorbitol, making it the limiting step of the stabilisation process. The presence of excess $\mathrm{H}_{2}$ resulted in its consumption in catalytic hydrogenolysis reactions, breaking down sorbitol to smaller polyols and ultimately producing $\mathrm{CH}_{4}$. Studies with different feedstock illustrate that stabilisation has potential as a promising pre-treatment step for coking feeds such as sugars and carbohydrates in hot compressed water.

Aqueous carbohydrates

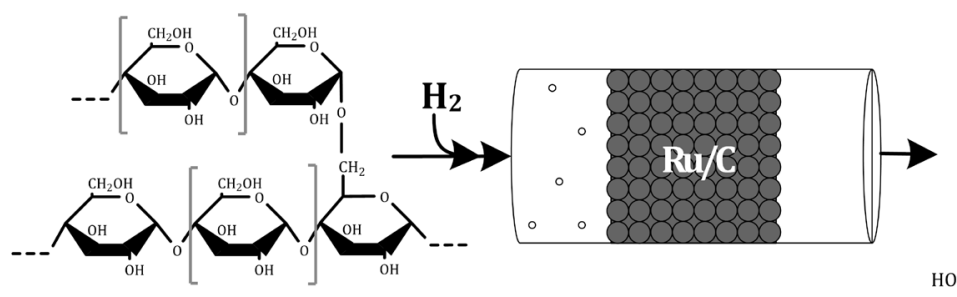

Stable alcohols<smiles>OC[C@@H](O)[C@@H](O)[C@H](O)[C@H](O)CO</smiles><smiles>CC(O)CO</smiles> 


\subsection{Introduction}

As introduced in Chapter 1, while the hydrothermal gasification of numerous wet biomasses has successfully been achieved [18], an issue with the gasification of sugars derived from biomass at sub-critical temperatures is the production of coke, which leads to lower gas yields $[44,45]$. In the proposed two-step process, this problem is circumvented by utilising a pre-treatment step called stabilisation prior to gasification in order to convert sugars to more stable sugar alcohols, making them less prone to form coke. Stabilisation, a low temperature hydrotreating step, has been studied extensively in the upgrading of pyrolysis oils derived from biomass [43, 46]. Stabilisation was introduced in order to reduce the reactivity towards polymerisation and condensation reactions, that lead to coking and plugging of reactor lines. In the field of pyrolysis, stabilisation involved hydrogenation, hydrogenolysis and hydrodeoxygenation (HDO) type reactions.

In this chapter, stabilisation in hot compressed water as a catalytic pre-treatment step prior to hydrothermal gasification is studied. It is envisioned that this step will be useful for highly coking feeds such as carbohydrates, as depicted in Figure 2.1. During stabilisation of sugars, in the presence of hydrogen and a suitable catalyst, hydrogenation and hydrogenolysis reactions occur that produce sugar alcohols. Both hydrogenation of sugars to sugar alcohols [47-55] and polyol hydrogenolysis [56-58] have been studied extensively in previous work. Sugar hydrogenation involves the addition of hydrogen to the hemiacetal or hemiketal in the ring of the sugar molecule, and proceeds at mild conditions $\left(80-120^{\circ} \mathrm{C}\right)$ in the presence of a catalyst. Extensive kinetic data are available on the hydrogenation of C5 and C6 sugars, such as xylose, glucose and fructose over Ru [49, 52, 59, 60], Ni [51, 61-64] and Rh [50] catalysts. Polyol hydrogenolysis typically requires more severe conditions than hydrogenation, and involves hydrogen enabled C-C and C-O cleavage reactions, breaking larger polyols to smaller polyols. The hydrogenolysis of glycerol and sorbitol to glycols has been extensively studied at temperatures of $160-260{ }^{\circ} \mathrm{C}$ using $\mathrm{Ni}$, $\mathrm{Cu}$ and $\mathrm{Ru}$ catalysts [65].

Fewer studies on the one-pot hydrolytic hydrogenation of polysaccharides are present. Studies with polysaccharides such as starch and cellulose suggest a step-wise process involving hydrolysis to glucose prior to catalytic hydrogenation to sorbitol, or hydrogenolysis to smaller polyols depending on the targeted liquid product [65].

In this work, the selectivity to a specific polyol is not of major concern since the polyols are further gasified. The potential of a one-pot stabilisation step to handle more complex feedstock is explored in this chapter. 


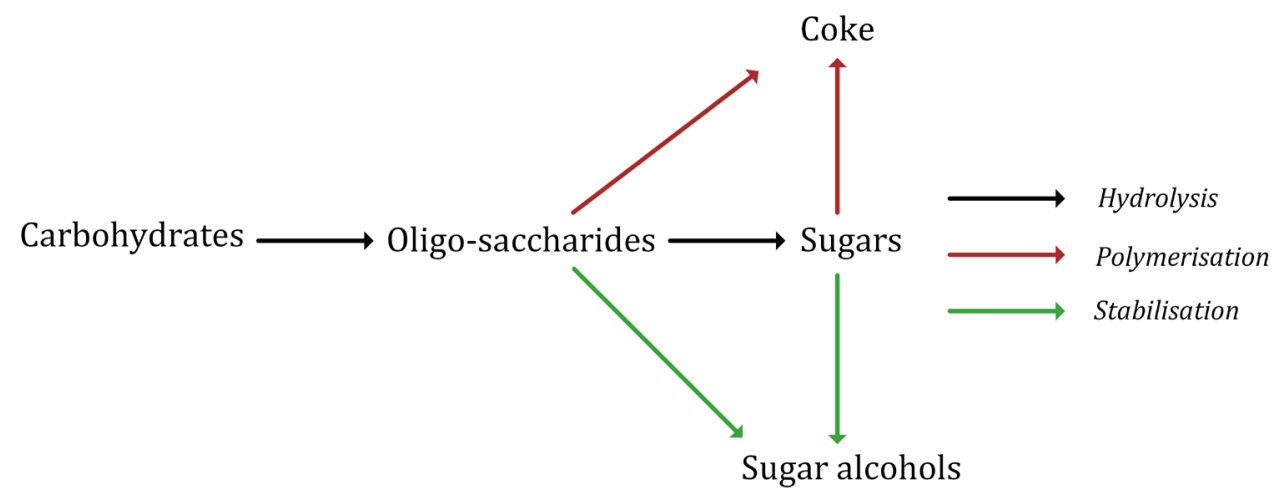

Figure 2.1: Possible transformations of carbohydrates in hot compressed water

\subsection{Feedstock}

Table 2.1 provides the composition of industrial wastes and wastewater streams that contain high fractions of carbohydrates. The two-step approach would be appropriate for such streams from the food and sugar industries. Model compounds such as monosaccharide sugars and sugar alcohols have been extensively studied.

While most studies have been focussed on model compounds, a step in moving from model compounds towards the industrially relevant feedstock listed in Table 2.1 is to increase feedstock complexity. Accordingly, three types of feedstock were evaluated in this study: sucrose, starch and sugar beet pulp. Sucrose was selected as a model compound representing sugars and short-chain oligosaccharides. Starch is a polysaccharide consisting of glucose monomers connected via alphalinkages. Starch is present in a number of food and agricultural wastewaters, for instance, corn, potato and wheat industry wastewaters. Wastewaters from potato processing plants contain high concentration of starch and proteins in addition to high COD (1000 - $8000 \mathrm{mg} \mathrm{L}^{-1}$ ) (Refer Table 2.1). Sugar beet pulp was selected as a real biomass feed due to its high hemi-cellulose and cellulose fractions and lower lignin content [66]. Table 2.2 provides the ultimate analysis of all the feedstock.

The rationale for the choice of feedstock for this study was to determine whether catalytic stabilisation in hot compressed water could directly be applied to polysaccharides, i.e, as a hydrolytic hydrogenation step, or if it could only be applied to monomeric sugars post hydrolysis, i.e, as a hydrogenation step. 


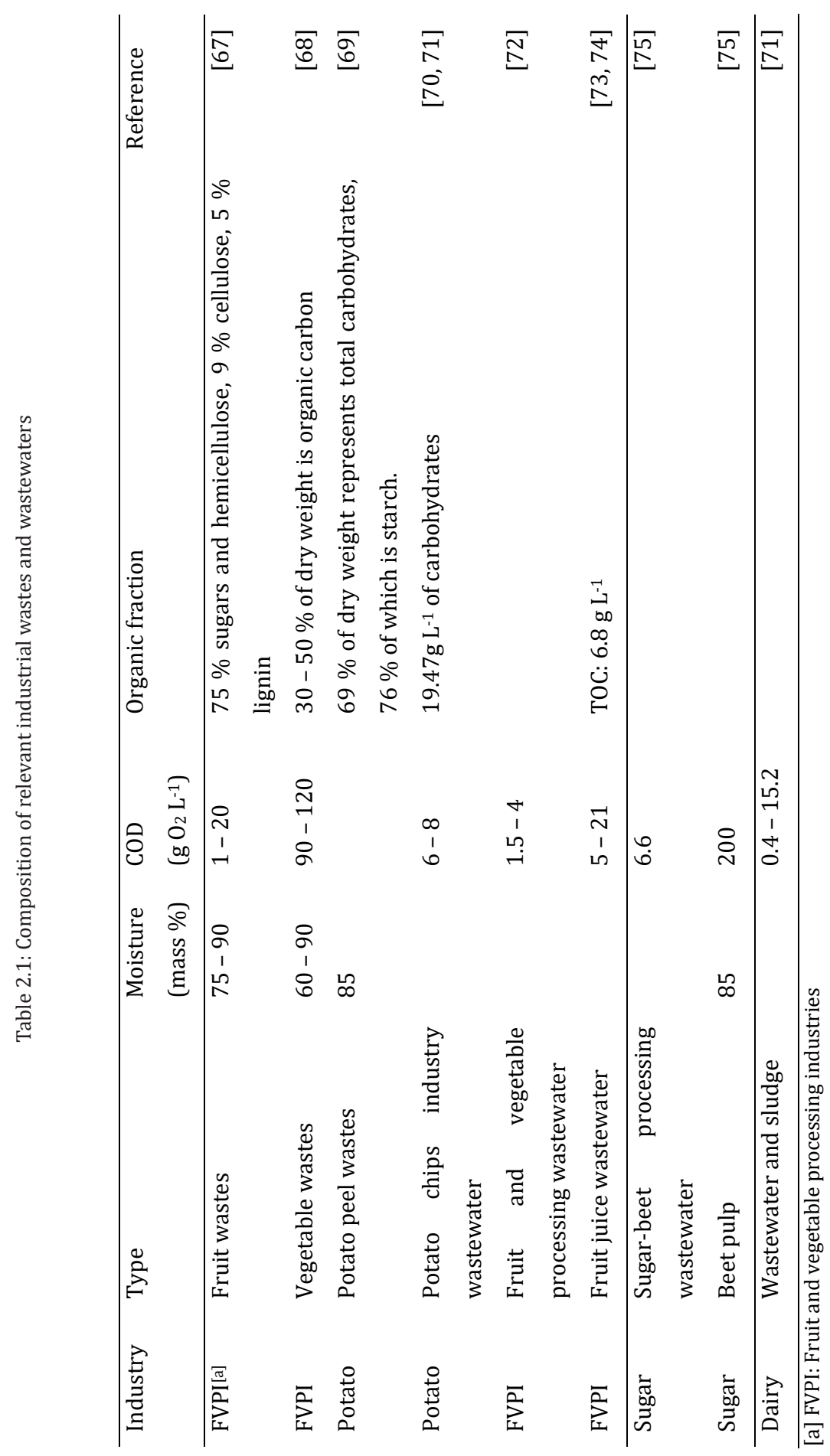


Table 2.2 presents the composition of the three feedstock studied. The ultimate analysis of the sugar beet pulp feedstock (with a measured moisture content of $75 \%$ ) after drying was determined using a Flash Elemental Analyser 2000.

Table 2.2: Feedstock studied for the two step process

\begin{tabular}{|c|c|c|c|}
\hline Ultimate analysis (mass \%) & Sucrose & Starch & $\begin{array}{l}\text { Sugar beet pulp } \\
\text { (dry basis) }\end{array}$ \\
\hline $\mathrm{C}$ & 42.1 & 44.4 & 30.1 \\
\hline $\mathrm{H}$ & 6.4 & 6.2 & 4.5 \\
\hline $\mathrm{N}$ & 0 & 0 & 0.8 \\
\hline 0 & 51.4 & 49.4 & 64.6 \\
\hline Feed concentration (wt \%) & 10 & 10 & 10 \\
\hline Carbon mass \% (used in experiments) & 4.2 & 4.4 & 0.75 \\
\hline
\end{tabular}

\subsection{Experimental section}

Sucrose and corn starch were obtained from Sigma-Aldrich, while sugar beet pulp was obtained as wet pulp fibres from Suiker Unie, located in the Netherlands. Stabilisation studies were conducted using a commercial Ru catalyst, with a $5 \%$ metal loading on a carbon support, obtained from Sigma-Aldrich.

\subsubsection{Setup}

All stabilisation experiments were conducted in a $45 \mathrm{~cm}^{3}$ autoclave reactor $(\mathrm{L}=12 \mathrm{~cm}$, ID $=2.2$ $\mathrm{cm}$ ) made of Inconel alloy. The setup is shown in Figure 2.2. The (exchangeable) reactor was equipped with two orifices, one for a thermocouple and the other to connect a pressure indicator and a gate valve. The pressure and the temperature of the reactor were recorded during the run. A pneumatic arm was used to immerse and raise the reactor from a hot fluidized sand bed, move the reactor and quench it in a cooling water bath. The sand bed was heated by an electric oven (with preheated fluidization gas). The electric oven had a heating rate of $0.6{ }^{\circ} \mathrm{C} \mathrm{s}^{-1}$. The set-up was equipped with a cylinder piston that enables the reactor to be moved from the sand bed to the water bath and vice versa. The autoclave was operated with a hollow shaft mechanical stirrer. For safety reasons, the setup was placed in a high pressure box with controls located outside the box so that experiments were carried out in a safe manner. A thermocouple was placed at the bottom of the reactor and was used to measure the temperature of the liquid inside. For pressure measurement, a pressure sensor was placed on the gas line at the top of the reactor. 


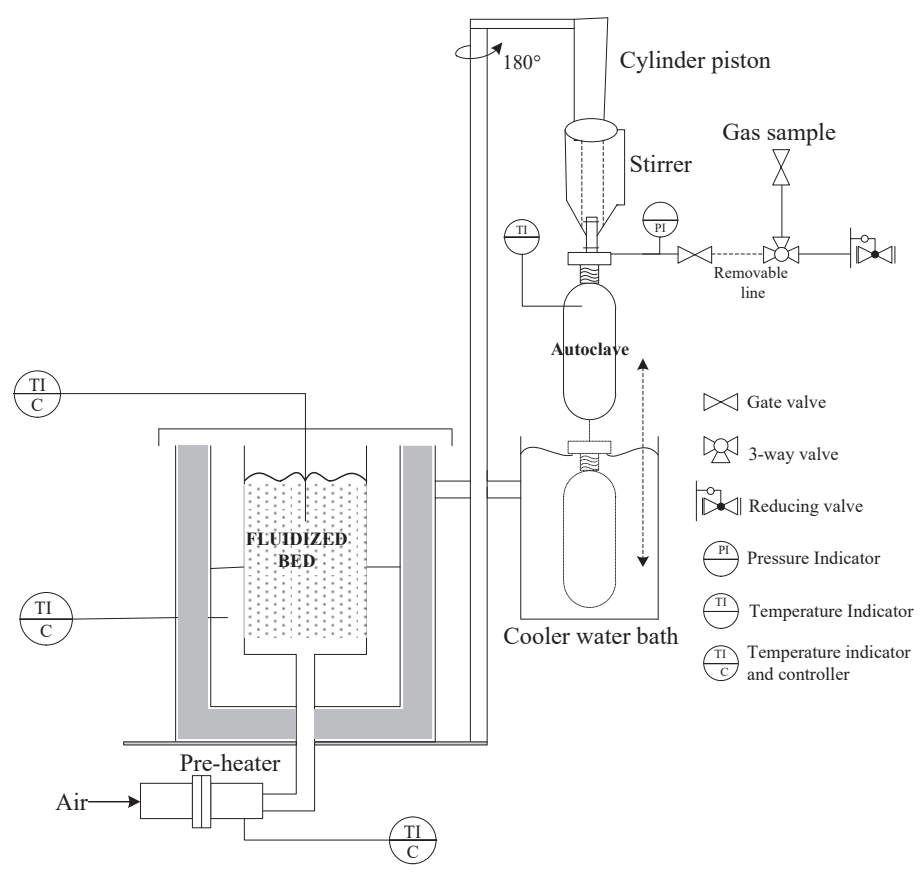

Figure 2.2: Scheme of the experimental setup

\subsubsection{Procedure}

Preceding a stabilisation test, the reactor was purged with $\mathrm{N}_{2}$. This created an inert environment for reaction and pressurised $\mathrm{N}_{2}$ was also used to ensure that there were no gas leaks through the fittings. The reactor was then purged with $\mathrm{H}_{2}$ before a suitable pressure was applied prior to reaction. With respect to the influence of the heating rate on stabilisation kinetics, at a heating rate of $0.6{ }^{\circ} \mathrm{C} \mathrm{s}^{-1}$, the reactor reached $95 \%$ of the set point temperature within 5 minutes, as illustrated in Figure A.1 in the Appendix A.1. It is assumed that this initial heating rate has a negligible effect on the reaction rate, considering that the data obtained for varying residence times proceeded from 15 minutes onwards.

\subsubsection{Analysis}

Mass balances were closed using weighing scales (KERN DS 8K0.05). Concentrations of liquid products obtained from stabilisation tests were measured using High Pressure Liquid Chromatography (Agilent 1200 series HPLC system equipped with Agilent Hi-Plex Pb or Hi-Plex H column (300 x $7.7 \mathrm{~mm}$ ) and Agilent 1200 series refractive index detector). Carbon balance closures were found to be $>97 \%$ for all stabilisation experiments. 


\subsubsection{Calculations}

Table A.1 in Appendix A.2 presents the standard deviation of the mean at $95 \%$ confidence levels. Triple measurements for sucrose stabilisation experiments at $140{ }^{\circ} \mathrm{C}$ and 15 minutes and duplicate measurements for starch stabilisation at $220^{\circ} \mathrm{C}$ and 60 minutes were used to represent the errors of the whole population at all temperatures and residence times.

The following equations were used for the calculation of feed conversion, selectivity, carbon to gas conversion, product yield, product carbon yield, and WHSV.

$$
\begin{aligned}
& X_{f}=\left(1-\frac{n_{f}}{n_{f, i n}}\right) \cdot 100\left(\frac{\text { Moles of feed consumed }}{\text { Initial moles of feed }}\right) \\
& S=\frac{n_{M n}}{n_{S b}}\left(\frac{\text { Moles of mannitol produced }}{\text { Moles of sorbitol produced }}\right) \\
& X_{C G}=\frac{\sum n_{C, g}}{n_{C, \text { in }}} \cdot 100\left(\frac{\text { Total moles of carbon in gas }}{\text { Initial moles of carbon }}\right) \\
& Y_{i}=\frac{n_{i}}{n_{f, i n}}\left(\frac{\text { Moles of } i \text { produced }}{\text { Initial moles of feed }}\right) \\
& Y_{C, i}=\frac{n_{C, i}}{n_{C, i n}}\left(\frac{\text { Moles of carbon in product } i}{\text { Initial moles of carbon }}\right) \\
& W H S V=\frac{m_{f}}{m_{\text {cat }} \cdot t}\left[\frac{g_{\text {feed }}}{g_{\text {cat }} \cdot h}\right]\left(\frac{\text { Initial mass of feed }}{\text { Mass of catalyst } \cdot \text { Residence time }}\right)
\end{aligned}
$$

\subsection{Sucrose results}

The hydrolysis and subsequent hydrogenation of sucrose produces C6 sugar alcohols sorbitol and mannitol, as shown in Figure 2.3. In this work, the kinetics of sucrose stabilisation were studied at varying residence times $(\mathrm{t})(15-180 \mathrm{~min})$, catalyst amounts $(0.02-0.1 \mathrm{~g})$, inlet $\mathrm{H}_{2}$ pressures $(10-120 \mathrm{bar})$ at room temperature, and stirring frequencies $\left(0-32 \mathrm{~s}^{-1}\right)$.

The kinetics of combined hydrolysis and hydrogenation of sucrose over Ru and $\mathrm{Ni}$ based catalysts has only been reported by a few authors. Castoldi et al. [76] developed autocatalytic kinetic models to describe the formation of sorbitol and mannitol using $\mathrm{Ru}-\mathrm{Al}_{2} \mathrm{O}_{3}$ and Raney-Ni catalysts at 130 ${ }^{\circ} \mathrm{C}$. Barbosa et al. [77] studied sucrose hydrogenation at $135^{\circ} \mathrm{C}$ using modified Ru catalysts. They described the kinetics using a pseudo-first order model. However, no indication of the influence of $\mathrm{H}_{2}$ pressure on the reaction rates was investigated. Maranhã et al. [78] described the kinetics of sugar hydrogenation at $140{ }^{\circ} \mathrm{C}$ using a $14.75 \mathrm{wt} \% \mathrm{Ni}$ on carbon catalyst. However, complete conversion of sucrose was not achieved under the studied operating conditions. 


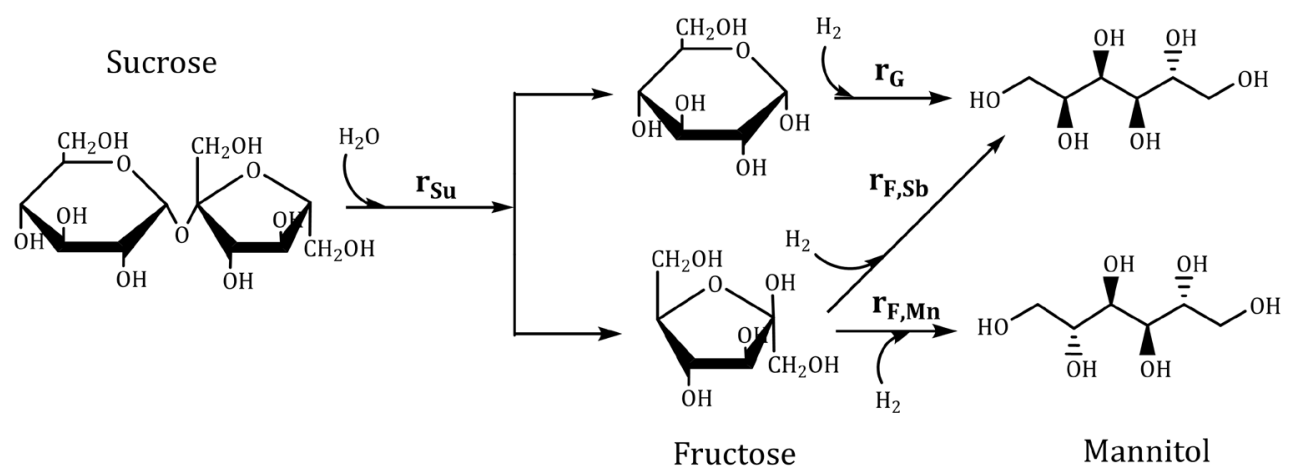

(a)

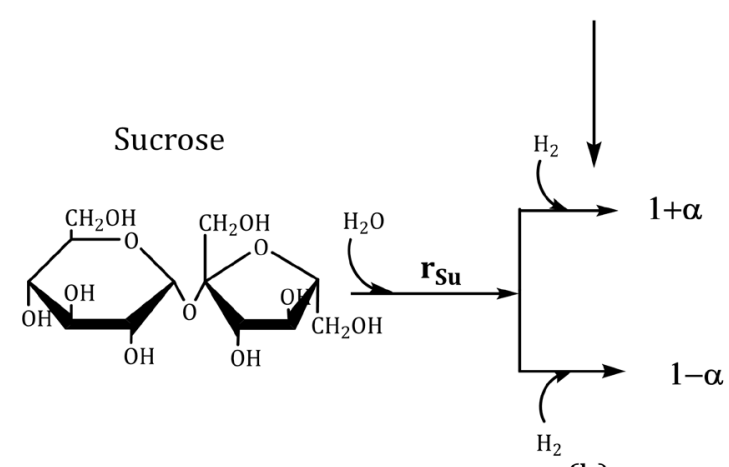

(b)

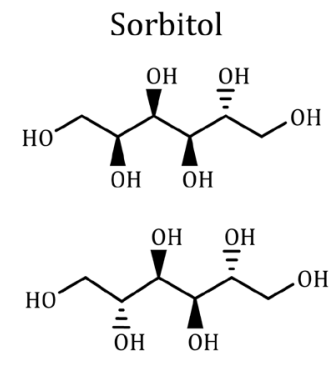

Mannitol

Figure 2.3: (a) Reaction scheme for sucrose stabilisation [77] (b) Simplified scheme for kinetic model

\subsubsection{Mass transfer}

Prior to kinetic measurements, it was ensured that mass transfer limitations could be excluded in order to obtain intrinsic kinetic data. The absence of gas-liquid mass transfer was confirmed by varying the agitation speed of the stirrer until invariance in the conversion was achieved, as well as by the found linear dependency of the reaction rate on the catalyst loading. A stirrer speed of $20 \mathrm{rps}^{-1}$ and $0.1 \mathrm{~g}$ of Ru-C were considered for kinetic experiments.

Figure 2.4(a) illustrates the effect of the stirrer speed on the conversion of sucrose, using $0.1 \mathrm{~g}$ of Ru-C. A speed larger than $15 \mathrm{rps}^{-1}$ results in a constant sucrose conversion. Therefore, a speed of $20 \mathrm{rps}^{-1}$ was considered for kinetic measurements. This result, in addition to the observation that in the experimental range considered, the reaction rate was proportional to the catalyst loading, as shown in Figure 2.4(b) ensured the absence of gas-liquid mass transfer limitations. 


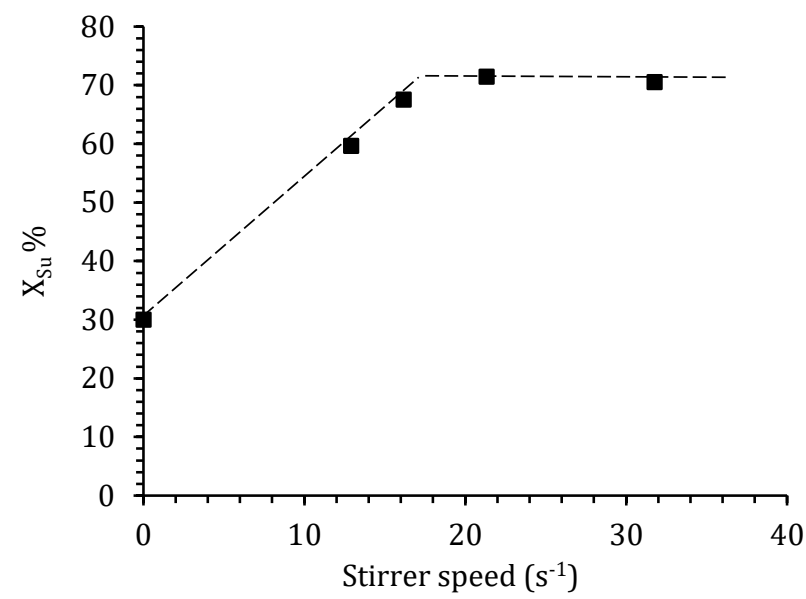

(a)

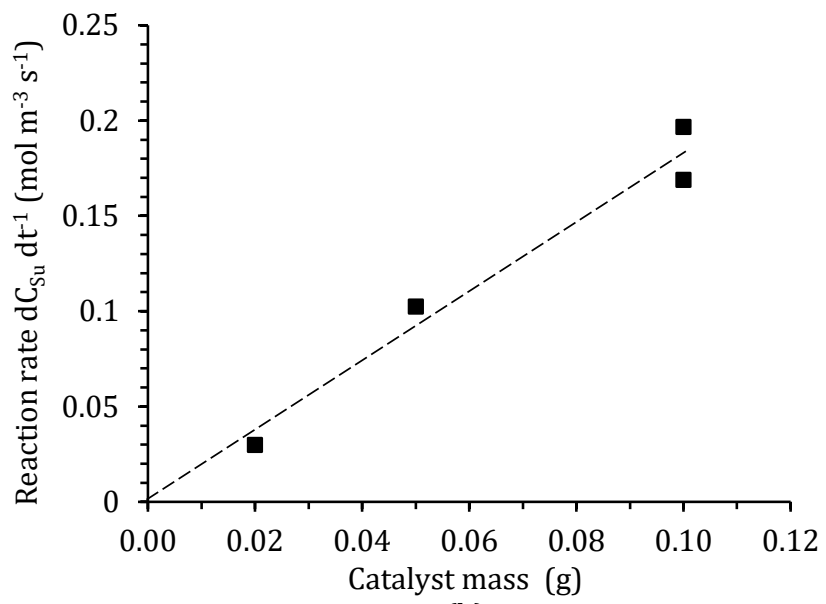

(b)

Figure 2.4: (a) Effect of stirrer frequency on sucrose conversion using $0.1 \mathrm{~g}$ of $\mathrm{Ru}-\mathrm{C}$ b) Effect of catalyst loading on the reaction rate at a stirrer frequency of $20 \mathrm{rps}^{-1}$. Experiments conducted with an initial sucrose concentration of $10 \mathrm{wt} \%$ at $140{ }^{\circ} \mathrm{C}, 100$ bar initial $\mathrm{H}_{2}$ pressure at room temperature and a residence time of 15 minutes.

Although there is no direct way of ensuring the absence of liquid-solid mass transfer limitations, common theoretical criteria (listed in Table 2.3) can provide an approximate indication of the effects. The Carberry criterion was used to check for limitations in the L-S interface. The criterion were found to be satisfied with a calculated value of $2.2 \cdot 10^{-6}$, less than 0.05 for a first order reaction where $n=1$. 
Table 2.3: Criteria to check for the absence of L-S and intra-particle mass transfer limitations

$$
\begin{aligned}
& \text { L-S mass transfer: Carberry criterion } \\
& C_{a_{L S}}=\frac{r_{o b s}}{k_{S} a_{s} \cdot C_{b}}<\frac{0.05}{|n|} \\
& \frac{0.14\left[\frac{\mathrm{mol} \mathrm{Su}}{\mathrm{m}_{f}^{3} \cdot \mathrm{s}}\right]}{1.8 \cdot 10^{-3}\left[\frac{\mathrm{m}}{\mathrm{s}}\right] \cdot \frac{6}{50.10^{-6}\left[\frac{\mathrm{m}^{2}}{\mathrm{~m}_{p}^{3}}\right] \cdot 291\left[\frac{\mathrm{mol} \mathrm{Su}}{\mathrm{m}_{f}^{3}}\right]}<\frac{0.05}{1}}
\end{aligned}
$$

where $k s$ is calculated by:

$$
\begin{aligned}
& k_{S}=\frac{S_{h} D}{d_{p}}=\frac{4.1 \cdot 2.23 \cdot 10^{-8}\left[\frac{\mathrm{m}^{2}}{\mathrm{~s}}\right]}{50 \cdot 10^{-6}[\mathrm{~m}]}=1.83 \cdot 10^{-3} \\
& S h=2+0.4\left(\frac{\varepsilon d_{p}{ }^{4}}{v^{3}}\right)^{0.25}\left(\frac{\mu}{D . \rho}\right)^{0.33} \\
& S h=2+0.4\left(\frac{0.05\left[\frac{\mathrm{m}^{2}}{\mathrm{~s}^{3}}\right]\left(50 \cdot 10^{-6}\right)^{4}[\mathrm{~m}]^{4}}{\left(2 \cdot 10^{-7}\right)^{3}\left[\frac{\mathrm{m}^{2}}{\mathrm{~s}}\right]^{3}}\right)^{0.25}\left(\frac{2 \cdot 10^{-7}\left[\frac{\mathrm{m}^{2}}{\mathrm{~s}}\right]}{2.23 \cdot 10^{-8}\left[\frac{\mathrm{m}^{2}}{\mathrm{~s}}\right]}\right)^{0.33}=4.1 \\
& \varepsilon=\frac{N_{p} l^{5} N^{3}}{V_{f}}=\frac{0.5 \cdot\left(1.2 \cdot 10^{-2}\right)^{5}[\mathrm{~m}]^{5} \cdot 20^{3}\left[\mathrm{~s}^{-1}\right]^{3}}{20 \cdot 10^{-6}\left[\mathrm{~m}^{3}\right]}=0.05\left[\frac{\mathrm{m}^{2}}{\mathrm{~s}^{3}}\right]
\end{aligned}
$$

Intra-particle mass transfer: Weisz-Prater criterion

$$
\emptyset_{w}=\frac{r_{o b s} \cdot r_{p}{ }^{2}}{C_{s} \cdot D_{e}}=\frac{0.14\left[\frac{\mathrm{mol} \mathrm{Su}}{\mathrm{m}_{f}^{3} \cdot s}\right] \cdot\left(25 \cdot 10^{-6}\right)^{2}[\mathrm{~m}]^{2}}{291\left[\frac{\mathrm{mol} \mathrm{Su}}{m_{f}^{3}}\right] \cdot 2.23 \cdot 10^{-9}\left[\frac{\mathrm{m}^{2}}{\mathrm{~s}}\right]}<1
$$

The main parameter that influences intra-particle transport is the particle size of the catalyst. In this work, ruthenium on carbon catalyst particles having a particle size lower than $50 \mu \mathrm{m}$ were utilised. As listed in Table 2.3, the Weisz-Prater criterion was used to check for intra-particle transport limitations. The effective diffusivity was approximated as an order of magnitude lower than the bulk phase diffusion coefficient. (De $=0.1 \cdot \mathrm{D}$ ). The calculated value was found to be $1.3 \cdot 10^{-4}$, orders of magnitude lower than 1 , indicating that intra-particle transport limitations are absent.

\section{Mass transfer coefficients}

The liquid-solid mass transfer coefficient is determined using the correlation of Sano et al. and was calculated to be $1.8 \cdot 10^{-3} \mathrm{~m} \mathrm{~s}^{-1}$ [79]. Equations used for the determination of mass transfer coefficients are shown in Table 2.3. Properties of water were considered at the highest temperature studied $\left(140^{\circ} \mathrm{C}\right)$ as the reaction rate is then maximal. 
The diffusion coefficient $\mathrm{D}$ of $\mathrm{H}_{2}$ in water was found to be $2.23 \cdot 10^{-8} \mathrm{~m}^{2} \mathrm{~s}^{-1}$ using the Wilke-Chang correlation [80]. The rate of energy dissipation $\varepsilon$ was calculated using a power number $\left(N_{p}\right)$ of 0.5 , within the range for turbines operating in the turbulent regime [81].

\section{$\underline{H}_{2}$ solubility effects}

Figure 2.5 depicts the effect of $\mathrm{H}_{2}$ pressure on the rate of sorbitol and mannitol production. Above an initial pressure of 40 bar (at room temperature), the observed reaction rate is independent of the $\mathrm{H}_{2}$ pressure, resulting in a constant polyol production rate. This could be attributed to the maximum adsorption of $\mathrm{H}_{2}$ on the catalyst surface sites. Experiments aiming at parameterizing a pseudo-first order kinetic model (first order in sucrose) were therefore performed at $\mathrm{H}_{2}$ pressure of 100 bar.

\subsubsection{Effect of temperature and residence time}

Figure 2.6 illustrates the degradation of sucrose with varying residence times and temperatures. As depicted, the maximum conversion achieved at $100{ }^{\circ} \mathrm{C}$ and 180 minutes was $12 \%$, whereas complete conversion is achieved within 15 minutes at $140{ }^{\circ} \mathrm{C}$. It can be inferred from this data that the hydrolysis of sucrose has a high activation energy.

\subsubsection{Kinetic model for sucrose stabilisation}

The process was optimised to produce sugar alcohols sorbitol and mannitol with > $99 \%$ conversion. It was found that the hydrolysis of sucrose to its monomeric sugars was the slowest step of the process. Under all experimental conditions studied, negligible glucose and fructose (< $0.1 \mathrm{wt} \%$ ) were found in the system, meaning that the rate of sucrose hydrolysis was orders of magnitude slower than the rate of hydrogenation of the sugars $\left(r_{S u} \ll r_{G^{\prime}}, r_{F}\right)$. Additionally, from experimental observation, it was shown that the selectivity towards mannitol production was unaffected by residence time, and was found to mildly increase with increasing temperatures, as illustrated in Figure 2.7. Based on these observations the reaction path scheme was simplified as shown in Figure 2.3(b). Under the experimental conditions considered in this work, sorbitol is produced by both glucose and fructose, while mannitol is exclusively produced by fructose. Therefore, the production of sorbitol and mannitol do not follow a 1:1 molar ratio. In order to account for the deviation from the 1:1 molar ratio, $\alpha$ is introduced.

For sucrose conversions, $(1+\alpha)$ represents the total moles of sorbitol produced, while for mannitol, this is represented by $(1-\alpha)$. $\alpha$ and $k_{S u}$ were fitted for data from each temperature set. Table 2.4 lists the equations used. 


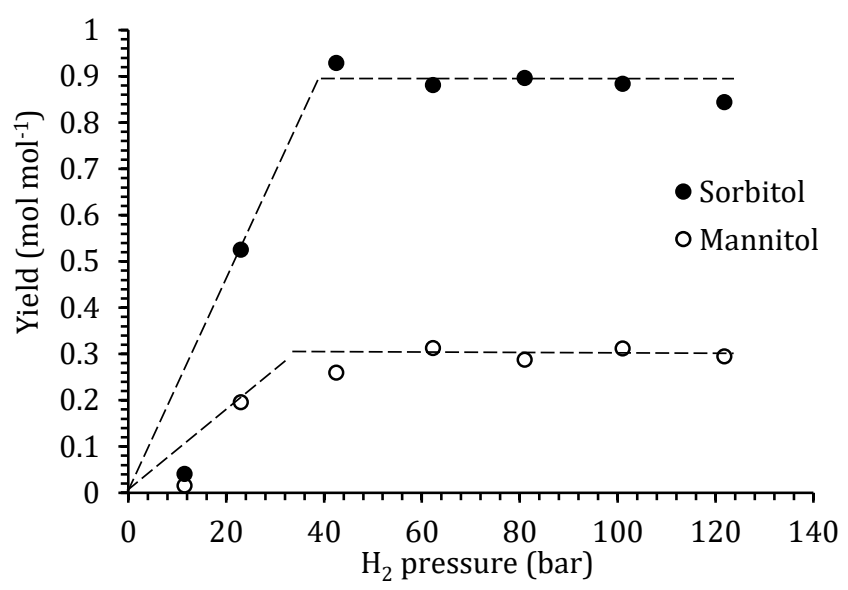

Figure 2.5: Effect of initial $\mathrm{H}_{2}$ pressure on the yield of sorbitol and mannitol. Experiments conducted using an initial aqueous sucrose concentration of $10 \mathrm{wt} \%, 0.1 \mathrm{~g}$ of $\mathrm{Ru}-\mathrm{C}$ at $140{ }^{\circ} \mathrm{C}$ and a residence time of 15 minutes.

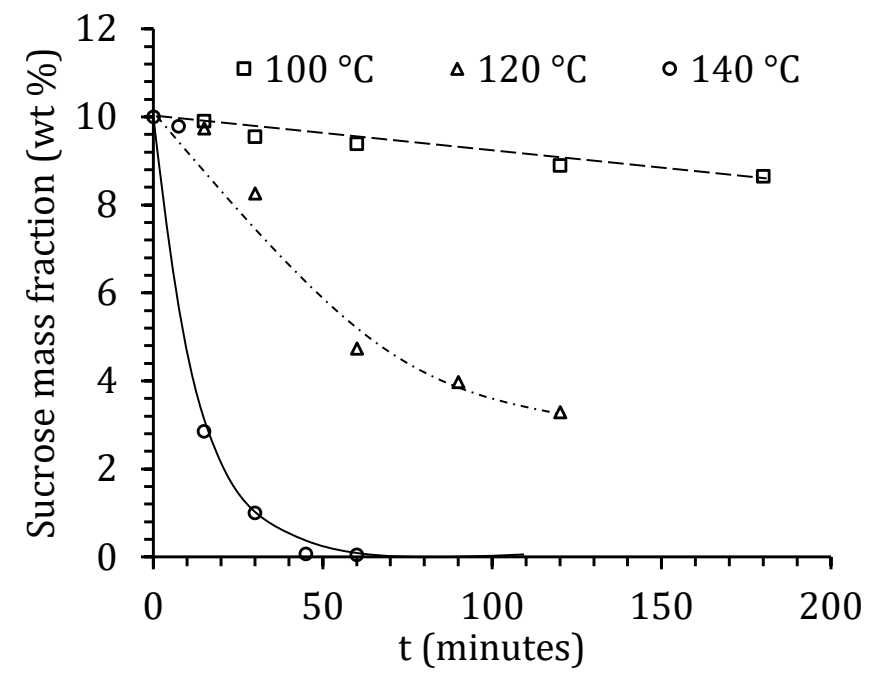

Figure 2.6: Experimental data points and model predictions for the temperature effect on the degradation of sucrose. Experiments conducted using a $10 \mathrm{wt} \%$ aqueous sucrose solution, $0.1 \mathrm{~g}$ of $\mathrm{Ru}-\mathrm{C}$ and $100 \mathrm{bar}$ of $\mathrm{H}_{2}$ pressure. Corresponding WHSV's range from 6.7 to $80 \mathrm{~h}^{-1}$. 


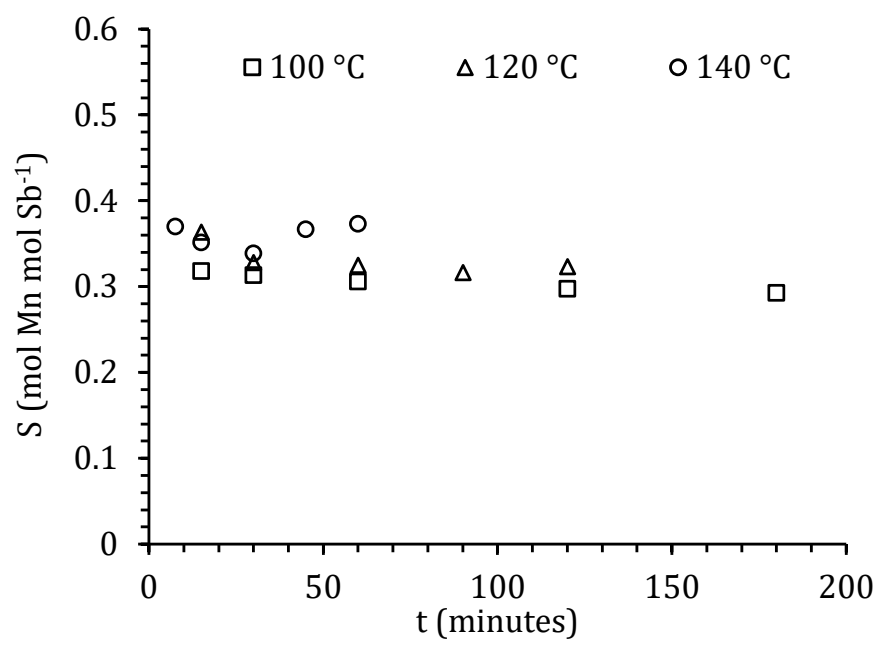

Figure 2.7: Selectivity of mannitol over sorbitol. Experiments conducted using an initial sucrose concentration of $10 \mathrm{wt} \%$ at $140{ }^{\circ} \mathrm{C}, 0.1 \mathrm{~g}$ of Ru-C, stirring frequency of $20 \mathrm{~s}^{-1}$ and an initial $\mathrm{H}_{2}$ pressure of 100 bar at room temperature.

Table 2.4: Modelling equations for reaction system presented in Figure 2.3.

\begin{tabular}{|c|c|}
\hline System of equations & $\begin{array}{l}\frac{d C_{S u}}{d t}=-m_{c a t} \cdot k_{S u} \cdot C_{S u} \\
\frac{d C_{S b}}{d t}=m_{c a t} \cdot(1+\alpha) \cdot k_{S u} \cdot C_{S u} \\
\frac{d C_{M n}}{d t}=m_{c a t} \cdot(1-\alpha) \cdot k_{S u} \cdot C_{S u}\end{array}$ \\
\hline Initial conditions & $C_{S u}=\frac{m_{f}}{V_{f}}, C_{S b}=0, C_{M n}=0$ \\
\hline
\end{tabular}

Table 2.5 presents the calculated parameters along with $95 \%$ confidence intervals and correlation coefficients. The measure of the linear dependence between $k_{S u}$ and $\alpha$ is represented by a correlation coefficient, a value of 1 meaning that the two variables are completely correlated and a value of 0 meaning that they are completely uncorrelated. 
Figure 2.8 illustrates the effect of varying residence time on the concentration of feed and final products. The model provides a very good fit to the data. At $140{ }^{\circ} \mathrm{C}$, complete conversion of sucrose is obtained in 60 minutes with $>99 \%$ selectivity towards the desired products.

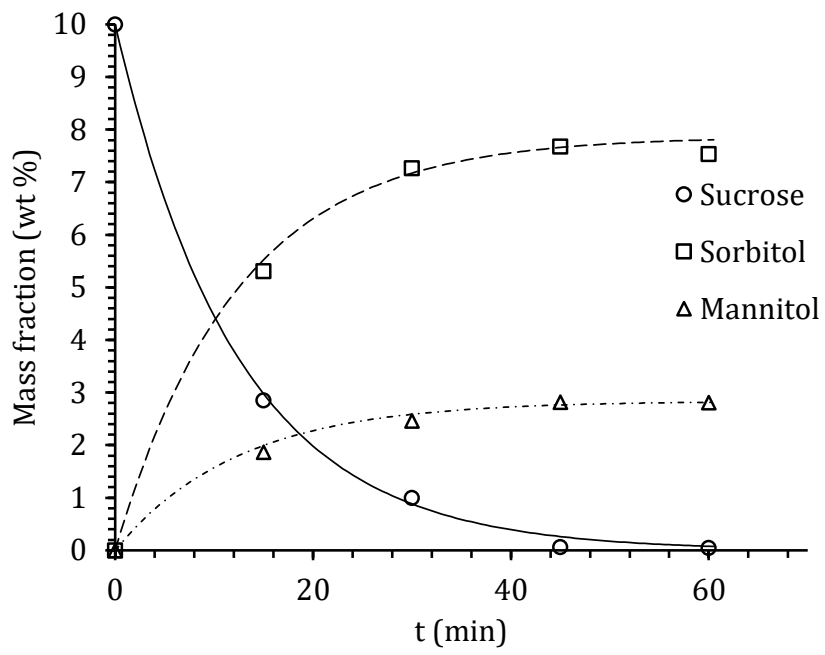

Figure 2.8: Experimental data points and modelled curves for the mass fractions of feed and products in water at varying residence times. Experiments conducted at $140{ }^{\circ} \mathrm{C}$ using a $10 \mathrm{wt} \%$ aqueous sucrose solution, $0.1 \mathrm{~g}$ of Ru-C and an initial $\mathrm{H}_{2}$ pressure of 100 bar. Corresponding WHSV's vary from 20 to $^{\circ} \mathrm{h}^{-1}$.

Table 2.5: Fitted parameters with $95 \%$ confidence intervals

\begin{tabular}{cccr}
\hline $\mathbf{T}$ & $\boldsymbol{k}$ su & $\boldsymbol{\alpha}$ & Correlation \\
${ }^{\circ} \mathrm{C}$ & $\mathrm{g}_{\mathrm{cat}^{-1} \mathrm{~S}^{-1}}$ & & \\
100 & $(1.2 \pm 0.1) \cdot 10^{-4}$ & $(5.3 \pm 0.1) \cdot 10^{-1}$ & -0.4 \\
120 & $(1.6 \pm 0.2) \cdot 10^{-3}$ & $(5.1 \pm 1.0) \cdot 10^{-1}$ & -0.4 \\
140 & $(1.3 \pm 0.1) \cdot 10^{-2}$ & $(4.7 \pm 0.2) \cdot 10^{-1}$ & -0.3 \\
$\mathrm{E}_{\mathrm{a}}(\mathrm{kJ} \mathrm{mol}-1)$ & 149 & & \\
\hline
\end{tabular}

Figure 2.9 displays a parity plot of experimental and model fitted yields of sucrose, sorbitol and mannitol at all temperatures. The legend indicates the mass fractions in wt \% of sucrose (Su), sorbitol (Sb) and mannitol (Mn) as well as the reaction temperatures. The activation energy calculated is $149 \mathrm{~kJ} \mathrm{~mol}^{-1}$, higher than the value of $110 \mathrm{~kJ} \mathrm{~mol}^{-1}$ obtained in studies by Tombari et al. in which enthalpy and heat capacity were measured during the $\mathrm{HCl}$ catalysed hydrolysis of sucrose [82]. 


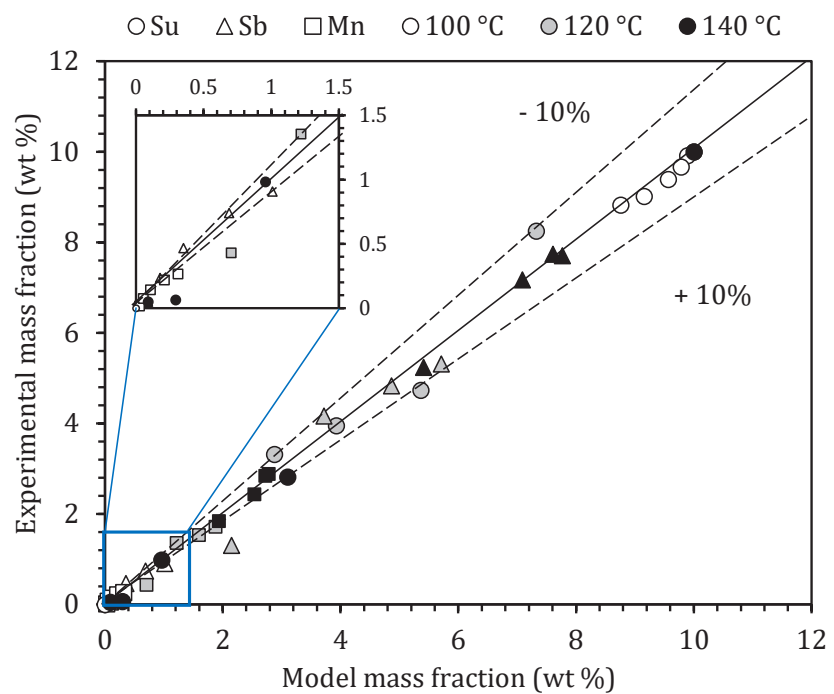

Figure 2.9: Parity plot of experimental vs fitted values for mass fractions (wt \%) of sucrose (circles), sorbitol (triangles) and mannitol (squares) at indicated temperatures of $100^{\circ} \mathrm{C}$ (empty), $120^{\circ} \mathrm{C}$ (grey) and $140^{\circ} \mathrm{C}$ (filled).

The value of $\alpha$ provides insight into the selectivity towards the polyols. It can also be seen is that with an increase in temperature, the selectivity towards mannitol production increases by $20 \%$ under the range of temperatures considered. This observation is consistent with previous work in which glucose and fructose mixtures were hydrogenated under similar operating conditions [50].

The calculated value of $1.3 \cdot 10^{-3} \mathrm{~s}^{-1}\left(k_{\text {Su }} \cdot m_{\text {cat }}=1.3 \cdot 10^{-2} \mathrm{~g}_{\text {cat }}{ }^{-1} \mathrm{~s}^{-1} \cdot 0.1 \mathrm{~g}_{\text {cat }}\right)$ for the first order rate constant $k_{S u}$ at $140{ }^{\circ} \mathrm{C}$ is five times higher than the rate constant of $2.8 \cdot 10^{-4} \mathrm{~s}^{-1}$ determined by Barbosa et al. [77] at $135^{\circ} \mathrm{C}$ using Ru on a zeolite support, and three times higher than the value of $4.3 \cdot 10^{-4} \mathrm{~s}^{-1}$ determined by Maranhã et al. [78] at $140{ }^{\circ} \mathrm{C}$ using a $\mathrm{Ni}-\mathrm{C}$ catalyst. A comparison of the experimental procedures revealed that the kinetics in these works were conducted using $\mathrm{H}_{2}$ pressures of 12 and 24 bar respectively. While the model developed by Barbosa et al. was also a pseudo-first order kinetic model, no verification of the effect of varying $\mathrm{H}_{2}$ pressures on the kinetics was conducted. This could be a reason for the slower kinetics. The model developed by Maranhã et al. was based on kinetics over a Nickel catalyst. Although Ni has a lower reactivity towards $\mathrm{C}$-C cleavage reactions in comparison to $\mathrm{Ru}$, $\mathrm{Ni}$ was selected for experiments for economic reasons. 


\subsection{Starch results}

Most studies on the hydrolytic hydrogenation of starch are based on a two-step process, the first in which starch is hydrolysed to glucose via an acidic or enzymatic hydrolysis, followed by the hydrogenation/hydrogenolysis of the sugars to polyols $[83,84]$. The hydrolysis of starch in hot compressed water alone has been studied previously, leading to coke formation and low sugar yields [85]. It was found that the addition of $\mathrm{CO}_{2}$ to the process enhanced the sugar yield and reduced the concentration of organic acids [86]. However, this was also found to increase the yield of degradation products of glucose, primarily 5-HMF [87].

Fewer mechanistic studies have focussed on a one-pot hydrolytic hydrogenation process. Simultaneous hydrolysis and hydrogenation/hydrogenolysis has been achieved through the addition of acidic or basic promoters [88], although this led to the formation of by-products. The use of bi-functional solid acid catalysts [89] has also been patented in which a Ru on acidic zeolite Y fulfilled catalytic requirements for the process.

In this work, the sequential hydrolysis and hydrogenation of starch stabilisation is compared to starch stabilisation (one-pot hydrolytic hydrogenation) in hot compressed water using 5 wt \% Ru-C as a hydrogenation catalyst. Higher temperatures $\left(200-240{ }^{\circ} \mathrm{C}\right)$ are utilised in order to facilitate the hydrolysis reaction.

\subsubsection{Sequential hydrolysis and hydrogenation of starch}

For starch hydrolysis in hot compressed water, preliminary tests with $2 \mathrm{wt} \%$ aqueous solutions were considered. Experiments were conducted at $220{ }^{\circ} \mathrm{C}$ and varying residence times. Figure 2.10 depicts the yield of glucose obtained from starch at varying residence times. The yield is calculated as the fraction of glucose concentration obtained with respect to the maximum glucose concentration that can be obtained from the starch solution. It can be seen that the glucose yield decreases with longer residence times. An analysis of the liquid effluent reveals degradation products including 5-HMF and furfural, consistent with previous work [85]. Mild coking was obtained in all experiments.

The HPLC spectrum of the liquid effluent as well as coking deposition on the reactor parts can be found in Appendix A.3 (Figures A.2 and A.3).

The hydrogenation of glucose to sorbitol has been studied extensively [48-52]. From literature and experimental work with sucrose as discussed earlier in this chapter, it is known that the complete conversion of glucose with $>99 \%$ selectivity towards sorbitol production can be attained at mild temperatures of $80-120^{\circ} \mathrm{C}$. 
Considering the maximum glucose yield of $50 \%$ achieved from the starch hydrolysis experiments, and that the glucose can be completely converted to sorbitol, the maximum sorbitol yield that can be obtained from the sequential hydrolysis and hydrogenation of starch under the operating conditions considered is $\sim 50 \%$. Further optimisation of the hydrolysis step by considering shorter residence times could enhance the glucose yields.

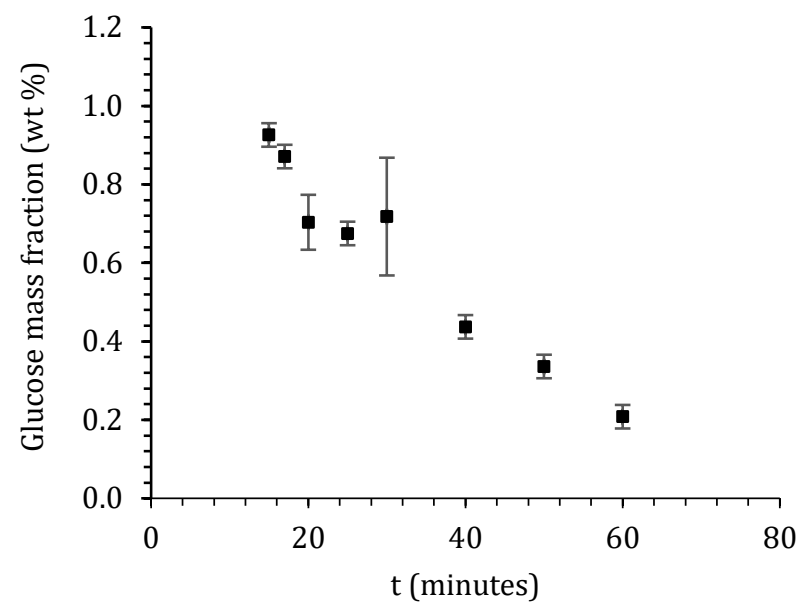

Figure 2.10: Glucose yields from starch hydrolysis in hot compressed water. Experiments conducted at 220 ${ }^{\circ} \mathrm{C}$ using a 2 wt $\%$ starch solution.

\subsubsection{Stabilisation (one-pot hydrolytic hydrogenation) of starch}

The key reactions occurring in the stabilisation of starch and considered in this work are the hydrolysis of starch to glucose monomers $\left(r_{H_{2}}\right)$, catalysed by water, the hydrogenation of glucose monomers to sorbitol $\left(r_{G}\right)$, and the hydrogenolysis of sorbitol to smaller alcohols that are further converted to $\mathrm{CH}_{4}\left(r_{s}\right)$, both catalysed by the $\mathrm{Ru}-\mathrm{C}$ hydrogenation catalyst.

Preliminary stabilisation experiments were conducted with 10 wt $\%$ starch using a $\mathrm{H}_{2}$ inlet pressure of 50 bar at room temperature, at varying temperatures $\left(200-240{ }^{\circ} \mathrm{C}\right), \mathrm{Ru}-\mathrm{C}$ quantities ( 0.1 and $0.2 \mathrm{~g}$ ), and residence times (30 - 120 minutes). Experiments with $0.2 \mathrm{~g}$ of catalyst resulted in over $20 \%$ of the feed carbon in the gas phase as $\mathrm{CH}_{4}$, meaning that $r_{G}$ and $r_{s}$ were occurring rapidly, therefore steering the reactants towards $\mathrm{CH}_{4}$ production. The catalyst amount was therefore lowered to $0.1 \mathrm{~g}$ for further experiments.

Figure 2.11(a) depicts the influence of residence time and temperature on the yield of sorbitol. The decrease in sorbitol yield at higher temperatures is due to the hydrogenolysis of sorbitol to smaller polyols [90], that were also detected in the liquid phase. 
Hydrogenolysis and hydrogen consuming reactions are favoured at higher temperatures, as illustrated in Figure 2.11(b) meaning that $r_{s}>r_{G}$. The $\mathrm{H}_{2}$ consumption was calculated as the absolute difference in the quantity of $\mathrm{H}_{2}$ before and after experiments. The HPLC spectrum of stabilised starch product can be found in Figure A.4. Higher temperatures also favour the hydrolysis reaction $r_{H_{2}}$, leading to glucose and its unstable decomposition products which are precursors to coke formation. This leads to a colouring tendency of the liquid, and can be visualised in Figure A.5 in Appendix A.4.

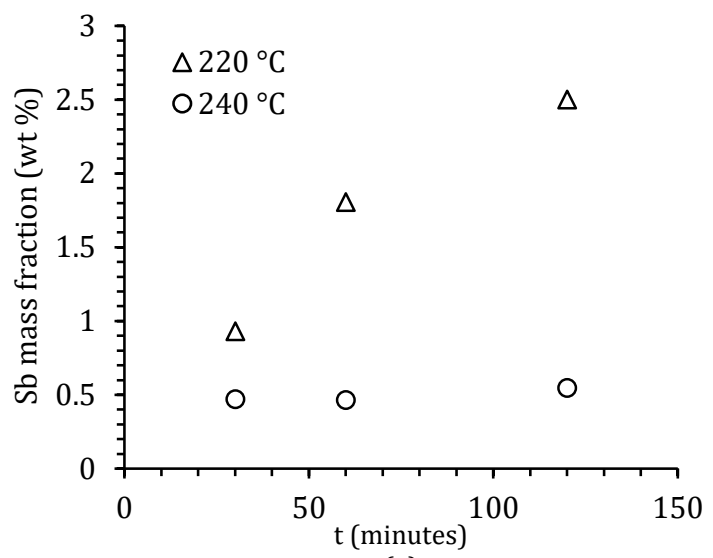

(a)

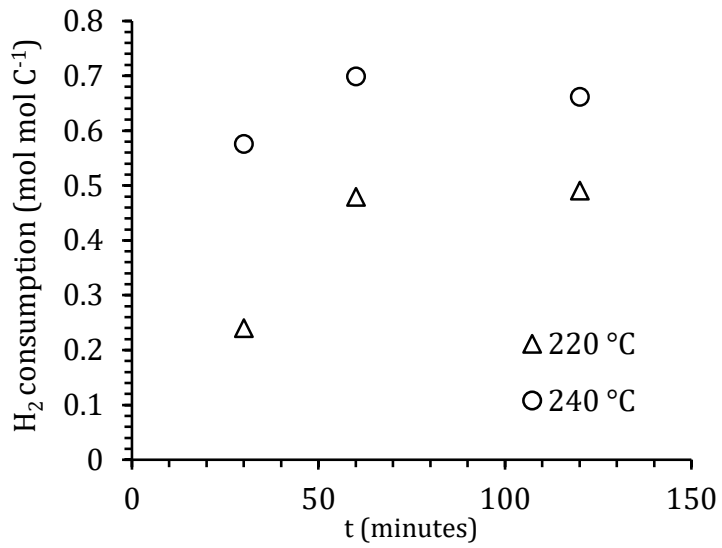

(b)

Figure 2.11: The effect of residence time and temperature on (a) sorbitol production and (b) $\mathrm{H}_{2}$ consumption. Experiments conducted using a $10 \mathrm{wt} \%$ starch solution, an initial $\mathrm{H}_{2}$ pressure of 50 bar at room temperature, and $0.1 \mathrm{~g}$ of Ru-C. WHSV's range from 10 to $40 \mathrm{~h}^{-1}$.

Figure 2.12 depicts the gas phase composition for experiments conducted at 220 and $240{ }^{\circ} \mathrm{C}$. Using a Ru-C catalyst at higher temperatures and longer residence times leads to methanation 
and reforming reactions, therefore producing $\mathrm{CH}_{4}$, and smaller amounts of $\mathrm{H}_{2}$ and $\mathrm{CO}_{2}$. It must be noted that the production of $\mathrm{H}_{2}$ can't directly be monitored since $\mathrm{H}_{2}$ is a reactant for stabilisation. However, the low yields of $\mathrm{CO}_{2}\left(<0.5 \% \mathrm{~mol} \mathrm{~mol} \mathrm{C}^{-1}\right)$ via reforming do indicate that $\mathrm{H}_{2}$ production is also low.

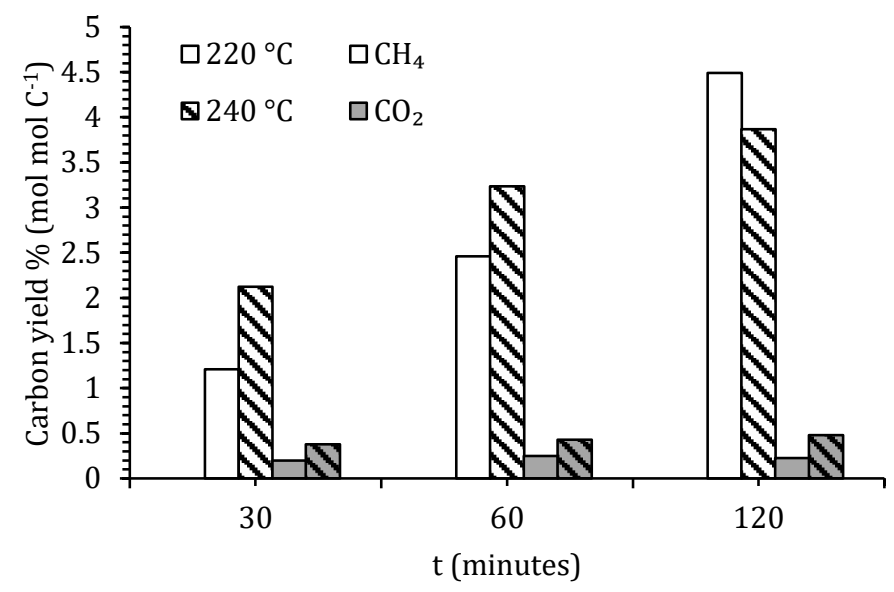

Figure 2.12: Gas phase composition of carbon constituents. Experiments conducted using $10 \mathrm{wt} \%$ starch solution, an initial $\mathrm{H}_{2}$ pressure of 50 bar at room temperature, and $0.1 \mathrm{~g}$ of Ru-C. WHSV's range from 10 to $40 \mathrm{~h}^{-1}$.

Preliminary gasification experiments of stabilised starch showed that a coking tendency was present in the discoloured samples as well as in partially hydrolysed samples. This is understandable, as the discolouration in the samples stabilised at higher temperatures occurred due to the increased rate of hydrolysis $\left(r_{H_{2} O}>r_{G}\right)$, thereby producing glucose monomers that degraded to coke precursors before they could be hydrogenated to sorbitol. In the case of partially hydrolysed stabilised samples at lower temperatures $\left(r_{H_{2} O}<r_{G}\right)$, glucose monomers released from the hydrolysates during gasification at higher temperatures are then prone to degradation to form coke. The success of a stabilisation experiment was therefore measured not based on the sorbitol yield, but based on the absence of sugars in the liquid product. This means that there is a requirement for complete conversion of the polysaccharide to polyols. This is supported by the visual appearance of the liquid effluent which provides an indication of coking tendencies. Figure 2.13 depicts the mechanisms involved in the degradation of starch in hot compressed water for both processes described above.

The most ideal situation is one in which the rate of hydrolysis of starch to glucose monomers is much slower than the rate of hydrogenation of glucose to sorbitol $\left(r_{H_{2}} \mathrm{O}<<r_{G}\right)$, making it the rate limiting step of the reaction. This eliminates the decomposition of glucose to coking products. This can be achieved by operating at lower temperatures. In addition, controlling the concentration of 
the Ru-C catalyst is necessary in order to avoid the conversion of sorbitol to $\mathrm{CH}_{4}$. No coke formation was observed during the one-pot process, presenting a significant advantage over the non-catalytic hydrolysis of starch in hot compressed water.

Although typically enzymatic and acidic methods are utilised for the degradation and hydrolysis of starch and other ligno-cellulosic biomasses with $>90 \%$ recovery of monosaccharide (reducing) sugars [91-93], in this work, higher temperatures in hot compressed water were used for the conversion of starch. The potential of stabilisation is further evaluated in Chapter 4, where the hydrothermal gasification of stabilised starch is compared to that of starch.

\subsection{Sugar beet pulp results}

Sugar beet pulp (SBP) was selected as a real feed in order to evaluate its degradation in hot compressed water and in the presence of hydrogen. Sugar beet pulp has been researched extensively as a potential source of energy and fuels due to its high polysaccharide and low lignin content [66]. Research on the hydrolysis of SBP has been conducted in the presence of acids [94, 95] and enzymes [96, 97]. Fewer studies have focused on SBP hydrolysis in hot compressed water, with a recent study by Martinez et al. [98] on the use of supercritical water for its hydrolysis. The yields of C5 and C6 sugars from the hemicellulose and cellulose fractions of SBP were found to be highest at a residence time of 0.11 seconds. At higher residence times, the sugars decomposed to aldehydes and acids. 

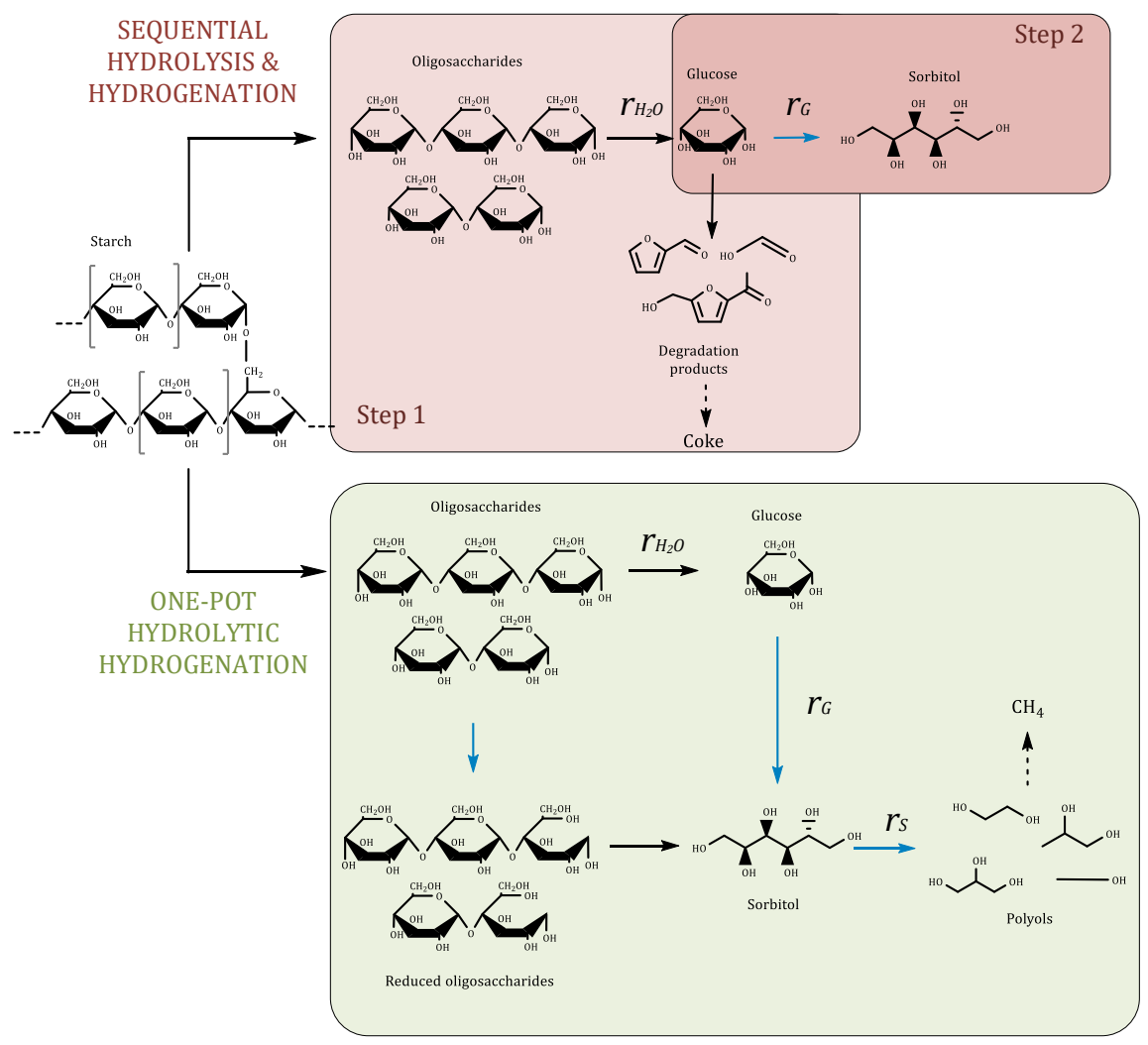

Figure 2.13: Starch degradation in hot compressed water

With respect to sub-critical hydrolysis in hot compressed water, to the authors' knowledge, no work has been published.

In this work, sub-critical temperatures were used to hydrolyse sugar beet pulp. Initially, a solution of $10 \mathrm{wt} \%$ sugar beet pulp (as received) was hydrolysed in hot compressed water at $200{ }^{\circ} \mathrm{C}$ for 2 minutes to solubilise the sugars. This dissolved $55-60 \%$ of the initial mass of the pulp into an extracted hydrolysate. The residual $40-45 \%$ remained as a cake after filtration. An ultimate analysis of the samples showed that the hydrolysate contained none of the nitrogen present in the feed, meaning that the proteins were not dissolved and remained in the residue.

The extracted hydrolysate therefore consisted of the hemi-cellulosic and pectin components of the pulp. The results can be visualised in Figure 2.14(a) and Figure 2.14(b). What is noticeable is that the colour of the extracted effluent in Figure 2.14(a) was dependent upon the heating rate of the autoclave. A quicker heating rate leading to an end temperature of $190{ }^{\circ} \mathrm{C}$ in sample a1 resulted in a darker liquid effluent than in sample a3. This could be attributed to degradation 
products of sugars detected in the liquid phase, such as 5-HMF and furfural.

Following the hydrolysis step, stabilisation experiments of the hydrolysates (Samples a1 and a2) were conducted using $0.05 \mathrm{~g}$ of $5 \mathrm{wt} \% \mathrm{Ru}-\mathrm{C}$ to produce clear solutions with water soluble compounds, shown in Figure 2.14(c). Samples c1 and c2 were obtained from the stabilisation of sample a1, while samples c3 and c4 from sample a2. No coking formation was observed during the stabilisation step. With respect to carbon distribution, $48 \%$ of the carbon in sugar beet pulp was extracted into the liquid phase. However, due to the large amounts of water utilised to dissolve the pulp, this resulted in the extracted stream containing $0.3-0.4$ wt \% carbon.

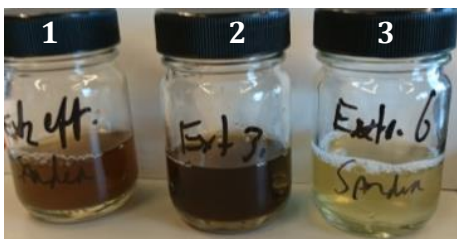

(a)

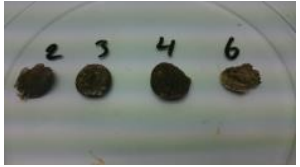

(b)

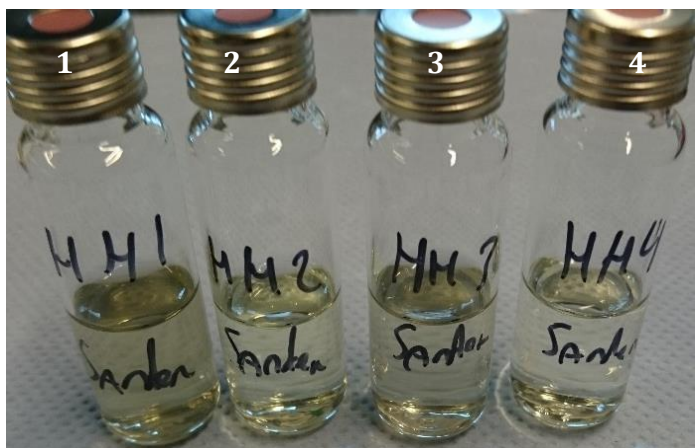

(c)

Figure 2.14: (a) Sugar beet pulp extracted hydrolysate at an end temperature and residence time of (1) 190 ${ }^{\circ} \mathrm{C}$ and 200 seconds, (2) $202{ }^{\circ} \mathrm{C}$ and 240 seconds, (3) $186{ }^{\circ} \mathrm{C}$ and 200 seconds. (b) Residues (cakes) after extraction and filtration (c) Stabilisation of extracted hydrolysate using $0.05 \mathrm{~g}$ of $\mathrm{Ru}-\mathrm{C}$, initial $\mathrm{H}_{2}$ pressure of 30 bar at (1) $220^{\circ} \mathrm{C}$ and 30 minutes, (2) $220^{\circ} \mathrm{C}$ and 60 minutes, (3) $240{ }^{\circ} \mathrm{C}$ and 30 minutes, (4) $260{ }^{\circ} \mathrm{C}$ and 20 minutes.

\subsection{Conclusion}

Stabilisation is a promising step for the processing of high coking feeds such as wastes and wastewaters rich in carbohydrates. In this work, the stabilisation of sucrose, starch and sugar beet pulp were studied in the presence of $\mathrm{H}_{2}$ using a $5 \mathrm{wt} \% \mathrm{Ru}-\mathrm{C}$ catalyst. The kinetics of sucrose stabilisation were studied between $100-140{ }^{\circ} \mathrm{C}$, and the reactions were found to proceed with a $100 \%$ conversion and $>99 \%$ selectivity to the stable polyol mixture. A mathematical model was developed that describes the stabilisation of sucrose to sorbitol and mannitol. The concept of stabilisation was extended from hydrogenation to hydrolytic hydrogenation using a polysaccharide, starch. Higher temperatures $\left(200-240{ }^{\circ} \mathrm{C}\right)$ were required to breakdown starch at similar WHSVs as used in the stabilisation of sucrose. 
Key identifiers for the success of stabilisation were the complete breakdown of starch, as well as the absence of sugars and their degradation products in the liquid product. Stabilisation of hemicelluloses extracted from sugar beet pulp led to a low carbon content of the stabilised mixture ( $<1 \mathrm{wt} \%)$, and processing such dilute streams could be energetically inefficient, as explored in Chapter 5. 


\section{A. Appendix}

\section{A.1 Batch autoclave heating rate}

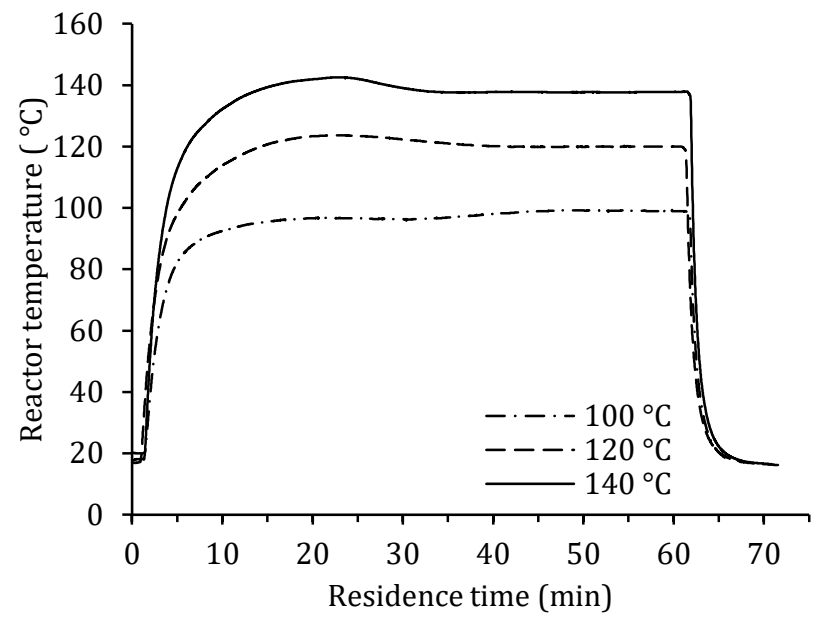

Figure A.1: Reactor temperature profiles during stabilisation experiments conducted at 100,120 and $140{ }^{\circ} \mathrm{C}$ for a residence time of 60 minutes.

\section{A.2 Error analysis}

The experimental data along with standard deviation calculated using $95 \%$ confidence levels are tabulated in Table A.1.

Table A.1: Error analysis for experimental data

Note: Values in bold are considered as errors for the whole population of experiments

\begin{tabular}{|c|c|c|c|c|}
\hline \multicolumn{5}{|c|}{ Stabilisation of sucrose at $140^{\circ} \mathrm{C}$ and 15 minutes } \\
\hline $\begin{array}{l}\text { Cucrose } \\
\text { wt \% }\end{array}$ & $\begin{array}{l}\mathrm{C}_{\text {Sorbitol }} \\
\text { wt } \%\end{array}$ & $\begin{array}{l}\mathrm{C}_{\text {Mannitol }} \\
\text { wt } \%\end{array}$ & & $\begin{array}{l}\mathrm{X}_{\mathrm{Su}} \\
\%\end{array}$ \\
\hline $2.7 \pm \mathbf{0 . 1}$ & $5.1 \pm \mathbf{0 . 2}$ & $1.8 \pm \mathbf{0 . 1}$ & & $74 \pm 2$ \\
\hline \multicolumn{5}{|c|}{ Stabilisation of starch at $220^{\circ} \mathrm{C}$ and 60 minutes } \\
\hline $\begin{array}{l}\text { CSorbitol } \\
\text { wt \% }\end{array}$ & $\begin{array}{l}\mathrm{H}_{2} \text { consumed } \\
\text { mol mol C-1 }\end{array}$ & $\begin{array}{l}\mathrm{YCH}_{4} \% \\
\mathrm{~mol} \mathrm{~mol} \mathrm{C}-1\end{array}$ & $\begin{array}{l}\mathrm{YCO}_{2} \% \\
\mathrm{~mol} \mathrm{~mol} \mathrm{C}-1\end{array}$ & $\begin{array}{l}\mathrm{X}_{\mathrm{CG}} \\
\%\end{array}$ \\
\hline $1.9 \pm \mathbf{0 . 1}$ & $0.49 \pm \mathbf{0 . 0 1}$ & $2.5 \pm 0.2$ & $0.24 \pm \mathbf{0 . 0 1}$ & $2.7 \pm \mathbf{0 . 2}$ \\
\hline
\end{tabular}




\section{A.3 Sequential hydrolysis and hydrogenation of starch}

The concentration of products in the liquid phase were measured using High Pressure Liquid Chromatography (Agilent 1200 series HPLC system equipped with Agilent Hi-Plex Pb column (300 x $7.7 \mathrm{~mm}$ ) and Agilent 1200 series refractive index detector).

Figure A.2 depicts the refractive index signal of liquid effluents following starch hydrolysis experiments at $220^{\circ} \mathrm{C}$. It can be seen that between 10 and 30 minutes, the polymeric carbohydrate is broken down into glucose monomers. At longer residence times, the concentration of 5-HMF, a glucose degradation product and precursor to coke formation increases.

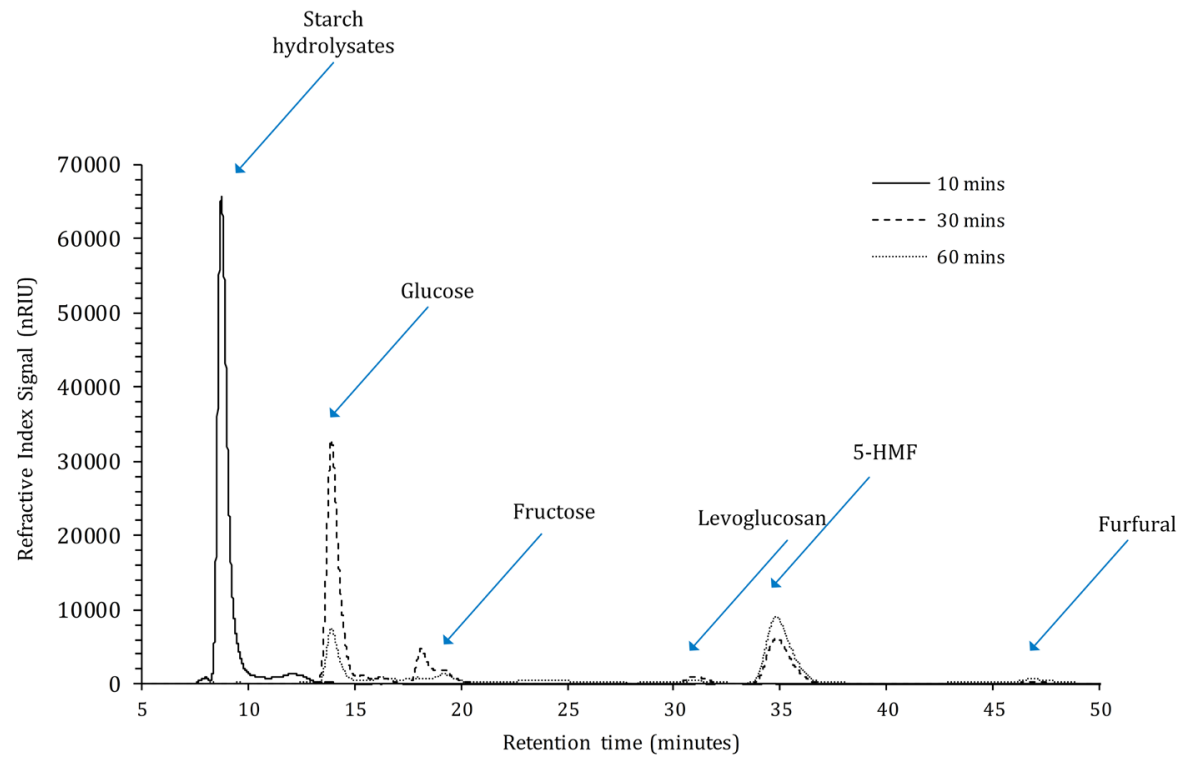

Figure A.2: HPLC spectrum of liquid effluent following starch hydrolysis. Experiments conducted using 2 wt $\%$ starch solutions at $220^{\circ} \mathrm{C}$. Analysis conducted on a $\mathrm{Pb}^{2+}$ column set at a temperature of $70^{\circ} \mathrm{C}$, using

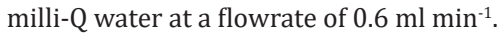




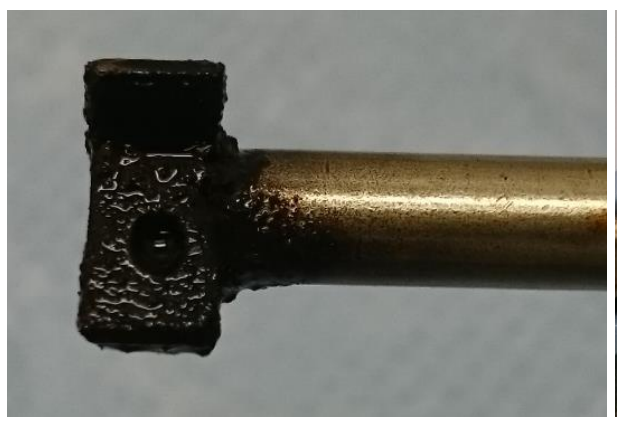

(a)

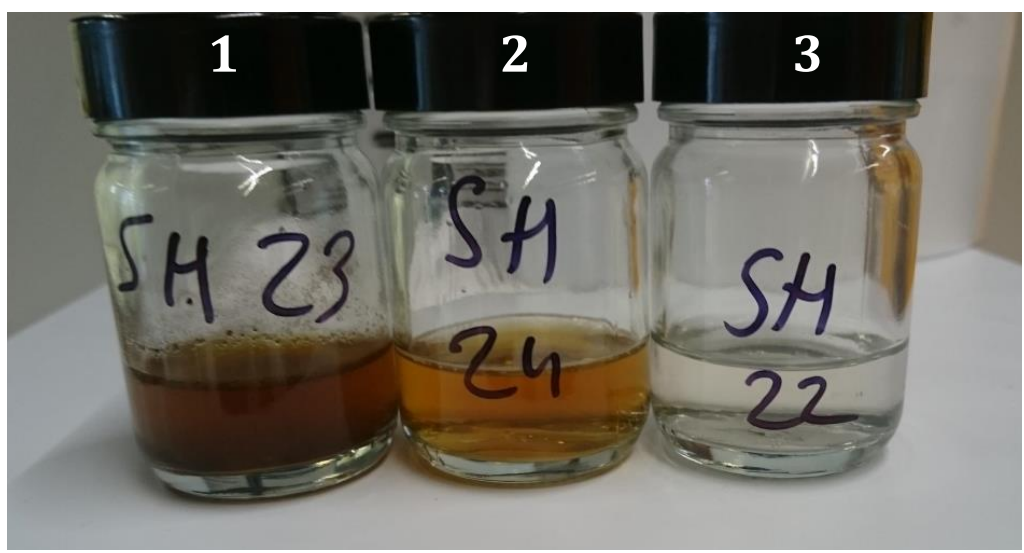

(c)

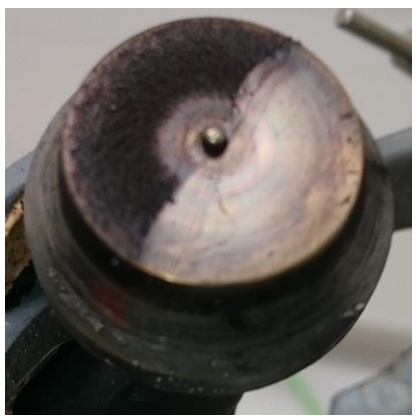

(b)

\section{3}

Figure A.3: Visual depiction of coke on (a) the stirrer, (b) the bottom of the reactor and (c) in the liquid effluents. Experiments conducted at - (c1) $240{ }^{\circ} \mathrm{C}$ and 20 minutes, (c2) $240^{\circ} \mathrm{C}$ and 10 minutes, (c3) $240{ }^{\circ} \mathrm{C}$ and 5 minutes. Corresponding glucose yields of 6, 43 and 0 wt \% were obtained.

\section{A.4 One-pot hydrolytic hydrogenation}

The concentration of sorbitol in the liquid phase was measured using High Pressure Liquid Chromatography (Agilent 1200 series HPLC system equipped with Agilent Hi-Plex H column (300 x $7.7 \mathrm{~mm}$ ) and Agilent 1200 series refractive index detector).

Figure A.4 illustrates the RID signal of the HPLC runs of the liquid products obtained from experiments conducted at $220^{\circ} \mathrm{C}$ and varying residence times of 30,60 and 120 minutes. It can be seen that 30 minutes is insufficient to completely breakdown starch to monosaccharides. At higher residence times, the yield of sorbitol increases, as does the yield of smaller polyols (glycerol, ethylene glycol, propylene glycol). 


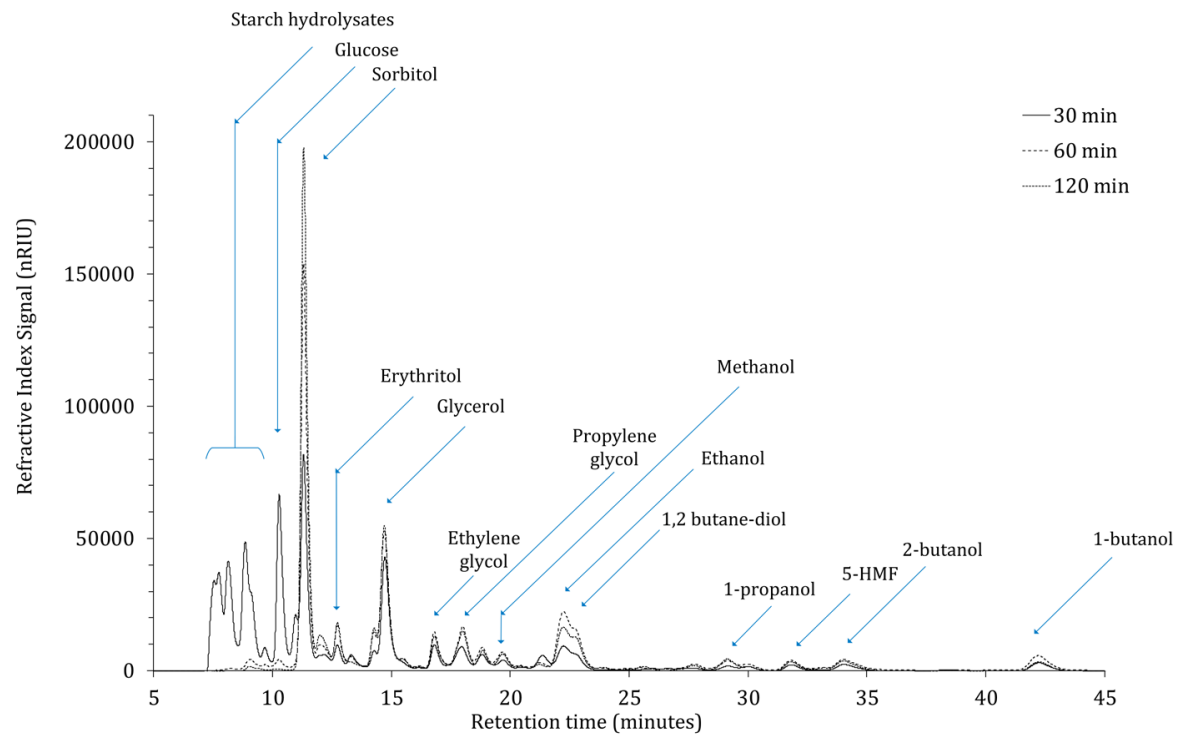

Figure A.4: HPLC spectrum of liquid effluent following starch stabilisation. Experiments conducted at 220

${ }^{\circ} \mathrm{C}$, an initial $\mathrm{H}_{2}$ pressure of 50 bar at room temperature, and $0.1 \mathrm{~g}$ of Ru-C. Analysis conducted on a $\mathrm{H}^{+}$ column set at a temperature of $65^{\circ} \mathrm{C}$, using $5 \mathrm{mM} \mathrm{H}_{2} \mathrm{SO}_{4}$ at a flowrate of $0.6 \mathrm{ml} \mathrm{min}^{-1}$.

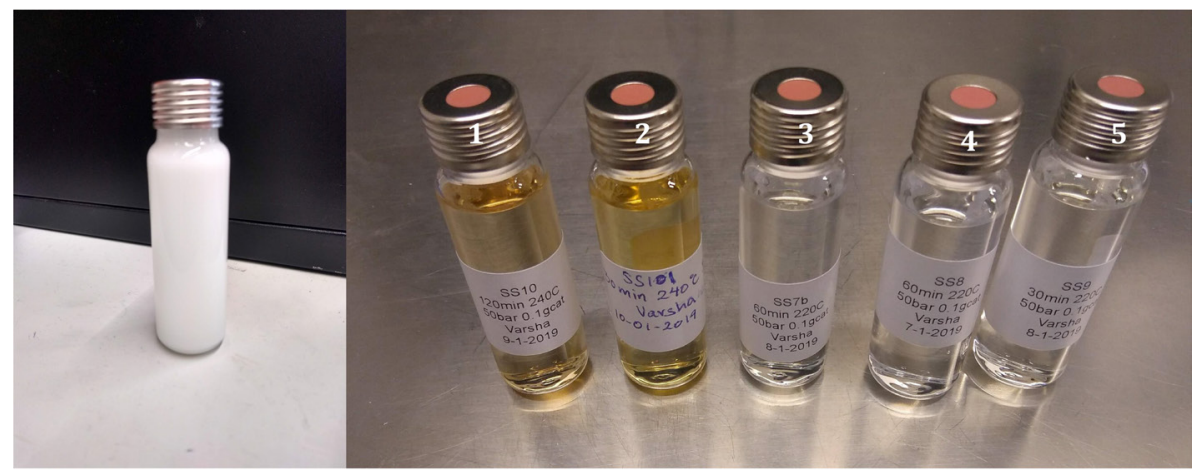

(a)

(b)

Figure A.5: (a) $10 \mathrm{wt} \%$ starch solution (b) stabilised starch at (1) $240{ }^{\circ} \mathrm{C}$ and 120 minutes, (2) $240{ }^{\circ} \mathrm{C}$ and 30 minutes, (3) $220^{\circ} \mathrm{C}$ and 60 minutes, (4) $220^{\circ} \mathrm{C}$ and 60 minutes, (5) $220^{\circ} \mathrm{C}$ and 30 minutes. Experiments conducted using an initial $\mathrm{H}_{2}$ pressure of 50 bar at room temperature, and $0.1 \mathrm{~g}$ of Ru-C. 


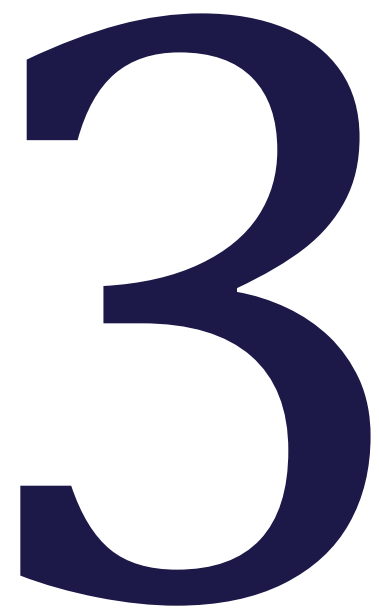

\section{Hydrothermal gasification of sorbitol} gasification efficiencies, Chemical Engineering Journal 358 (2019) 351-361. 


\section{Abstract}

Using both experiments and modelling, hydrothermal gasification of sorbitol aiming at maximal carbon to gas conversion and $\mathrm{H}_{2}$ production was investigated over a wide temperature range $\left(270-350{ }^{\circ} \mathrm{C}\right)$. Kinetics were studied in a continuous tubular reactor using a Pt on $\gamma-\mathrm{Al}_{2} \mathrm{O}_{3}$ catalyst. The addition of $\mathrm{N}_{2}$, resulting in lower $\mathrm{H}_{2}$ concentrations in the liquid phase, was found to have a beneficial effect in terms of higher $\mathrm{H}_{2}$ yield without compromising on the carbon gasification. The highest $\mathrm{H}_{2}$ yield obtained in this experimental work was 4 moles $\mathrm{H}_{2}$ per mole sorbitol. Existing reaction schemes for sorbitol gasification were used to derive kinetic rate equations and constants using a path-lumped scheme. A multi-phase reactor model including the path-lumped scheme and gas-liquid-solid mass transfer was developed and parameterized based on data sets with varying temperature, space velocity, inlet gas composition $\left(\mathrm{N}_{2}\right.$ or $\left.\mathrm{H}_{2}\right)$ and gas-liquid flow ratio. The developed model was used to provide guidelines for the design of an industrial reactor for the gasification of 10 tons $\mathrm{h}^{-1}$ of $10 \mathrm{wt} \%$ aqueous sorbitol. The effect of $\mathrm{N}_{2}$ stripping and

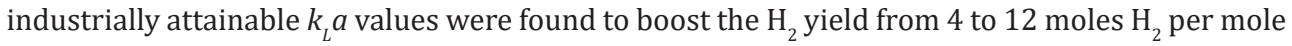
sorbitol making it an attractive process for further consideration.

Aqueous sorbitol

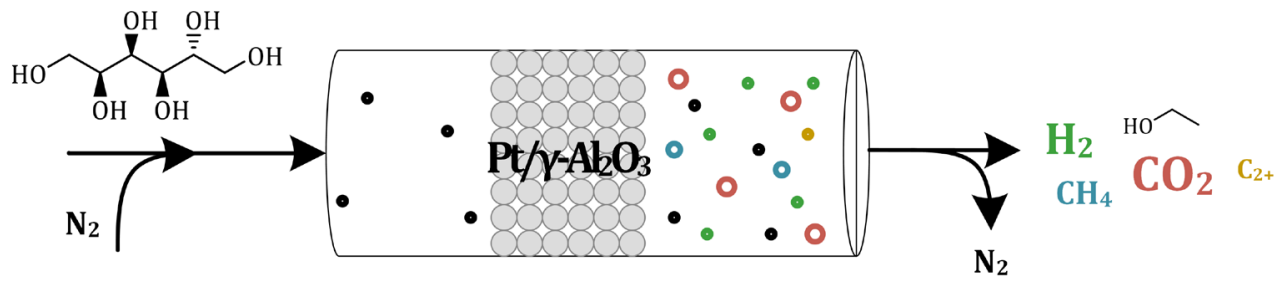




\subsection{Introduction}

Hydrothermal gasification of biomass feeds to valuable chemicals and fuels has received a significant amount of attention in the past two decades. Typically, this type of gasification has been categorised based on temperature ranges of operation. The youngest technology is aqueous phase reforming (APR), developed by Dumesic et al. [37]. It requires lower temperatures (200 $280^{\circ} \mathrm{C}$ ) and has been found to be successful in the production of $\mathrm{H}_{2}$ and alkanes from oxygenates [99]. APR was found to be promising due to its low energy requirements, especially when considering dilute organic streams. Despite many studies in the past decade in the areas of catalyst development and mechanistic studies for model compounds, there is no commercial application yet for relatively complex biomass feeds. Challenges include long operation times (large reactors) due to low kinetic activity at low temperatures and moving from noble metal catalysts towards bi-metallic catalysts to reduce costs while maintaining a good selectivity towards $\mathrm{H}_{2}$ production [100].

At higher, but still sub-critical temperatures $\left(280-350^{\circ} \mathrm{C}\right)$, shorter residence times can be used. Work in this temperature region is limited in comparison to APR and is typically conducted in conjunction with super-critical water gasification (SCWG) $[25,101]$. SCWG $\left(400-800{ }^{\circ} \mathrm{C}\right)$ has also been extensively studied for complex biomass feedstock. SCWG was found to provide a high reaction rate and selectivity (catalytic) to $\mathrm{H}_{2}$ at higher temperatures by taking advantage of the thermo-physical properties of water under these conditions, which enable radical based cracking of biomass to small molecules, ending up in the gas phase. However, due to the need for harsh conditions, corrosion of construction material is significant, and considering the limited value of the products the process is often not economically justified $[14,102]$.

Figure 3.1 shows the studies towards hydrothermal gasification of C6 sugars and sugar alcohols over the entire temperature range, as well as the range considered in this work, indicating the knowledge gap that the current contribution addresses.

Among biomass-derived materials, sorbitol has been used as a key model oxygenate compound. Sorbitol was found to be more stable under reforming conditions $\left(220-275^{\circ} \mathrm{C}\right)$ in comparison to glucose, it's dehydrogenated counterpart, leading to an increase in $\mathrm{H}_{2}$ selectivity from 13 to $62 \%$ under APR conditions [107]. Sorbitol therefore offers a cleaner route towards efficient gas production in comparison to glucose. In Chapter 2, the stabilisation of carbohydrates to a mixture of polyols was studied. Sorbitol was therefore chosen as the start point for this work, representing polyols derived from the stabilisation of carbohydrates. 


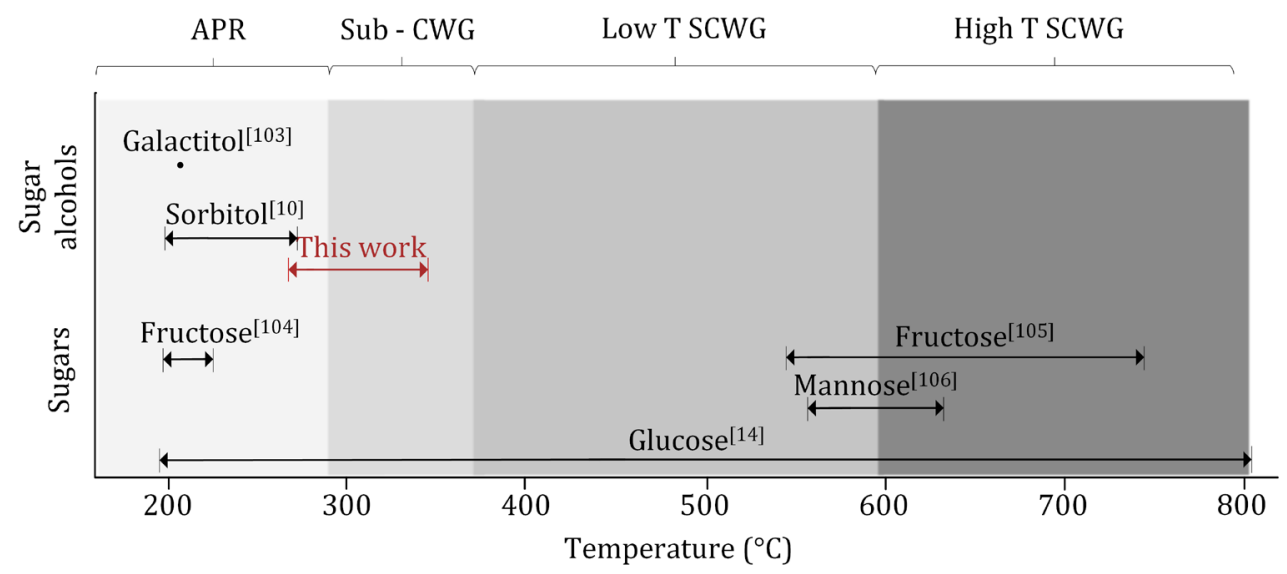

Figure 3.1: Studied temperature ranges for hydrothermal gasification of C6 sugar alcohols - galactitol [103], sorbitol [10], and C6 sugars - fructose [104, 105] , mannose [106] and glucose [14].

The conversion of sorbitol consists of a complex network of reactions and several studies have been conducted to gain more insight into the reaction mechanism [108-110]. However, all the studies have been conducted within a limited temperature range under APR conditions [10]. With respect to kinetic modelling, Aiouache et al. [111] conducted batch experiments in a temperature range of $220-250{ }^{\circ} \mathrm{C}$ using mono and bi-metallic Ni catalysts and developed a path lumped model for the reforming of sorbitol by using a pseudo-generic intermediate. Kirilin et al. [112] conducted continuous tests in a fixed bed reactor and developed a kinetic model to describe sorbitol reforming at $220^{\circ} \mathrm{C}$ using a Pt- $\mathrm{Al}_{2} \mathrm{O}_{3}$ catalyst. Figure 3.2 highlights key reactions reported for the hydrothermal gasification of sorbitol.

In this work, the kinetics of the hydrothermal gasification of sorbitol are investigated over a wider temperature range, encompassing both APR and sub-critical conditions $\left(270-350{ }^{\circ} \mathrm{C}\right)$. Experiments are conducted using a commercial 5 wt \% Pt- $\mathrm{Al}_{2} \mathrm{O}_{3}$ catalyst (Sigma-Aldrich) in a continuous up-flow packed bed reactor. It is known that Pt catalysts are expensive and $\mathrm{Pt}_{-} \mathrm{Al}_{2} \mathrm{O}_{3}$ needs improvements with respect to hydrothermal stability $[113,114]$. However, this work does not focus on catalyst development but on the use of an existing commercially available catalyst in the development of a model that can be used for predictions of $\mathrm{H}_{2}$ production and carbon gasification on an industrial scale. In this regard, $\mathrm{Pt}-\mathrm{Al}_{2} \mathrm{O}_{3}$ is a benchmark catalyst suitable for the production of $\mathrm{H}_{2}$ from aqueous biomass streams [10]. 
The main experimental goal is to determine the optimum $\mathrm{H}_{2}$ production within the operating window considered. While it is known that higher $\mathrm{H}_{2}$ selectivity is obtained at lower conversions, feed concentrations and temperatures [115], this study aims to investigate optimum $\mathrm{H}_{2}$ production rates at higher temperatures and carbon gasification efficiencies. The work presented in this chapter is part of an effort to evaluate the feasibility of complete hydrothermal gasification of sorbitol on an industrial scale. To that effect, a reactor model that incorporates both reaction kinetics and mass transfer is developed to enable the design of a reactor for industrial scale purposes. 

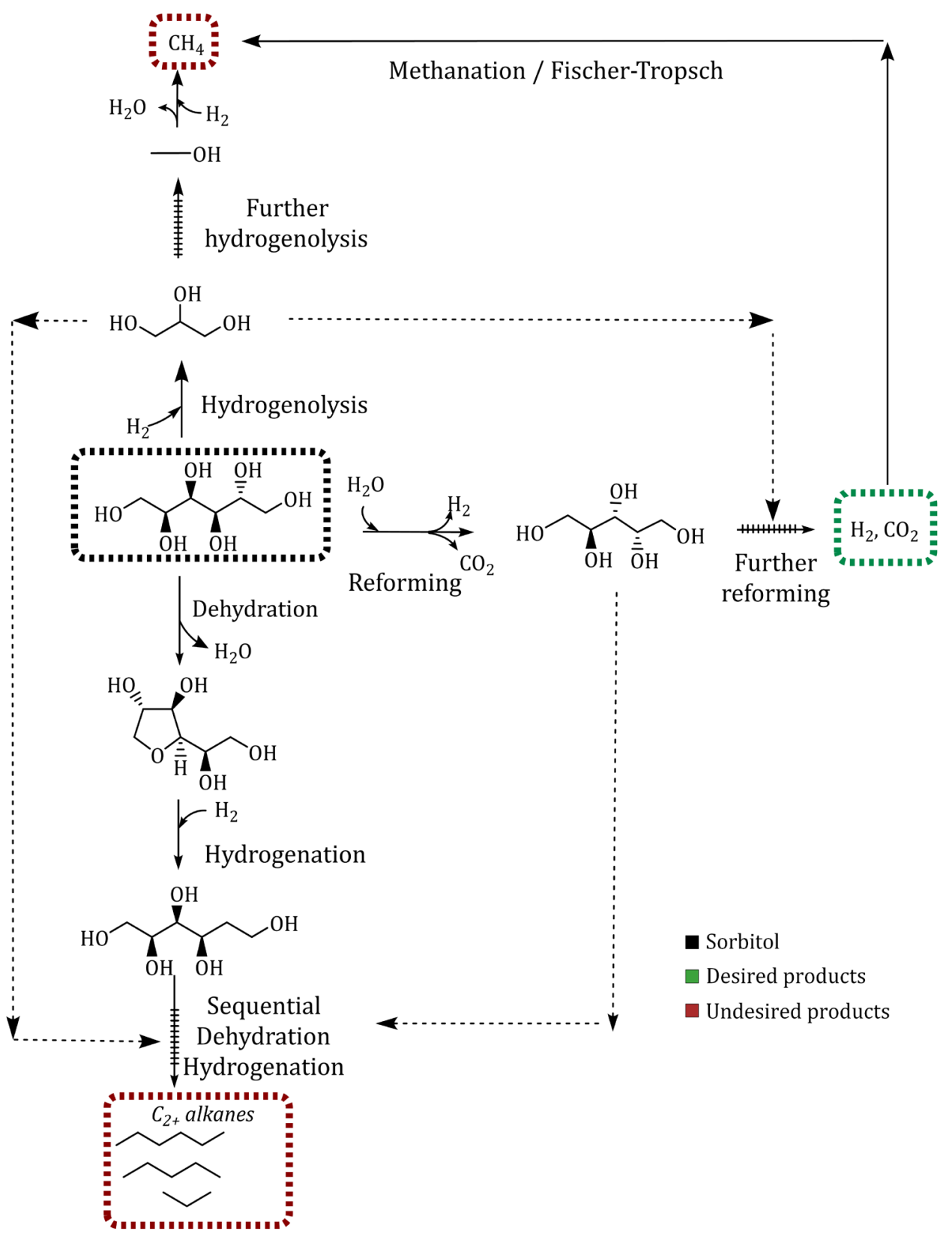

Figure 3.2: Scheme for APR of sorbitol [108-110] 


\subsection{Experimental section}

\subsubsection{Catalyst}

Experiments were conducted using a commercial 5 wt \% $\mathrm{Pt}_{-} \mathrm{Al}_{2} \mathrm{O}_{3}$ catalyst obtained from SigmaAldrich. The surface area of the catalyst was measured using a BET analyser and was determined to be $162.5 \mathrm{~m}^{2} \mathrm{~g}^{-1}$. XRF studies were conducted to confirm the loading of metal on the support and this was found to be $4.65 \%$ by weight.

\subsubsection{Experimental setup}

The continuous experimental setup is shown in Figure 3.3. The vessel for the feed solution stood on a balance that measured its rate of throughput. An additional storage vessel for water was used for purging and cleaning the reactor before and after an experimental run. A 3-way valve that could switch between the two vessels connected to a high pressure dual head piston HPLC pump (Instrument Solutions LU class), which fed liquid solution continuously within a range of 0.1 - $3 \mathrm{ml} \mathrm{min}^{-1}$. A mass flow controller (Brooks SLA5850) was used to feed $10-60 \mathrm{Nml} \mathrm{min}^{-1}$ of pressurized $\mathrm{N}_{2}$ into the reactor. Two check valves in series on the gas line were used to ensure that there was no back flow of liquid to the line. The gas and liquid flows were pre-mixed in a T-junction prior to entering the reactor. The reactor was designed as an Inconel tube (ID $=13 \mathrm{~mm}$, $\mathrm{L}=20 \mathrm{~cm}$ ) and was divided into three sections. The entrance of the reactor was filled with inert sand particles. This provided a uniform distribution of gas and liquid in the reactor, and also heated up the feed to the desired temperature. The central section was filled with $5 \mathrm{wt} \% \mathrm{Pt}-\mathrm{Al}_{2} \mathrm{O}_{3}$ catalyst particles (> $50 \mu \mathrm{m})$, homogeneously mixed with inert sand $(100 \mu \mathrm{m})$. The exit section was also filled with inert sand. This was done in order to reduce the void volume of the reactor by minimising liquid and gas holdup and hence minimising homogeneous decomposition reactions. For temperature control, three thermocouples (T1, T2 and T3) were attached to its outer wall. The reactor temperature was maintained using three electric ovens. The reactor temperature was considered as the average of the three temperatures. The ovens were operated individually such that all three thermocouples of the reactor were at the same temperature $\left( \pm 3^{\circ} \mathrm{C}\right)$. Cooling water was used to cool the product fluids downstream of the reactor in a co-current tubular heat exchanger. The pressure of the system was controlled via a backpressure regulator (Dutch Regulators GBT8S). The operating pressure at the set temperature was always at least 20 bar higher than the vapour pressure of water at that temperature. This way, it was ensured that sufficient water was present in the liquid phase. Pressure drop across the reactor was measured using two pressure sensors at the entrance and exit of the reactor (P1 and P2). 
The mixture of liquids and gases was separated in a gas-liquid separator, operated under atmospheric conditions. A 3-way valve switched between two gas-liquid separators, one which collected product from the experiment, while the other was used for water collection during start up and cool down of the setup. The whole setup was placed in a high pressure box with controls located outside the box so that experiments could be carried out in a safe manner.

Gas products along with $\mathrm{N}_{2}$ were sent to a gas meter operated under atmospheric conditions, and a Rapid Refinery Gas Analyser (Varian) that was connected via a T-junction. The RGA consists of three channels. Channel 1 was used for the separation and detection of $\mathrm{H}_{2}$ using Hayesep Q 80 and Molsieve 5A 80 columns. The column was equipped with a thermal conductivity detector (TCD) using $\mathrm{N}_{2}$ as carrier gas. Channel 2 was used for the separation and detection of permanent gases $\left(\mathrm{CO}_{2}, \mathrm{CO}, \mathrm{O}_{2}\right.$ and $\left.\mathrm{N}_{2}\right)$ using Hayesep Q 80, Hayesep N 80 and Molsieve 13X 80. It was equipped with a TCD detector using Helium as carrier gas. Channel 3 was used for the separation and detection of gaseous hydrocarbons using $\mathrm{Cp}$-sil5 $\mathrm{CB}$ and Select $\mathrm{Al}_{2} \mathrm{O}_{3}$-MAPD. The column was equipped with a flame ionisation detector (FID) and used Helium as carrier gas. Liquid products were analysed off-line for their carbon content using a Flash 2000 Elemental Analyser and for residual sorbitol concentrations using a HPLC column (HiPlex H+, RID detector).

Mass balances were closed using the weighing scales (KERN DS 8K0.05) for the feed and product containers, and the gas meter for the total volume of gas produced. Carbon balances were closed by using the Elemental Analyser for liquid feed and liquid product streams. Carbon in the gas phase was obtained from the volume of gas recorded in the gas meter and the composition of the product gas stream obtained from the RGA analysis. Carbon balance closure was found to be $>87$ $\%$ for all experiments considered with an average closure of $93 \%$. 


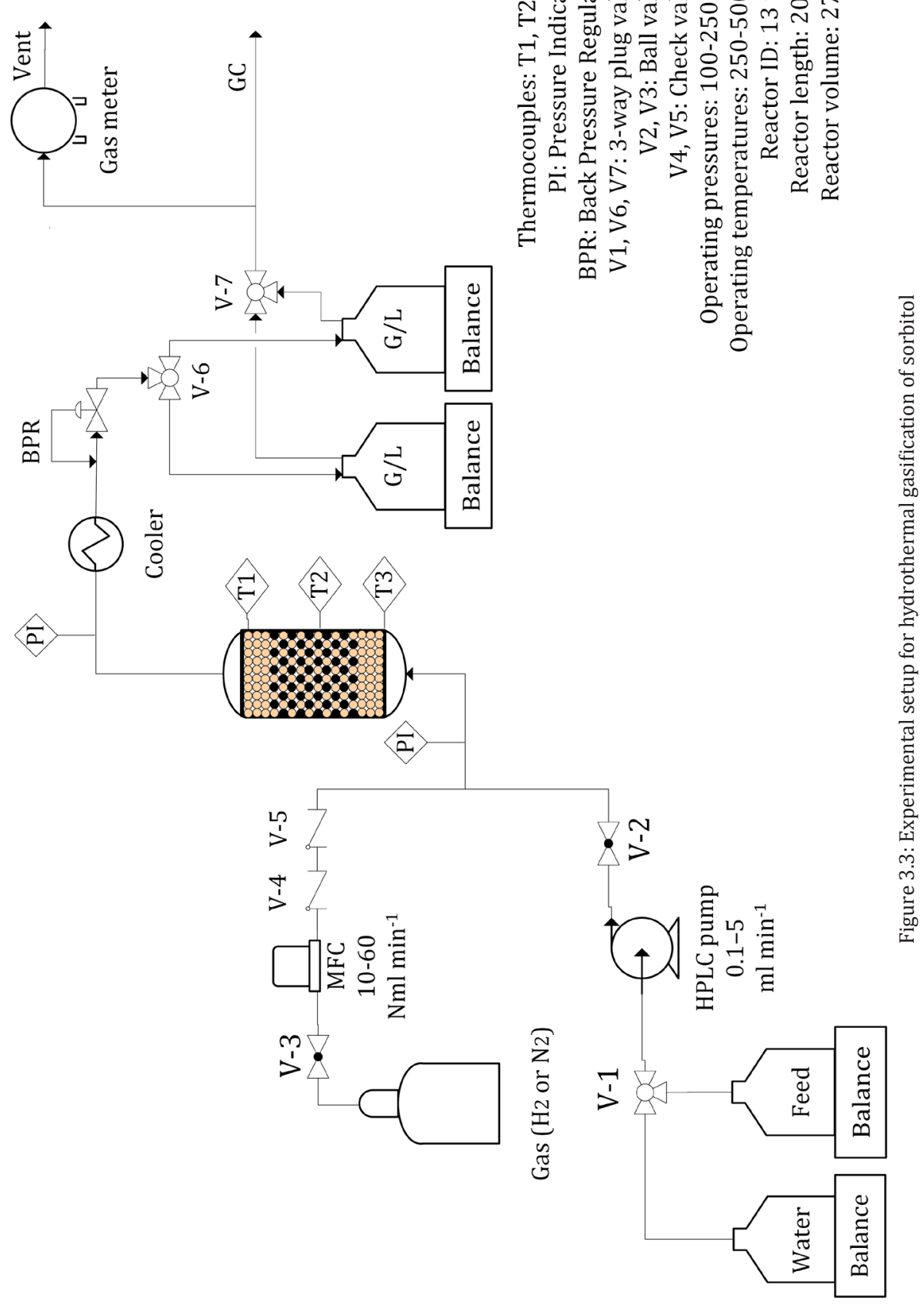

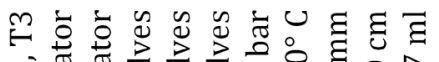
넙

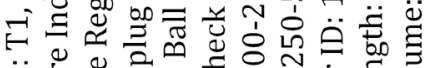

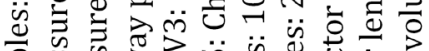

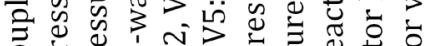

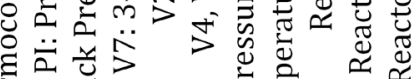
हाँ 藏齐 


\subsubsection{Experimental procedure}

Initially, the catalyst was reduced in-situ by flowing $30 \mathrm{Nml} \mathrm{min}^{-1} \mathrm{H}_{2}$ over the catalyst bed for 2 hours at a temperature of $400{ }^{\circ} \mathrm{C}$ and atmospheric pressure.

Prior to a catalytic test, the reactor was flushed with water and was pressurised (to above the saturation pressure of water) using the back pressure regulator. $\mathrm{N}_{2}$ or $\mathrm{H}_{2}$ was co-fed to the reactor and was pre-mixed with the water at a T-junction upstream of the reactor. Once the setup reached steady-state with the pressurised water- $\mathrm{N}_{2}$ or water- $\mathrm{H}_{2}$ mixture, the reactor was pre-heated to the desired temperature. At isothermal and isobaric conditions, the 3-way valve was used to switch from water to the aqueous feed solution. Sorbitol, obtained from Sigma-Aldrich was used as a feedstock and $10 \mathrm{wt} \%$ aqueous sorbitol solution in Milli-Q water was prepared as the feed solution. At least two times the residence time in the reactor was provided to ensure that steady state conditions were reached. The setup was at 'steady state' once the gas production rate reached a constant value, at a constant system temperature and pressure. A series of catalytic tests was conducted by varying feed flow rate $\left(0.1-2 \mathrm{ml} \mathrm{min}^{-1}\right), \mathrm{N}_{2}$ flow rate $\left(0-60 \mathrm{Nml} \mathrm{min}^{-1}\right), \mathrm{H}_{2}$

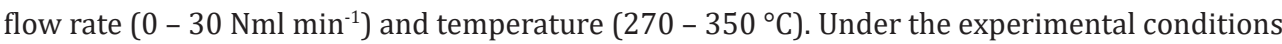
studied, the reactor is operated at all times with three phases present in the system (gas, liquid and solid).

Errors are represented by the standard deviation of the mean at $95 \%$ confidence levels. Quadruple measurements at $270{ }^{\circ} \mathrm{C}$ and $310{ }^{\circ} \mathrm{C}$ were used to calculate the standard deviation at $95 \%$ confidence levels. These values represent the errors of the whole population at all temperatures and residence times. Refer to Table B.1 in Appendix B.1 for the relevant data.

The following expressions were used for the calculation of residence time (Eq. 3.1), sorbitol conversion (Eq. 3.2), $\mathrm{H}_{2}$ yield (Eq. 3.3), product carbon yield for calculation of carbon content in the Liquids, $\mathrm{CO}_{2}$ and Alkanes (Eq. 3.4) and carbon to gas conversion (Eq. 3.5). Alkanes refers to C1-C6 alkanes detected in the gas phase while Liquids refers to other organic species that remain in the aqueous phase.

While it is typical for studies on continuous reactors to use WHSV as a definition for the residence time in the reactor, in this work, as in the work of D'Angelo et al. [116], the residence time is defined as the inverse of the WHSV in molar terms. 


$$
\begin{aligned}
& \tau=\frac{N_{P t}}{F_{S b, \text { in }}}\left[\frac{\text { s·mol } P t}{\text { mol Sb}}\right]\left(\frac{\text { Moles of } P t}{\text { Molar flowrate of } S b}\right) \\
& X_{S b}=\left(1-\frac{F_{S b}}{F_{S b, i n}}\right) \cdot 100\left(\frac{\text { Moles of Sb consumed }}{\text { Initial moles of } S b}\right) \\
& Y_{H_{2}}=\frac{F_{H_{2}}}{F_{S b, i n}}\left(\frac{\text { Moles of } H_{2} \text { produced }}{\text { Initial moles of } S b}\right) \\
& Y_{C, i}=\frac{F_{C, i}}{F_{C, \text { in }}}\left(\frac{\text { Moles of carbon in product } i}{\text { Initial moles of carbon in Sb }}\right) \\
& X_{C G}=\frac{\sum_{C, i}}{F_{C, \text { in }}} \cdot 100\left(\frac{\text { Total moles of carbon in gas products } i}{\text { Initial moles of carbon in } S b}\right) \\
& W H S V=\frac{F_{S b, i n} \cdot 182.2 \cdot 3600}{m_{\text {cat }}}\left[\frac{g_{S b}}{g_{\text {cat }} \cdot h}\right]\left(\frac{\text { Mass flowrate of } S b}{\text { Mass of catalyst }}\right)
\end{aligned}
$$

\subsubsection{Experimental reproducibility}

Spent catalysts were analysed after a series of runs, with a time on stream of $50-60$ hours. To ensure that the catalyst was not deactivated during the measurement series, one in five experiments conducted in a series was a duplicate, thereby ensuring the reproducibility of the experimental data and that the catalyst activity was maintained. The reproducibility of the data was satisfied within an error of $\pm 5 \%$ for the experiments conducted.

One set of deactivated catalyst obtained from measurements conducted at the harshest conditions ( $350^{\circ} \mathrm{C}$ and 185 bar) was analysed and compared to the fresh catalyst as shown in Table 3.1. As can be seen, the surface area of the spent catalyst was drastically reduced. This has been attributed in literature to the poor stability of $\gamma-\mathrm{Al}_{2} \mathrm{O}_{3}$ under hydrothermal conditions, and it's irreversible deactivation to boehmite (AlOOH) [117]. Additionally, the carbon content of the catalyst was measured using Elemental Analysis for the determination of coke deposition. As can be seen, the carbon content of the spent catalyst was $1.45 \mathrm{wt} \%$, confirming that coke deposition was present under the experimental conditions studied. The presence of carbonaceous deposits was found to improve the stability of $\mathrm{Al}_{2} \mathrm{O}_{3}$ catalysts in comparison to their deactivation in hot compressed water, lowering the conversion to boehmite [113]. Nevertheless, significant improvements in catalyst stability under hydrothermal processing conditions are necessary in order to consider the long-term application of a catalyst on an industrial scale.

Table 3.1: Catalyst properties before and after experiments conducted at $350{ }^{\circ} \mathrm{C}$ and 180 bar

\begin{tabular}{cccc}
\hline $\mathrm{Pt}^{-\mathrm{Al}_{2} \mathrm{O}_{3}}$ & $\begin{array}{c}\text { BET surface area } \\
\left(\mathrm{m}^{2} \mathrm{~g}^{-1}\right)\end{array}$ & $\begin{array}{c}\text { Pt loading } \\
(\mathrm{wt} \%)\end{array}$ & $\begin{array}{c}\text { Carbon content } \\
(\mathrm{wt} \%)\end{array}$ \\
\hline Fresh catalyst & 162.5 & 4.65 & $8.5 \cdot 10^{-2}$ \\
Spent catalyst & 65.5 & 4.69 & 1.45 \\
\hline
\end{tabular}




\subsection{Experimental results}

\subsubsection{Homogeneous reactions}

Experimental tests made in the absence of the catalyst under all the conditions considered in this work showed poor gasification $\left(<10 \%\right.$ at $350^{\circ} \mathrm{C}$ ) and the production of an oil phase that had a carbon contribution of $20 \%$. While the higher temperatures $>300{ }^{\circ} \mathrm{C}$ lead to the homogeneous decomposition of sorbitol, the presence of a catalyst is very much required for the conversion of aqueous carbon to gas phase compounds at sub-critical conditions.

\subsubsection{Effect of residence time}

Figure 3.4(a) illustrates the effect of residence time on the carbon distribution of sorbitol, Liquids, $\mathrm{CO}_{2}$ and Alkanes at $270^{\circ} \mathrm{C}$. As expected, longer residence times increase the carbon conversion to gas. Initially, the yield of $\mathrm{CO}_{2}$ increases rapidly as function of the residence time. From 200 to 450 $\mathrm{s} \cdot \mathrm{mol} \mathrm{Pt} \mathrm{mol} \mathrm{Sb}{ }^{-1}$ the increase is considerably less. This may be attributed to the inhibiting effect of $\mathrm{H}_{2}$ on the reforming reaction which has been previously observed for APR of ethylene glycol [118] and sorbitol [116]. On the other hand, the yield of Alkanes and Liquids show a (nearly) linear trend with increasing residence times. Although the yield of Alkanes does not exceed a total of 0.5 moles mol Sb${ }^{-1}\left(0.25 \mathrm{~mol} \mathrm{C} \mathrm{mol} \mathrm{C}^{-1}\right)$, the linearly increasing trend has a significant influence on the total carbon gasification as shown in Figure 3.4(a). At the longest residence time studied, this accounts for $25 \%$ of the total carbon fed and can be attributed to the carbon contribution of $\mathrm{C}_{4}-\mathrm{C}_{6}$ alkanes in the gaseous product.

Figure 3.4(b) depicts the $\mathrm{H}_{2}$ yield as a function of sorbitol conversion. It is interesting to see that the production of $\mathrm{H}_{2}$ increases most after the complete degradation of sorbitol. From this it is deduced that the majority of the $\mathrm{H}_{2}$ is produced via the reforming of intermediates in the liquid phase formed from the fast degradation of sorbitol. Apparently, direct sorbitol reforming to $\mathrm{H}_{2}$ is a slow reaction under the experimental conditions considered in this work. 


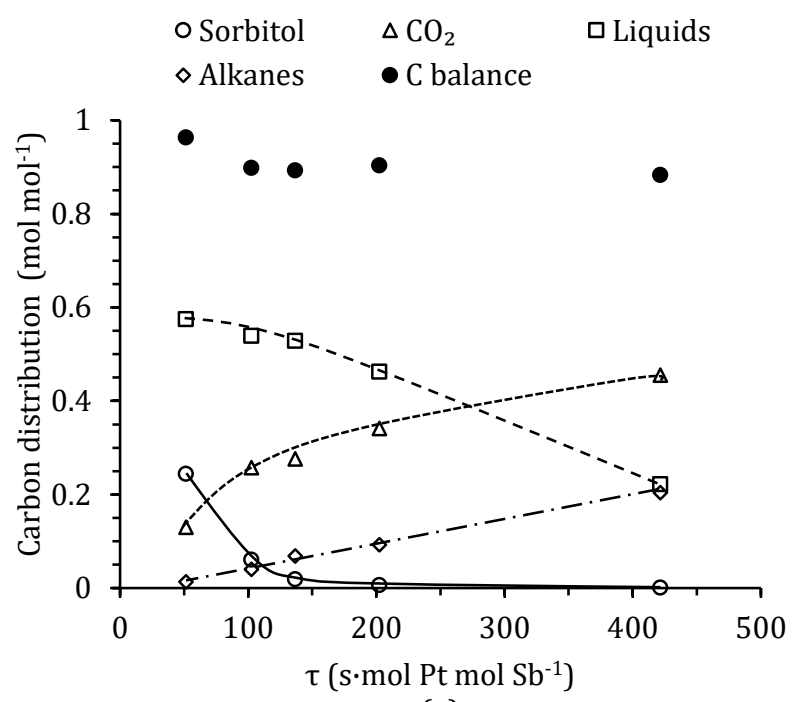

(a)

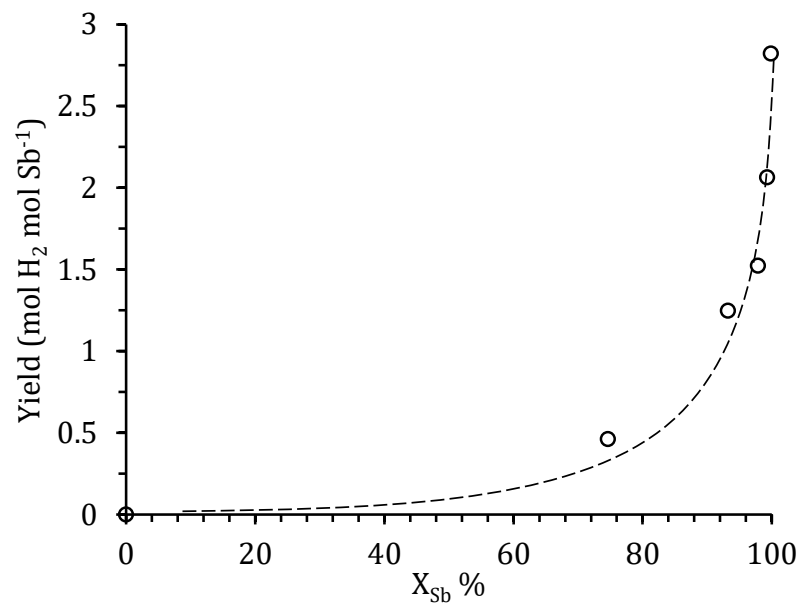

(b)

Figure 3.4: (a) Effect of residence time on carbon distribution among Sorbitol, Liquids, $\mathrm{CO}_{2}$ and Alkanes. WHSV varied from 3.3 to $0.4 \mathrm{~h}^{-1}$ (b) $\mathrm{H}_{2}$ yield as a function of sorbitol conversion at corresponding residence times. Experiments conducted at $270{ }^{\circ} \mathrm{C}$ and 85 bar using $4 \mathrm{~g}$ of $\mathrm{Pt}_{-} \mathrm{Al}_{2} \mathrm{O}_{3}$ and $30 \mathrm{Nml} \mathrm{N} \mathrm{min}^{-1}$. Note: The lines are an aid to the eye 


\subsubsection{Effect of temperature}

Experimental data in the temperature range studied showed that the $\mathrm{H}_{2}$ yield has a maximum at $310{ }^{\circ} \mathrm{C}$, as illustrated in Figure 3.5. The decrease above $310^{\circ} \mathrm{C}$ is attributed to the increased reactivity of $\mathrm{H}_{2}$ consuming reactions towards the production of intermediate liquid species and alkanes. Figure 3.5 shows the effect of temperature on the distribution of atomic hydrogen. Although water is consumed and produced during reactions, it is not possible to quantify it due to its presence in excess in the feed. So the amount of atomic hydrogen in Liquids was calculated by difference between the atomic hydrogen in sorbitol and the total atomic $\mathrm{H}$ in all gaseous species. The purpose of Figure 3.5 is to provide an insight into the distribution of the atomic hydrogen derived from sorbitol among the different products. As illustrated, at $350{ }^{\circ} \mathrm{C}$, the atomic hydrogen in the form of gaseous $\mathrm{H}_{2}$ reduces and it can be seen that the $\mathrm{H}$ contribution in Alkanes and Liquids is higher. The increase in $\mathrm{H}_{2}$ content of Alkanes is also reflected in the total carbon gasification, which increase from $35 \%$ to $78 \%$ at a residence time of $100 \mathrm{~s} \cdot \mathrm{mol} \mathrm{Pt} \mathrm{mol} \mathrm{Sb}{ }^{-1}$.

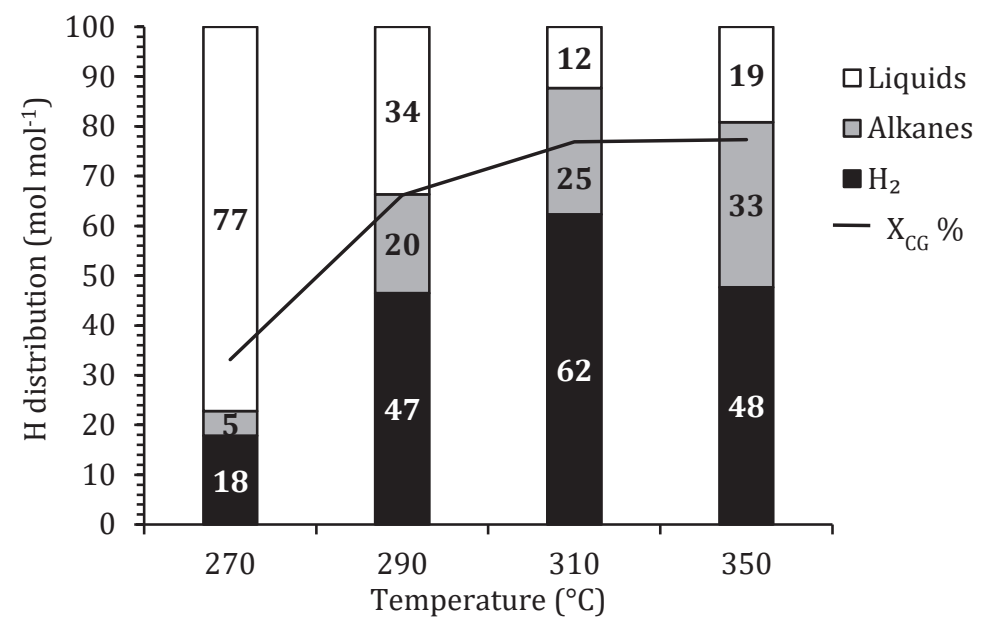

Figure 3.5: Effect of temperature on $\mathrm{H}$ distribution. Experiments conducted at a residence time of $100 \mathrm{~s} \cdot \mathrm{mol}$ $\mathrm{Pt} \mathrm{mol} \mathrm{Sb}^{-1}$ (WHSV of $1.6 \mathrm{~h}^{-1}$ ) using $4 \mathrm{~g}$ of Pt- $\mathrm{Al}_{2} \mathrm{O}_{3^{3}}, 10 \mathrm{wt} \%$ sorbitol solution and $30 \mathrm{Nml} \mathrm{N}_{2} \mathrm{~min}^{-1}$.

\subsubsection{Effect of $\mathrm{N}_{2}$ flow}

The influence of $\mathrm{N}_{2}$ flow has been studied extensively by D'Angelo et al., albeit at lower conversions and temperatures [116]. It was found that utilising $\mathrm{N}_{2}$ as a stripping gas enhanced the $\mathrm{H}_{2}$ yield by decreasing the concentration of $\mathrm{H}_{2}$ in the gas phase and therefore increasing the driving force for mass transfer which results in a lower $\mathrm{H}_{2}$ concentration in the liquid phase. In this work, this effect was verified and studied at higher temperatures and conversions. 
Figure 3.6 shows this effect of $\mathrm{N}_{2}$ flow by comparing a constant $\mathrm{N}_{2}$ flow of $30 \mathrm{Nml} \mathrm{min}^{-1}$ at residence times between 40 and $200 \mathrm{~s} \cdot \mathrm{mol} \mathrm{Pt} \mathrm{mol} \mathrm{Sb}{ }^{-1}$ with a constant inlet gas-liquid ratio of $30\left(\mathrm{Nm}^{3} \mathrm{~m}^{-3}\right.$ liquid) at similar residence times.

As illustrated in Figure 3.6(a), the $\mathrm{N}_{2}$ flow has a large effect on the $\mathrm{H}_{2}$ yield at longer residence times. At a residence time of $100 \mathrm{~s} \cdot \mathrm{mol} \mathrm{Pt} \mathrm{mol} \mathrm{Sb}^{-1}$, the $\mathrm{N}_{2}$ flow of $30 \mathrm{ml} \mathrm{min}^{-1}$ equals a $\mathrm{R}_{\mathrm{GL}}$ of 30 . Hence, the data points presented are a duplicate measurement. At longer residence times, a $\mathrm{N}_{2}$ flow of $30 \mathrm{ml} \mathrm{min}^{-1}$ causes the $\mathrm{R}_{\mathrm{GL}}$ to be larger than 30 . For instance, at a residence time of 200 $\mathrm{s} \cdot \mathrm{mol} \mathrm{Pt} \mathrm{mol} \mathrm{Sb}{ }^{-1}$, the liquid feed flowrate is $0.5 \mathrm{ml} \mathrm{min}^{-1}$, causing the $\mathrm{R}_{\mathrm{GL}}$ to be 60 at a $\mathrm{N}_{2}$ flowrate of $30 \mathrm{ml} \mathrm{min}^{-1}$. This leads to a larger stripping effect. At this residence time, $\mathrm{H}_{2}$ yield increased from 3 to $3.8 \mathrm{~mol} \mathrm{~mol} \mathrm{Sb}{ }^{-1}$. The positive effect of $\mathrm{N}_{2}$ flow on the $\mathrm{H}_{2}$ yield confirms that the extraction of $\mathrm{H}_{2}$ from the liquid phase has a significant influence on the overall production of $\mathrm{H}_{2}$. In comparison, as seen in Figure 3.6(b), the effect of $\mathrm{N}_{2}$ has a negligible influence on the total carbon gasification. This can be attributed to the combined change in the yields of carbonaceous species in the gas phase. The stripping effect enhances the $\mathrm{CO}_{2}$ yield in a manner similar to the effect of $\mathrm{N}_{2}$ on the $\mathrm{H}_{2}$ yield; i.e, by reducing its concentration in the gas phase. However, the opposite trend is seen for the production of gaseous alkane species whose yield is decreased due to the presence of a lower concentration of $\mathrm{H}_{2}$. By stripping $\mathrm{H}_{2}$ out of the liquid phase, there is less $\mathrm{H}_{2}$ available for reactions that produce gaseous alkanes, therefore reducing the carbon contribution of alkanes in the gas phase. Thus, higher $\mathrm{CO}_{2}$ yields are balanced by the lower alkane yields, not affecting the total carbon gasification. 


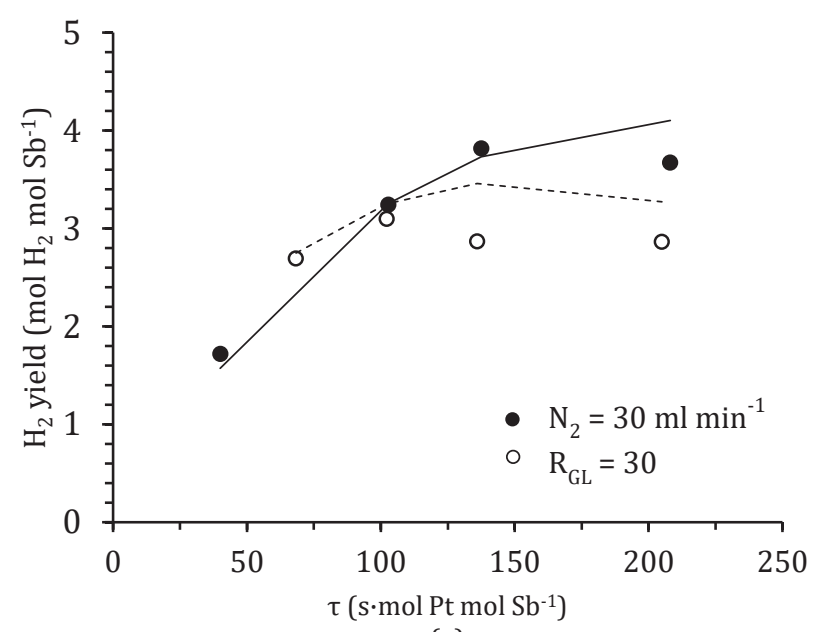

(a)

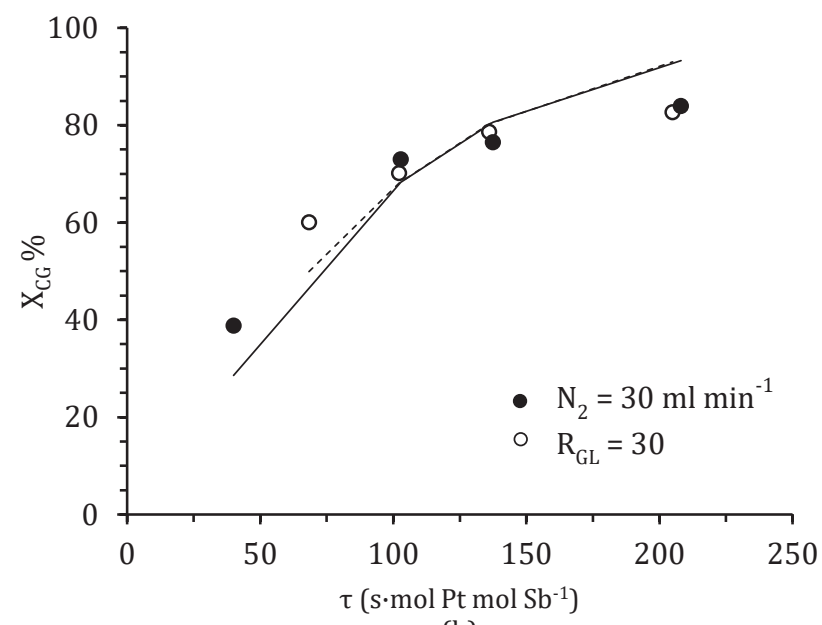

(b)

Figure 3.6: Experimental data points and model curves of the effect of $\mathrm{N}_{2}$ on (a) $\mathrm{H}_{2}$ yield and (b) carbon to gas conversion. WHSV varied from 3.3 to $0.8 \mathrm{~h}^{-1}$. Experiments conducted at $310^{\circ} \mathrm{C}$ and 120 bar using $4 \mathrm{~g}$ of Pt- $\mathrm{Al}_{2} \mathrm{O}_{3}$ and 10 wt $\%$ sorbitol solution. 


\subsubsection{Effect of $\mathbf{H}_{2}$ flow}

The influence of $\mathrm{H}_{2}$ flow on the reforming and alkane production rates was studied at $270{ }^{\circ} \mathrm{C}$ at varying residence times. By feeding $\mathrm{H}_{2}$ instead of $\mathrm{N}_{2}$, the $\mathrm{H}_{2}$ partial pressure at the inlet of the reactor could be increased to maximally 30 bar, which was much higher than that could be achieved at any length of the reactor by changing the $\mathrm{N}_{2}$ flow.

Figure 3.7 illustrates the carbon yields of $\mathrm{CO}_{2}$ and gaseous alkanes. According to the figure, the addition of $\mathrm{H}_{2}$ causes a significant reduction in the $\mathrm{CO}_{2}$ yield. This can be attributed to the inhibiting effect of $\mathrm{H}_{2}$ on the reforming reaction and is consistent with studies of D'Angelo et al. [116] on the effect of changing partial pressures of $\mathrm{H}_{2}$ on the reforming reaction. On the other hand, the alkanes showed an increased yield in the presence of $\mathrm{H}_{2}$, indicating the positive effect of the $\mathrm{H}_{2}$ concentration on the alkane production rate. As the $\mathrm{H}_{2}$ partial pressures increase with increasing residence time, the alkane production rate increases. With respect to sorbitol conversion (not shown in the figure), no significant difference was seen in the sorbitol decay rate in the presence of $\mathrm{H}_{2}$. This contradicts the study of D'Angelo et al. in which the $\mathrm{H}_{2}$ partial pressure reduced the sorbitol conversion, which was ascribed to inhibition of the reforming reaction. At the higher temperatures considered in this study, such an inhibiting effect was not observed. A possible explanation is that this could be offset by the increase in sorbitol hydrogenolysis reactions that are enhanced in the presence of $\mathrm{H}_{2}$.

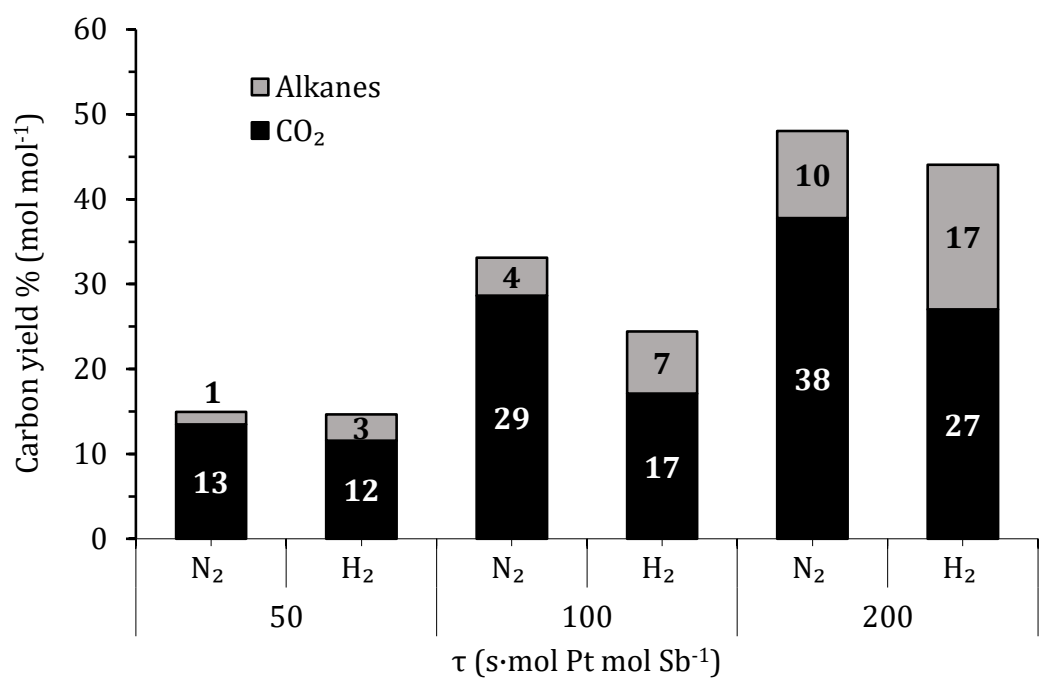

Figure 3.7: Effect of $\mathrm{N}_{2}$ and $\mathrm{H}_{2}$ flow on the carbon yield of $\mathrm{CO}_{2}$ and alkanes at varying residence times. Corresponding WHSV: 3.3 to $0.8 \mathrm{~h}^{-1}$. Experiments conducted at $270{ }^{\circ} \mathrm{C}$ and 85 bar using $4 \mathrm{~g}$ of Pt- $\mathrm{Al}_{2} \mathrm{O}_{3}$ and

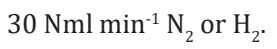




\subsection{Reactor model}

\subsubsection{Path lumped scheme development}

As mentioned previously, the reforming of sorbitol consists of a complex network of reactions, with more than 80 intermediates and products identified [108]. Therefore a path-lumped kinetic scheme has been developed for engineering purposes. The starting point was the reaction network depicted in Figure 3.8(a) which has been developed based on existing reaction mechanisms proposed for sorbitol reforming (Refer Figure 3.2).

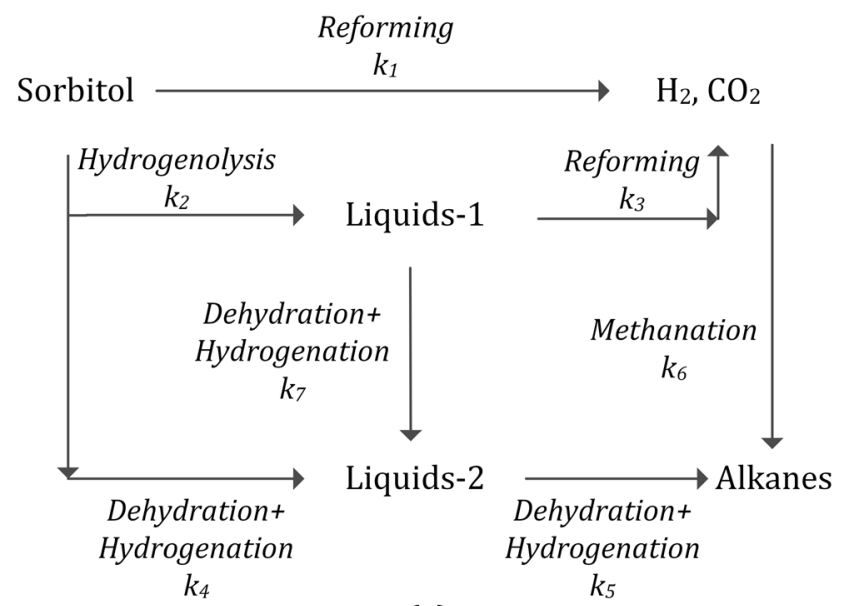

(a)

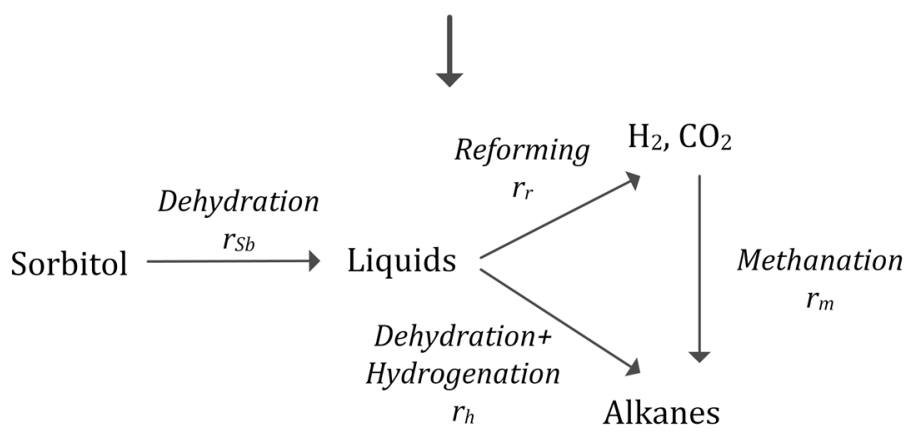

(b)

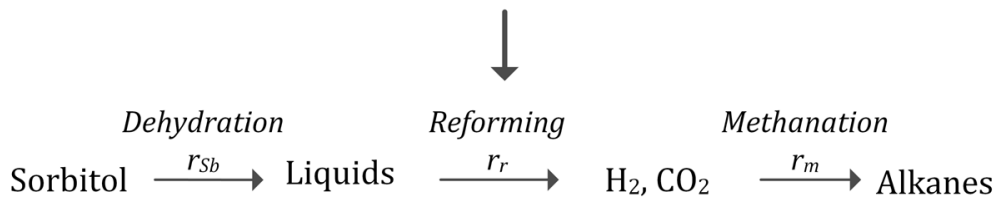

(c)

Figure 3.8: $(a, b, c)$ Development of path lumped model 
In the scheme shown in Figure 3.8(a), sorbitol undergoes reforming to produce $\mathrm{H}_{2}$ and $\mathrm{CO}_{2}$. Produced $\mathrm{H}_{2}$ is consumed in hydrogenolysis reactions of sorbitol to produce Liquids-1, representing compounds exhibiting similar chemistry as sorbitol $(\mathrm{OH}$ to $\mathrm{C}$ ratio equal to 1$)$. Sorbitol also undergoes dehydration to produce Liquids-2 $(\mathrm{OH}$ to $\mathrm{C}$ ratio less than 1$)$ that could undergo further sequential dehydration-hydrogenation reactions to produce Alkanes. $\mathrm{H}_{2}$ and $\mathrm{CO}_{2}$ are also consumed in methanation reactions to produce Alkanes. This model consists of 7 reaction rates and 8 parameters to be fitted. While the model performed well in describing the experimental data at all temperatures, the parameters were found to be highly correlated, causing large discrepancies in the fitted parameters and broad confidence intervals. The model was therefore simplified to the final one shown in Figure 3.8(c) in the following ways:

1) The direct reforming pathway of sorbitol to $\mathrm{H}_{2}$ is considered negligible based on experimental results presented in Figure 3.4(b) (insignificant $\mathrm{H}_{2}$ production below $80 \%$ sorbitol conversion).

2) The decay rate of sorbitol is fast as a result of which incomplete conversion was only measured up to $290^{\circ} \mathrm{C}$. Based on experimental results, the rate of sorbitol decay at $270{ }^{\circ} \mathrm{C}$ was found to be unaffected by $\mathrm{H}_{2}$ partial pressure, as discussed in Section 3.3.5, and therefore this rate is modelled as first order with respect to sorbitol concentration.

An activation energy of $33 \mathrm{~kJ} \mathrm{~mol}^{-1}$ for the homogeneous hydrothermal degradation of sorbitol from literature was found to be describe the sorbitol degradation ineffectively [119]. In the presence of a catalyst, sorbitol degrades almost completely above $250{ }^{\circ} \mathrm{C}$. Therefore, batch reactor data at $250^{\circ} \mathrm{C}$ and $290^{\circ} \mathrm{C}$ were used to fit the decay rate of sorbitol $\left(r_{S b}\right)$. Using the Arrhenius equation, the calculated activation energy of $169 \mathrm{~kJ} \mathrm{~mol}^{-1}$ was used for the determination of sorbitol decay rates in the continuous reactor. A description of the batch reactor used can be found in Chapter 2. Appendix B.2 contains the batch reactor data for sorbitol degradation.

Sorbitol is converted to liquid intermediates, represented by the lump Liquids, which are further reformed to $\mathrm{H}_{2}, \mathrm{CO}_{2}$ and alkanes. For modelling purposes, Liquids is represented by 1,4 anhydro-sorbitol, the dehydrated counter-part of sorbitol.

3) Since there are innumerable liquid intermediates during the conversion of sorbitol to gas, the only information known about the liquids at all residence times and temperatures is the concentration of carbon in the water. Therefore, Liquids-1 and Liquids-2 were lumped into one group referred to as Liquids. 
4) Liquids are converted to $\mathrm{H}_{2}$ and $\mathrm{CO}_{2}$ via a reforming pathway $\left(r_{r}\right)$ and a competing hydrogenation pathway $\left(r_{h}\right)$ converts Liquids to Alkanes represented by propane. The reforming pathway is modelled using a Langmuir-Hinshelwood type mechanism, based on studies in which the blockage of catalytic sites by adsorption of $\mathrm{H}_{2}$ was found to reduce the reforming rate [120]. This inhibition is taken into consideration by introducing an adsorption constant $K_{e q}$ for $\mathrm{H}_{2}$ (Refer Table 3.2) that is fitted at $270^{\circ} \mathrm{C}$ using the experimental data with $\mathrm{H}_{2}$ flows (Refer Figure 3.7). By utilising an exothermic heat of adsorption $\left(\Delta H_{a d s}\right)$ of $33 \mathrm{~kJ} \mathrm{~mol}^{-1}$ for $\mathrm{H}_{2}$ adsorption on $\mathrm{Pt}_{-} \mathrm{Al}_{2} \mathrm{O}_{3}$ [121], $K_{e q}$ is pre-determined for the fitting at higher temperatures using the Van't Hoff equation shown in Eq (3.7). Additionally, $\mathrm{H}_{2}$ and $\mathrm{CO}_{2}$ can be converted to Alkanes via a methanation pathway $\left(\mathrm{r}_{\mathrm{m}}\right)$.

$\frac{d}{d T} \ln K_{e q}=\frac{\Delta H_{a d s}}{R T^{2}}$

5) Fitting of kinetic parameters at all temperatures resulted in a negligible rate of Alkanes formation via Liquids $\left(r_{h}\right)$ indicating that the production of Alkanes could be represented by a dominating methanation rate $\left(r_{m}\right)$. The correlation matrix showed that the rate constant $k_{h}$, in Figure 3.8(b) was found to be highly correlated ( $>0.95$ ) with rate constant $k_{m}$ and a very broad confidence interval. Therefore rate $r_{h}$ was eliminated from the model leading to a path lumped scheme represented by series reactions, as shown in Figure 3.8(c). The stoichiometric equations used are shown in Figure 3.9.<smiles>OC[C@@H](O)[C@@H](O)[C@H](O)[C@H](O)CO</smiles><smiles>OC[C@@H](O)C1OC[C@@H](O)[C@H]1O</smiles>

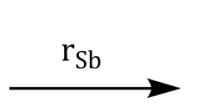<smiles>OC[C@@H](O)C1OC[C@@H](O)[C@H]1O</smiles>

To model the reactor a set of plausible assumptions was made, to arrive at the molar balances:

1) The reactor is assumed to be an ideal fixed bed reactor, with co-current gas and liquid flow in plug flow without axial dispersion.

2) The reactor operates under isothermal conditions. 
3) The catalyst is fully wetted by the liquid.

4) The reactor operates at steady state. Catalyst deactivation is not considered.

5) There is neither coke production on the surface of the catalyst nor in the liquid phase.

6) With respect to liquid-solid external mass transfer limitations, suitable correlations and model calculations were performed to ensure that liquid-solid mass transfer rate >> reaction rate. Therefore, liquid-solid mass transfer resistance is not considered. Further information can be found in Appendix B.3.

7) Based on analysis of the effectiveness factor, the concentration of the species in the liquid phase is considered to be the same as that in the catalyst particle. Further information can be found in Appendix B.3.

Table 3.2 lists the modelling equations used. More information on development of the equations is provided in Appendix B.4. 


\begin{tabular}{|c|}
\hline Intrinsic reaction rate (moles $\mathrm{C}_{\mathrm{i}}$ moles $\mathrm{Pt}^{-1} \mathrm{~s}^{-1}$ ) \\
\hline$r_{S b}=k_{S b} \cdot c_{S b}^{l}$ \\
\hline$r_{r}=\frac{k_{r} \cdot c_{l i q}{ }^{l}}{1+K_{e q} \cdot c_{H_{2}}{ }^{l}}$ \\
\hline$r_{m}=k_{m} \cdot c_{\mathrm{CO}_{2}}{ }^{l} \cdot c_{\mathrm{H}_{2}}{ }^{l}$ \\
\hline Rate of reaction for species \\
\hline Sorbitol: $\quad R_{S b}=-r_{S b}$ \\
\hline Liquids: $\quad R_{\text {liq }}=r_{S b}-r_{r}$ \\
\hline $\mathrm{H}_{2}: \quad R_{H_{2}}=-13 r_{r}+10 r_{m}$ \\
\hline $\mathrm{CO}_{2}: \quad R_{\mathrm{CO}_{2}}=-6 r_{r}+3 r_{m}$ \\
\hline Alkanes: $R_{\text {Alk }}=r_{m}$ \\
\hline
\end{tabular}

\section{System of equations}

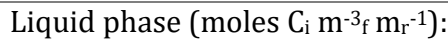

$\frac{d c_{S b}{ }^{l}}{d z}=\frac{C_{P t}}{u_{l}} .\left(-R_{S b}\right)$

$\frac{d c_{l i q}{ }^{l}}{d z}=\frac{C_{P t}}{u_{l}} \cdot\left(R_{l i q}\right)$

$\frac{d c_{i}^{l}}{d z}=\frac{C_{P t}}{u_{l}} \cdot\left(R_{i}\right)-\frac{\left(k_{L} a\right)_{i}}{u_{l}} \cdot\left(c_{i}^{l}-\frac{p_{i}}{H_{i}}\right)$ for $i=\mathrm{H}_{2}, \mathrm{CO}_{2}, \mathrm{C}_{3} \mathrm{H}_{8}$

$\frac{d c_{i}^{l}}{d z}=-\frac{\left(k_{L} a\right)_{i}}{u_{l}} \cdot\left(c_{i}^{l}-\frac{p_{i}}{H_{i}}\right)$ for $i=\mathrm{N}_{2}$

Gas phase (moles s ${ }^{-1}$ ):

$\frac{d F_{i}{ }^{g}}{d z}=-\left(k_{L} a\right)_{i} \cdot A \cdot\left(\frac{p_{i}}{H_{i}}-c_{i}^{l}\right)$ for $i=\mathrm{H}_{2}, \mathrm{CO}_{2}, \mathrm{C}_{3} \mathrm{H}_{8}, \mathrm{~N}_{2}$

$p_{i}=\frac{F_{i}{ }^{g}}{\sum F_{\text {gas }}} \cdot\left(p_{T}-p_{\mathrm{H}_{2} \mathrm{O}}\right)$ for $i=\mathrm{H}_{2}, \mathrm{CO}_{2}, \mathrm{C}_{3} \mathrm{H}_{8}, \mathrm{~N}_{2}$

\section{Initial conditions}

$c_{S b}=x_{S b} \cdot \frac{\rho_{S b}}{M_{S b}}, c_{l i q}=0$,

$F_{i}{ }^{g}=0$, except for ${F_{N_{2}}}^{g}=\frac{P_{0} Q_{N_{2, i n}}}{R T_{0}}$,

$p_{i}=0$, except for $p_{N_{2}}=P_{T}-P_{v}$ 


\subsection{2 $k_{L} a$ estimation}

In order to estimate true kinetic parameters, it is necessary to know the value of the liquid-side volumetric mass transfer coefficient $\left(k_{L} a\right)$ in the experimental setup and under the conditions used. The estimation and measurement of $k_{L} a$ in batch reactors is more straightforward and has been studied extensively with multiple methods used for its determination [122]. The estimation of $k_{L} a$ in continuous packed bubble bed columns, on the other hand, is not as simple. Typically for such systems, empirical methods based on experimental data are sought in order to predict the $k_{L} a$ reliably. From the experimental results discussed in section 3.3.4 it can be seen that mass transfer has a significant influence on the $\mathrm{H}_{2}$ yield. Therefore, a strategy was developed to address this issue, considering two different cases. In Case $\mathrm{A}$, the $k_{L} a$ is fitted simultaneously along with the reaction rate constants based on experiments conducted at $310{ }^{\circ} \mathrm{C}$ with changing $\mathrm{N}_{2}$ flows. Although in reality the $k_{L} a$ changes along the length of the reactor, it is assumed to be constant in this work.

In Case B, the $k_{L} a$ is determined using a correlation, while only the kinetic parameters are fitted. Since no suitable correlation was found for packed bubble columns, a correlation for a trickle-bed reactor has been used as an approximation, since the experimental conditions used in this study were covered by the correlation and underlying database. This correlation has been derived using artificial neural network and dimensionless analysis upon consideration of a wide experimental database [123]. The $k_{L} a$ was calculated to be $1.74 \cdot 10^{-1}\left(\mathrm{~s}^{-1}\right)$. For the gas-liquid interfacial area, the recommended correlation for a packed bed column was used to obtain a value of $350 \mathrm{~m}^{2} \mathrm{~m}^{-3}$. These values are within the range of expected values for laboratory scale packed bed columns.

\subsubsection{Model evaluation}

The comparison between Case A and Case B is made using a root mean square error method (RMSE). The calculated root mean square error is an estimation of the goodness of fit between the experimental and model data. RMSE is calculated as the square root of the sum of the squared difference between experimental and predicted values over the number of samples. Calculated RMSE values were found to be 0.154 using the estimated $k_{L} a$ value and 0.139 using the fitted $k_{L} a$ value. An improved overall fit is obtained with the fitted $k_{L} a$ of $3.1 \cdot 10^{-2}\left(\mathrm{~s}^{-1}\right)$. The fitting procedure was conducted in Matlab R2017a. More information can be found in Appendix B.5.

It is noteworthy to mention that the fitted $k_{L} a$ of $3.1 \cdot 10^{-2}\left(\mathrm{~s}^{-1}\right)$ is five times lower than the estimated $k_{L} a$ determined by empirical methods as discussed in section 3.4.2. As mentioned previously, the estimated $k_{L} a$ was derived using a correlation for trickle-bed reactors, due to lack of a suitable specific correlation for the determination of $k_{L}$ in packed bubble columns. 
While the estimated $k_{L} a$ works quite well in predicting the data, the fitted $k_{L} a$ is still more accurate and is therefore selected as a constant for the kinetic fitting at the other temperatures.

The correlation matrix from the simultaneous fitting of parameters $k_{r}, k_{m}$ and $K_{e q}$ at $270{ }^{\circ} \mathrm{C}$ show that the correlation between $k_{r}$ and $K_{e q}$ was 0.9 . However, the inhibitory effect of $\mathrm{H}_{2}$ on the reforming reaction is required to describe the experimental results adequately. This inhibitory effect is illustrated in Figure B.2 in Appendix B.6. $K_{e q}$ was estimated to be $7 \cdot 10^{-3}\left(\mathrm{~m}_{\mathrm{f}}^{3} \mathrm{~mol}^{-1}\right)$.

Table 3.3 presents the fitted kinetic parameters with $95 \%$ confidence intervals. The table also shows the pre-exponential factors and activation energies for $r_{r}$ and $r_{m}$ calculated from the Arrhenius plot.

Figure 3.6(a) illustrates the model prediction of the stripping effect of $\mathrm{N}_{2}$ at a constant flow and constant $\mathrm{R}_{\mathrm{GL}}$ on the $\mathrm{H}_{2}$ yield at all residence times considered. It is notable that the model captures the trends in the $\mathrm{H}_{2}$ yields effectively. Figure 3.6(b) depicts the carbon to gas conversion as a function of residence time. $\mathrm{X}_{\mathrm{CG}}$ is obtained as the sum of the yields of $\mathrm{CO}_{2}$ and Alkanes. With respect to the stripping effect of $\mathrm{N}_{2}$ on the total carbon gasification, the model predicts a negligible difference, as also observed in the experiments.

Figure 3.10 shows the parity plots of experimental and fitted product yields at all temperatures studied. As can be seen, the model provides a reasonably good fit (within $25 \%$ deviation from experimental data) for $\mathrm{H}_{2}, \mathrm{CO}_{2}$ and Alkanes at all temperatures. Although the model over-predicts the Alkanes carbon yield and under predicts the $\mathrm{CO}_{2}$ yield, the total carbon gasification predictions are within $15 \%$ deviation from experimental data. 
Table 3.3: Fitted rate parameters with $95 \%$ confidence intervals and calculated RMSE for experimental data from continuous reactor experiments

Degradation of sorbitol at $270{ }^{\circ} \mathrm{C}$

\begin{tabular}{|c|c|c|c|c|}
\hline $\begin{array}{l}\text { Parameter } \\
\boldsymbol{k}_{S b}\end{array}$ & $\begin{array}{l}\text { Value } \\
(6.3 \pm 0.2) \cdot 10^{-5}\end{array}$ & $\begin{array}{l}\text { Correlation } \\
-\end{array}$ & $\begin{array}{l}\text { RMSE } \\
3.14 \cdot 10^{-3}\end{array}$ & $\begin{array}{l}\text { Units } \\
\mathrm{m}^{3} \mathrm{f} \text { mol Pt } \mathrm{Pt}^{-1} \mathrm{~s}^{-1}\end{array}$ \\
\hline $\begin{array}{l}\text { Fitting at } 27 \\
\boldsymbol{k}_{\boldsymbol{r}} \\
\boldsymbol{k}_{\boldsymbol{m}} \\
\end{array}$ & $\begin{array}{l}{ }^{\circ} \mathrm{C} \\
(2 \pm 1) \cdot 10^{-5} \\
(2 \pm 1) \cdot 10^{-7} \\
\end{array}$ & 0.2 & 0.069 & $\begin{array}{l}\mathrm{m}^{3} \mathrm{f} \mathrm{mol} \mathrm{Pt}^{-1} \mathrm{~s}^{-1} \\
\mathrm{~m}^{3} \mathrm{fol} \mathrm{Pt} \mathrm{mol}^{-1} \mathrm{~s}^{-1}\end{array}$ \\
\hline $\begin{array}{l}\text { Fitting at } 29 \\
\boldsymbol{k}_{\boldsymbol{r}} \\
\boldsymbol{k}_{\boldsymbol{m}} \\
\end{array}$ & $\begin{array}{l}{ }^{\circ} \mathrm{C} \\
(4 \pm 1) \cdot 10^{-5} \\
(6 \pm 1) \cdot 10^{-7} \\
\end{array}$ & 0.2 & 0.145 & $\begin{array}{l}\mathrm{m}^{3} \mathrm{f} \text { mol Pt-1 } \mathrm{s}^{-1} \\
\mathrm{~m}^{3} \mathrm{fol} \mathrm{Pt} \mathrm{mol}^{-1} \mathrm{~s}^{-1}\end{array}$ \\
\hline $\begin{array}{l}\text { Fitting at } 31 \\
\boldsymbol{k}_{\boldsymbol{r}} \\
\boldsymbol{k}_{\boldsymbol{m}}\end{array}$ & $\begin{array}{l}{ }^{\circ} \mathrm{C} \\
(5 \pm 1) \cdot 10^{-5} \\
(7 \pm 2) \cdot 10^{-7}\end{array}$ & 0.1 & 0.139 & $\begin{array}{l}\mathrm{m}^{3} \mathrm{f} \mathrm{mol} \mathrm{Pt}^{-1} \mathrm{~s}^{-1} \\
\mathrm{~m}^{3} \mathrm{f} \mathrm{mol} \mathrm{Pt}^{-1} \mathrm{~s}^{-1}\end{array}$ \\
\hline $\begin{array}{l}\text { Fitting at } 35 \\
\boldsymbol{k}_{\boldsymbol{r}} \\
\boldsymbol{k}_{\boldsymbol{m}} \\
\end{array}$ & $\begin{array}{l}{ }^{\circ} \mathrm{C} \\
(9 \pm 2) \cdot 10^{-5} \\
(1.8 \pm 0.4) \cdot 10^{-6}\end{array}$ & 0.2 & 0.134 & $\begin{array}{l}\mathrm{m}^{3} \mathrm{f} \mathrm{mol} \mathrm{Pt}^{-1} \mathrm{~s}^{-1} \\
\mathrm{~m}^{3} \mathrm{fol} \mathrm{Pt} \mathrm{mol}^{-1} \mathrm{~s}^{-1}\end{array}$ \\
\hline $\begin{array}{l}\text { Pre-expone } \\
k o, s b \\
k 0, r \\
k o, m \\
\end{array}$ & $\begin{array}{l}\text { tial factors } \\
1.1 \cdot 10^{12} \\
1.74 \\
1.63 \\
\end{array}$ & & & $\begin{array}{l}\mathrm{m}^{3} \mathrm{f} \mathrm{mol} \mathrm{Pt}^{-1} \mathrm{~s}^{-1} \\
\mathrm{~m}^{3} \mathrm{fol} \mathrm{Pt}-1 \mathrm{~s}^{-1} \\
\mathrm{~m}^{3} \mathrm{~mol} \mathrm{Pt} \mathrm{mol}^{-1} \mathrm{~s}^{-1}\end{array}$ \\
\hline $\begin{array}{l}\text { Activation } \epsilon \\
E a_{, S b} \\
E a_{r} \\
E a_{m}\end{array}$ & $\begin{array}{l}\text { ergies } \\
169 \\
51 \\
71 \\
\end{array}$ & & & $\begin{array}{l}\mathrm{kJ} \mathrm{mol}^{-1} \\
\mathrm{~kJ} \mathrm{~mol}-1 \\
\mathrm{~kJ} \mathrm{~mol}^{-1}\end{array}$ \\
\hline $\begin{array}{l}\text { Heat of ads } \\
\Delta H_{a d s}\end{array}$ & $\begin{array}{l}\text { rption } \\
-33\end{array}$ & & & $\mathrm{~kJ} \mathrm{~mol}^{-1}[121]$ \\
\hline
\end{tabular}




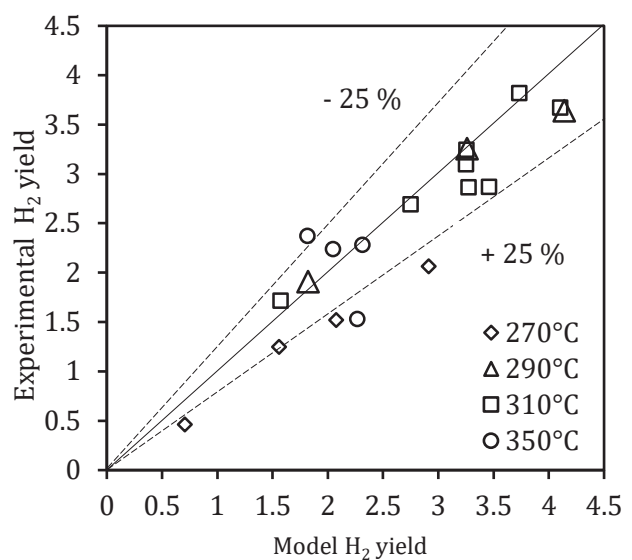

(a)

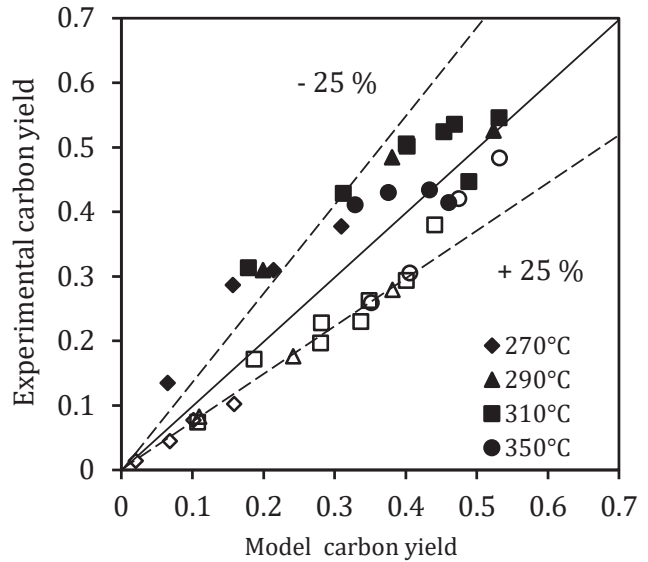

(b)

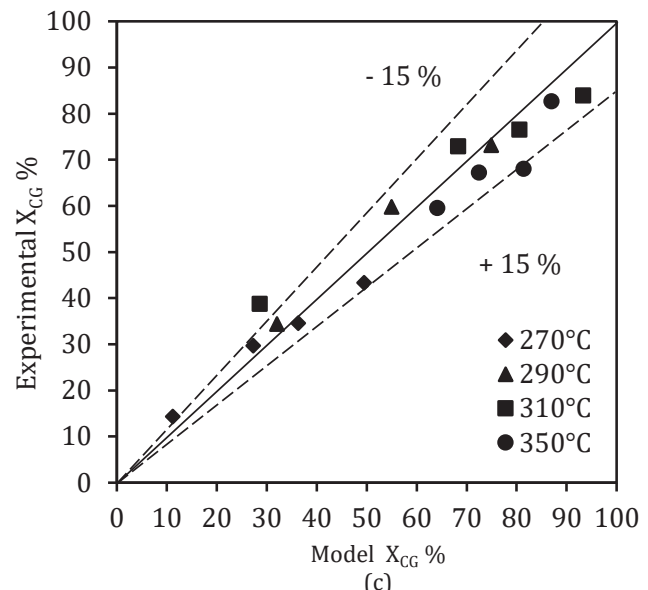

Figure 3.10: Parity plots for (a) $\mathrm{H}_{2}$ yields (b) gaseous carbon yields and (c) $\mathrm{X}_{\mathrm{CG}}$ at temperatures $270{ }^{\circ} \mathrm{C}, 290$ ${ }^{\circ} \mathrm{C}, 310{ }^{\circ} \mathrm{C}$ and $350{ }^{\circ} \mathrm{C}$. In (b) filled points are yields of $\mathrm{CO}_{2}$ and empty points are carbon. 
In order to further validate the kinetic model, model predictions were compared to experiments conducted in an intensively stirred, $45 \mathrm{ml}$ batch autoclave reactor at $290^{\circ} \mathrm{C}$. Experiments were conducted using $15 \mathrm{~g}$ of $10 \mathrm{wt} \%$ aqueous sorbitol solutions and $0.75 \mathrm{~g}$ of $5 \mathrm{wt} \% \mathrm{Pt}-\mathrm{Al}_{2} \mathrm{O}_{3}$ catalyst. Figure 3.11 depicts the yields of $\mathrm{H}_{2}$ and $\mathrm{CO}_{2}$ obtained in the batch reactor. The residence time in the reactor is defined in a similar manner as was done in the experiments in the continuous setup. (Refer Eq. (3.1)). The model predicts the initial rates of production of these gaseous species very well (within $10 \%$ deviation). Unfortunately the yield of carbonaceous species in alkanes could not be well predicted by the model due to condensation of higher alkanes into the liquid phase in the batch experiments, when cooling down the autoclave reactor before opening.

\subsubsection{Model predictions}

Through experimental work it is seen that the addition of $\mathrm{N}_{2}$ as a stripping agent enhances the $\mathrm{H}_{2}$ yield. The developed model is used to predict this effect of mass transfer on the $\mathrm{H}_{2}$ yield. As shown in Eq. (3.8), the positive effect of mass transfer on the $\mathrm{H}_{2}$ flux, $\mathrm{JH}_{2}\left(\mathrm{~mol} \mathrm{H}_{2} \mathrm{~m}^{-2} \mathrm{~s}^{-1}\right)$ is a consequence of two contributing factors; $k_{L}$, a measurable mass transfer coefficient, and the difference in concentrations of $\mathrm{H}_{2}$ in the gas and liquid phases, i.e., the driving force for mass transfer. The magnitude of $k_{L}$ is determined based on the hydrodynamics of the system, influenced by physical properties (such as density and viscosity) as well as by geometry (such as packing material), while the driving force is enhanced by separating the $\mathrm{H}_{2}$ from the gas phase. In this work, this is achieved using $\mathrm{N}_{2}$ as a stripping agent. The addition of $\mathrm{N}_{2}$ also increases $a$, the gas-liquid interfacial area for mass transfer.

$$
J_{H_{2}}=k_{L} \cdot\left(\frac{p_{i}}{H_{i}}-c_{i}^{l}\right)
$$

Figure 3.12 depicts the influence of increasing $\mathrm{R}_{\mathrm{GL}}$ ratios on the $\mathrm{H}_{2}$ yield along the length of the reactor at the constant fitted $k_{L} a$ of $0.03 \mathrm{~s}^{-1}$. It can be seen that with increasing $\mathrm{R}_{\mathrm{GL}}$, the $\mathrm{H}_{2}$ yield increases. This is because, at a constant total pressure, the addition of $\mathrm{N}_{2}$ increases the partial pressure of $\mathrm{N}_{2}$, thereby decreasing the partial pressure of $\mathrm{H}_{2}$ in the gas phase. A higher $\mathrm{H}_{2}$ pressure leads to a higher concentration of $\mathrm{H}_{2}$ in the liquid phase, thereby inhibiting the reforming reaction and enhancing the production of alkanes. This is in agreement with experimental work (Refer Figure 3.6(a)). 


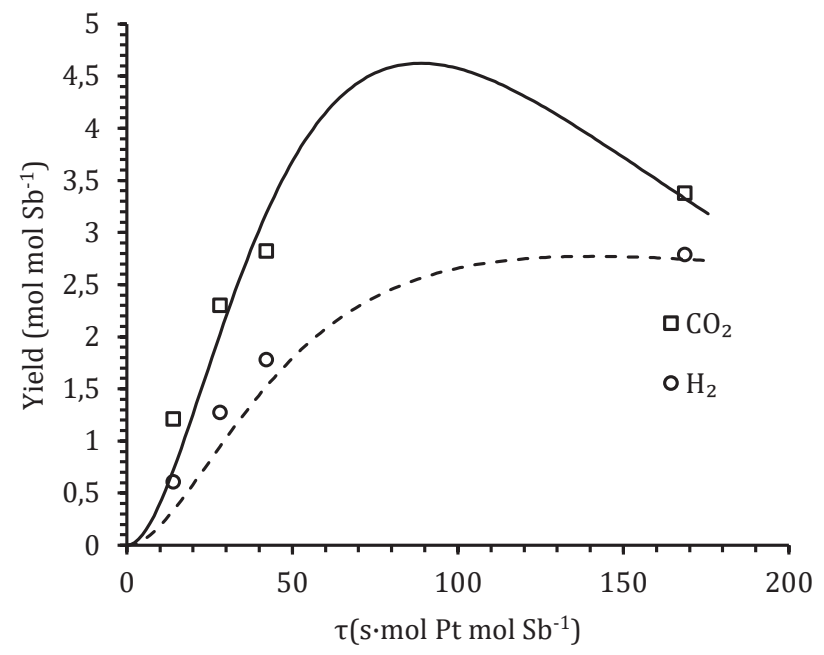

Figure 3.11: Experimental data points and model curves for $\mathrm{H}_{2}$ and $\mathrm{CO}_{2}$ yields obtained in the batch reactor. Solid curve: $\mathrm{H}_{2}$, dashed curve: $\mathrm{CO}_{2}$

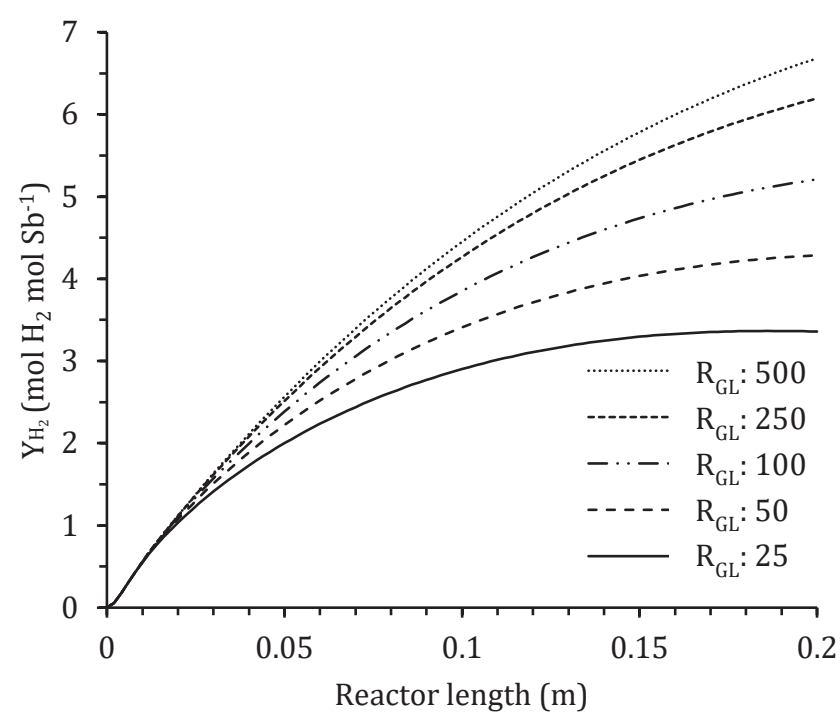

Figure 3.12: Effect of increasing $\mathrm{R}_{\mathrm{GL}}$ on the $\mathrm{H}_{2}$ yield at the fitted $k_{L} a$ of $0.03 \mathrm{~s}^{-1}$ at a WHSV of $1.2 \mathrm{~h}^{-1}$ and temperature of $310^{\circ} \mathrm{C}$ and total pressure of 120 bar. Model parameters calculated using lab-scale reactor length of $20 \mathrm{~cm}$ and $4 \mathrm{~g}$ of $\mathrm{Pt}-\mathrm{Al}_{2} \mathrm{O}_{3}$. 


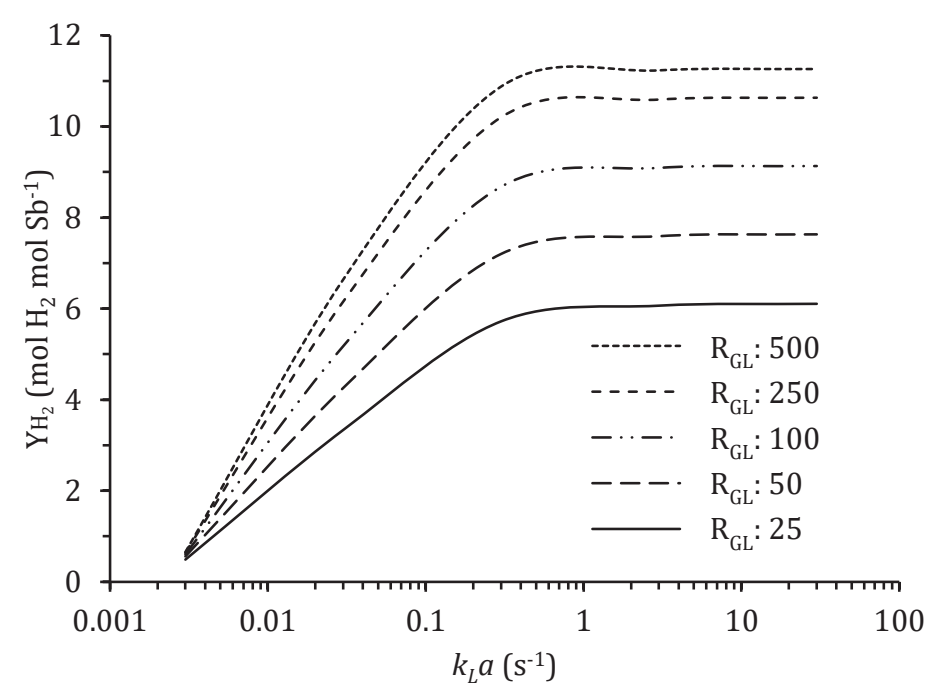

Figure 3.13: Effect of $k_{L} a$ and $\mathrm{R}_{\mathrm{GL}}$ on the $\mathrm{H}_{2}$ yield at a WHSV of $1.2 \mathrm{~h}^{-1}$ and temperature of $310{ }^{\circ} \mathrm{C}$ and a total pressure of 120 bar. Model parameters calculated using lab-scale reactor length of $20 \mathrm{~cm}$ and $4 \mathrm{~g}$ of Pt- $\mathrm{Al}_{2} \mathrm{O}_{3}$.

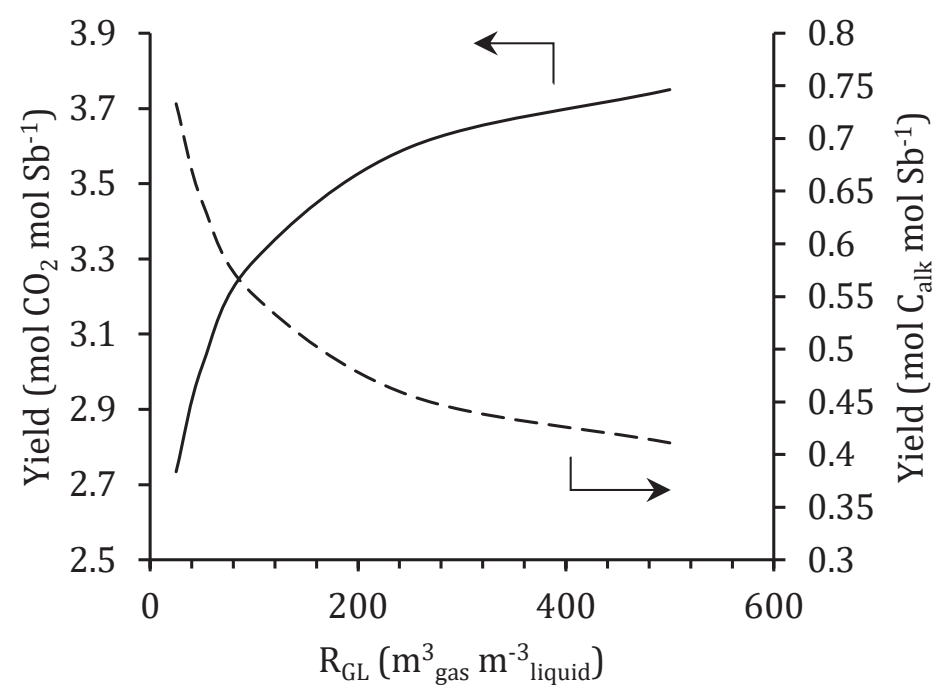

Figure 3.14: Effect of $\mathrm{R}_{\mathrm{GL}}$ on carbon product distribution at a WHSV of $1.2 \mathrm{~h}^{-1}$ and temperature of $310^{\circ} \mathrm{C}$ 
Figure 3.13 illustrates the combined effect of $k_{L} a$ and $\mathrm{R}_{\mathrm{GL}}$ on the $\mathrm{H}_{2}$ yield. The utilisation of $\mathrm{N}_{2}$ as a stripping gas is impractical at low $k_{L} a^{\prime} s\left(\sim 0.005 \mathrm{~s}^{-1}\right)$ if the mass transfer rate is lower than the reaction rate. At $k_{L} a^{\prime}$ s between $0.01-1 \mathrm{~s}^{-1}$, the positive effect of $\mathrm{N}_{2}$ stripping is seen. At $k_{L} a^{\prime}$ s higher than $1 \mathrm{~s}^{-1}$, the mass transfer rate is fast, and physical equilibrium between the $\mathrm{H}_{2}$ concentration in the gas and liquid phases is achieved immediately. Therefore, the $\mathrm{H}_{2}$ yield remains invariant with increasing $k_{L} a$ 's.

The effect of $\mathrm{N}_{2}$ stripping on the carbon product yields $\left(\mathrm{CO}_{2}\right.$ and alkanes $)$ is depicted in Figure 3.14. In agreement with experimental data shown in Figure 3.6(b), at changing $\mathrm{R}_{\mathrm{G}}$, the total carbon gasification remains unchanged due to the increase in $\mathrm{CO}_{2}$ yield due to enhanced reforming and the decrease in the alkane yield due to the presence of lower amount of $\mathrm{H}_{2}$ in the liquid phase for methanation reactions.

\subsubsection{Reactor design considerations}

The developed 1-D reactor model is used to predict the maximum amount of $\mathrm{H}_{2}$ that can be produced at high carbon gasification by tuning the reactor parameter $k_{L} a$ and operating conditions including absolute pressure, temperature and $\mathrm{R}_{\mathrm{GL}}$. The design criteria selected is to achieve a minimum of $95 \%$ carbon gasification. This criteria is selected in order to obtain less than $0.5 \mathrm{wt} \%$ carbon residues in water making this process simultaneously attractive for water clean-up and $\mathrm{H}_{2}$ production.

Based on experimental observations, a temperature of $310{ }^{\circ} \mathrm{C}$ is selected because the highest $\mathrm{H}_{2}$ yields along with high carbon gasification were obtained at this temperature. At lower temperatures, although a slightly higher $\mathrm{H}_{2}$ selectivity is observed, this comes at the cost of lower carbon gasification. At higher temperatures, $\mathrm{H}_{2}$ selectivity is reduced considerably and production of gaseous alkanes is favoured, thereby increasing the carbon gasification.

\section{PFR vs. CSTR}

The path-lumped kinetic and mass transfer model is used to evaluate which reactor is preferred: a PFR or CSTR. Based on the high carbon gasification constraint and the slow reaction kinetics, the selection of the type of continuous reactor (CSTR or PFR) is limited to PFR, keeping all operating conditions constant and considering a $k_{L} a$ of $0.03 \mathrm{~s}^{-1}$ for both reactors, as illustrated in Figure 3.15(a). The required residence time in the CSTR is 5 times longer than that of the PFR in order to obtain $95 \%$ carbon gasification. Figure 3.15(b) illustrates the $\mathrm{H}_{2}$ yield $\left(\mathrm{YH}_{2}\right)$ obtained from both reactors as a function of carbon to gas conversion $\left(\mathrm{X}_{\mathrm{CG}}\right)$. The $\mathrm{YH}_{2}$ in the case of the CSTR is always lower than that of the PFR at the same $\mathrm{X}_{\mathrm{CG}}$. Considering that the path-lumped scheme is represented by consecutive reactions, and if both reactors can be represented by identical conditions, higher selectivity and yield can be achieved in PFRs. 
Regardless of the choice of reactor, $\mathrm{YH}_{2}$ decreases at higher $\mathrm{X}_{\mathrm{CG}} \%$. This is because the partial pressure of $\mathrm{H}_{2}$ increases at longer residence times, leading to an increased $\mathrm{H}_{2}$ concentration in the liquid phase and its consumption in side reactions. The $\mathrm{YH}_{2}$ can be increased by increasing the $k_{L} a$ and $\mathrm{R}_{\mathrm{GL}^{\prime}}$ as discussed above, as well as by decreasing the total pressure, as discussed below.

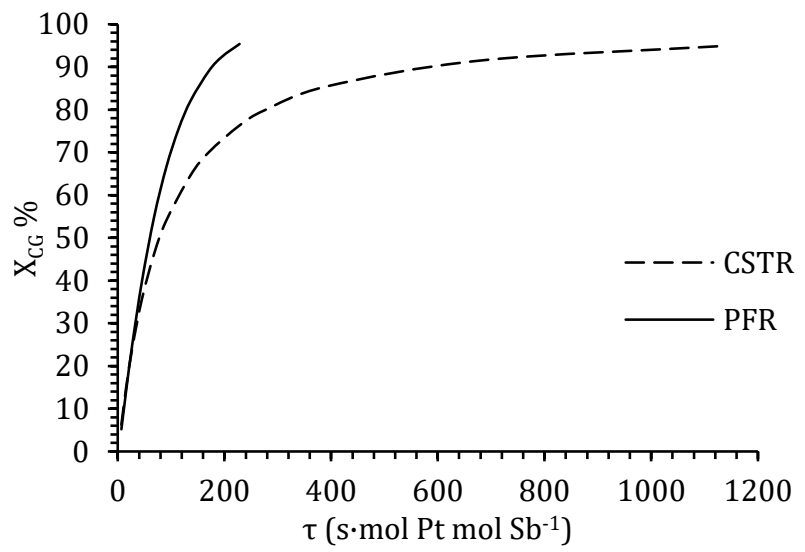

(a)

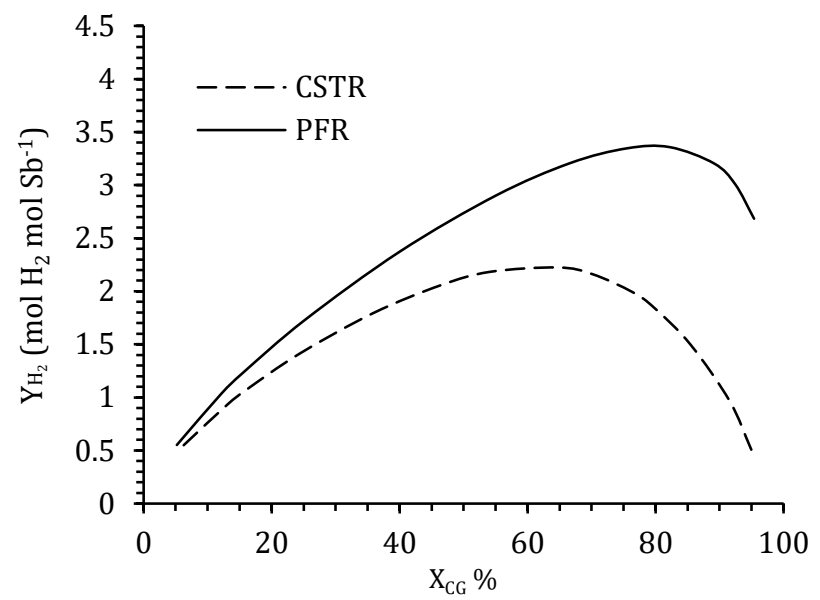

(b)

Figure 3.15: PFR vs. CSTR (a) Required residence times based on desired conversion (b) $\mathrm{H}_{2}$ yield as a function of carbon to gas conversion. Model parameters calculated using lab-scale reactor volume of 22.6 $\mathrm{cm}^{3}, 4 \mathrm{~g}$ of Pt- $\mathrm{Al}_{2} \mathrm{O}_{3^{3}}, 310^{\circ} \mathrm{C}, 120$ bar, a $k_{L} a$ of $0.03 \mathrm{~s}^{-1}$ and a $\mathrm{R}_{\mathrm{GL}}$ of $25 \mathrm{~m}_{\mathrm{g}}^{3} \mathrm{~m}^{-3}{ }_{\mathrm{r}}$. For the CSTR model, a liquid hold-up of $0.8 \mathrm{~m}_{1}^{3} \mathrm{~m}_{\mathrm{r}}^{-3}$ is considered. 
Figure 3.16 illustrates the effect of total pressure on the $\mathrm{H}_{2}$ yield for both reactor types, considering a constant $\mathrm{X}_{\mathrm{CG}}$ of $95 \%$ and $k_{L} a$ of $0.03 \mathrm{~s}^{-1}$. The increase in $\mathrm{Y}_{\mathrm{H}_{2}}$ is caused by the decrease in $\mathrm{H}_{2}$ partial pressure. This can be achieved by decreasing the total pressure, and by increasing the partial pressure of $\mathrm{N}_{2}$. As illustrated, at larger total pressures, $\mathrm{Y}_{\mathrm{H}_{2}}$ is lower due to the large $\mathrm{H}_{2}$ partial pressure. The stripping effect is therefore more beneficial because the addition of $\mathrm{N}_{2}$ greatly reduces the partial pressure of $\mathrm{H}_{2}$. On the other hand, if the reactor is operated close to the vapour pressure of water, the partial pressure of $\mathrm{H}_{2}$ is already low, and therefore the addition of $\mathrm{N}_{2}$ does not have as much of an effect.

One advantage of a CSTR is that the total pressure can be reduced to slightly above the vapour pressure of water. In the case of the PFR, the total pressure needs to account for the pressure drop across the reactor. Since a pressure drop calculation has not been incorporated in the model, the effect of reduced total pressure for both reactor types are compared. Figure 3.16 illustrates the effect of varying total pressure on the $\mathrm{YH}_{2}$ in the case of both CSTR and PFR. It can be seen that higher $\mathrm{YH}_{2}$ can be achieved in a CSTR at lower total pressures. However, since large reactor volumes are necessary in order to achieve an $\mathrm{X}_{\mathrm{CG}}$ of $95 \%$, CSTRs have a lower $\mathrm{H}_{2}$ productivity than PFRs.

The effect of increasing $\mathrm{R}_{\mathrm{GL}}$ is similar in both reactor types, i.e, an increase in $\mathrm{R}_{\mathrm{GL}}$ leads to an increase in $\mathrm{H}_{2}$ yield. However, it can be seen that in the case of the CSTR, there is a bigger influence of the stripping effect at a pressure of 120 bar in comparison to the PFR. This is because of the longer residence time (1141 s.mol Pt mol Sb${ }^{-1}$ ) required in order to achieve an $\mathrm{X}_{\mathrm{CG}}$ of $95 \%$ in comparison to a residence time of $228 \mathrm{~s} \cdot \mathrm{mol} \mathrm{Pt} \mathrm{mol} \mathrm{Sb}{ }^{-1}$ required for the PFR, as depicted in Figure 3.15(a). Longer residence times translate to higher partial pressures of $\mathrm{H}_{2}$ and therefore higher concentrations of $\mathrm{H}_{2}$ in the liquid phase, leading to its consumption in alkane production.

In order to get an impression of the feasibility of the process on an industrial scale, a basis of 10 tons $\mathrm{h}^{-1}$ of $10 \mathrm{wt} \%$ aqueous sorbitol solution is considered as the feed. Figure 3.17 illustrates how the $\mathrm{H}_{2}$ yield can be maximised by increased $k_{L} a, \mathrm{R}_{\mathrm{GL}}$ and decreased absolute pressure. Additionally, the effect of these variables on the total reactor volume requirement can be visualised through the $\mathrm{H}_{2}$ productivity ( $\mathrm{mol} \mathrm{H}_{2} \mathrm{~kg}_{\text {cat }} \mathrm{h}^{-1}$ ). In this study, a maximum of 4 moles $\mathrm{H}_{2} \mathrm{~mol} \mathrm{Sb}^{-1}$ was achieved at $310{ }^{\circ} \mathrm{C}$ and at a WHSV of $1.2 \mathrm{~h}^{-1}$. The maximum $\mathrm{YH}_{2}$ achieved with high feed concentrations of 10 wt $\%$ and high carbon gasification of $>95 \%$ was a value of 6.7 moles $\mathrm{H}_{2}$ mol Sb$^{-1}$ obtained by Davda et al. [107]. From the stoichiometric reforming equation, the theoretical maximum that can be achieved is 13 moles $\mathrm{H}_{2}$ mol Sb${ }^{-1}$. Such a high $\mathrm{H}_{2}$ yield has not yet been reported in literature for feeds with significant sorbitol content. 


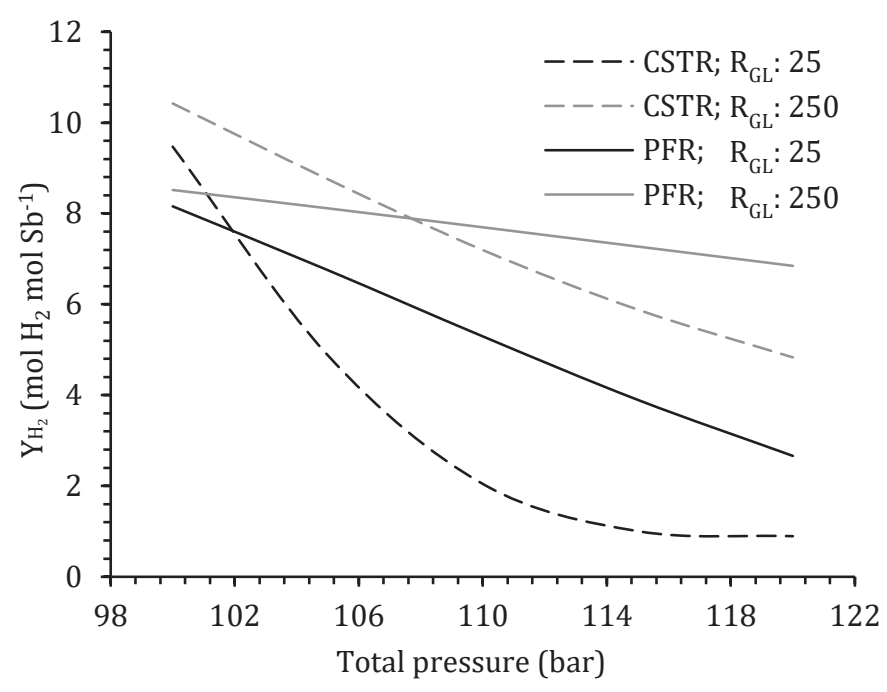

Figure 3.16: PFR vs. CSTR - Effect of total pressure on the $\mathrm{H}_{2}$ yield at a constant $\mathrm{X}_{\mathrm{CG}}$ of $95 \%$. Model parameters calculated using lab-scale reactor volume of $22.6 \mathrm{~cm}^{3}, 4 \mathrm{~g}$ of $\mathrm{Pt}-\mathrm{Al}_{2} \mathrm{O}_{3}, 310{ }^{\circ} \mathrm{C}$, and a $k_{L} a$ of 0.03 $\mathrm{s}^{-1}$.The saturation pressure of water at $310^{\circ} \mathrm{C}$ is $98 \mathrm{bar}$.

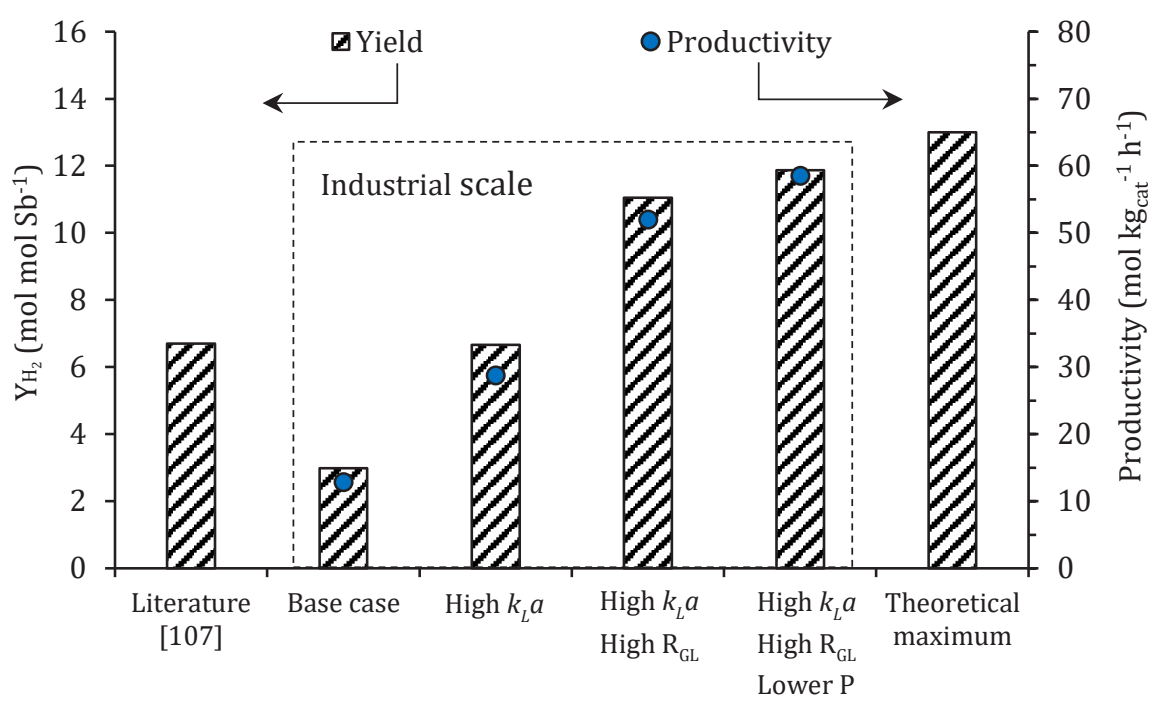

Figure 3.17: Increasing $\mathrm{H}_{2}$ yield and productivity. Model predictions conducted at $310{ }^{\circ} \mathrm{C}$ and at a WHSV of $0.8 \mathrm{~h}^{-1}$. 
In this study, from the cases considered for an envisaged industrial scale, the model predicts that by increasing $k_{\mathrm{L}} a$ from 0.1 to $1 \mathrm{~s}^{-1}, \mathrm{R}_{\mathrm{GL}}$ from 25 to $250 \mathrm{Nm}^{3} \mathrm{~g}^{-3}{ }_{\mathrm{l}}$, and lowering the absolute pressure from 120 to 105 bar (at $310{ }^{\circ} \mathrm{C}$ ), the $\mathrm{H}_{2}$ yield can be increased from 2.7 to 12 moles $\mathrm{H}_{2} \mathrm{~mol} \mathrm{Sb}^{-1}$. Because the change in $k_{L} a, \mathrm{R}_{\mathrm{GL}}$ and pressure have a negligible effect on the total carbon gasification in these ranges, the change in the volume of the reactor is insignificant. Therefore, there is also a five-fold increase in the $\mathrm{H}_{2}$ productivity. Considering a bulk density of $\gamma-\mathrm{Al}_{2} \mathrm{O}_{3}$ of $1000 \mathrm{~kg} \mathrm{~m}^{-3}$, this translates to 58 moles $\mathrm{H}_{2} \mathrm{~kg}_{\text {cat }}{ }^{-1} \mathrm{~h}^{-1}$, two times higher than that obtained in this experimental study (26 moles $\mathrm{H}_{2} \mathrm{~kg}_{\text {cat }}{ }^{-1} \mathrm{~h}^{-1}$ ) and in literature (22 moles $\mathrm{H}_{2} \mathrm{~kg}_{\text {cat }}{ }^{-1} \mathrm{~h}^{-1}$ ) [124]. By selecting reactors in which larger $k_{L} a$ values can be achieved, such as bubble columns or slurry reactors, the $\mathrm{H}_{2}$ yield can be enhanced. Additionally, reactors can be designed such that the $\mathrm{H}_{2}$ can be separated as soon as it is produced before its consumption in side reactions (for example, a membrane reactor [115]). In such cases there will be no requirement for $\mathrm{N}_{2}$ addition and no further separation costs downstream of the reactor. With improved reactor design as well as further energy and economic evaluations, this process can be suitably applied on an industrial scale.

\subsection{Conclusions}

The influence of a wide range of sub-critical temperatures on the hydrothermal gasification of sorbitol is investigated in this study. Experimental results validate previously known information about reaction mechanisms, specifically the production and consequent consumption of $\mathrm{H}_{2}$. Further insight is gained into the influence of $\mathrm{N}_{2}$ and $\mathrm{H}_{2}$ on the optimum $\mathrm{H}_{2}$ production at higher temperatures and carbon conversions.

This work also includes the development of the first temperature-dependent kinetic and mass transfer model for the hydrothermal gasification of sorbitol. The model approximates the complex reaction mechanism by using a path lumped strategy. Both experiments and model predictions show that mass transfer plays an important role in the $\mathrm{H}_{2}$ yield, but does not influence the total carbon gasification significantly. Under conditions of high carbon gasification, the liquid feed flowrate is low and consequently fitted $k_{L} a$ was relatively low. With increasing $\mathrm{N}_{2}$ gas flow rate, the desired product $\mathrm{H}_{2}$ is stripped out of the reactive liquid phase before reacting in consecutive reactions. The model is in good agreement with experimental results and is used to predict $\mathrm{H}_{2}$ yields at high carbon gasification on an industrial scale. By tailoring the process parameters such as temperature, pressure, gas-liquid ratio $\left(\mathrm{R}_{\mathrm{GL}}\right)$ and gas-liquid mass transfer $\left(k_{L} a\right)$, greater $\mathrm{H}_{2}$ yields can be obtained, making this a promising process. 


\section{B. Appendix}

\section{B.1 Error analysis}

The experimental data along with standard deviation calculated using $95 \%$ confidence levels are tabulated in Table B.1.

Table B.1: Experimental data with standard deviation calculated using 95\% confidence intervals Note: Values in bold are considered as the errors for all data points

\begin{tabular}{llllll}
\hline $\mathrm{T}\left({ }^{\circ} \mathrm{C}\right)$ & $\begin{array}{l}\mathrm{Y}_{\mathrm{H} 2} \\
\left(\mathrm{~mol} \mathrm{~mol} \mathrm{Sb}^{-1}\right)\end{array}$ & $\begin{array}{l}{\mathrm{YC}, \mathrm{CO}_{2}}_{\left(\mathrm{mol} \mathrm{mol}^{-1}\right)} \\
\left(\mathrm{mol} \mathrm{mol}^{-1}\right)\end{array}$ & $\begin{array}{l}\mathrm{Y}_{\mathrm{C}, \text { liq }} \\
\left(\mathrm{mol} \mathrm{mol}^{-1}\right)\end{array}$ & $\begin{array}{l}\mathrm{X}_{\mathrm{CG}} \\
\%\end{array}$ \\
\hline 270 & $1.17 \pm \mathbf{0 . 0 5}$ & $0.26 \pm \mathbf{0 . 0 2}$ & $0.65 \pm \mathbf{0 . 0 2}$ & $0.03 \pm \mathbf{0 . 0 1}$ & $31 \pm \mathbf{1}$ \\
310 & $4.26 \pm \mathbf{0 . 0 7}$ & $0.51 \pm \mathbf{0 . 0 3}$ & $0.25 \pm \mathbf{0 . 0 1}$ & $0.19 \pm \mathbf{0 . 0 1}$ & $72 \pm \mathbf{2}$
\end{tabular}

\section{B.2 Batch data}

Batch experimental data for the degradation of sorbitol is illustrated in Figure B.1.

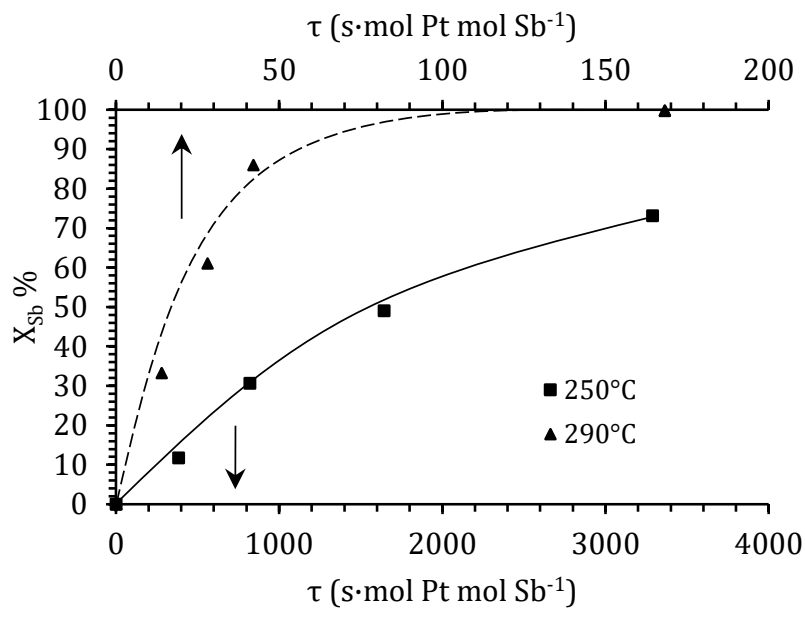

Figure B.1: Batch data for sorbitol degradation. Experiments conducted using $10 \mathrm{wt} \%$ sorbitol and $0.75 \mathrm{~g}$ of

$$
\text { Pt- } \mathrm{Al}_{2} \mathrm{O}_{3} \text {. }
$$




\section{B.3 Mass transfer}

The liquid-solid mass transfer coefficient for packed bubble columns can be estimated using the following correlation [125].

$S h=\frac{k_{S} d_{p}}{D}=0.221 \cdot R e_{D}^{0.64} \cdot S c^{0.5}$

$R e_{\mathrm{D}}$ is the Reynolds number defined on the basis of the dispersion density, $\rho_{L}\left(1-\beta_{G}\right)$, where $\beta_{G}$ represents the gas hold-up in the column. The liquid hold up $\beta_{L}$ is calculated using the following correlation where $J_{D F}$ is the drift flux and is a function of the gas velocity [126]. $J_{D F}$ is defined as a volumetric flux of gas relative to a surface moving at the average liquid velocity and was found to provide an accurate means to estimate the liquid holdup in fixed bed reactors.

$J_{D F}=u_{G} \cdot \beta_{L}-u_{l} \cdot\left(1-\beta_{L}\right)$

In a plot of $\mathrm{J}_{\mathrm{DF}}=\mathrm{A} \cdot \mathrm{u}_{\mathrm{G} 0}{ }^{\mathrm{b}}, \mathrm{A}$ and $\mathrm{B}$ were determined to be in the range of $0.40<\mathrm{A}<0.49$ and $0.92<$ B $<1.00$ determined by Larachi et al [127] for upflow, high pressure experiments. These values are used resulting in a $k_{S} a_{S}$ of $1.62\left(\mathrm{~s}^{-1}\right)$. Therefore, the concentration of the species in the liquid phase is considered to be the same as that in the catalyst particle and liquid-solid mass transfer is neglected in the model. For further confirmation, the maximum flux $k_{S} a_{S} \cdot \mathrm{C}_{\mathrm{Sb}}\left(\mathrm{mol} \mathrm{Sb} \mathrm{m}{ }_{\mathrm{p}}^{-3} \mathrm{~s}^{-1}\right)$ calculated using this value is 9 orders of magnitude larger than the reaction rate.

With respect to intraparticle transport, for an isothermal spherical particle with a first-order reaction, the Weisz-Prater criterion is used [128].

$\frac{r_{o b s} \cdot r_{p}^{2}}{C_{s} \cdot D_{e}}<1$

where $r_{o b s}$ is the observed reaction rate per unit particle volume $=4 \cdot 10^{-3}\left(\mathrm{~mol} \mathrm{Sb} \mathrm{kg}_{\text {cat }}{ }^{-1} \mathrm{~s}^{-1}\right) \cdot 3500$ $\left(\mathrm{kg}_{\text {cat }} \mathrm{m}_{\mathrm{p}}^{-3}\right), r_{p}$ is the radius of the particle $=100 \cdot 10^{-6}\left(\mathrm{~m}_{\mathrm{p}}\right), C_{s}$ is the concentration of the reactant at the catalyst surface and is considered to be the same as the bulk concentration of the reactant in the liquid phase $=421 \mathrm{~mol} \mathrm{Sb} \mathrm{m}^{-3}$, and $D_{e}$ is the effective diffusivity in a porous catalyst $=6.78 \cdot 10^{-9}$ $\left(\mathrm{m}^{2} \mathrm{~s}^{-1}\right) . D_{e}$ is calculated using the empirical correlation of Wilke and Chang [80]. The criterion is satisfied with the calculated value being $0.05 \ll 1$.

\section{B.4 Reactor model development}

Reaction rates were incorporated into differential equations representing the rate of consumption or production of species over the length of the fixed bed reactor $\left(\mathrm{mol} \mathrm{C}_{\mathrm{i}} \mathrm{m}_{\mathrm{f}}^{-3} \mathrm{~m}_{\mathrm{r}}^{-1}\right) . C_{P t}$ is the concentration of platinum in the reactor (moles $\mathrm{Pt} \mathrm{m}_{\mathrm{r}}^{-3}$ ) and $u_{l}$ is the superficial liquid velocity in the reactor $\left(\mathrm{m}_{\mathrm{f}}^{3} \mathrm{~m}^{-2} \mathrm{~s}^{-1}\right)$. For liquid species, the following equations were constructed: 
$\frac{d c_{S b}{ }^{l}}{d z}=\frac{C_{P t}}{u_{l}} \cdot\left(R_{S b}\right)$

$\frac{d c_{l i q}{ }^{l}}{d z}=\frac{C_{P t}}{u_{l}} \cdot\left(R_{\text {liq }}\right)$

For the gaseous species, mole balances in the liquid phase include terms for reaction, as well as for mass transfer from the gas to liquid phase. The $k_{L} a\left(\mathrm{~s}^{-1}\right)$ term is the volumetric liquid-film mass transfer coefficient. $\mathrm{p}_{\mathrm{i}}^{\mathrm{g}}$ are the partial pressures of $\mathrm{H}_{2}, \mathrm{CO}_{2}$ and Alkanes. The term $\mathrm{p}_{\mathrm{i}}^{\mathrm{g}} / \mathrm{H}_{\mathrm{i}}$ represents the equilibrium between liquid-phase concentrations of the gaseous species and the bulk partial pressure. It is assumed that the gas-liquid equilibrium can be described by Henry's law. The Henry's solubility coefficients for $\mathrm{H}_{2}, \mathrm{CO}_{2}$ and methane in water are obtained from solubility data and the values used in the model along with the associated operating temperatures and pressures are presented in Table B.2.

$$
\frac{d c_{i}^{l}}{d z}=\frac{C_{P t}}{u_{l}} \cdot\left(R_{i}\right)-\frac{\left(k_{L} a\right)}{u_{l}} \cdot\left(c_{i}^{l}-\frac{p_{i}^{g}}{H_{i}}\right)
$$

Since $\mathrm{N}_{2}$ does not participate in the reactions, the liquid-phase balance for $\mathrm{N}_{2}$ consists of the mass transfer term alone.

$$
\frac{d c_{N_{2}}{ }^{l}}{d z}=-\frac{\left(k_{L} a\right)}{u_{l}} \cdot\left(c_{N_{2}}^{l}-\frac{p_{N_{2}}^{g}}{H_{N_{2}}}\right)
$$

Since no reaction occurs in the gas phase, mole balances for all the components in the gas phase ( $\mathrm{F}$ in moles s${ }^{-1}$ ) were constructed as a function of the mass transfer coefficient $k_{L} a$, cross-sectional area of the reactor $\left(\mathrm{m}^{2}\right)$, and the concentration difference of the species between liquid and gas phases. Here, $i$ represents $\mathrm{H}_{2}, \mathrm{CO}_{2}$, Alkanes and $\mathrm{N}_{2}$.

$$
\frac{d F_{i}^{g}}{d z}=-\left(k_{L} a\right) \cdot A \cdot\left(\frac{p_{i}^{g}}{H_{i}}-c_{i}^{l}\right)
$$

For $\mathrm{N}_{2}$ used as stripping gas, molar flow of $\mathrm{N}_{2}$ is calculated using the ideal gas law at inlet (atmospheric) conditions.

$F_{N_{2}}^{g}=\frac{P_{0} \cdot Q_{N_{2}}}{R \cdot T_{0}}$

The partial pressures of gases $\mathrm{H}_{2}, \mathrm{CO}_{2}$, Alkanes and $\mathrm{N}_{2}$ in the gas phase are calculated using Dalton's law, assuming an ideal gas mixture.

$$
\begin{aligned}
& P_{T}=P_{v}+\sum p_{\text {gas }} \\
& \frac{p_{i}}{P_{T}-P_{v}}=\frac{F_{i}{ }^{g}}{\sum F_{g a s}} \\
& p_{i}=\frac{F_{i}{ }^{g}}{\sum F_{g a s}} \cdot\left(P_{T}-P_{v}\right)
\end{aligned}
$$


Table B.2: Henry's solubility data for the gaseous species in water used in the model

\begin{tabular}{cccccc}
\hline $\mathrm{T}\left({ }^{\circ} \mathrm{C}\right)$ & $\mathrm{P}($ bar $)$ & $\begin{array}{c}\mathrm{H}_{\mathrm{H}_{2}} \\
\left(\mathrm{~m}^{3} \mathrm{bar} \mathrm{mol}-1\right) \\
{[129]}\end{array}$ & $\begin{array}{c}\mathrm{H}_{\mathrm{CO}_{2}} \\
\left(\mathrm{~m}^{3} \mathrm{bar} \mathrm{mol}^{-1}\right)\end{array}$ & $\begin{array}{c}\mathrm{H}_{\mathrm{CH}_{4}} \\
\left(\mathrm{~m}^{3} \mathrm{bar} \mathrm{mol}^{-1}\right)\end{array}$ & $\begin{array}{c}H_{N_{2}} \\
\left(\mathrm{~m}^{3} \mathrm{bar} \mathrm{mol}^{-1}\right)\end{array}$ \\
\hline 270 & 85 & 0.25 & 0.086 & 0.128 & {$[131]$} \\
290 & 100 & 0.25 & 0.086 & 0.128 & 0.416 \\
310 & 120 & 0.20 & 0.086 & 0.042 & 0.159 \\
350 & 180 & 0.13 & 0.097 & 0.044 & 0.159 \\
\hline
\end{tabular}

Note: 1) If solubility data was not available at the operating temperature at which experiments were conducted, the closest available values were selected. 2) For alkanes, the solubility of methane in water was considered.

\section{B.5 Fitting procedure}

The system of 10 differential equations ((B.4) to (B.8)) and 4 algebraic equations representing the partial pressures of species (B.9) are solved simultaneously in Matlab R2017a using ode15s. The rate constants were determined by fitting the rate equations to experimental data using a non-linear least squares method.

The kinetic parameters and $k_{L} a$ were estimated using lsqcurvefit, a tool used for the minimisation of a constrained nonlinear multivariable function $\mathrm{F}$. F is the squared difference between the measured yield of product $i\left(\mathrm{Sb}\right.$, Liquids, $\mathrm{H}_{2}, \mathrm{CO}_{2}$ and Alkanes) obtained at residence time $j$ obtained from experiments $y_{\text {exp, }, j}$ and the calculated yield obtained from the model $y_{\text {model }, i j^{*}}$ $F=\sum_{i=1}^{n} \sum_{j=1}^{N}\left(y_{\text {exp }, i j}-y_{\text {model }, i j}\right)^{2}$

$\mathrm{F}$ is subject to non-linear constraints in which all $\mathrm{k}$ values must be positive.

\section{B.6 Inhibitory effect of $\boldsymbol{K}_{\text {eq }}$}

Figure B.2 depicts the model prediction for the carbon yield of Liquids by comparing the influence of $K_{e q}$ on consumption of Liquids. As shown, the inhibitory effect of $\mathrm{H}_{2}$ on the reforming of the Liquids can clearly be seen in the experimental data. In the presence of $\mathrm{H}_{2}$, more carbon is retained in the liquid phase at all residence times. On the other hand, the stripping effect of $\mathrm{N}_{2}$ enhances the reforming rate thereby decreasing the carbon concentration in the Liquids. The presence of $K_{e q}$ in the reforming rate is necessary in order for the model to predict the differences in the carbon yield of the Liquids in the presence of $\mathrm{N}_{2}$ and $\mathrm{H}_{2}$ (depicted by the grey lines). 


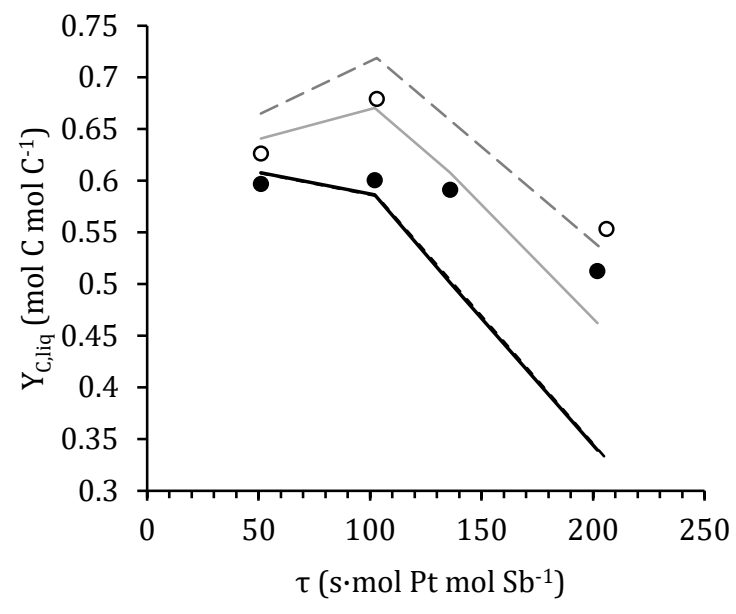

Figure B.2: Influence of $K_{e q}$ (grey lines) on the carbon yield of Liquids. Experiments conducted at $270{ }^{\circ} \mathrm{C}$ and 85 bar using $4 \mathrm{~g}$ of Pt- $\mathrm{Al}_{2} \mathrm{O}_{3}$ and $30 \mathrm{Nml} \mathrm{N}_{2}$ min $^{-1}$ (full circles) and $30 \mathrm{Nml} \mathrm{H}_{2} \min ^{-1}$ (empty circles). The model prediction in the absence of $K_{\text {eq }}$ leads to the same results in the concentration of carbon in Liquids irrespective of whether $\mathrm{N}_{2}$ or $\mathrm{H}_{2}$ has been added to the system (depicted by the black lines). 



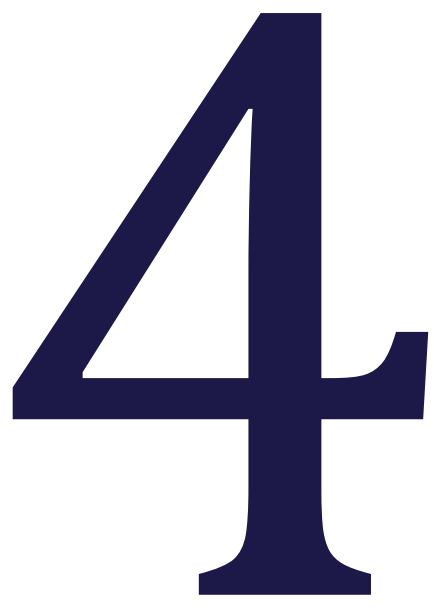

\section{Sequential Pt-Ru catalysts for increased productivity}




\section{Abstract}

Increasing the productivity of hydrothermal gasification with respect to both $\mathrm{H}_{2}$ production and carbon gasification is one of the main challenges in the field of sub-critical gasification and APR studies. In this work, this is tackled by exploiting the sequential use of two catalysts, Pt, selective towards $\mathrm{H}_{2}$ production, and $\mathrm{Ru}$, selective towards total carbon gasification. Higher $\mathrm{H}_{2}$ productivity (30- $70 \mathrm{~mol} \mathrm{H}_{2} \mathrm{~kg}_{\text {cat }}{ }^{-1} \mathrm{~h}^{-1}$ ) at high carbon to gas conversions (87 - 99\%) was attained by operating at higher $\mathrm{WHSV}_{c}\left(0.67-2 \mathrm{~h}^{-1}\right)$ as compared to earlier reported studies. The dual benefit accomplished through the Pt-Ru combination is that the process offers opportunities not only as a $\mathrm{H}_{2}$ production process from renewable wet biomass, but through the production of a dischargeable water stream, is also applicable as a water clean-up technology process to treat relevant wastes and wastewaters.

Aqueous polyols

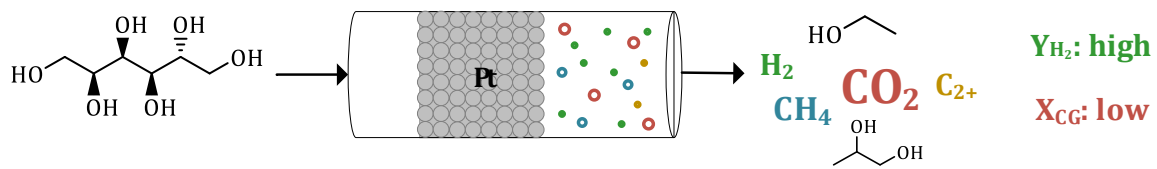

Aqueous polyols

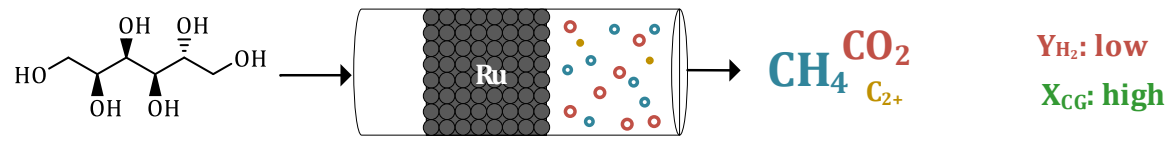

Aqueous polyols

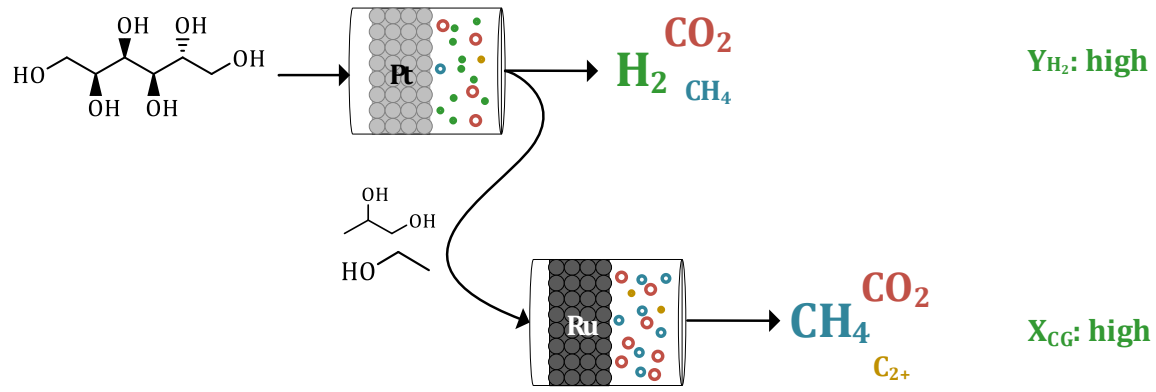




\subsection{Introduction}

$\mathrm{H}_{2}$ production from biomass oxygenates via aqueous phase reforming and hydrothermal gasification has been the topic of extensive research in recent years $[38,132]$. In the field of APR, most studies have focussed on the development of innovative catalysts that show improved selectivity (mol $\mathrm{H}_{2}$ per mol feed converted) towards $\mathrm{H}_{2}$ production [10,37]. From a process perspective however, the $\mathrm{H}_{2}$ productivity $\left(\mathrm{mol} \mathrm{H}_{2} \mathrm{~kg}_{\text {cat }}{ }^{-1} \mathrm{~h}^{-1}\right)$ is a better measure of the performance of the process than $\mathrm{H}_{2}$ selectivity is. Higher productivities translate to the requirement for smaller reactors, and/or lower amounts of catalysts. In addition, with respect to carbon gasification, the use of lower temperatures in APR led to the need for longer residence times, i.e, lower productivity. The complete carbon gasification of wet biomasses via hydrothermal gasification has been achieved and is not a new field of study. However, the main gas product produced has been $\mathrm{CH}_{4}$. Elliott et al. [42] gasified $1.3-7.3$ wt \% of dairy manure and fermentation residues from the distillery industry at $350{ }^{\circ} \mathrm{C}$ and 210 bar, using ruthenium on carbon catalysts, achieving $100 \%$ carbon conversion to gas, primarily to $\mathrm{CH}_{4}(50-60 \mathrm{~mol} \%)$. Calculated productivities are in the range of $5-10 \mathrm{~mol} \mathrm{CH}_{4} \mathrm{~kg}_{\text {cat }}{ }^{-1} \mathrm{~h}^{-1}$. Further studies on catalyst stability showed that ruthenium catalysts on rutile and carbon supports showed lifetimes of 19 and 11 weeks respectively, producing complete carbon to gas conversion in this duration [41]. In this work, $\mathrm{H}_{2}$ production coupled with complete carbon gasification is proposed at increased productivities in order to make the two-step process attractive on an industrial scale.

The two-step approach was first introduced by Davda et al. [107]. They reported the gasification of $10 \mathrm{wt} \%$ aqueous glucose and its stabilised counterpart, sorbitol, at $120{ }^{\circ} \mathrm{C}$ in a hydrogenation reactor followed by a reforming reactor using a Pt on $\gamma-\mathrm{Al}_{2} \mathrm{O}_{3}$ nanofibre catalyst at $265{ }^{\circ} \mathrm{C}$. For both cases of sorbitol and glucose feeds, similar $\mathrm{H}_{2}$ yields of 6.5 and 5.8 mole per mole feed and similar carbon gasification efficiencies of $100 \%$ and $93 \%$ respectively were obtained. The used WHSV $_{\mathrm{c}}$ was very low, around $0.02 \mathrm{~h}^{-1}$.

Although no further publications on the two-step process for gas production are present since the work of Davda et al., this is part of a patented technology called BioForming® by Virent, Inc for the conversion of sugars, starches and carbohydrates into liquid fuels [133].

The potential of stabilisation is the focus of the first part of this chapter in which a comparative study between the hydrothermal gasification of carbohydrates (sucrose and starch) and stabilised carbohydrates (Refer Chapter 2 ) is conducted. The complete gasification of the stabilised mixture is targeted in order to obtain a dischargeable water stream (COD $<125 \mathrm{mg} \mathrm{L}^{-1}$ water [134]) along with valuable gas products $\left(\mathrm{H}_{2}\right.$ and $\left.\mathrm{CH}_{4}\right)$. 
The second part of this chapter is dedicated to improving productivities through the utilisation of both Pt and Ru catalysts. As studied in Chapter 3, the usage of Pt for complete carbon gasification leads to reduced $\mathrm{H}_{2}$ productivity due to its consumption in side reactions towards alkane production. In this work, the usage of a highly reactive $\mathrm{Ru}$ catalyst, in combination with a Pt catalyst, is proposed.

While it is known that both Pt and Ru are expensive catalysts, the focus of this work was to use existing commercially available catalysts in the development of a process for the hydrothermal gasification of carbohydrates. With respect to the stability of the supports, it is known that carbon presents good stability under hydrothermal conditions, while $\gamma-\mathrm{Al}_{2} \mathrm{O}_{3}$ degrades to boehmite $(\mathrm{AlOOH})$ with a drastic reduction in surface area [135]. However, the use of $\gamma-\mathrm{Al}_{2} \mathrm{O}_{3}$ as a support for the Pt was considered in order to quantify the coke deposited on the catalyst.

\subsection{Experimental section}

The $45 \mathrm{ml}$ batch autoclave reactor used for gasification experiments is described in Chapter 2 .

\subsubsection{Experimental procedure}

Gasification experiments were conducted at $300^{\circ} \mathrm{C}$ at varying residence times ( 15 - 180 minutes) using 5 wt \% Pt on $\gamma-\mathrm{Al}_{2} \mathrm{O}_{3}$ and 5 wt \% Ru-C catalysts obtained from Sigma-Aldrich. Prior to a gasification catalytic test, the reactor was purged with $\mathrm{N}_{2}$ and an initial pressure of 3 bar $\mathrm{N}_{2}$ was used. Following the experiment, gas products were collected and analysed. Since $\mathrm{N}_{2}$ did not participate in the reaction, a $\mathrm{N}_{2}$ balance was considered by calculating the total moles of $\mathrm{N}_{2}$ before and after the gasification test. $\mathrm{A} \mathrm{N}_{2}$ balance closure of $>95 \%$ ensured that no gas leaks took place during the experiments.

\subsubsection{Analysis}

Gas products were collected in a 2 litre glass U-tube manometer using a $75 \%$ saturated acidified $\mathrm{NaCl}$ solution (pH 2) as a barrier solution [136]. Gas compositions were measured using a Rapid Refinery Gas Analyser (Varian). Mass balances were closed using weighing scales (KERN DS 8K0.05) and using the U-tube manometer for the total volume of gas produced.

Carbon balances were closed by using a Flash 2000 Elemental Analyser for the liquid product as well as the spent $\mathrm{Pt}-\mathrm{Al}_{2} \mathrm{O}_{3}$ catalyst. Although the coke deposition on the $\mathrm{Ru}-\mathrm{C}$ catalyst could not be quantified, an approximate estimation was made by determining the difference in weight of the (dried) catalyst before and after the experiments. Carbon in the gas phase was calculated from the composition of the product gas stream obtained from RGA analysis.

Carbon balance closures were found to be $>90 \%$ for all the gasification experiments considered. 


\subsubsection{Calculations}

Experimental errors represent the standard deviation of the mean at $95 \%$ confidence levels. For error bars not shown on graphs, quadruple measurements for gasification of stabilised sucrose over $5 \mathrm{wt} \% \mathrm{Pt}_{-} \mathrm{Al}_{2} \mathrm{O}_{3}$ at $300{ }^{\circ} \mathrm{C}$ and a residence time of 60 minutes were used to represent the errors of the whole population at all temperatures and residence times. The experimental data and associated errors are tabulated in Table C.1 in Appendix C.

The following equations were used for the calculation of carbon conversion to gas, $\mathrm{H}_{2}$ yield on a carbon basis, product carbon yield and WHSV $_{c^{\prime}}$ In this work, the $\mathrm{H}_{2}$ yield and WHSV are defined based on the mass of carbon in the feed rather than the mass of the feed $\left(\mathrm{YH}_{2 \mathrm{C}}\right.$ and $\left.\mathrm{WHSV}_{\mathrm{c}}\right)$ since only the carbon content of the feed was known for experiments using Ru in the Pt-Ru series.

$$
\begin{aligned}
& X_{C G}=\frac{\sum n_{C, g}}{n_{C, i n}} \cdot 100\left(\frac{\text { Total moles of carbon in gas }}{\text { Initial moles of carbon in feed }}\right) \\
& Y_{H_{2, C}}=\frac{n_{H_{2}}}{n_{C, \text { in }}}\left(\frac{\text { Moles of } \mathrm{H}_{2} \text { produced }}{\text { Initial moles of carbon in } \text { feed }}\right) \\
& Y_{C, i}=\frac{n_{C, i}}{n_{C, \text { in }}}\left(\frac{\text { Moles of carbon in product } i}{\text { Initial moles of carbon in } \text { feed }}\right) \\
& W H S V_{C}=\frac{m_{C, \text { in }}}{m_{\text {cat }} \cdot t}\left[\frac{g_{C, f}}{g_{\text {cat }} \cdot h}\right]\left(\frac{\text { Initial mass of carbon in } \text { feed }}{\text { mass of catalyst } \cdot \text { residence time }}\right)
\end{aligned}
$$

\subsection{Results}

\subsubsection{Unstabilised vs stabilised feed}

The direct gasification of sucrose and starch (unstabilised feed) was compared to the gasification of the polyol mixture (stabilised feed) obtained from sucrose and starch stabilisation.

For sucrose, Figure 4.1 depicts the carbon distribution of different products obtained from the gasification of these feeds using both catalysts at a WHSV of $1 \mathrm{~h}^{-1}$. As illustrated, experiments conducted with unstabilised sucrose (Runs \# 8 and 10 as shown in Table 4.2 and Figure 4.1) led to the production of coke on the catalyst and an acetone soluble phase hereon referred to as 'oil'. This result of high coking and poor gasification is consistent with previous works on gasification of sucrose and glucose at sub- and super critical conditions [11, 19,44]. This is however inconsistent with the work of Davda et al. [107], which remains an outlier in published work on sugar gasification. Their publication contains no information on the production of coke, and at a $\mathrm{WHSV}_{\mathrm{c}}$ of $0.009 \mathrm{~h}^{-1}$, carbon gasification obtained from glucose reforming was $91 \%$. 


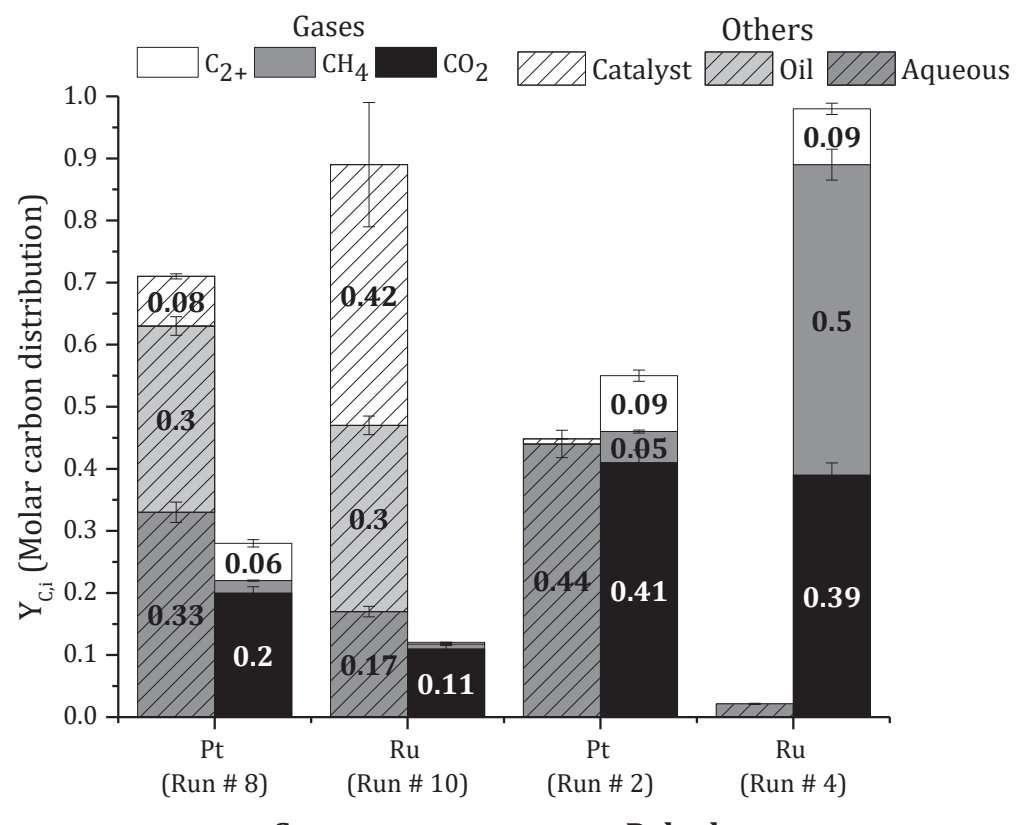

Sucrose

Polyols

Figure 4.1: Molar distribution of carbon in gaseous products $\left(\mathrm{CO}_{2^{\prime}}, \mathrm{CH}_{4} \mathrm{C}_{2+}\right)$, aqueous phase, oil and as coke on the catalyst for sucrose and polyols using stabilised and unstabilised sucrose using $\mathrm{Pt}^{-} \mathrm{Al}_{2} \mathrm{O}_{3}$ and $\mathrm{Ru}-\mathrm{C}$.

Experiments conducted at $300^{\circ} \mathrm{C}$ for 120 minutes (WHSV ${ }_{c} 1 \mathrm{~h}^{-1}$ ) using $0.3 \mathrm{~g}$ of catalyst.

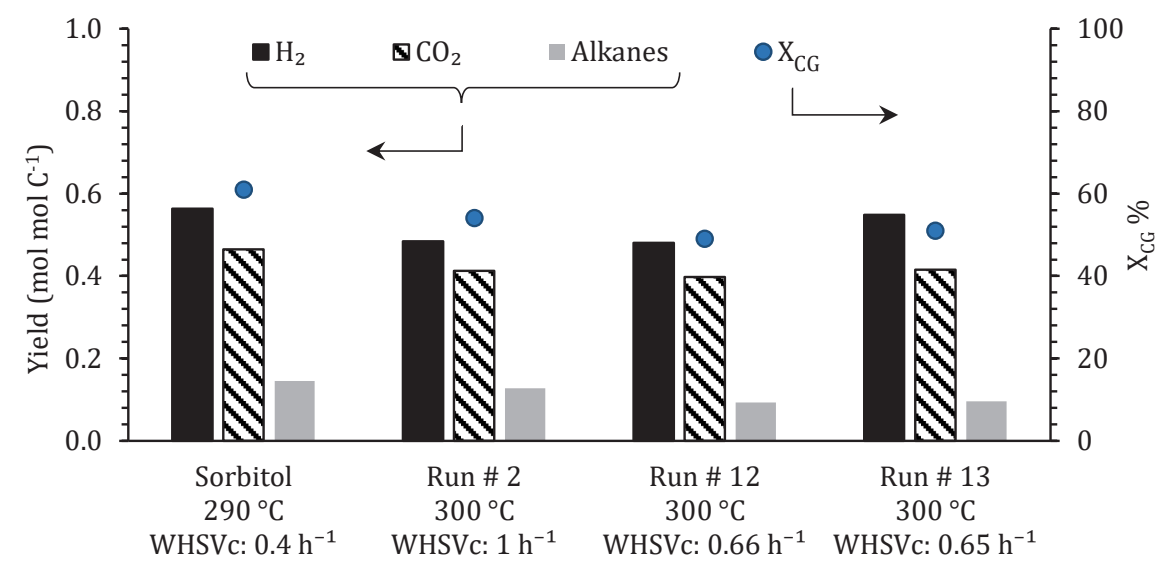

Figure 4.2: Comparison of carbon to gas conversion of stabilised starch to stabilised sucrose and sorbitol. Experiments were conducted using $\mathrm{Pt}-\mathrm{Al}_{2} \mathrm{O}_{3}$. 
Experiments conducted with the stabilised feed ("polyol" mixture of sorbitol and mannitol in ratios obtained from the stabilisation step) show better overall performance in terms of gas yields with both catalysts (Runs \# 2 and 4). It is important to notice that no oil formation was observed. A single aqueous phase with dissolved organics was obtained in all experiments conducted with the stabilised feed using both catalysts. With respect to coke deposition on the surface of the catalyst, spent $\mathrm{Pt}-\mathrm{Al}_{2} \mathrm{O}_{3}$ samples were found to contain carbonaceous deposits regardless of the choice of feed. The mass fraction of coke on catalyst is tabulated in Table 4.1. It can be seen that the quantity of coke deposited is an order of magnitude higher in the case of experiments with the unstabilised feed compared to the stabilised feed.

Table 4.1: Elemental analysis of spent $\mathrm{Pt}-\mathrm{Al}_{2} \mathrm{O}_{3}$ catalysts

\begin{tabular}{lrr}
\hline Spent catalyst & Run \# & Mass fraction of coke on catalyst (\%) \\
\hline Unstabilised sucrose & 8 & $17.0 \pm 2.0$ \\
Stabilised sucrose & 2 & $2.0 \pm 0.1$ \\
Unstabilised starch & 14 & $4.0 \pm 1.0$ \\
Stabilised starch & 12 & $0.4 \pm 0.1$ \\
\hline
\end{tabular}

It is clear that the gasification of more stable sugar alcohols in comparison to their sugar counterparts increased the gasification efficiency significantly.

In a similar manner, the gasification of starch was compared to the gasification of stabilised starch using Pt- $\mathrm{Al}_{2} \mathrm{O}_{3}$. Table 4.2 displays the results.

Figure 4.2 compares gasification results of the mixtures produced from the stabilisation of starch and sucrose, to the gasification of model compound sorbitol in water over Pt- $\mathrm{Al}_{2} \mathrm{O}_{3}$. It is important to note that while a slightly lower temperature for sorbitol gasification is used for comparison $\left(290^{\circ} \mathrm{C}\right)$, a lower weight hourly space velocity on a carbon basis $\left(\mathrm{WHSV}_{\mathrm{c}}\right)$ of $0.4 \mathrm{~h}^{-1}$ is also used. It can be seen that the carbon to gas conversion $\left(\mathrm{X}_{\mathrm{CG}}\right)$ of starch stabilised for 120 minutes is similar to that of stabilised sucrose under the studied, comparable, conditions.

\subsubsection{Effect of residence time}

Table 4.2 also displays the effect of the residence time on the $\mathrm{H}_{2}$ yield and total carbon gasification. Overall, for both catalysts, an increase in residence time leads to an increase in gas production. Gasification of stabilised sucrose using the $\mathrm{Pt}_{-} \mathrm{Al}_{2} \mathrm{O}_{3}$ catalyst proceeds very slowly (Runs \# 1 and 2). Studies on Pt catalysts in the reforming on glycerol have shown that its activity is decreased due to the interaction of $\mathrm{CO}$ and adsorbed hydrogen with Pt [137]. Additionally, the presence of $\mathrm{H}_{2}$ in the reaction environment was found to inhibit further reforming, as presented in Chapter 
3, and described in literature [120]. Gasification of the stabilised feed using the $\mathrm{Ru}-\mathrm{C}$ catalyst proceeds at a higher rate (Runs \# 3 and 4), achieving (near) complete gasification within 120 minutes. This is in good agreement with catalytic studies on the reforming of sugar alcohols and can be attributed to the increased $\mathrm{C}$-C scission activity and higher activity of $\mathrm{Ru}$ compared to Pt catalysts [37].

With respect to unstabilised sucrose, gasification using both catalysts at varying residence times showed that the fraction of oil produced, is again reduced at longer residence times (Runs \# 7 and 8). It can therefore be concluded from this observation that the oil represents intermediate species that can undergo further gasification at longer residence times.

\subsubsection{Effect of catalyst}

Figure 4.1 also illustrates the influence of the type of catalyst on the product distribution. For the stabilised feed, experiments show that utilising $\mathrm{Ru}-\mathrm{C}$ resulted in higher $\mathrm{CH}_{4}$ yields and therefore better carbon gasification (> $95 \%$ ) under similar experimental conditions. Pt and Ru based catalysts have both been found to be efficient reforming catalysts. As illustrated in Figure 4.3 and in Table 4.2 (Runs \# 1 to \# 4), similar $\mathrm{CO}_{2}$ yields were observed using both catalysts. However, $\mathrm{Ru}$ catalysts also showed high activity in hydrogenolysis and methanation reactions, thereby increasing the yield of $\mathrm{CH}_{4}$ by consuming $\mathrm{H}_{2}$ produced in reforming reactions [120]. Additionally, the high reactivity of the Ru catalyst is reflected in the increased carbon gasification. Considering stabilised sucrose, at the same $\mathrm{WHSV}_{c}$ of $1 \mathrm{~h}^{-1}$, the total carbon gasification over Pt- $\mathrm{Al}_{2} \mathrm{O}_{3}$ was 54 $\%$ in comparison to the value of $97 \%$ obtained using $\mathrm{Ru}-\mathrm{C}$.

The utilisation of bimetallic catalysts containing Pt and Ru has been studied in the field of APR [138-140]. Although such catalysts have been found to improve reactivity and reaction rates, this comes at the cost of reduced $\mathrm{H}_{2}$ production due to its consumption in the formation of methane [140]. Studies on improving the $\mathrm{H}_{2}$ yield using a microchannel reactor or $\mathrm{N}_{2}$ as a stripping agent have shown that it is possible to achieve higher yields of $\mathrm{H}_{2}$ by stripping it out of the reactor before it can be consumed in side reactions $[120,141]$. By combining this with the use of a bi-metallic Pt$\mathrm{Ru}$ catalyst, a higher reactivity and a neutral effect in terms of $\mathrm{H}_{2}$ production were obtained [120]. The use of physical mixtures of $5 \mathrm{wt} \% \mathrm{Pt}$ and Ru on carbon supports in a mass ratio of 1:5 was also reported [140]. A lower sorbitol concentration (1 wt \%) was considered. $100 \%$ carbon to gas conversion was achieved at a WHSV ${ }_{c}$ of $0.16 \mathrm{~h}^{-1}$, with $\mathrm{H}_{2}$ and $\mathrm{CH}_{4}$ productivities being 2.9 and $5.9 \mathrm{~mol} \mathrm{~kg}_{\text {cat }}{ }^{-1} \mathrm{~h}^{-1}$ respectively. With respect to catalyst development, studies on a tin promoted Raney-Ni catalyst were found to show comparable performance to Pt for the production of $\mathrm{H}_{2}$ from sugar alcohols [40]. 
In this work the aim is two-fold; production of a dischargeable water stream (TOC $<0.01 \mathrm{wt} \%$ ) by complete gasification of sugars, while realizing a high yield of $\mathrm{H}_{2}$ at higher temperatures and feedstock concentrations. In order to obtain high carbon gasification efficiencies as well as high $\mathrm{H}_{2}$ yields, experiments were conducted using both gasification catalysts in series. By running the stabilised feed over a Pt catalyst, high $\mathrm{H}_{2}$ yields can be obtained at lower reactivity. The remainder of the organic carbon present in the liquid phase can be converted over the Ru catalyst to produce $\mathrm{CH}_{4}$. Figure 4.3 compares the hydrogen yield and total carbon gasification for experiments conducted with stabilised sucrose, using Pt- $\mathrm{Al}_{2} \mathrm{O}_{3}, \mathrm{Ru}-\mathrm{C}$ and the combination of Pt- $\mathrm{Al}_{2} \mathrm{O}_{3}$ and $\mathrm{Ru}-\mathrm{C}$ in series, keeping the total residence time (and WHSV ${ }_{c}$ ) constant (Runs \# 1, 3, 5 and 2, 4, 6 for a residence time of 60 and 120 minutes respectively). As shown, the low carbon gasification of $\mathrm{Pt}_{-} \mathrm{Al}_{2} \mathrm{O}_{3}$ (Run \# 2) is balanced by the high methane production of Ru-C (Run \# 4) leading to high overall carbon gasification with no compromise on the $\mathrm{H}_{2}$ yield (Run \# 6).

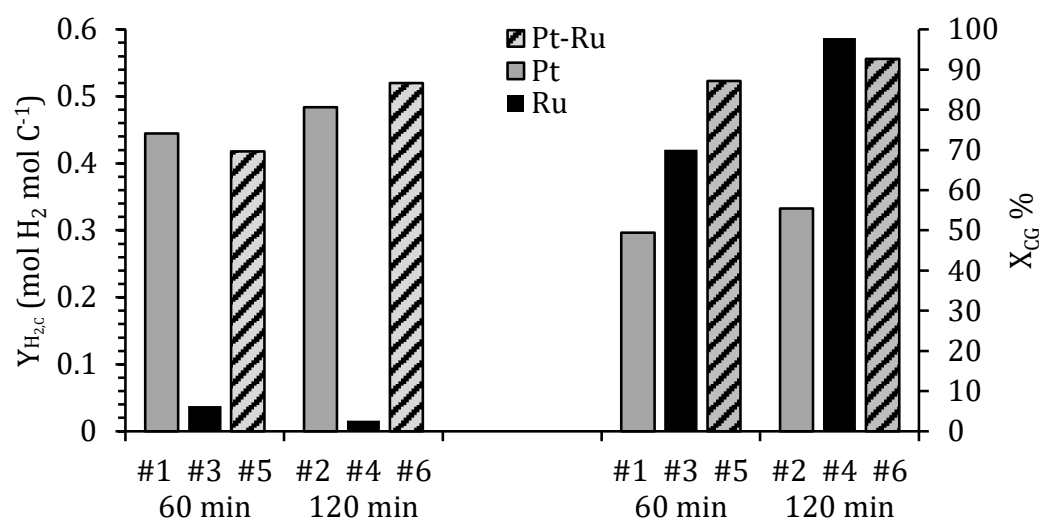

Figure 4.3: $\mathrm{H}_{2}$ yield and carbon to gas conversion $\mathrm{X}_{\mathrm{CG}}$ of stabilised sucrose as a function of type of catalyst.

Experiments conducted at $300{ }^{\circ} \mathrm{C}$ for 60 and 120 minutes. Corresponding WHSV $: 2$ and $1 \mathrm{~h}^{-1}$.

The successful achievement of both objectives, complete gasification and high hydrogen yield is possible, as evidenced by Runs \# 5, 6 and 11. Therefore, the proposed scheme of stabilisation followed by a stepwise hydrogen production and complete gasification is attractive for further evaluations. 

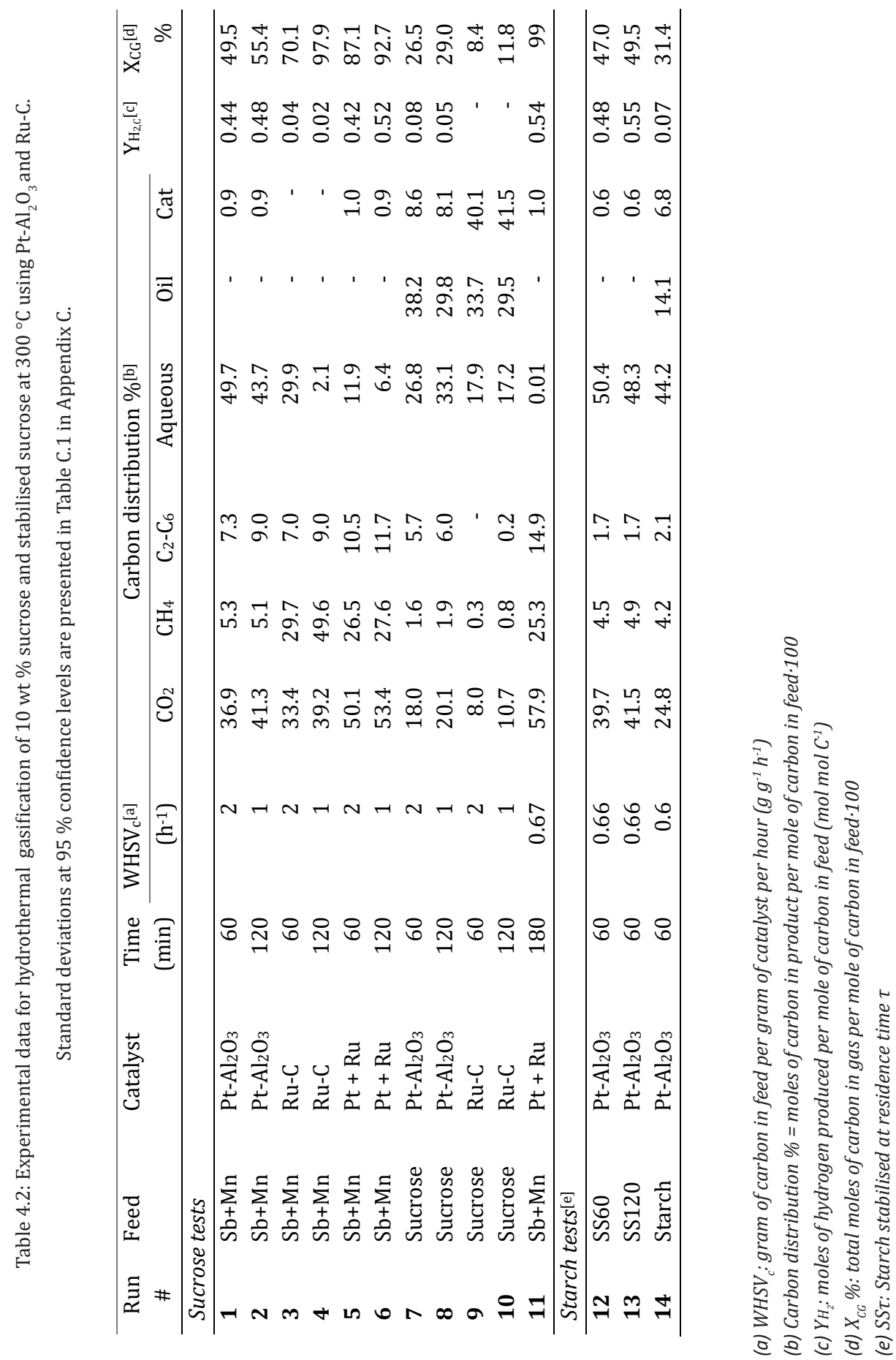


\subsection{Discussion}

Figure 4.4 compares reported $\mathrm{H}_{2}$ yields $\left(\mathrm{YH}_{2, \mathrm{C}}\right)$ and carbon to gas conversion $\left(\mathrm{X}_{\mathrm{CG}}\right)$ of hydrothermal gasification or aqueous phase reforming of sorbitol at feedstock concentrations of $10 \mathrm{wt} \%$ or higher using a Pt catalyst. This information is also tabulated in Table C.2 in Appendix C. Other works on APR of sorbitol at lower feedstock concentrations (1 - 5 wt \%) have been studied [120, 124] but not considered for the comparison. It can be seen that the $\mathrm{X}_{\mathrm{CG}}$ and associated high $\mathrm{YH}_{2, \mathrm{C}}$ as obtained by Davda et al. [107] have not been reproduced in subsequent work. The key reason for this is the low $\mathrm{WHSV}_{c}$ of $0.02 \mathrm{~h}^{-1}$ utilised. Such a WHSV ${ }_{c}$ would require large reactors. As a quick calculation, consider a flowrate of $2.8 \mathrm{~kg} \mathrm{~s}^{-1}\left(10 \mathrm{tons} \mathrm{h}^{-1}\right)$ of aqueous sorbitol solutions at a concentration of $10 \mathrm{wt} \%$. Using a WHSV of $0.02 \mathrm{~h}^{-1}$ results in a catalyst requirement of 15,380 kg. Considering a catalyst particle density of $1400 \mathrm{~kg} \mathrm{~m}_{\mathrm{p}}^{-3}$ and a bed voidage of 0.5 , this would require a reactor with volume $22 \mathrm{~m}^{3}$. Using a $\mathrm{H}_{2}$ yield of 6.5 moles per mole sorbitol then leads to a $\mathrm{H}_{2}$ productivity of $2.27 \mathrm{~mol} \mathrm{H}_{2} \mathrm{~kg}_{\text {cat }}{ }^{-1} \mathrm{~h}^{-1}$, significantly lower than the value of $26 \mathrm{~mol} \mathrm{H}_{2} \mathrm{~kg}_{\text {cat }}{ }^{-1} \mathrm{~h}^{-1}$ achieved in our previous work [141]. From Figure 4.4(b) it can be seen that while the complete carbon gasification of sorbitol over $\mathrm{Pt}-\mathrm{Al}_{2} \mathrm{O}_{3}$ is possible, long residence times (and therefore small $\mathrm{WHSV}_{c}$ 's) are required, especially at APR temperatures $\left(200-270{ }^{\circ} \mathrm{C}\right)$.

The complete carbon gasification (> $99 \%$ ) obtained at a WHSV ${ }_{c}$ of $0.67 \mathrm{~h}^{-1}$ (Run \# 11) is in the range of WHSV 's studied in previous work with wet biomasses using a Ru catalyst $[42,142]$.

The advantage of using a sequential combination of Pt-Ru is also illustrated in Figure 4.4(b). High carbon gasification (87-99\%) is achieved at $300{ }^{\circ} \mathrm{C}$ at WHSV 's between 1 and $4 \mathrm{~h}^{-1}$ through the use of Ru, significantly higher than $12-40 \%$ achieved using Pt alone. The high reactivity of Ru for $\mathrm{C}$-C cleavage reactions complements the low reactivity of Pt for the same. Therefore, by increasing the WHSV over the Pt catalyst, high $\mathrm{H}_{2}$ selectivity is obtained at low carbon gasification. The rest of the organics are converted over the Ru catalyst to achieve complete carbon gasification. 


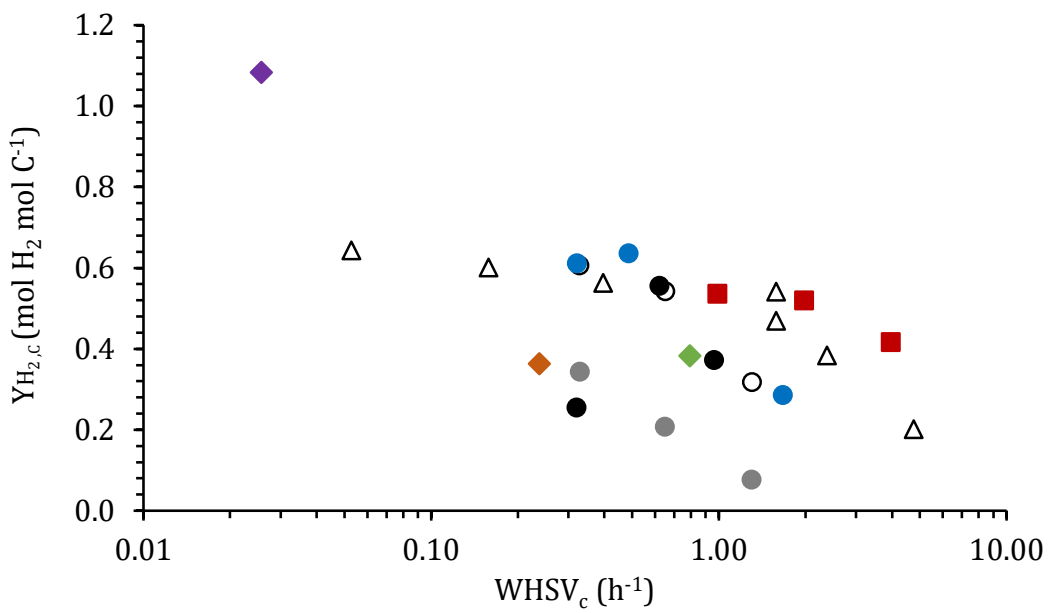

(a)

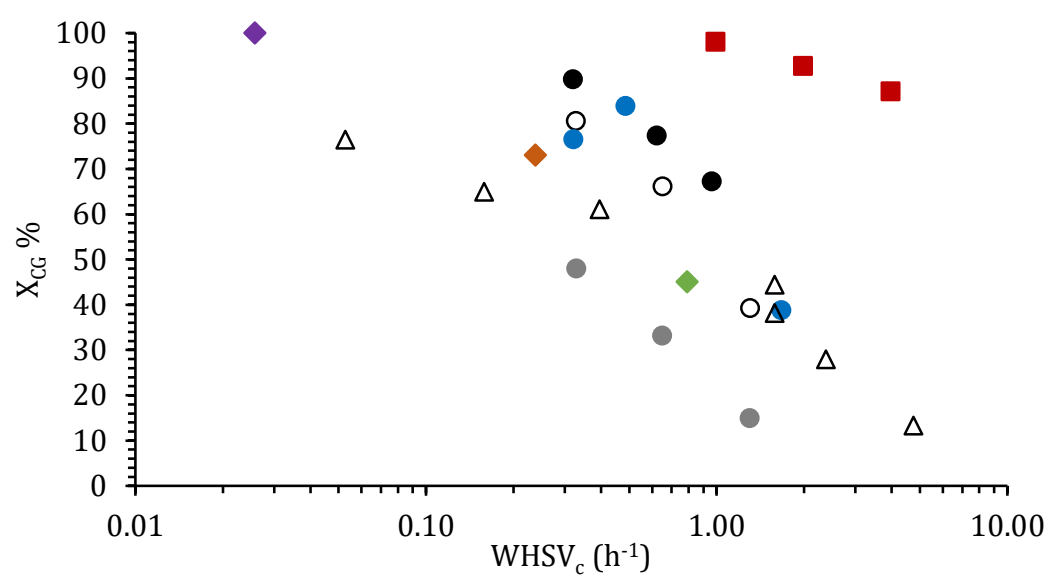

(b)

$\begin{array}{lll}-270^{\circ} \mathrm{C}[141] & \circ 290^{\circ} \mathrm{C}[141] & \bullet 310^{\circ} \mathrm{C}[141] \\ \bullet-350^{\circ} \mathrm{C}[141] & \Delta 290^{\circ} \mathrm{C}[141] & \bullet 265^{\circ} \mathrm{C}[107] \\ -225^{\circ} \mathrm{C}[112] & \bullet 250{ }^{\circ} \mathrm{C}[143] & \end{array}$

Figure 4.4: Influence of WHSV on (a) $\mathrm{Y}_{\mathrm{H}_{2}}$ and (b) $\mathrm{X}_{\mathrm{CG}}$ of $10 \mathrm{wt} \%$ sorbitol from batch experiments (triangles) [141], continuous experiments (circles, squares)[141], other published work (diamonds) over Pt catalysts at metal loadings of $3 \%$ on $\gamma-\mathrm{Al}_{2} \mathrm{O}_{3}$ nanofibres [107], $5 \%$ on $\gamma-\mathrm{Al}_{2} \mathrm{O}_{3}$ [112] and $7 \%$ on mesoporous carbon [143] and sequential Pt+Ru combination (red squares) used in this work. 


\subsection{Conclusion}

The work presented in this chapter focusses on increasing the productivity of hydrothermal gasification with respect to both $\mathrm{H}_{2}$ production and carbon gasification. This dual benefit is achieved by exploiting the sequential use of two catalysts, Pt and Ru. High carbon to gas conversion was achieved at $\mathrm{WHSV}_{\mathrm{c}^{\prime}} \mathrm{s}$ of $1-4 \mathrm{~h}^{-1}$, orders of magnitude faster than productivity in earlier reported studies. Key advantage of utilising the Pt-Ru combination is that the process offers opportunities not only as a $\mathrm{H}_{2}$ production process from renewable wet biomass, but through the production of a dischargeable water stream, is also applicable as a water clean-up technology process to treat relevant wastes and wastewaters. The advantages of utilising dual catalysts in terms of energy efficiencies and process economics are further studied in the next chapter. 


\section{Appendix}

\section{C.1 Error analysis}

The experimental data along with standard deviation calculated using $95 \%$ confidence levels are tabulated in Table C.1.

Table C.1: Error analysis for experimental data

Note: Values in bold are considered as errors for the whole population of experiments

\begin{tabular}{lllll}
\hline \multicolumn{5}{l}{ Gasification of stabilised sucrose } \\
\hline $\mathrm{YH}_{2, c}$ & $\mathrm{YCO}_{2}$ & $\mathrm{YCH}_{4}$ & $\mathrm{YC}_{\text {alk }}$ & $\mathrm{X}$ \\
$\mathrm{mol} \mathrm{mol} \mathrm{C}^{-1}$ & $\mathrm{~mol} \mathrm{~mol} \mathrm{C}^{-1}$ & $\mathrm{~mol} \mathrm{~mol} \mathrm{C}^{-1}$ & $\mathrm{~mol} \mathrm{C} \mathrm{mol} \mathrm{C}$ & $\%$ \\
$0.43 \pm \mathbf{0 . 0 2}$ & $0.37 \pm \mathbf{0 . 0 2}$ & $0.05 \pm \mathbf{0 . 0 1}$ & $0.07 \pm \mathbf{0 . 0 1}$ & $50 \pm \mathbf{2}$ \\
\hline
\end{tabular}

\section{C.2 Literature data}

Table C.2 presents a comparison between the published work and this work on the hydrothermal gasification of sorbitol at feedstock concentrations of $10 \mathrm{wt} \%$ or higher. 


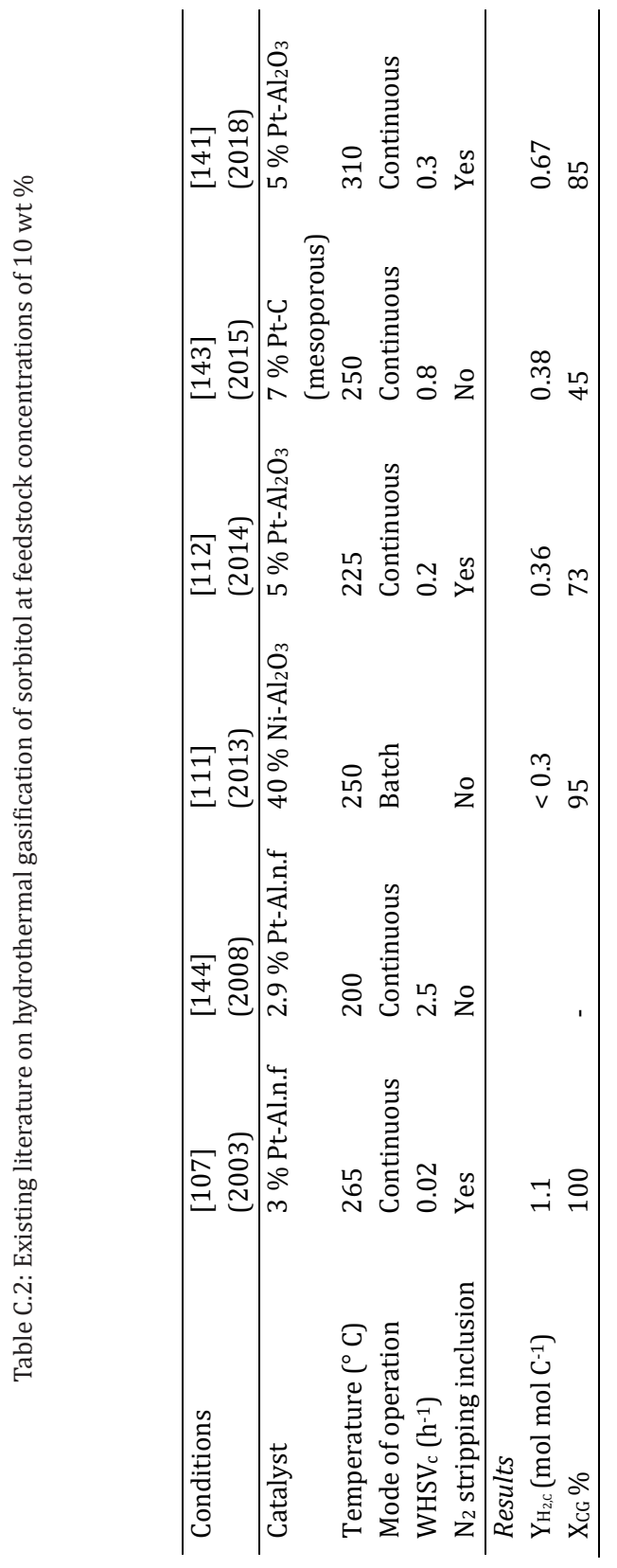





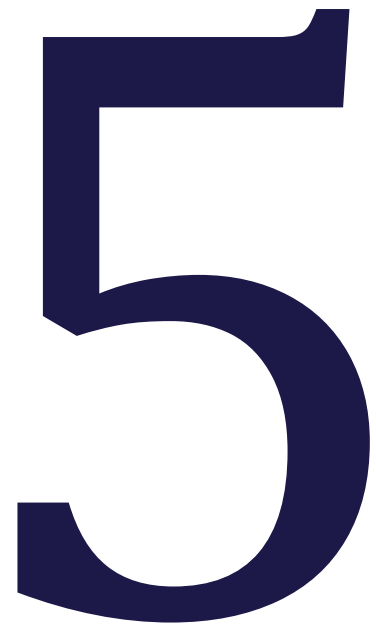

\section{Process design and}

\section{Economic evaluation}

This chapter has been adapted from:

V.R. Paida, S.R.A. Kersten, A.G.J. van der Ham, D.W.F. Brilman, A two-step approach to hydrothermal gasification: Process design and Economic evaluation (submitted) 


\section{Abstract}

Experimental data and kinetic models are used to further develop the two-step approach for industrial scale. A preliminary process design is conducted in order to assess the potential of the two-step process. For stabilisation, two cases are considered: the use of excess vs. stoichiometric $\mathrm{H}_{2}$, and for gasification, the utilisation of sequential reactors for gasification housing Pt and $\mathrm{Ru}$ catalysts is compared to a single reactor with Pt alone. A total of four options are conceptually designed and economically evaluated. Using state-of-the-art insights, process techniques and the current market scenario, a minimum $\mathrm{H}_{2}$ selling price of $3.4 \$ \mathrm{~kg}^{-1}$ was obtained for the most promising option.

A sensitivity study showed that the feedstock price, concentration and quantity, played a crucial role in the selling price of $\mathrm{H}_{2}$. These variables are all correlated and are dependent on the industry from where the feedstock is obtained. Industrial wastewater streams rich in carbohydrate residues and associated with gate fees were found to be promising feedstock for the process. 


\subsection{Introduction}

In the previous chapters, the two-step approach, as depicted in Figure 5.1, was tested using sucrose and starch as model carbohydrates. While bench-scale studies on hydrothermal gasification have been conducted for a wide variety of feedstock $[142,145,146]$, to date, there have been limited pilot-scale studies on $\mathrm{H}_{2}$ production from real feedstock at sub-critical temperatures. Most studies focus on obtaining clean water by producing $\mathrm{CH}_{4}$, similar to biological routes like aerobic and anaerobic digestion, which treat organic wastes to produce biogas. Challenges include poor $\mathrm{H}_{2}$ selectivity at lower temperatures using heterogeneous catalysts, and poor yields due to microbial inhibition using fermentation. The two-step approach offers a potentially economical attractive route to hydrothermal gasification, by focussing on the production of $\mathrm{H}_{2}$.

The objective of this work was to evaluate the two-step approach to hydrothermal gasification for hydrogen production and water clean-up on an industrial scale. The developed kinetic models for stabilisation (Chapter 2) and gasification (Chapter 3) were used to size industrial scale reactors. The economics of the process are assessed by calculating a minimum $\mathrm{H}_{2}$ selling price. The market potential of the process is estimated by comparing it to competitive renewable $\mathrm{H}_{2}$ production technologies.

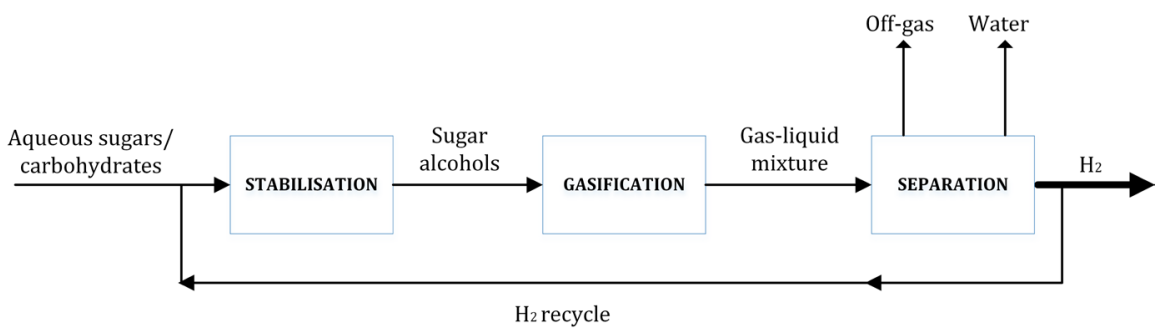

Figure 5.1: Scheme of the two-step approach to hydrothermal gasification

\subsection{Feedstock}

The type and composition of feedstock is crucial for the process design and economics. Depending on the source of material, biomass can vary in its carbohydrate, lignin and ash content. Hydrothermal biomass processing focusses on aqueous biomass streams that have a moisture content of $70-95 \%$. Wastes and wastewater streams from food and feed industries are therefore valuable feedstock for the process, as well as sewage sludge, domestic and agricultural residues. More specifically, the process under consideration is most suited for highly coking feeds such as wastewater streams rich in sugars and carbohydrates, for instance from the fruit and vegetable processing sectors. An example is apple pomace, a fruit waste containing 80-90\% moisture with a large carbohydrate content. While this is currently used as animal feed, its high moisture, low 
protein and low vitamin content limit its nutritional value, making it a suitable feedstock for hydrothermal processing [67]. An overview of the typical composition of industrial wastewaters relevant as feedstock for the process can be found in Chapter 2 .

\subsection{Conceptual process design}

\subsubsection{Plant size}

The total flow of wastewater in the current design is selected to be $200,000 \mathrm{~kg} \mathrm{~h}^{-1}$ at a concentration of $100 \mathrm{~g} \mathrm{~L}^{-1}$. This corresponds to a COD of $47 \mathrm{~g} \mathrm{O}_{2} \mathrm{~L}^{-1}$, similar to wastewater streams tabulated in Table 2.1. The process is designed based on experimental work with $100 \mathrm{~g} \mathrm{~L}^{-1}$ aqueous sucrose. The process described here focusses on the production of $\mathrm{H}_{2}$ from aqueous biomass streams via a two-step process. The process is divided into the following sections, as shown in the block diagram in Figure 5.2. The inside battery limits (ISBL) for the process design are enclosed in the red border.

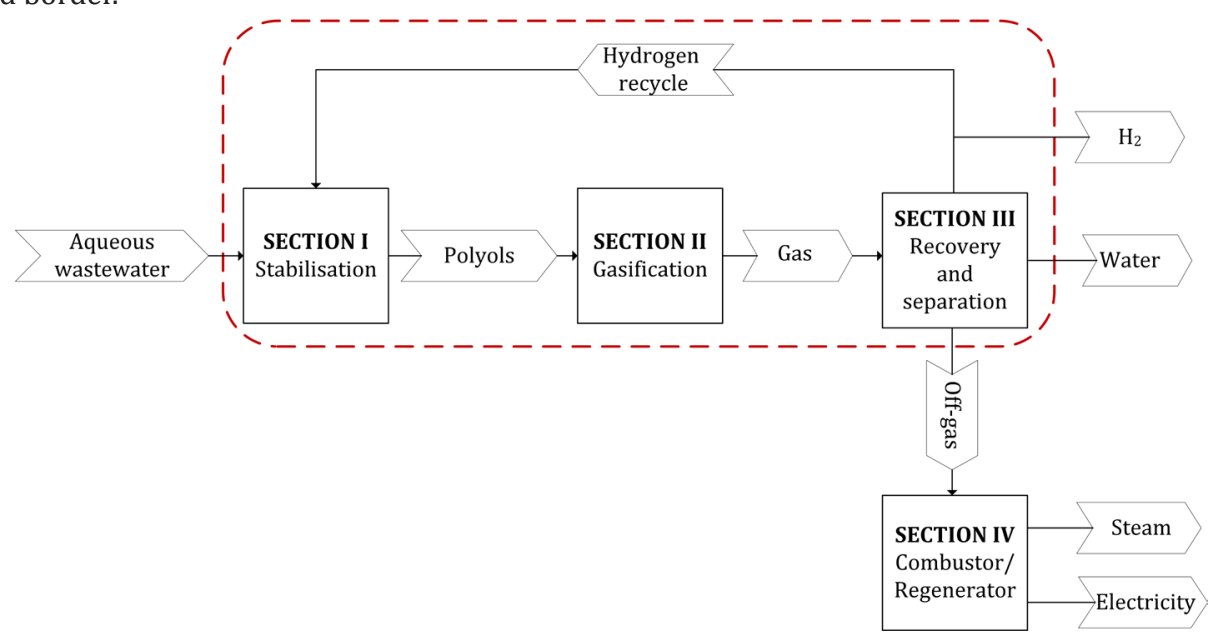

Figure 5.2: Block diagram of the overall process

\subsubsection{Techno-economic approach}

From our previous work, kinetic models developed in Matlab R2017a based on experimental studies were used to design and size the reactors for both stabilisation and gasification steps. The desired conversions and gas yields were incorporated in yield reactors in Aspen Plus V10, integrated within process flow diagrams to obtain thermodynamically feasible material and energy balances for unit operations in the process. This data is used in determining the size and bare equipment cost of the unit operations involved, by utilising Aspen Process Economic Analyzer (APEA). Peters et al. [147] and Seider et al. [148] are used to double check the bare equipment costs. While the differences in the costs for some equipment are large, the sum of all equipment 
costs are in the same order of magnitude $( \pm 30 \%)$, as tabulated in Table D.1 in Appendix D.1. Therefore, the determination of the total capital investment (TCI) and total production cost (TPC) is based on the bare equipment costs obtained from APEA. A discounted cash flow analysis is used to calculate the minimum selling price for $\mathrm{H}_{2}$ at zero net present value (NPV).

This study uses ' $\mathrm{n}^{\text {th }}$-plant' economics, assuming that this is not a pioneer plant, rather, one of $n$ plants using the same technology. This assumption avoids risk financing, longer start-ups, equipment overdesign and additional costs typically associated with a pioneer plant, thereby inhibiting these costs from influencing the economics of the process [149].

\subsubsection{Aspen Plus property method}

The property method in Aspen Plus is used to determine the thermodynamic properties of the components of the system. Keeping in mind the system under consideration, the choice of property method can significantly influence the partial pressures of the gases in water. High pressure systems require the use of an equation of state (EOS) model since activity coefficient models are not suitable for pressures over 10 bar. Previous comparative studies of hydrothermal biomass systems in near-critical and super critical conditions show that using an EOS method along with a suitable mixing rule (alpha function), led to less than $2 \%$ difference in hydrogen production between the different suitable combinations [150]. One of the considered EOS methods with a mixing rule, RKS-BM was therefore selected in this study.

\subsection{Stabilisation}

Stabilisation, a low temperature hydrotreating step, has been studied extensively in the upgrading of pyrolysis oils derived from biomass $[43,46]$. Stabilisation was introduced in order to reduce the reactivity towards polymerisation and condensation reactions, that lead to coking and plugging of reactor lines. In the field of pyrolysis, stabilisation involved hydrogenation, hydrogenolysis and hydrodeoxygenation (HDO) type reactions.

In the process concept considered, stabilisation is utilised as a pre-treatment step prior to gasification in order to convert aqueous sugars or carbohydrate streams derived from biomass to $\mathrm{H}_{2}$ and $\mathrm{CH}_{4}$. Experimental work with three types of feedstock confirm that stabilisation of sugars and polysaccharides produces more stable mixtures of polyols and alcohols, which have improved gasification efficiencies and show no coke formation in comparison to their carbohydrate counterparts.

Although typically enzymatic and acidic methods are utilised for the degradation and hydrolysis of starch and other ligno-cellulosic biomasses with > $90 \%$ recovery of reducing sugars [91-93], the choice of hot compressed water in this work is more suitable because it is a one-pot catalytic 
process that requires no further downstream separation of additional chemicals.

Additionally, obtaining monosaccharides prior to stabilisation is no longer a requisite for the process since stabilisation with sufficient $\mathrm{H}_{2}$ pressure and a catalyst satisfactorily converts polysaccharides to stable compounds that can be gasified without coke formation.

Experimental work confirms that stabilisation of both starch and SBP hydrolysate was successful due to the absence of sugars in the stabilised products. For design purposes the kinetics of sucrose stabilisation will be utilised to size the reactor.

\subsubsection{Design}

In the stabilisation step, the feed stream is hydrogenated with $\mathrm{H}_{2}$ recycled from the gasification reactions. Hydrogenation reduces ringed sugars to linear sugar alcohol forms, which were found to be more stable in hot compressed water and lead to reduced coke formation. Typical catalysts for hydrogenation of sugars, organic acids, aldehydes and ketones include Raney-Nickel, titanium, carbon, or alumina supports doped with group VIII metals including ruthenium, platinum or rhenium [149].

The hydrogenation of sucrose over $5 \mathrm{wt} \% \mathrm{Ru}-\mathrm{C}$ in the presence of an excess amount of $\mathrm{H}_{2}$ was studied between $100-140{ }^{\circ} \mathrm{C}$ in batch autoclave tests, as reported in Chapter 2 . In these experiments, $100 \%$ conversion and selectivity towards polyol production was achieved. A pseudo-first order kinetic model was developed in order to describe the kinetics of the reaction. The overall reaction stoichiometry for the hydrolysis of sucrose and subsequent hydrogenation of its monomeric sugars is shown below.

$$
\mathrm{C}_{12} \mathrm{H}_{22} \mathrm{O}_{11}+\mathrm{H}_{2} \mathrm{O}+2 \mathrm{H}_{2} \rightarrow 2 \mathrm{C}_{6} \mathrm{H}_{14} \mathrm{O}_{6} \quad \Delta \mathrm{Hr}_{\mathrm{s}}=-56.3 \mathrm{~kJ} \mathrm{~mol}^{-1}
$$

The hydrogenation of sucrose to sorbitol and mannitol is an exothermic reaction with a calculated reaction enthalpy of $-56.3 \mathrm{~kJ} \mathrm{~mol}^{-1}$. This is calculated by combining the reaction enthalpy of hydrolysis of sucrose, determined to be $-19.4 \mathrm{~kJ} \mathrm{~mol}^{-1}$ which is consistent with that determined by Tombari et al. [82], and the reaction enthalpy of hydrogenation of glucose, determined to be -40.5 $\mathrm{kJ} \mathrm{mol}{ }^{-1}$. Considering the enthalpy change associated with the phase change of water, this leads to a $\Delta \mathrm{Hr}_{\mathrm{s}}$ of $-56.3 \mathrm{~kJ} \mathrm{~mol}^{-1}$ which translates to an adiabatic temperature rise of $4^{\circ} \mathrm{C}$ considering complete conversion of sucrose. Therefore, an adiabatic tubular reactor is considered for stabilisation. Table 5.1 presents the kinetic information used to design the stabilisation reactor. 


\begin{tabular}{|c|c|c|}
\hline \multicolumn{3}{|l|}{ Overall modelling parameters } \\
\hline Total feed flow rate & 200 & tons $\mathrm{h}^{-1}$ \\
\hline Feed concentration & 10 & wt $\%$ \\
\hline $\mathrm{H}_{2}$ flow & 260 & $\mathrm{~kg} \mathrm{~h}^{-1}$ \\
\hline Temperature & 140-144 (inlet-outlet) & ${ }^{\circ} \mathrm{C}$ \\
\hline Pressure & 120 & bar \\
\hline \multicolumn{3}{|l|}{ Reaction parameters } \\
\hline WHSV & 40 & $\mathrm{~h}^{-1}$ \\
\hline Catalyst type & 5 wt \% Ru-C & \\
\hline Total catalyst requirement & 500 & $\mathrm{~kg}$ \\
\hline \multicolumn{3}{|l|}{ Polyol yields } \\
\hline Sorbitol & 1.46 & mol (mol Sucrose) $)^{-1}$ \\
\hline Mannitol & 0.53 & mol (mol Sucrose) $)^{-1}$ \\
\hline
\end{tabular}

For design purposes, two cases for stabilisation are considered, as depicted in Figure 5.3.

In Case A, as in the work of Westerterp et al. [151], the stabilisation step is designed in such a way that the $\mathrm{H}_{2}$ supply is minimised to a little over the stoichiometric requirement. While the use of an excess amount of $\mathrm{H}_{2}$ is useful in terms of enhanced reaction rates, the separation of $\mathrm{H}_{2}$ post stabilisation, followed by re-compression of the recycle $\mathrm{H}_{2}$, becomes expensive. The supply of a stoichiometric quantity of $\mathrm{H}_{2}$ at high system pressures ensures that there is a high partial pressure of $\mathrm{H}_{2}$ in the liquid, thereby maintaining high reaction rates and minimising $\mathrm{H}_{2}$ consumption in consecutive side reactions. In Case B, the use of an excess amount of $\mathrm{H}_{2}$ for stabilisation is considered, followed by $\mathrm{H}_{2}$ separation, recycle and recompression. 


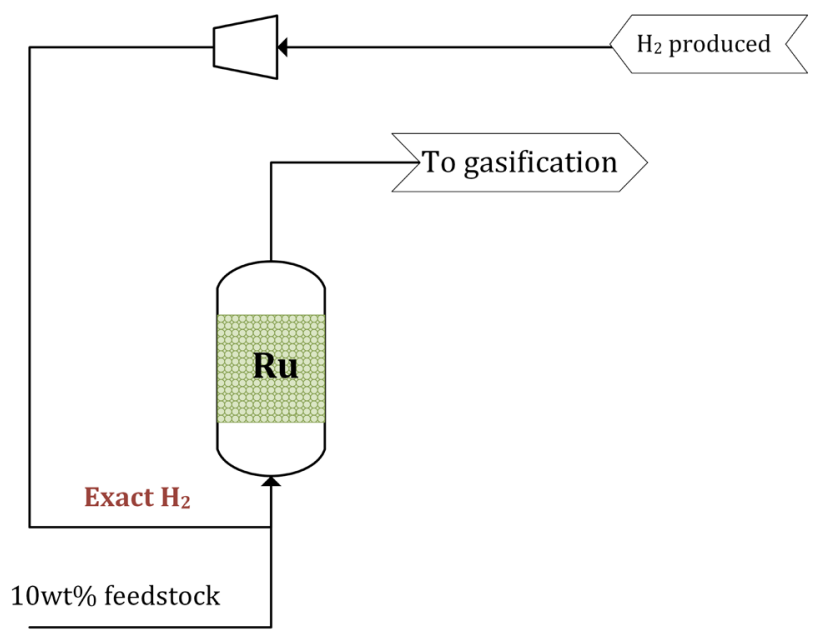

(a)

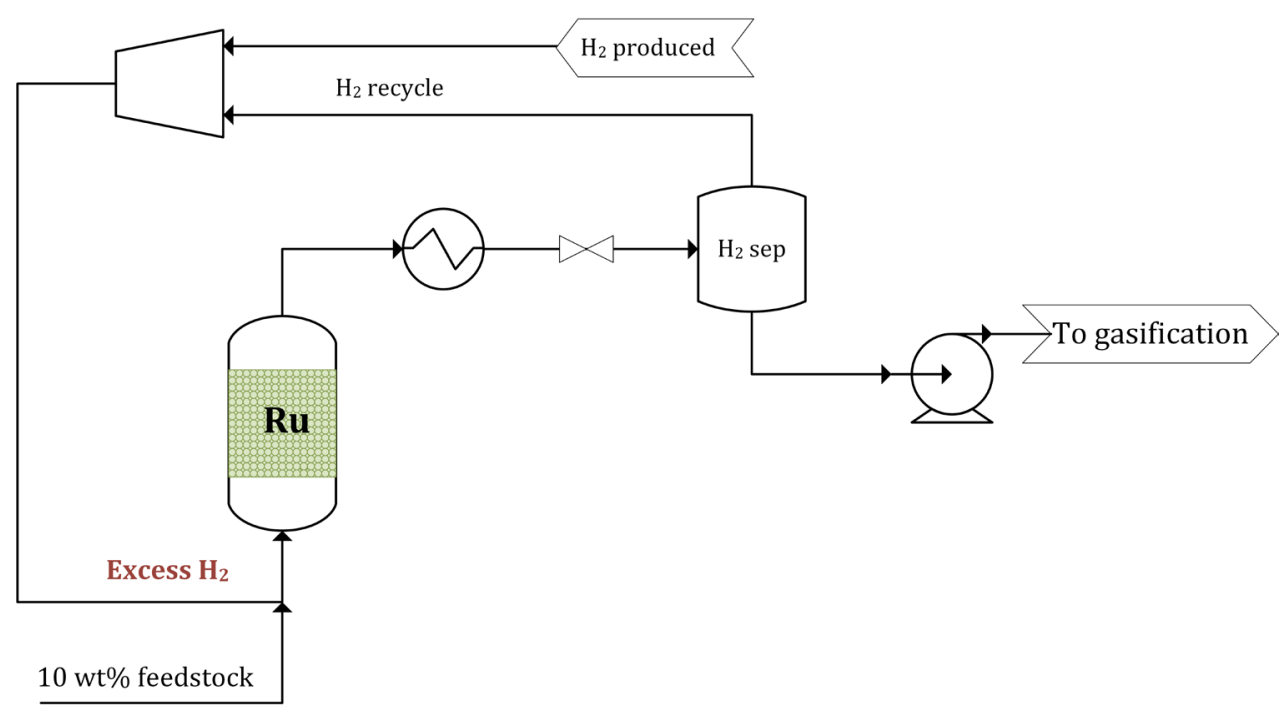

(b)

Figure 5.3: Stabilisation cases A and B considered for design 


\subsubsection{Sizing}

The stabilisation reactor is designed as a multi-tubular adiabatic reactor. A large WHSV ensures good wetting of the catalyst particles, and therefore, the packed bed reactor is operated as a cocurrent down-flow trickle flow reactor since this best approaches plug flow behaviour.

A commercial $5 \mathrm{wt} \% \mathrm{Ru}-\mathrm{C}$ catalyst is considered for the process. The target 2-year lifetimes of the catalysts is similar to standard lifetimes of catalysts used in refineries. Regeneration of the catalyst by standard combustion techniques is typically conducted once or twice a year in the petroleum industry. For catalysts supported on carbon however, the catalyst is regenerated by hot hydrogen stripping [149].

Considering the low molecular weight of $\mathrm{H}_{2}$, and the requirement for a large discharge pressure, the $\mathrm{H}_{2}$ compressor is designed as a reciprocal compressor with a polytropic efficiency of $75 \%$. The high pressure feed pump is designed as a centrifugal pump with an inlet feed flowrate of 200 $\mathrm{m}^{3} \mathrm{~h}^{-1}$ and an efficiency of $70 \%$. A static mixer is used to mix the pressurised $\mathrm{H}_{2}$ and liquid feed.

Table 5.2: Reactor sizing summary for the stabilisation reactor

\begin{tabular}{lcr}
\hline Parameter & Value & Units \\
\hline Reactor specifications & 6 & $\mathrm{~m}$ \\
Tube length & 0.03 & $\mathrm{~m}$ \\
Tube OD & 283 & - \\
Number of tubes & 500 & $\mathrm{~kg}$ \\
Total catalyst load & 600 & $\mathrm{~kg} \mathrm{~m}^{-3}$ \\
Catalyst bulk density & 2 & years \\
Catalyst lifetime & 0.5 & years \\
Time between regeneration & &
\end{tabular}

\subsection{Gasification}

This section begins with an aqueous polyol stream consisting of sorbitol and mannitol (10 wt $\%$ in water) entering the gasification reactor. From experimental findings and literature work, it is known that the productivity of $\mathrm{H}_{2}$ can be enhanced by improving its separation from the gas mixture as soon as it is produced. What is also known in terms of catalyst activity is that platinum catalysts show high selectivity towards $\mathrm{H}_{2}$ production, but lower reactivity in terms of $\mathrm{C}-\mathrm{C}$ cleavage. Ruthenium catalysts on the other hand are highly active in terms of C-C cleavage and consume $\mathrm{H}_{2}$ in methanation reactions. Keeping these insights in mind, three options are considered for the gasification reactor configuration in order to simultaneously maximise carbon gasification and obtain optimum $\mathrm{H}_{2}$ yields. Figure 5.4 depicts the options. 


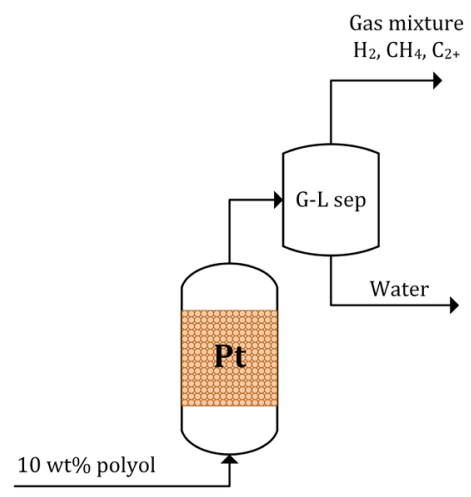

(1)

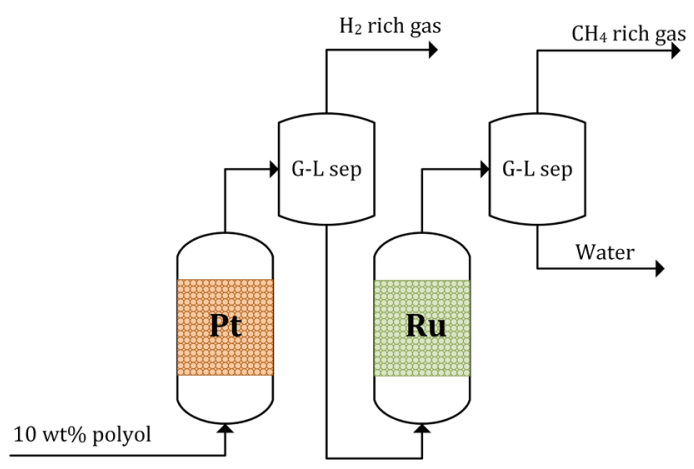

(2)

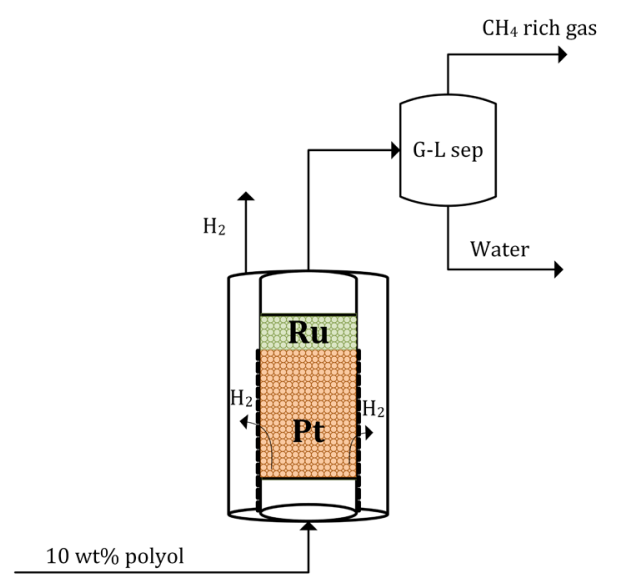

(3)

Figure 5.4: Reactor configuration options 1, 2 and 3 


\subsubsection{Design}

In the gasification step, a hydrogenated mixture of polyols is heated to the inlet reactor operating temperature of $300^{\circ} \mathrm{C}$. The polyols are reformed to produce $\mathrm{H}_{2}, \mathrm{CO}_{2}$, and light alkanes, through multiple pathways that involve intermediate oxygenates dissolved in water. Typical reforming catalysts include titania, zirconia, carbon and oxide supports like silica alumina doped with metals including platinum $(\mathrm{Pt})$, nickel $(\mathrm{Ni})$, ruthenium $(\mathrm{Ru})$, copper $(\mathrm{Cu})$, palladium $(\mathrm{Pd})$, cobalt (Co) [149].

For Option 1 (gasification over a platinum catalyst), a path lumped model was developed based on experimental results to describe the conversion of sorbitol to gases in a temperature range of $270-350{ }^{\circ} \mathrm{C}$ [141]. This model developed in Matlab 2017a was used to determine the yields of $\mathrm{H}_{2}$ and $\mathrm{CO}_{2}$ produced at $300{ }^{\circ} \mathrm{C}$ using a design constraint of $>95 \%$ carbon conversion to gas. $5 \%$ of the carbon remains as dissolved oxygenates in water, represented as $\mathrm{C}_{\text {oxy }}$ in Eq. (5.1). In the kinetic model, all the gaseous alkanes produced $\left(\mathrm{C}_{1}-\mathrm{C}_{6}\right)$ were assumed to be represented by propane. However, for the design, experimental yields of $\mathrm{CH}_{4}$ were considered, while the rest were lumped as $\mathrm{C}_{2+}$ gaseous alkanes and were represented by $\mathrm{C}_{2} \mathrm{H}_{6}$. It must be noted that the carbon representation in gaseous alkanes in order to calculate the total carbon gasification $\mathrm{X}_{\mathrm{CG}}$ was the emphasis of this work rather than the contribution of each individual alkane detected. The stoichiometry considered for the gasification reactions over $5 \mathrm{wt} \% \mathrm{Pt}-\mathrm{Al}_{2} \mathrm{O}_{3}$ for Option 1 are as follows:

$\mathrm{C}_{6} \mathrm{H}_{14} \mathrm{O}_{6}+\mathrm{H}_{2} \mathrm{O} \rightarrow 3.4 \mathrm{H}_{2}+3 \mathrm{CO}_{2}+0.3 \mathrm{CH}_{4}+1.2 \mathrm{C}_{2+}+0.3 \mathrm{C}_{\text {oxy }}$

For the second case, the path lumped model was used for the partial gasification of sorbitol at $300{ }^{\circ} \mathrm{C}$ under which conditions maximum $\mathrm{H}_{2}$ was produced. This was achieved at a total carbon gasification of $77 \%$. The yield of the gases obtained from the gasification of the remaining dissolved organics over the ruthenium catalyst were based on experimental data (Refer Chapter 4). The stoichiometry of the overall gasification reaction over the $5 \mathrm{wt} \% \mathrm{Pt}-\mathrm{Al}_{2} \mathrm{O}_{3}$ and $5 \mathrm{wt} \% \mathrm{Ru}-\mathrm{C}$ series for Option 2 based on experimental results alone, and optimised using the path-lumped model for $\mathrm{H}_{2}$ production over Pt- $\mathrm{Al}_{2} \mathrm{O}_{3}$, are shown below as Eq. (5.2) and (5.3) respectively.

$$
\mathrm{C}_{6} \mathrm{H}_{14} \mathrm{O}_{6}+\mathrm{H}_{2} \mathrm{O} \rightarrow 3.22 \mathrm{H}_{2}+3.5 \mathrm{CO}_{2}+1.51 \mathrm{CH}_{4}+0.52 \mathrm{C}_{2+}
$$

$$
\Delta \mathrm{H}_{\mathrm{rg}}=63.5 \mathrm{~kJ} \mathrm{~mol}^{-1}
$$

$$
\mathrm{C}_{6} \mathrm{H}_{14} \mathrm{O}_{6}+1.21 \mathrm{H}_{2} \mathrm{O} \rightarrow 5.18 \mathrm{H}_{2}+3.6 \mathrm{CO}_{2}+0.9 \mathrm{CH}_{4}+0.75 \mathrm{C}_{2+}
$$

In option 3 , the utilisation of an ideal industrial catalytic (packed bed) membrane reactor that can be used for the hydrothermal gasification of clean aqueous polyol streams derived from biomass is envisaged. Gas yields for option 3 are calculated based on experiments conducted in a fixed bed reactor using $\mathrm{N}_{2}$ as a stripping agent in order to increase $\mathrm{H}_{2}$ yields. The underlying principle 
of the extraction of a desired product before its consumption in the reaction environment is synonymous in the case of a catalytic membrane reactor and the use of an inert sweep gas as a stripping agent. While this by no means suggests an exact similarity between the two reactor types, experimental data using $\mathrm{N}_{2}$ can provide insight into the advantages of increasing $\mathrm{H}_{2}$ yields at the cost of a more expensive separation unit.

The path lumped model developed for the hydrothermal gasification of sorbitol taking into account the inlet $\mathrm{N}_{2}$ to liquid feed ratio $\left(\mathrm{R}_{\mathrm{GL}}=50 \mathrm{~m}^{3} \mathrm{~N}_{2} \mathrm{~m}^{-3}{ }_{1} \mathrm{NTP}\right)$ is used to determine the reaction parameters and gas yields for the partial gasification of sorbitol over Pt- $\mathrm{Al}_{2} \mathrm{O}_{3}$ in Option 3 . The calculation of gas yields for the resulting stream that is treated with $\mathrm{Ru}-\mathrm{C}$ is performed in a manner similar to that conducted for option 2 . The overall stoichiometry is given as follows:

$$
\mathrm{C}_{6} \mathrm{H}_{14} \mathrm{O}_{6}+3.25 \mathrm{H}_{2} \mathrm{O} \rightarrow 8.02 \mathrm{H}_{2}+4.62 \mathrm{CO}_{2}+0.38 \mathrm{CH}_{4}+\mathrm{C}_{2+}
$$

While it is difficult to study the consumption and production of water in the gasification reactions under hydrothermal conditions, due to the excess amount of water, it is known that dehydration reactions promote the production of alkanes, while reforming reactions that consume water promote the production of $\mathrm{H}_{2}$ [37].

Membrane reactors for the production and separation of $\mathrm{H}_{2}$ have been studied extensively [152]. Pd-based membranes and zeolites have been utilised successfully for steam reforming reactions at high temperatures $\left(>600^{\circ} \mathrm{C}\right)$ and pressures $>10$ bar. However, the application of catalytic membrane reactors in the field of hydrothermal gasification has been limited. D'Angelo et al. [153] utilised a carbon coated ceramic membrane reactor under aqueous phase reforming conditions ( $200{ }^{\circ} \mathrm{C}$ and 25 bar) for the production and separation of $\mathrm{H}_{2}$ from the reforming of sorbitol. The membrane reactor yielded 2.5 times more $\mathrm{H}_{2}$ than a reference tubular reactor when operated at low residence times. The successful implementation and economic viability of membranes on an industrial scale requires improvements in hydrothermal stability and high pressure operation. Of the three options considered, it can be seen from Table 5.3 that options 2 and 3 provide significant improvements with respect to $\mathrm{H}_{2}$ productivities. This is due to the higher $\mathrm{H}_{2}$ selectivity obtained at lower residence times and lower carbon to gas conversion $\mathrm{X}_{\mathrm{CG}}$ over the $\mathrm{Pt}_{-} \mathrm{Al}_{2} \mathrm{O}_{3}$ catalyst. Additionally, the advantage of utilising $\mathrm{Ru}-\mathrm{C}$ instead of $\mathrm{Pt}-\mathrm{Al}_{2} \mathrm{O}_{3}$ for the carbon to gas conversion is the high reactivity of the former towards C-C cleavage reactions.

The enthalpy of reaction $\Delta \mathrm{Hr}_{\mathrm{g}}\left(\mathrm{kJ} \mathrm{mol}^{-1}\right)$ is estimated for gasification steps using Aspen Plus V10. Since the overall reaction comprises of reforming reactions that are endothermic, and methanation and alkane formation reactions that are exothermic, the overall reaction is mildly endothermic, as seen in Eq (5.2). Sorbitol reforming was calculated to be strongly endothermic considering $\mathrm{H}_{2} \mathrm{O}$ in the aqueous phase. 
This is in line with recent work on the thermodynamics of reforming of sugar alcohols [154].

Sorbitol reforming: $\quad \mathrm{C}_{6} \mathrm{H}_{14} \mathrm{O}_{6}+6 \mathrm{H}_{2} \mathrm{O} \rightarrow 13 \mathrm{H}_{2}+6 \mathrm{CO}_{2}$

$$
\Delta \mathrm{H}_{\mathrm{r}}=722.8 \mathrm{~kJ} \mathrm{~mol}^{-1}
$$

The heat of reactions for Eq. (5.1), (5.3) and (5.4) cannot easily be obtained since the $\mathrm{C}_{\text {oxy }}$ and $\mathrm{C}_{2+}$ terms cannot entirely be represented by one molecule. It must be noted that for the process simulations conducted in Aspen Plus, $\mathrm{C}_{\text {oxy }}$ and $\mathrm{C}_{2+}$ are represented by unconverted sorbitol and ethane respectively. The errors in the overall oxygen and hydrogen balances are within $\pm 5 \%$. 


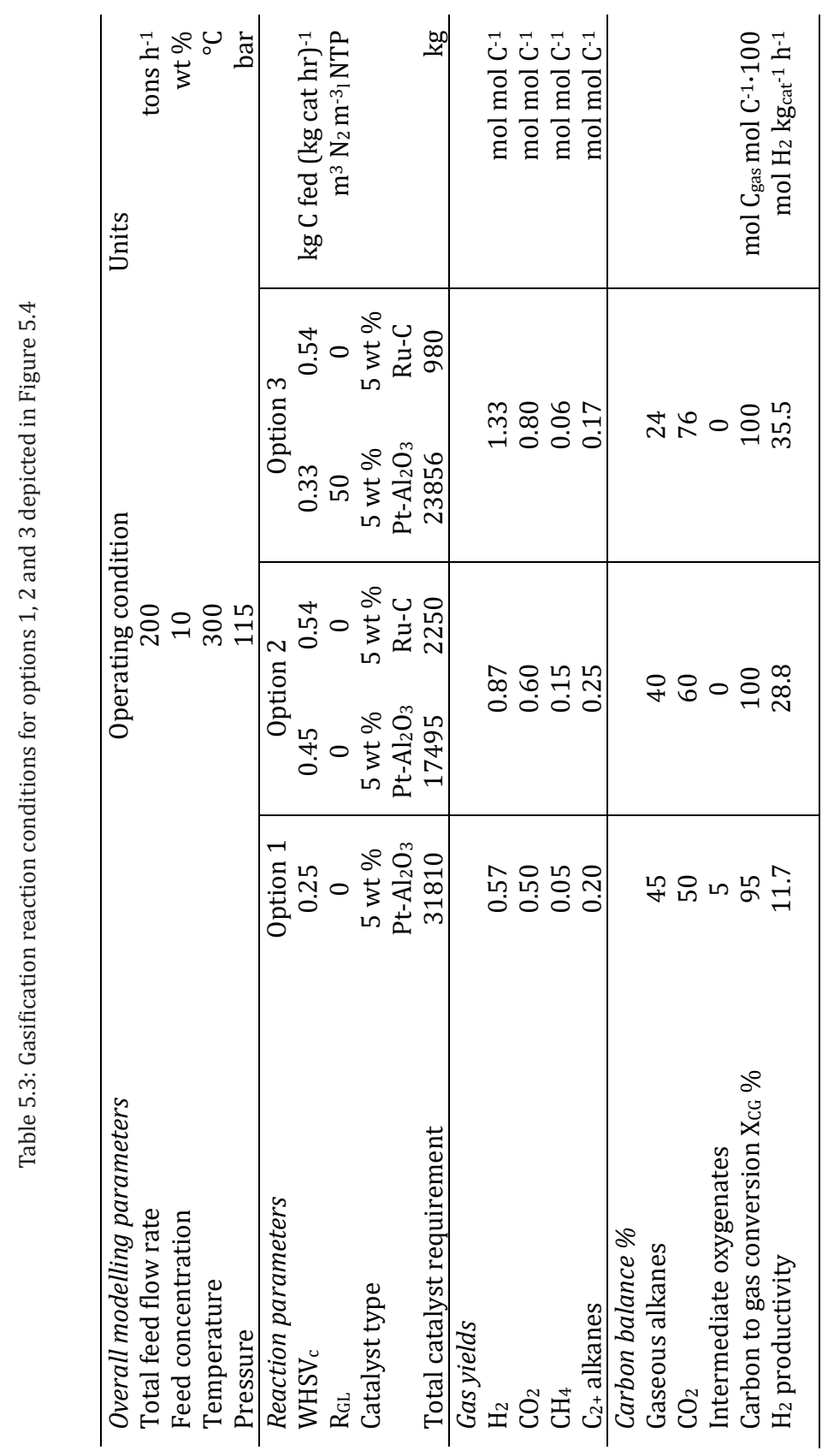




\subsubsection{Sizing}

Based on the reactor configuration options depicted in Figure 5.4, the downstream recovery and separation steps vary. Options 1, 2 and 3 tabulated in Table 5.3 are evaluated in this section. Reactor sizing is tabulated in Table 5.4. In all cases a catalyst lifetime of two years is assumed with catalyst reactivation every 6 months.

The reactors are designed as multi-tubular adiabatic fixed bed reactors. Considering the reactions presented in Section 5.5.1, the combined endothermicity of the reforming reactions and exothermicity of the methanation reactions leads to an adiabatic temperature drop of $9{ }^{\circ} \mathrm{C}$.

$\left(63.5\left[\mathrm{~kJ} \mathrm{~mol}^{-1}\right] \cdot 115 \cdot 10^{3}\left[\mathrm{~mol} \mathrm{~h}^{-1}\right] / 2 \cdot 10^{5}\left[\mathrm{~kg} \mathrm{~h}^{-1}\right] / 4.18\left[\mathrm{~kJ} \mathrm{~kg}^{-1}{ }^{\circ} \mathrm{C}^{-1}\right]\right)$

By selecting a tube diameter and length, the inside volume of the tubes are calculated. A 2 inch outside diameter is selected, ensuring good flow distribution and minimal wall effects [147]. For cost estimation, the cost of a shell-and-tube heat exchanger is estimated, taking into account the high pressure ( 120 bar). The costs are estimated using Aspen Process Economic Analyzer V10. For the membrane reactor option, the required area was determined by calculating the $\mathrm{H}_{2}$ flux ( $m o l H_{2} \mathrm{~m}^{-2} \mathrm{~s}^{-1}$ ) using Sievert's law, which relates the solubility of a diatomic gas in metal to the square root of the partial pressure of the gas in thermodynamic equilibrium, as shown in the Eq (5.5) [155]:

$J_{H_{2}}=k \cdot\left(P_{H_{2, \text { ret }}}^{0.5}-P_{H_{2, \text { perm }}}^{0.5}\right)$

Permeation data from different types of membranes show that the permeance of $\mathrm{H}_{2}$ varies from $10^{-2}$ to $10^{-8} \mathrm{~mol} \mathrm{H}_{2} \mathrm{~m}^{-2} \mathrm{~s}^{-1} \mathrm{~Pa}^{-0.5}$ [155]. Considering a permeance $(\mathrm{k})$ of $10^{-3} \mathrm{~mol} \mathrm{H}_{2} \mathrm{~m}^{-2} \mathrm{~s}^{-1} \mathrm{~Pa}^{-0.5}$, a realistic $\mathrm{H}_{2}$ retentate-side partial pressure of 6 bar $(30 \mathrm{vol} \%$ of gas considering a total system pressure of 115 bar and a water saturation pressure of 86 bar at $300{ }^{\circ} \mathrm{C}$ ), a $\mathrm{H}_{2}$ permeate-side partial pressure of 4 bar gives a $\mathrm{H}_{2}$ flux of $4.5 \cdot 10^{-4} \mathrm{~mol} \mathrm{H}_{2} \mathrm{~m}^{-2} \mathrm{~s}^{-1}$. This value is orders of magnitude lower than the DOE target $\mathrm{H}_{2}$ flux of $1.135 \mathrm{~mol} \mathrm{H}_{2} \mathrm{~m}^{-2} \mathrm{~s}^{-1}$ due to the low partial pressures of $\mathrm{H}_{2}$ present under hydrothermal conditions. Increasing the flux would require extremely large quantities of sweep gas to reduce the $\mathrm{P}_{\mathrm{H} 2 \text {,perm }}$ or the utilisation of thinner membranes in order to increase permeance $k$ through the membrane. Using the calculated flux of $4.5 \cdot 10^{-4} \mathrm{~mol} \mathrm{H}_{2} \mathrm{~m}^{-2} \mathrm{~s}^{-1}$, an area of 542,000 $\mathrm{m}^{2}$ would be required to meet the flux demand of $244 \mathrm{~mol} \mathrm{H}_{2} \mathrm{~s}^{-1}$. Considering the 2015 DOE target costs of $<5400 \$ \mathrm{~m}^{-2}$ for a palladium membrane [155], this would lead to a significant installed cost of 3 billion $\$$. The membrane reactor option is therefore not considered for further economic calculations, considering current cost estimates. 
Table 5.4: Reactor sizing and cost summary for gasification reactors

\begin{tabular}{l|c|cc|r}
\hline Parameter & $\begin{array}{c}\text { Option 1 } \\
\text { (Pt-based) }\end{array}$ & \multicolumn{2}{c}{$\begin{array}{c}\text { Option 2 } \\
\text { (Ru-based) }\end{array}$} \\
\hline Tube length & 10 & 10 & 6 & $\mathrm{~m}$ \\
Tube OD & 0.051 & 0.051 & 0.03 & $\mathrm{~m}$ \\
Number of tubes & 2000 & 1100 & 320 & - \\
Catalyst load & 31810 & 17495 & 563 & $\mathrm{~kg}$ \\
Catalyst bulk density & 1000 & 1000 & 600 & $\mathrm{~kg} \mathrm{~m}^{-3}$ \\
\hline
\end{tabular}

\subsection{Recovery and separation}

This section involves the separation of the gases from the water, followed by the separation of pure $\mathrm{H}_{2}$ from the gas mixture including $\mathrm{CO}_{2}, \mathrm{CH}_{4}$ and light alkanes. The separation of $\mathrm{H}_{2}$ from gas mixtures on an industrial scale is typically achieved using pressure swing adsorption, cryogenic distillation, and more recently, through the use of membranes [156]. The choice of separation technology depends on the composition of the gas stream, as well as the pressure and temperature requirements of the stream prior and post gas separation. In this work, the state-ofthe-art commercial technology of pressure swing adsorption is selected because $\mathrm{H}_{2}$ is recovered at high pressure. Membranes, on the other hand, require a positive $\mathrm{H}_{2}$ partial pressure driving force, which limit recovery and lead to lower pressures of recovered $\mathrm{H}_{2}$, thereby increasing recompression costs [157].

\subsection{Mass and energy balances}

An overview of the mass and energy balances is shown in Figure 5.5 for option A2. The following assumptions have been made for the energy balance.

1) $\mathrm{C}_{2+}$ gases represent a small fraction of the total gases produced. For the energy balance equation, the carbon content of this fraction is collectively represented by ethane. Therefore, the molar mass and HHV of ethane are used for the calculation of the energy content of the $\mathrm{C}_{2+}$ fraction in the streams.

2) The specific heats of all the materials are considered to be constants and independent of temperature.

3) It is assumed that the chemistry of the gasification reactions remains the same with changing feedstock concentrations from 1 to $25 \mathrm{wt} \%$.

Of the carbon input, $56 \%$ exits the process as gaseous $\mathrm{CO}_{2}$. Theoretically, all the carbon can be converted to $\mathrm{CO}_{2}$ when the maximum amount of $\mathrm{H}_{2}$ is produced. Realistically however, this varies from $48-60 \%$ based on choice of catalyst and reactor design. 
While the process produces significant amounts of carbon-neutral $\mathrm{CO}_{2}$, it is recovered as a richstream and carbon negative emissions can be obtained by its sequestration or alternatively the $\mathrm{CO}_{2}$ can be used e.g. as feed to algal farms. In general, the more efficient the process, the more $\mathrm{CO}_{2}$ is produced. The non- $\mathrm{CO}_{2}$ part of the carbon leaving the process exits as alkanes, $40 \%$ of which is methane.

With respect to hydrogen, roughly $6 \%$ of the total hydrogen is available in the input as dissolved oxygenates, the rest being water. The realistic values of $\mathrm{H}_{2}$ obtained as product gas vary from 3.8 to $7.2 \%$ of the total hydrogen present in the system, for the options A1, A2, B1 and B2. A further increase in $\mathrm{H}_{2}$ gas production is associated with the consumption of $\mathrm{H}_{2} \mathrm{O}$ via the reforming reaction. As mentioned earlier, part of the produced $\mathrm{H}_{2}$ gas will be consumed in side-reactions leading to gaseous alkanes.

When inspecting the energy balance it is noticed that $35 \%$ of the energy of the feed is recovered as $\mathrm{H}_{2}$ product. The rest of the energy present in the off-gas is used to generate steam, electricity and fired heat for the process. Excess energy is sold as electricity (co-product) to the grid. In these calculations thermal efficiencies of $75 \%, 30 \%$ and $75 \%$ for boiler, turbine and fired heaters respectively are assumed. The residual off-gases contain $114 \mathrm{GJ} \mathrm{h}^{-1}$ of energy, as shown in Figure 5.5 , leading to an overall energy recovery to marketable products of $70 \%\left(35 \%\right.$ as $\mathrm{H}_{2}$ and 35 $\%$ as calorific off-gas). This can be increased by enhancing the $\mathrm{H}_{2}$ yield or by considering higher feedstock concentrations.

Two indicators are used to determine the feasibility of the process on an energy basis: efficiency and EROEI (Energy Return On Energy Investment). The efficiency $\eta$ is calculated as the ratio of the usable energy produced to the energy content of the feedstock. This parameter is used as a performance indicator of the process. The EROEI is calculated as the ratio of usable energy to the energy provided to deliver the usable energy. While EROEI values typically include energies associated with construction and decommission of a project, in this case, the EROEI is calculated based only on the energy required to operate the plant. A value lower than 1 indicates that the process requires more energy to run the process than is obtainable as usable energy. The EROEI is calculated as shown in Eq (5.6).

$E R O E I=\frac{\eta}{\eta-1}$

Figure 5.6 illustrates the effect of feed concentration on the efficiency and EROEI ${ }_{\text {op }}$ of the process for option A2. The EROEI increases exponentially with increasing feedstock concentrations. As illustrated, a minimum value of $7 \mathrm{wt} \%$ is required for an EROEI of 1, i.e, an energy neutral process. 


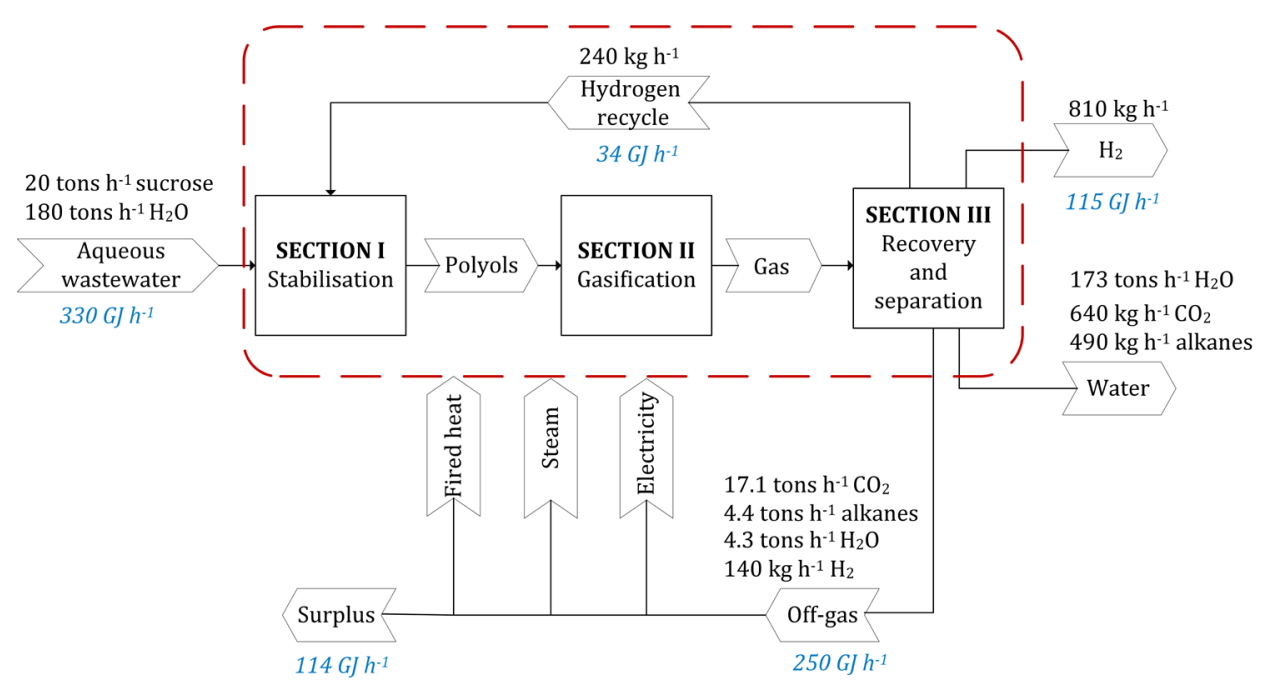

Figure 5.5: Mass and energy balances for option A2

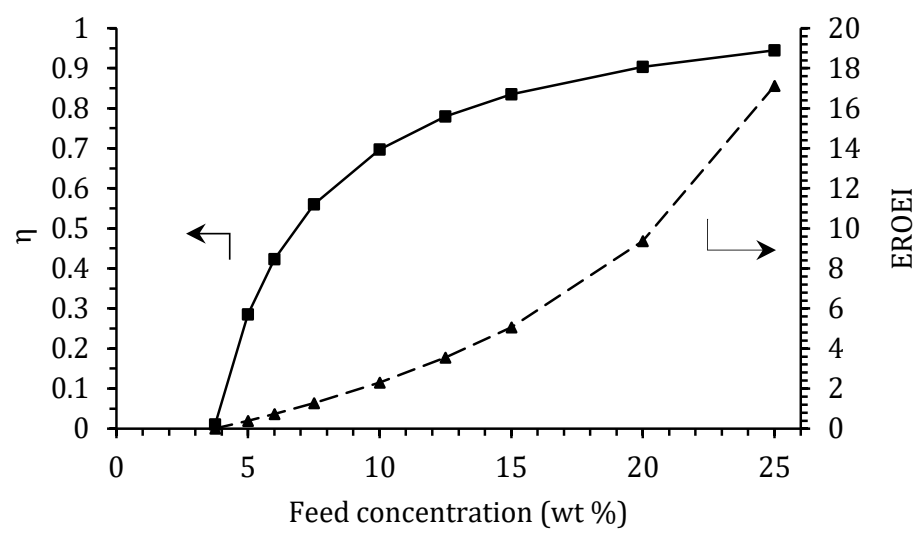

Figure 5.6: Influence of feed concentration on the efficiency and EROEI for option A2 


\subsection{Process Economics}

The economic evaluation of the two-step hydrothermal gasification process is conducted in order to assess its potential as a means of cleaning wastewater streams and, simultaneously, producing useful energy. Four different options are considered for the economic study, by combining the stabilisation cases A and B, with the gasification options 1 and 2 leading to options A1, A2, B1 and B2. Appendix D.2 provides the process flow diagrams for the four options.

Appendix D.3 lists the bare equipment cost (BEC) and installation cost of each piece of equipment in the process. All bare equipment costs are determined using Aspen Process Economic Analyzer (1Q 2016) and installation factors are taken from Peters et al. [147]. The exceptions are installation factors for the PSA package unit and the fired heater, for which values of 2.47 and 1.21 were considered respectively [158].

The cost-year of 2017 was chosen in this analysis, using the Chemical Engineering Plant Cost Index (CEPCI) of 562.1. All equipment cost determined in a year other than 2017 were adjusted using the CEPCI index. The bare equipment cost obtained from APEA in the year 1Q 2016 were considered to have a CEPCI of 541.7. The cost of utilities remains unchanged from the Aspen Process Economic Analyser, that uses costs from 1Q 2016. The costs of catalysts were determined based on the price of precious metals in the year 2017 [159], with an additional $20 \%$ considered for regeneration costs. The PSA package cost is calculated based on the costs provided in literature [158] using a scaling exponent of 0.8 .

Table D.1 in Appendix D.1 tabulates the bare equipment costs calculated on APEA, in comparison to equipment costs calculated from Peters et al. and Seider et al. $[147,148]$. It can be seen that on the basis of certain equipment, the differences in the costs are large. However, the sum of the costs based on APEA ( $6328 \mathrm{k} \$$ ) are $\pm 30 \%$ of the totals estimated using the methods of Peters et al. (5672 $\mathrm{k} \$$ ) and Seider et al. (7815 k\$). The total bare equipment costs obtained from APEA are therefore considered for the process economics.

For the heat exchanger tubes, reactor tubes, $\mathrm{H}_{2}$ compressor and pumps, the material of construction was considered to be stainless steel. For the other auxiliary equipment, carbon steel was used. The material of construction and pressure adjustment factors were taken into consideration when using Peters et al. and Seider et al.

\subsubsection{Total Capital Investment}

The Total Capital Investment (TCI) is determined as a percentage of delivered equipment cost, based on the methods of Peters et al. [147]. The expected accuracy of this estimate is $\pm 30 \%$. Delivered equipment costs are based on a delivery allowance of $10 \%$ of the bare equipment cost. Figure 5.7 compares installed equipment costs for all the cases (A1, A2, B1 and B2). 


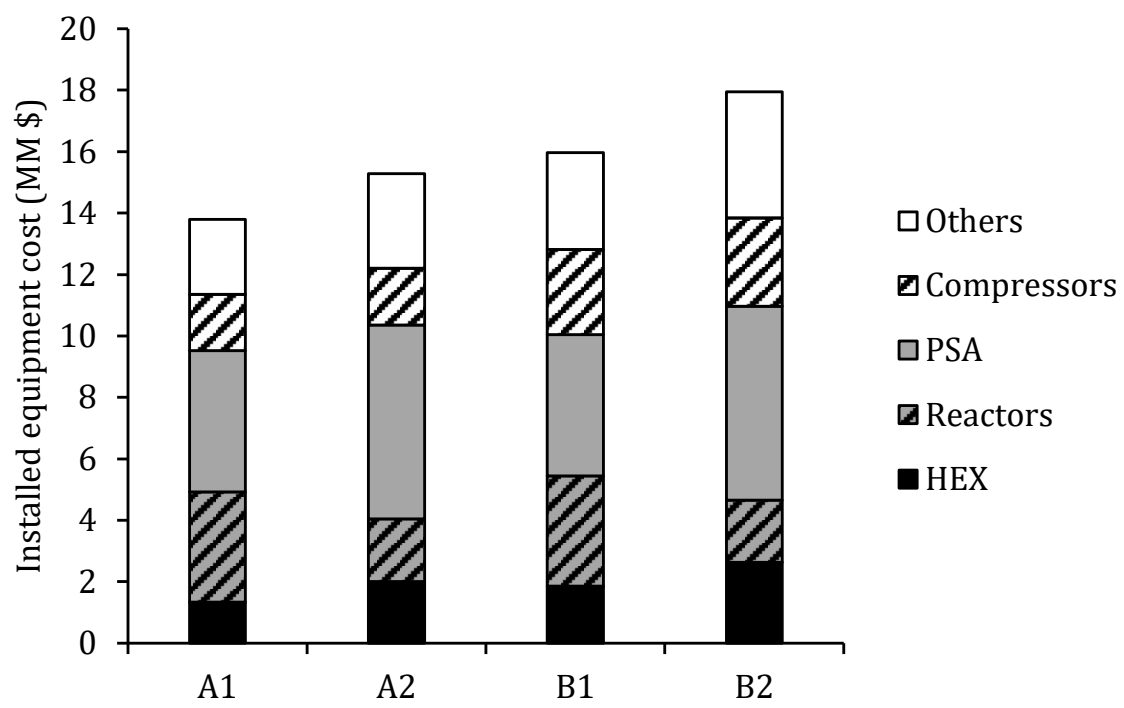

Figure 5.7: Contribution of unit operations to the total installed equipment cost

Table 5.5: Costs of raw materials and utilities

\begin{tabular}{llll}
\hline Item & Cost & Unit & Source \\
Raw materials & & & \\
Feedstock & 75 & $\$$ ton $^{-1}$ (organics) & Assumed \\
$\mathrm{Pt}$ & 30,333 & $\$ \mathrm{~kg}^{-1}$ & {$[159]$} \\
$\mathrm{Ru}$ & 2167 & $\$ \mathrm{~kg}^{-1}$ & {$[159]$} \\
$\mathrm{Ni}$ & 11 & $\$ \mathrm{~kg}^{-1}$ & {$[163]$} \\
Activated carbon/Alumina & 33 & $\$ \mathrm{~kg}^{-1}$ & {$[158]$} \\
Utilities & & & \\
Electricity & 0.0775 & $\$ \mathrm{kWh}^{-1}$ & APEA \\
Cooling water & 0.0317 & $\$ \mathrm{~m}^{-3}$ & APEA \\
MP steam & 2.2 & $\$ \mathrm{GJ}^{-1}$ & APEA \\
Fired heat & 4.25 & $\$ \mathrm{GJ}^{-1}$ & APEA \\
\hline
\end{tabular}

[a]: APEA - Aspen Process Economic Analyser 
A comparison between cases A and B show that the larger costs associated with cases B are primarily due to larger compressor requirements. Additionally, options 2 (dual Pt-Ru reactors) reduce the reactor costs by $40 \%$ due to the combined desired results of high $\mathrm{H}_{2}$ yields and high carbon gasification achieved by the dual catalysts. The higher $\mathrm{H}_{2}$ yields obtained in options 2 translate to larger PSA costs for its recovery.

The additional direct and indirect costs as well as a breakdown of the Total Capital Investment for each of the cases is tabulated in Table D.10 in Appendix D.4. The initial charge of catalysts for the reactors are added to the TCI.

\subsubsection{Total production cost}

The total production cost (TPC) is calculated based on Peters et al. and Seider et al. [147, 148]. It is comprised of manufacturing costs, as well as general expenses. A breakdown of the TPC for each of the options is tabulated in Table D.12 in Appendix D.4.

The cost of feedstock is dependent upon its source. The clean-up of a wastewater stream or waste is typically associated with a gate fee, the cost of which varies depending on geography, feed composition, and the type of treatment required [160,161]. Gate fees for composting, landfills and anaerobic digestion in the Netherlands vary from 20 - $85 €$ per ton organics [161]. On the other hand, costs of aqueous sugar streams derived from ligno-cellulosic biomasses vary from $280-350 \$$ per ton organics considering upstream operations including biomass deconstruction, solids removal and optional sugar concentration [149]. Therefore, for all cases, a constant value of $75 \$$ per ton of organics as the cost of the feedstock is considered. A reflection of the varying feedstock cost and its implications on the minimum selling price of $\mathrm{H}_{2}$ can be found in the sensitivity analysis.

The prices of the catalysts are estimated, based on price charts of the precious and base metals used from 2017 and an additional 20 \% for regeneration costs. Replacing Pt with more affordable base metals such as $\mathrm{Ni}$ and $\mathrm{Sn}$ for aqueous phase reforming has been widely studied. Studies have demonstrated that base metals in combination with a lower loading of precious metals also show high $\mathrm{H}_{2}$ selectivity $[37,162]$. Therefore, in this work, the price is calculated based on a bi-metallic Pt-Ni (0.5 : 4.5 wt \%) system, leading to a cost for the catalyst of $220 \$ \mathrm{~kg}^{-1}$.

A summary of the yields, costs and selling price of $\mathrm{H}_{2}$ for each of the cases considered, is presented in Table 5.6. The minimum $\mathrm{H}_{2}$ selling price is calculated based on a discounted cash flow analysis. More information can be found in Appendix D.5. The cost of feedstock is a major portion of the raw material costs, amounting to $12 \mathrm{MM} \$ \mathrm{yr}^{-1}$. The differences in the cost of raw materials among the options is due to the costs of the catalysts required. 
Differences in the cost of utilities among options A compared to B are due to additional electricity requirements for compression and pumping in case of the latter, due to the use of excess $\mathrm{H}_{2}$. A comparison of $\mathrm{H}_{2}$ yields shows that the dual-reactor options A2 and B2 show improved $\mathrm{H}_{2}$ yields and productivities in comparison to A1 and B1. Discrepancies between productivities for the cases $\mathrm{A} 1$ and $\mathrm{B} 1$ are due to $\mathrm{H}_{2}$ that is unrecovered during separation and recycling when using it in excess. These losses are however considered in the co-product sales, which is calculated based on the calorific value of the off-gases. The off-gases contain methane, $\mathrm{C}_{2+}$ alkanes, and small amounts of $\mathrm{H}_{2}$. Considering a thermal efficiency of $30 \%$, the energy from the off-gases is used to produce electricity for the process and any excess electricity is sold to the grid at a price of 0.0775 $\$ \mathrm{kWh}^{-1}$. As a double check, the off-gas sales were also calculated based on the price of energy at $6 \$ \mathrm{GJ}^{-1}$, and considering the $\mathrm{HHV}$ of $\mathrm{CH}_{4}$ as $55 \mathrm{MJ} \mathrm{kg}^{-1}$. The off-gas sales calculated using these two methods were within $\pm 10 \%$ of each other. Spent catalysts are regenerated and $75 \%$ of the precious metal is considered to be recovered.

\subsection{Discussion}

\subsubsection{Cost comparison among alternatives}

Figure 5.8 compares the cost breakdowns for all the alternatives considered. The two main cost drivers are the cost of raw materials and the off-gas sales. As mentioned previously, the cost of raw materials is driven by the cost of the feedstock considered. While the production of alkanes (primarily $\mathrm{CH}_{4}$ ) upon gasification is undesirable due to the consumption of $\mathrm{H}_{2}$ required for its production, it can be seen that it still presents a significant benefit to the $\mathrm{H}_{2}$ price.

The advantage of utilising a combination of catalysts for gasification in options A2 and B2 ( $\mathrm{Pt}$ followed by $\mathrm{Ru}$ ) is that the process effluent is a disposable water stream due to complete gasification. In comparison, options A1 and B1 that utilise only a Pt catalyst show a $95 \%$ carbon gasification which results in an aqueous effluent with $2-3$ g carbon per litre water (COD: $6-7 \mathrm{~g}$ $\mathrm{L}^{-1}$ ). This is orders of magnitude above the effluent discharge standards of $125 \mathrm{mg} \mathrm{L}^{-1}$ compliant with the EU [134]. For the Pt followed by Ru case the gasification is essentially complete and an effluent is obtained that complies with the COD discharge standards.

\subsubsection{Sensitivity}

A sensitivity analysis is conducted for option A2, which is considered most promising. Realistic ranges for varying the parameters are considered in order to assess the resulting impact on the selling price of $\mathrm{H}_{2}$. The change in each variable was conducted keeping in mind the other variables that could be affected. Table 5.7 lists the parameters varied and assumptions made for the sensitivity. 
Table 5.6: Summary of key costs and yields (details in Table D.10 and D.12)

\begin{tabular}{lrrrrr}
\hline & & A1 & A2 & B1 & B2 \\
Bare equipment costs (BEC) & MM \$ & 8.3 & 8.9 & 9.6 & 10.7 \\
Delivered equipment costs (DEC) & MM \$ & 9.1 & 9.8 & 10.6 & 11.8 \\
Total Capital Investment (TCI) & MM S & 53.1 & 53.8 & 60.3 & 63.3 \\
\hline Raw materials & MM \$ yr-1 & 16.3 & 14.6 & 16.3 & 14.6 \\
Utilities & MM \$ yr-1 & 3.5 & 4.3 & 4.2 & 5.8 \\
Total Production Cost & MM \$ yr-1 & 29.0 & 28.5 & 30.6 & 31.3 \\
Co-product sales & MM \$ yr-1 & 15.8 & 14.3 & 15.8 & 14.6 \\
\hline $\mathrm{H}_{2}$ yield & $\mathrm{mol} \mathrm{mol} \mathrm{C-1}^{-1}$ & 0.57 & 0.87 & 0.57 & 0.87 \\
$\mathrm{H}_{2}$ production rate & $\mathrm{kg} \mathrm{h}^{-1}$ & 460 & 810 & 420 & 770 \\
Minimum $\mathrm{H}_{2}$ price & $\$ \mathrm{~kg}^{-1}$ & 5.6 & 3.4 & 6.9 & 4.2 \\
\hline
\end{tabular}

Note: $T C I=(5.4$ to 6$) \cdot D E C$. This is consistent with the expected Lang factor of 6 for fluid operations, for the estimation of TCI from DEC [147].

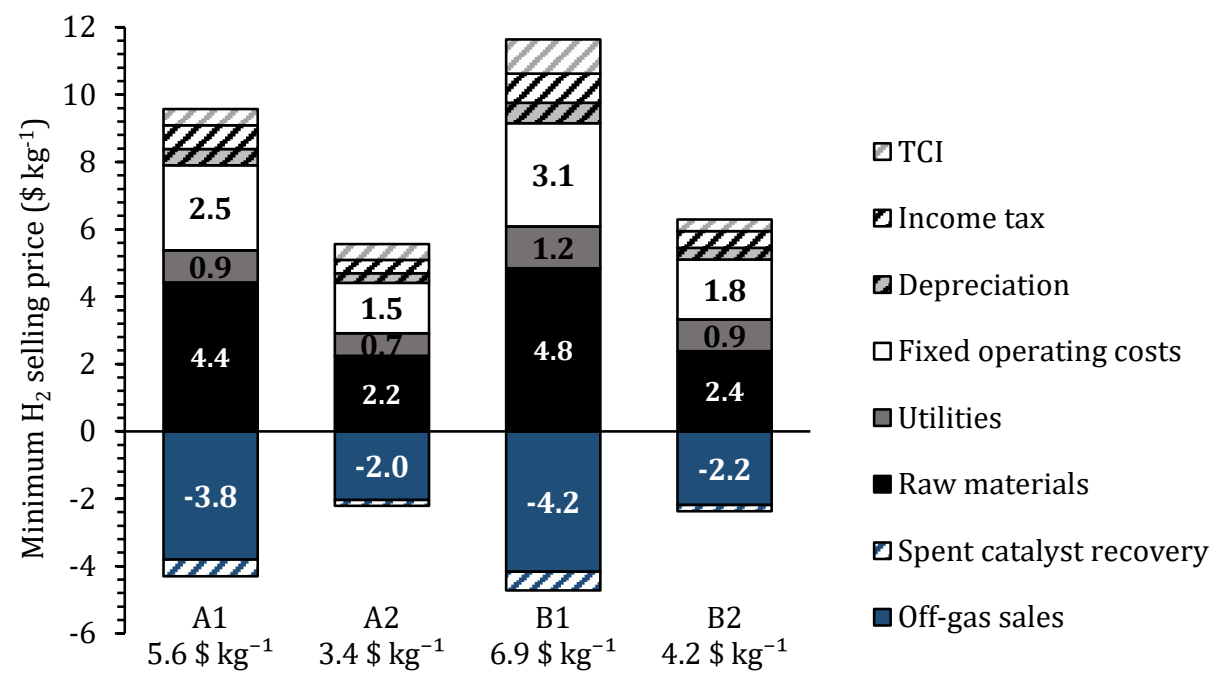

Figure 5.8: Cost comparison among alternatives 
Figure 5.9 depicts the sensitivity charts for option A2. The high $\mathrm{H}_{2}$ selling price upon consideration of a feedstock price of 280 \$ per ton organics shows that the process is not economical for mono saccharide sugars derived from ligno-cellulosic biomass. Focus should therefore be on using the process to clean wastewater streams that have a sufficient high organic loading, such as those listed in Chapter 2. Considering a trade-off between feedstock price and feedstock concentration from the sensitivity, wastewaters associated with gate fees or negligible costs and lower feedstock concentrations ( $<5 \mathrm{wt} \%$ ) can also be handled by the process, making it promising for industrially relevant wastes and wastewaters.

Figure 5.9 also depicts the influence of plant capacity on the minimum price of $\mathrm{H}_{2}$. The bare equipment costs are calculated using typical scaling exponents from Peters et al. [147]. It can be seen that for a smaller plant capacity of 20 tons $\mathrm{h}^{-1}$, the minimum price of $\mathrm{H}_{2}$ is $8.7 \$ \mathrm{~kg}^{-1}$. The selection of this technology for the treatment of a relevant wastewater stream therefore depends not only on the feedstock price and composition, but also on the available volume of wastewater that requires treatment.

These three variables are dependent on the industry and the availability of the wastewater stream. In order to illustrate the combined effect of these three variables, a few cases are considered and compared to the base case, as shown in Figure 5.10. It must be emphasized that there is a correlation between feedstock price and concentration. Therefore, the likelihood of the cases must be evaluated based on real data. For example, wastewaters from the potato industry are large in quantity $\left(17 \mathrm{~m}^{3}\right.$ per ton potatoes processed) but low in concentration ( $\left.1-2 \mathrm{wt} \%\right)$ and are available without additional costs [164]. On the other hand, sugar beet pulp is a more expensive feedstock because it is pelletised and used as animal feed, but contains higher concentration of sugars ( $5-8 \mathrm{wt} \%)$ and is also produced in large quantities ( 0.5 tons per ton of sugar beet). 


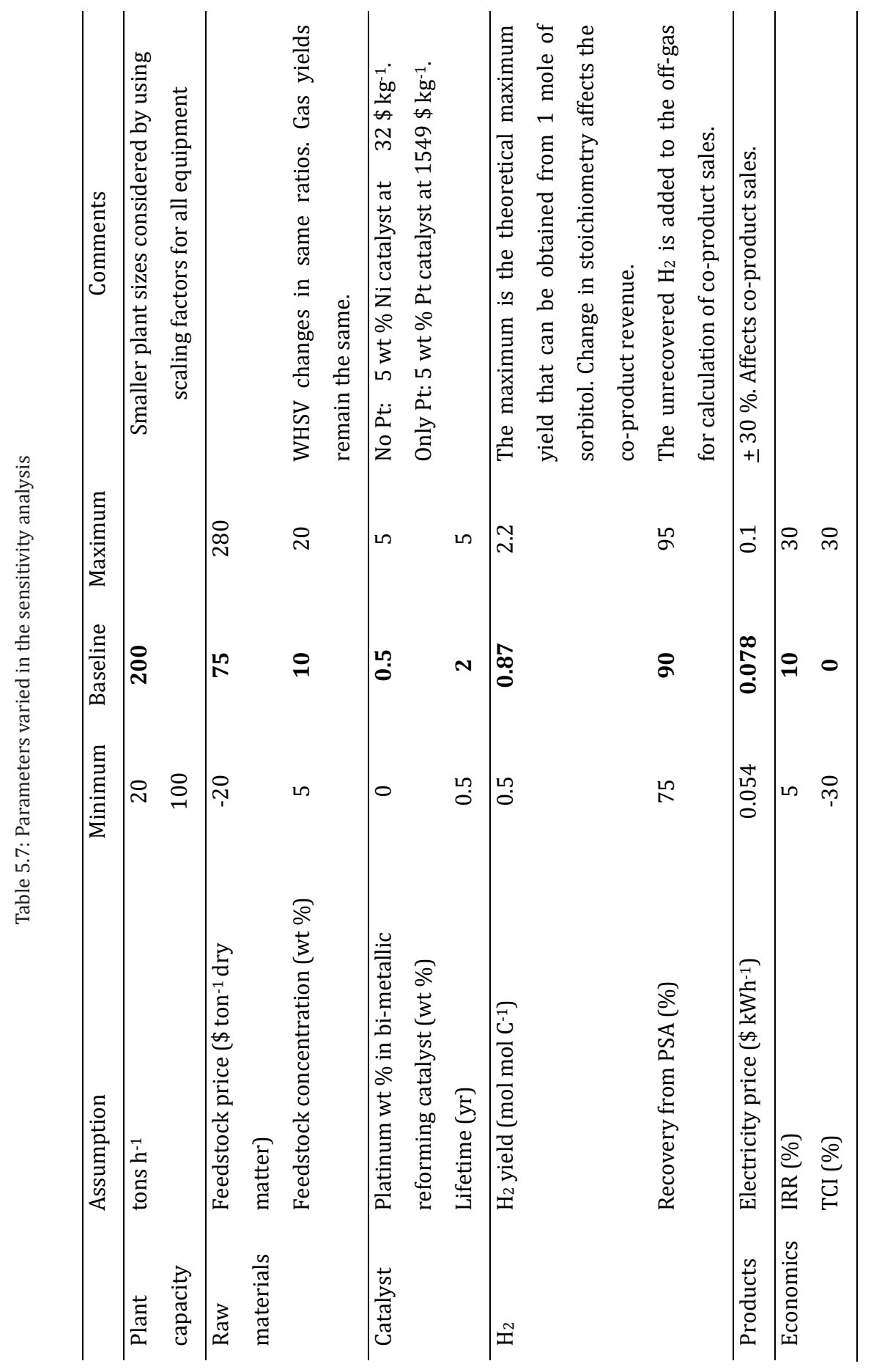




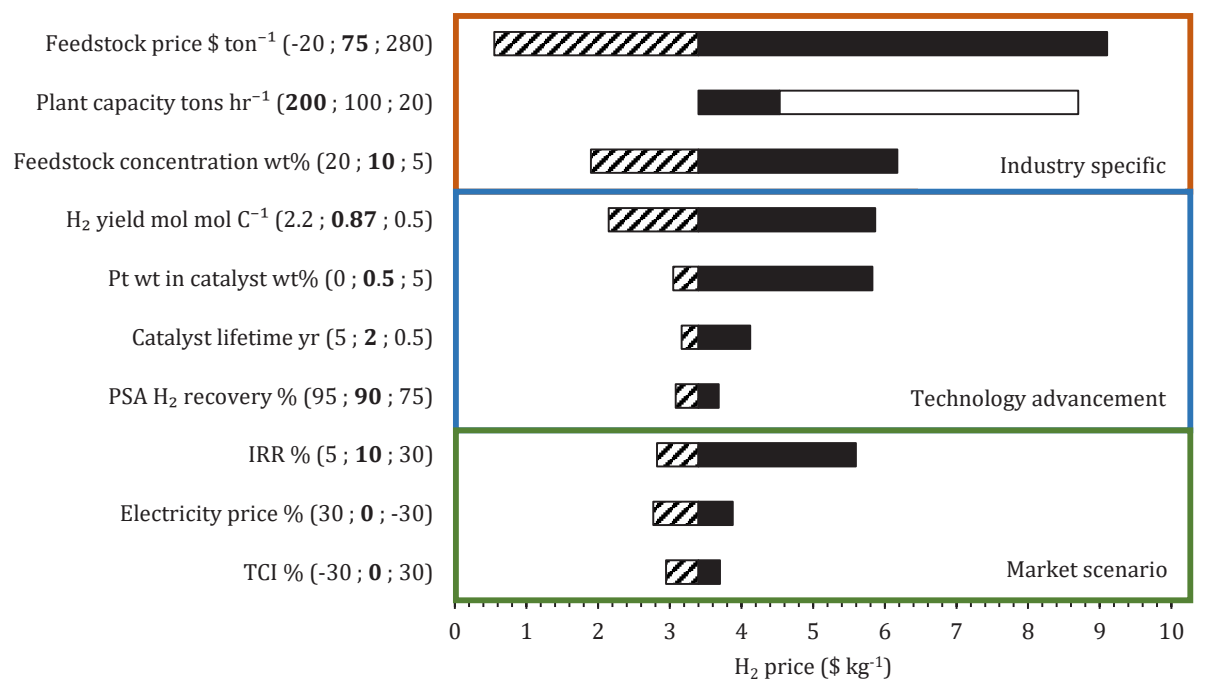

Figure 5.9: Sensitivity of Option A2

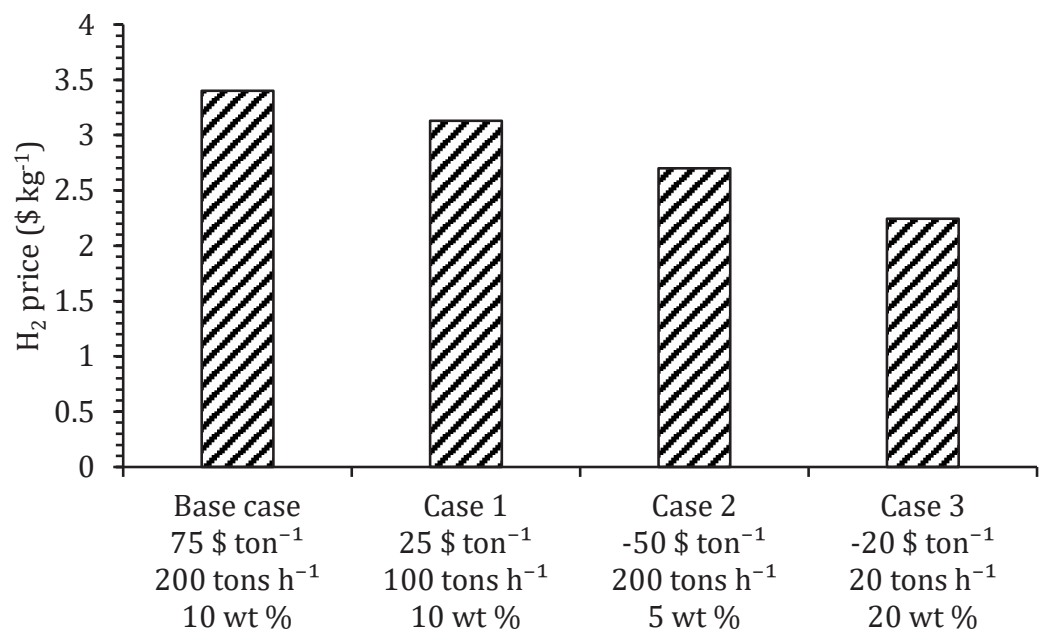

Figure 5.10: Influence of combinations of feedstock price, concentration and capacity on the $\mathrm{H}_{2}$ price 


\subsubsection{Comparison to competing technologies}

\section{$\underline{H}_{2}$ production}

Table 5.8 presents the minimum $\mathrm{H}_{2}$ selling price obtained in this study in comparison to renewable $\mathrm{H}_{2}$ produced from other technologies, as well as the current technology of steam methane reforming. It must be emphasised that the values reported for $\mathrm{H}_{2}$ production from biomass gasification/pyrolysis are based on pilot-scale results of gasification for power generation combined with information from similar processes. Currently, there is no biomass gasification process designed specifically for $\mathrm{H}_{2}$ production at any scale.

Presently, $4 \%$ of the world $\mathrm{H}_{2}$ production is produced via electrolysis. Significant technology advancements including reduced capital costs and increased efficiencies have reduced costs, making the 2020 DOE target of $2.3 \$ \mathrm{~kg}^{-1}$ attainable. The technology of fermentation for the production of $\mathrm{H}_{2}$ has also been employed for renewable organic wastes [165, 166]. However, the economics of the process are limited by the inhibitory effect of metabolites in the fermentation medium, leading to poor $\mathrm{H}_{2}$ yields [167].

The most promising option A2 requires a $\mathrm{H}_{2}$ selling price of at least $3.4 \$ \mathrm{~kg}^{-1}$, which is still markedly higher than the current $\mathrm{H}_{2}$ price of $2.1 \$ \mathrm{~kg}^{-1}$ as obtained from natural gas SMR. It should be realised that local conditions (feedstock price and availability) and additional technology development may further increase the attractiveness of the TSHG process developed here, next to the sustainability benefits in comparison with the current fossil fuel based $\mathrm{H}_{2}$ production.

\section{Wastewater treatment}

As discussed previously, the current technology of hydrothermal gasification can be utilised for both, $\mathrm{H}_{2}$ production, and as a water-clean up technology for relevant industrial wastewater streams that are rich in carbohydrate residues. Therefore, a comparison is made between this process and the production of biogas from organic waste through aerobic and anaerobic methods. The advantage of anaerobic digestion is in its ability to handle a wide range of wastes as substrates for biogas production. However, biogas production in anaerobic digesters typically lasts for days. A comparison between anaerobic digestion and this study can be made by considering the electricity produced from each process. Electricity produced from anaerobic digestion per ton of fresh matter range from 20 to $1690 \mathrm{kWh}$ [169]. In comparison, the current process considers the production of $\mathrm{H}_{2}$ as the primary product, in addition to the production of electricity from offgases at a thermal efficiency of $30 \%$ leading to $530-1130 \mathrm{kWh}$ electricity produced per ton of organics in feed.

Considering similar capacities (3500 - $8000 \mathrm{~m}^{3}$ day $\left.^{-1}\right)$, typical capital costs for water treatment technologies such as activated sludge, reverse osmosis are between 10 and 15 MM \$ [170]. While this is significantly lower than the capital required for this process, the unit cost of water is $0.5-1$ 
$\$ \mathrm{~m}^{3}$, which is similar to that obtained from this process considering a $\mathrm{H}_{2}$ price of $3-3.5 \$ \mathrm{~kg}^{-1}$. Therefore, for wastes that contain a large carbohydrate fraction, hydrothermal gasification would be a promising economical option in comparison to other wastewater treatment technologies.

\subsection{Conclusions}

In this work, a process design and economic evaluation of a two-step hydrothermal gasification process is made, which offers a promising route for the conversion of carbohydrate-rich wastewater streams to $\mathrm{H}_{2}$. The design is based on experimental findings. Different processing options for the design are considered and the economic evaluation of each of these options shows that the calculated $\mathrm{H}_{2}$ selling price for a typical feed can be reduced to $3.4 \$ \mathrm{~kg}^{-1}$ by utilising a stepwise combination of catalysts.

The economics of the process were found to be strongly dependent on the feedstock price, concentration and quantity. Most promising feeds are carbohydrate-rich organic wastes and wastewaters, which could potentially reduce the $\mathrm{H}_{2}$ selling price when associated with gate fees. 


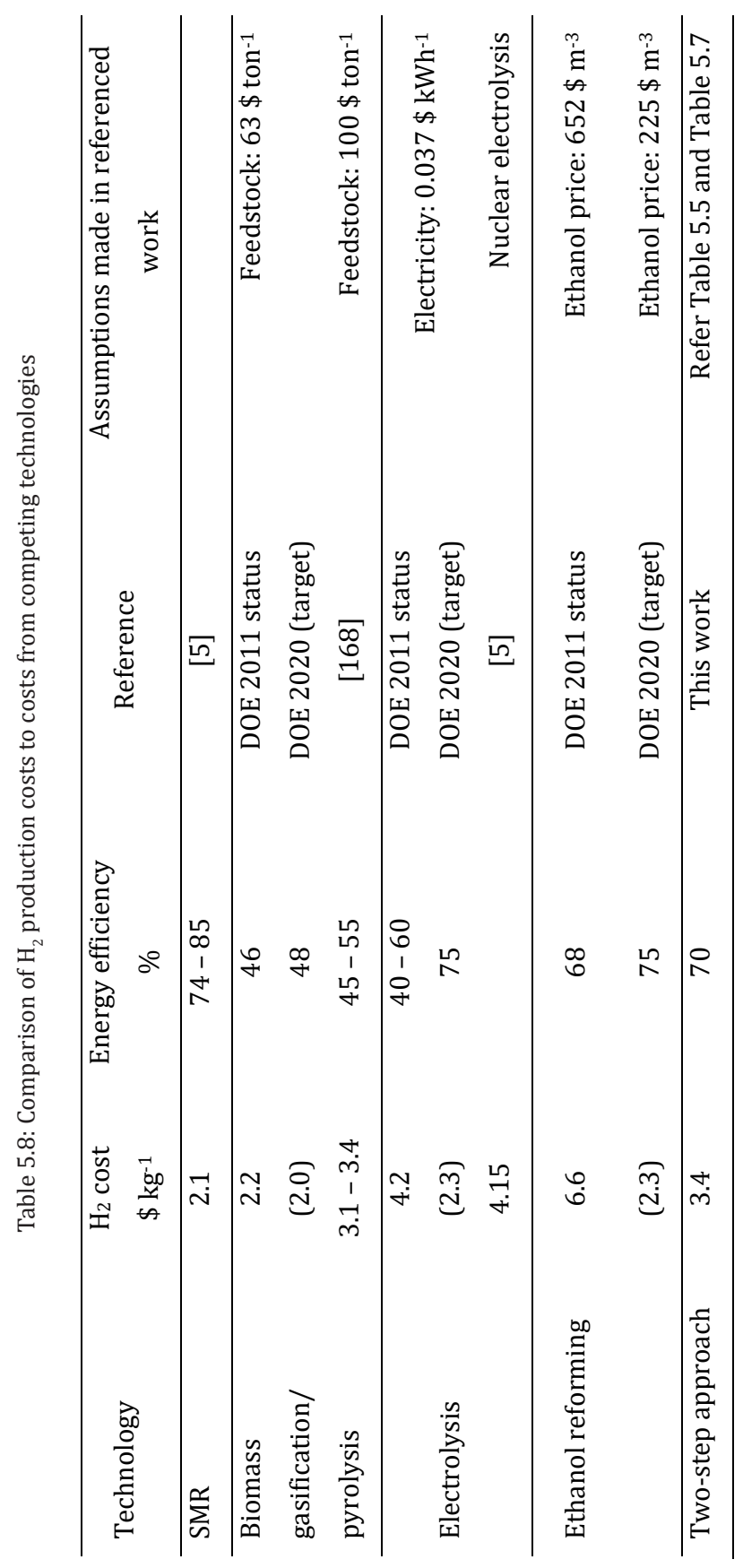

Process design and Economic evaluation | 123 


\section{Appendix}

\section{D.1 Bare equipment cost comparison}

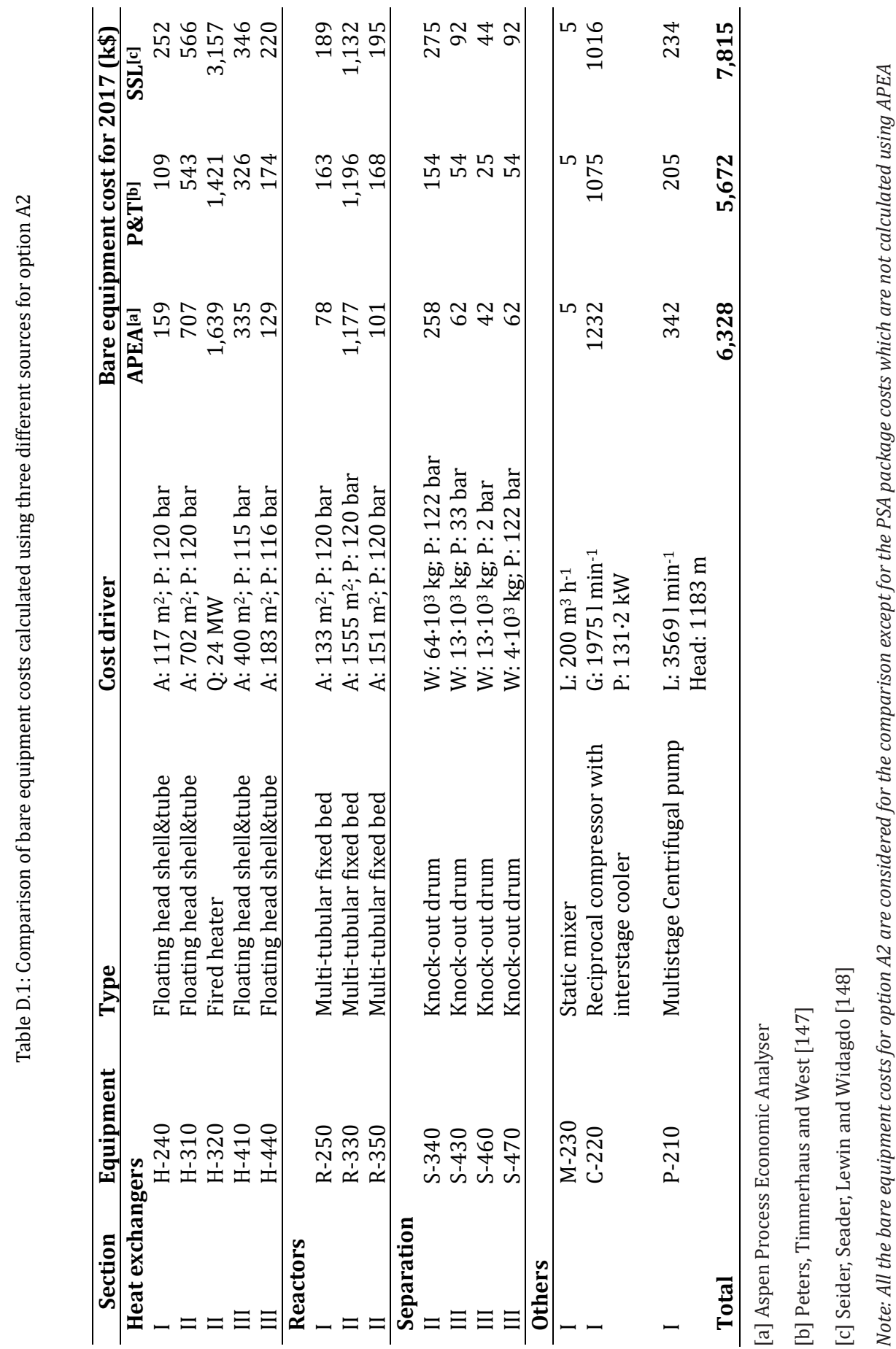




\section{D.2 Process flow diagrams}

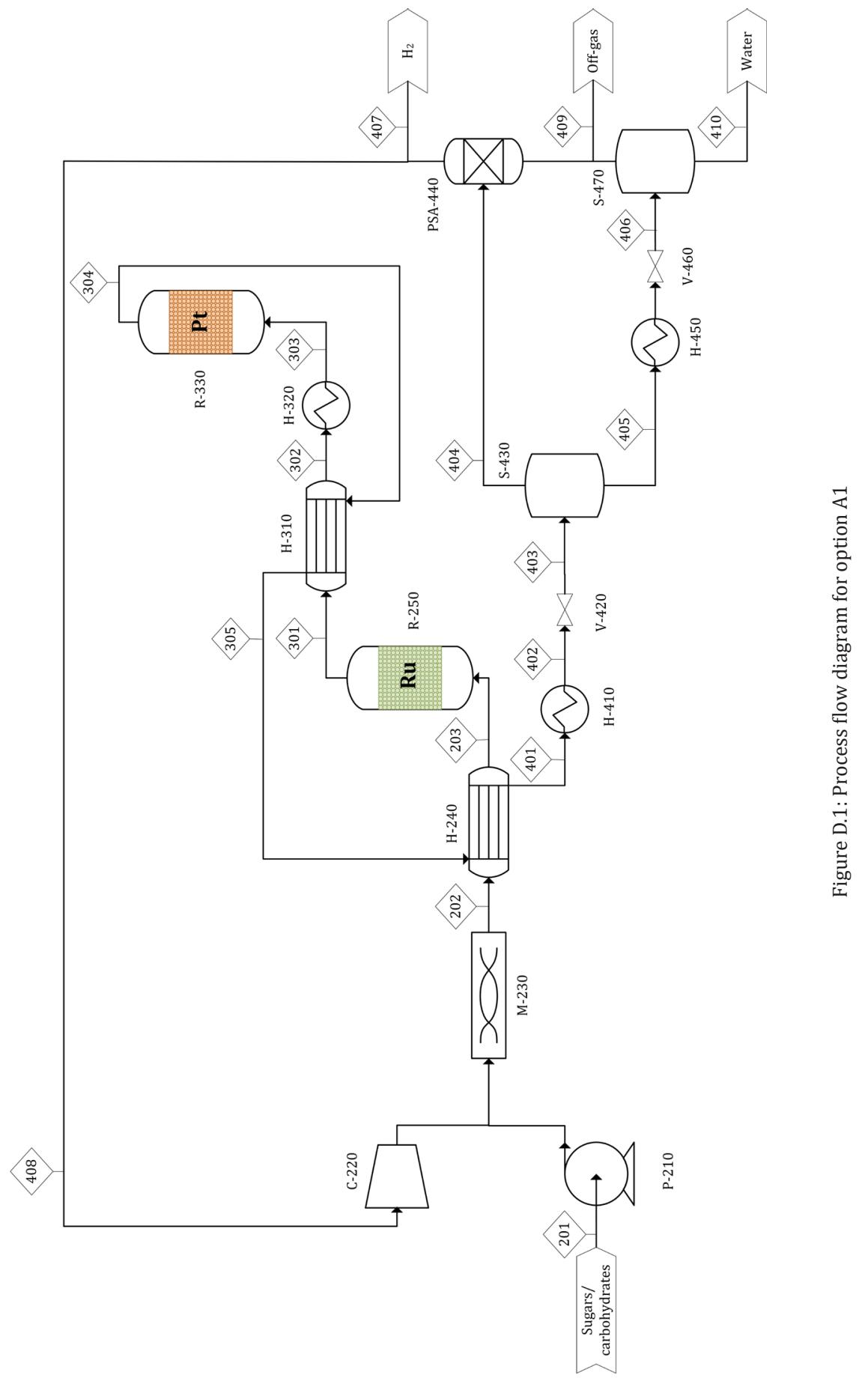




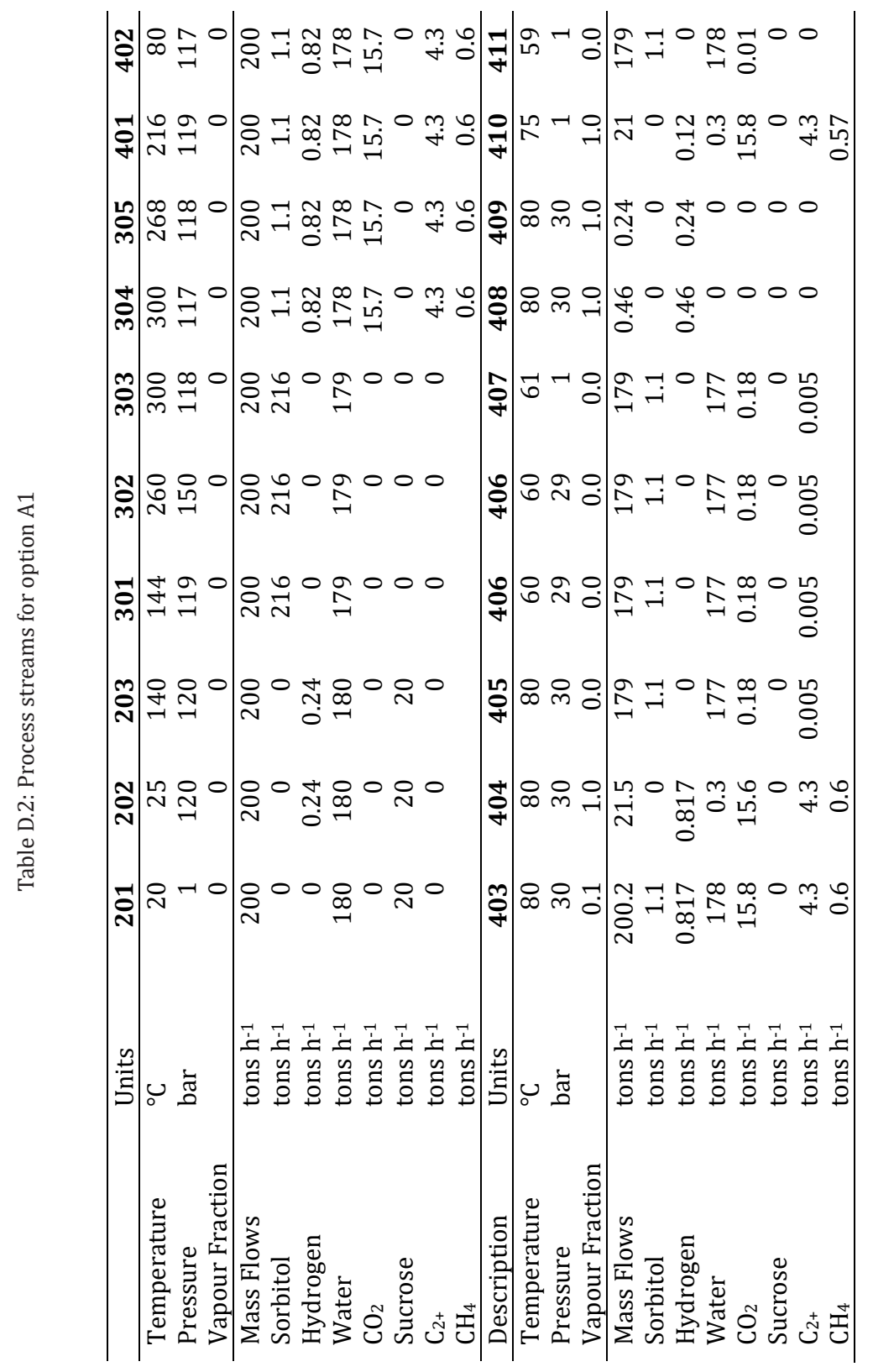




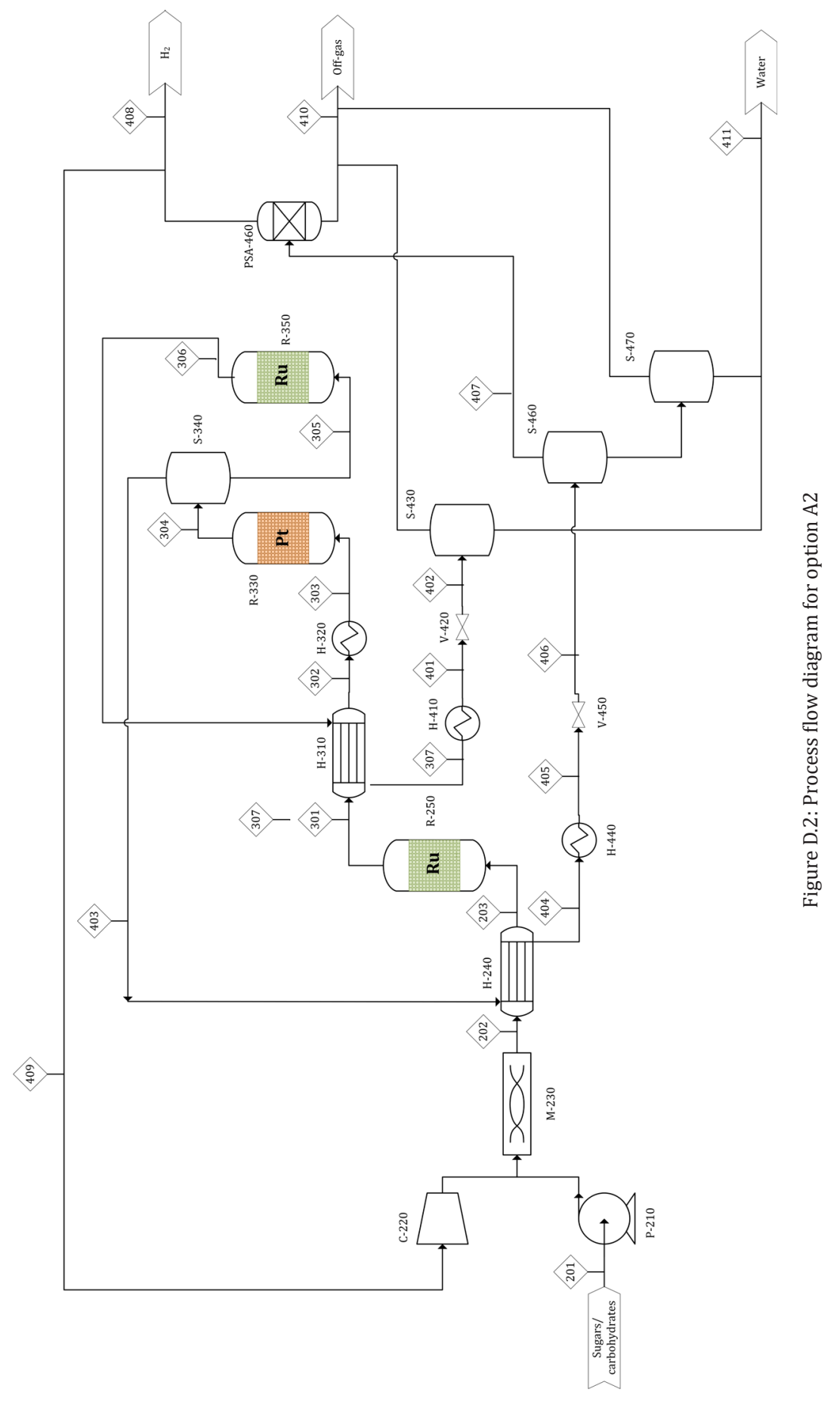




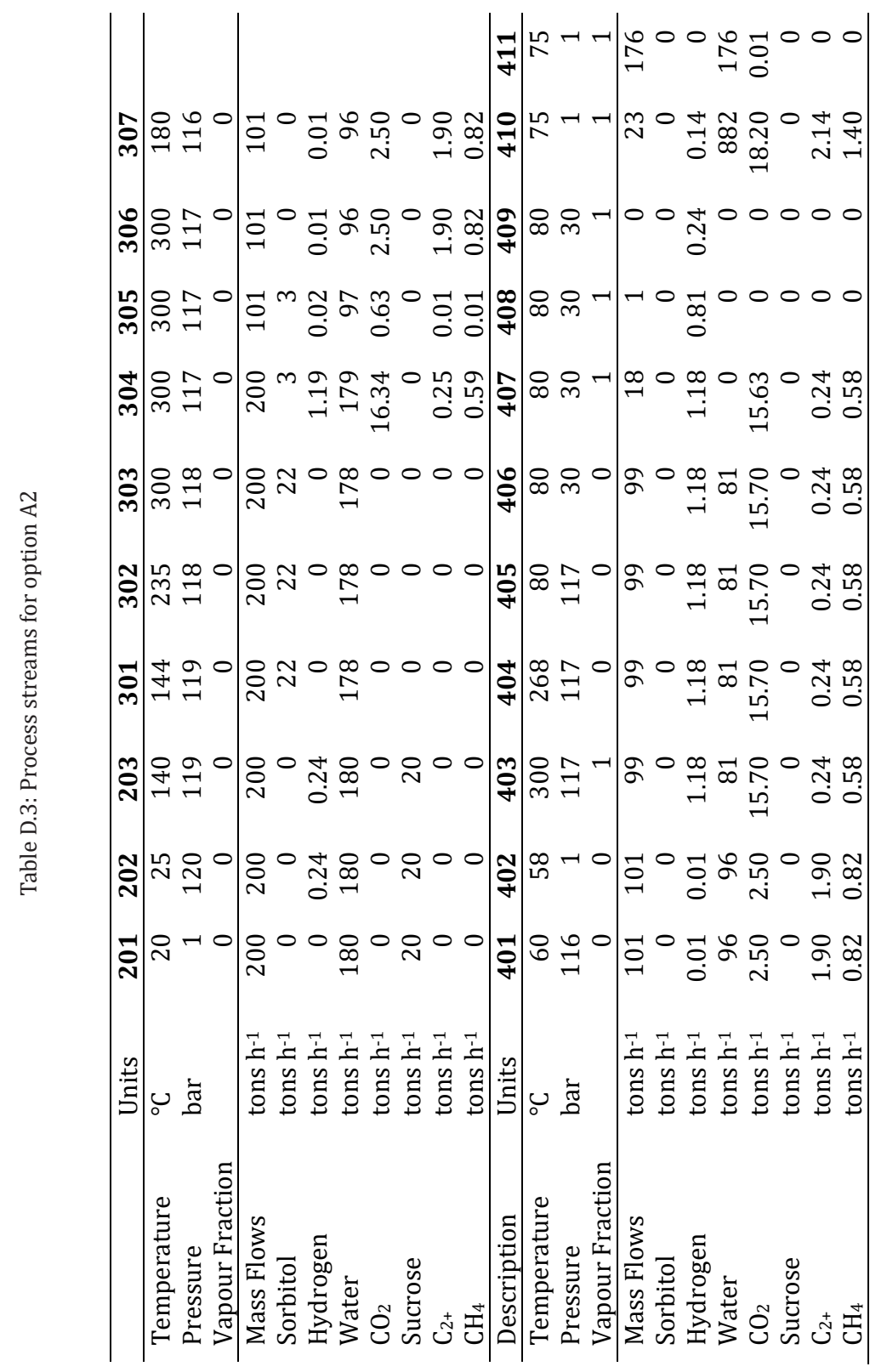




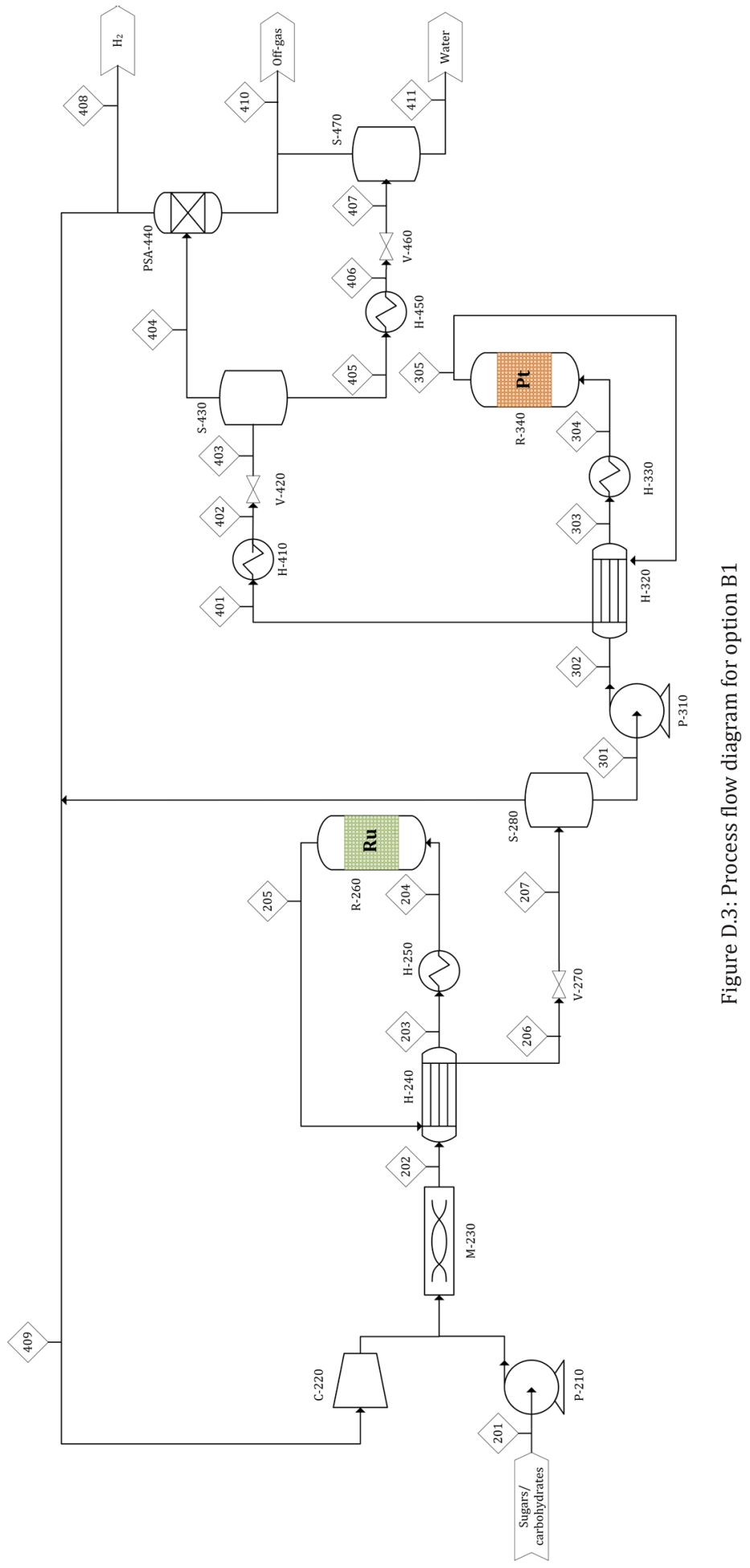

Process design and Economic evaluation | 129 


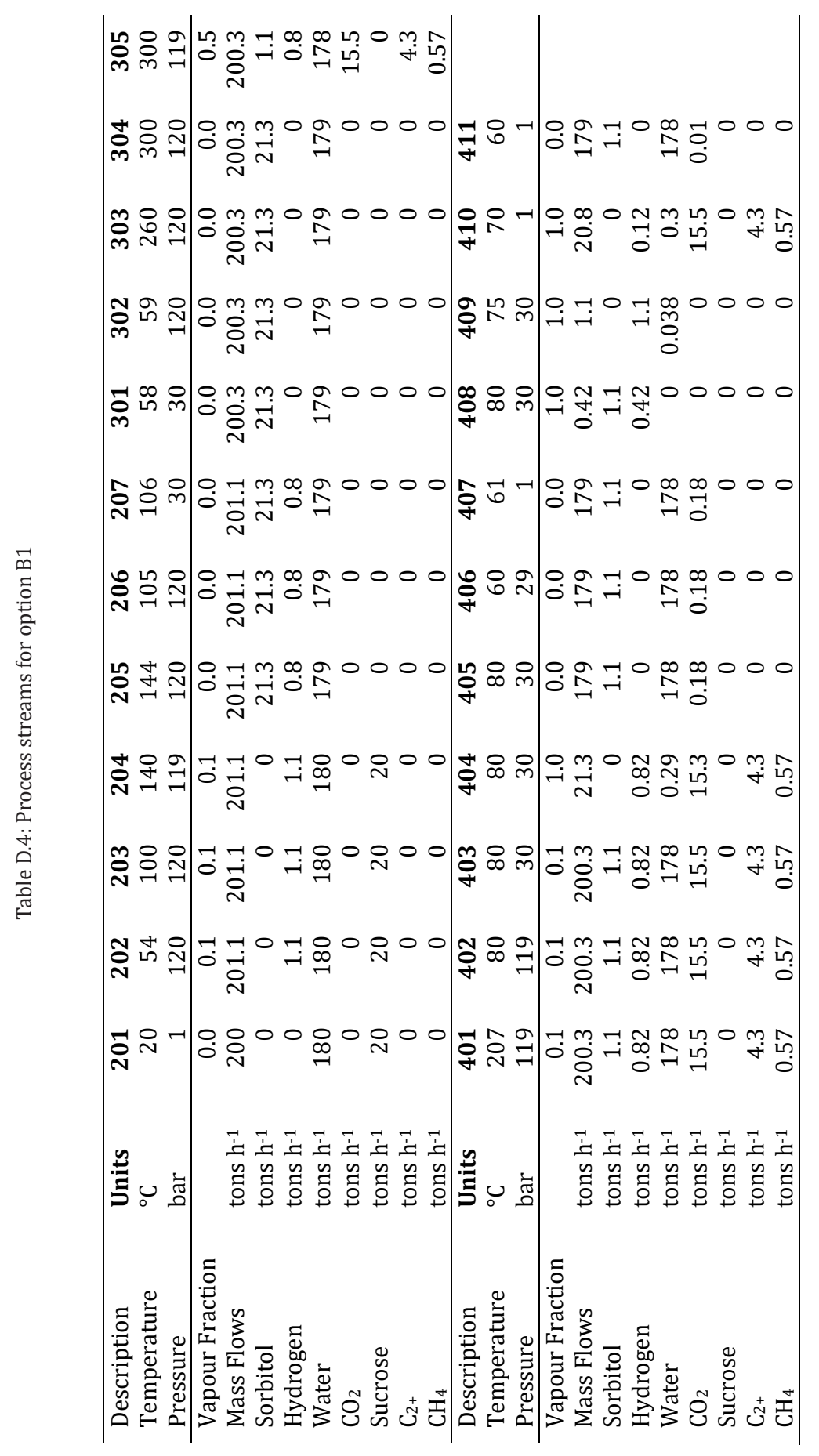




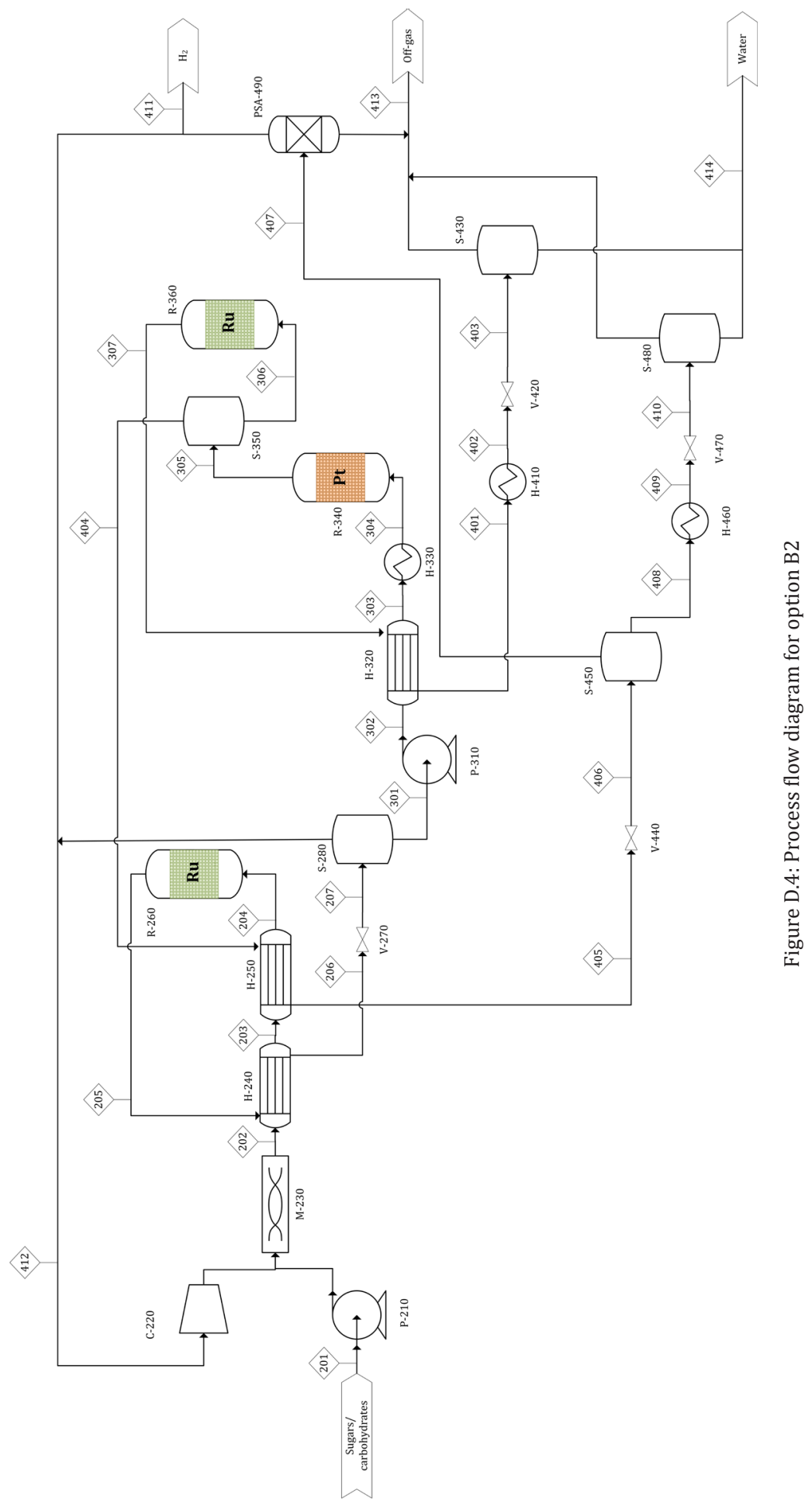

Process design and Economic evaluation | 131 


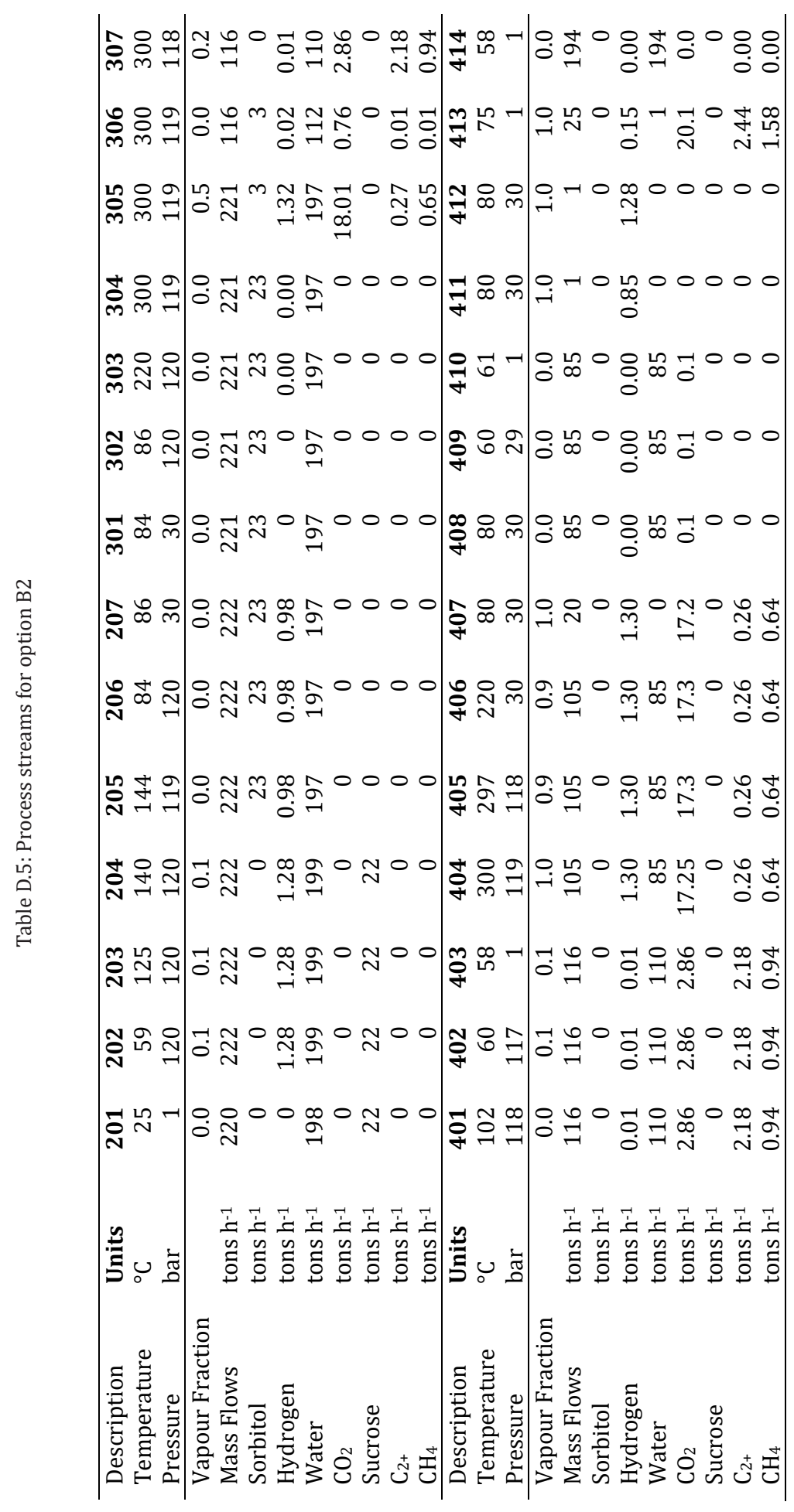




\section{D.3 Equipment costs for all options}

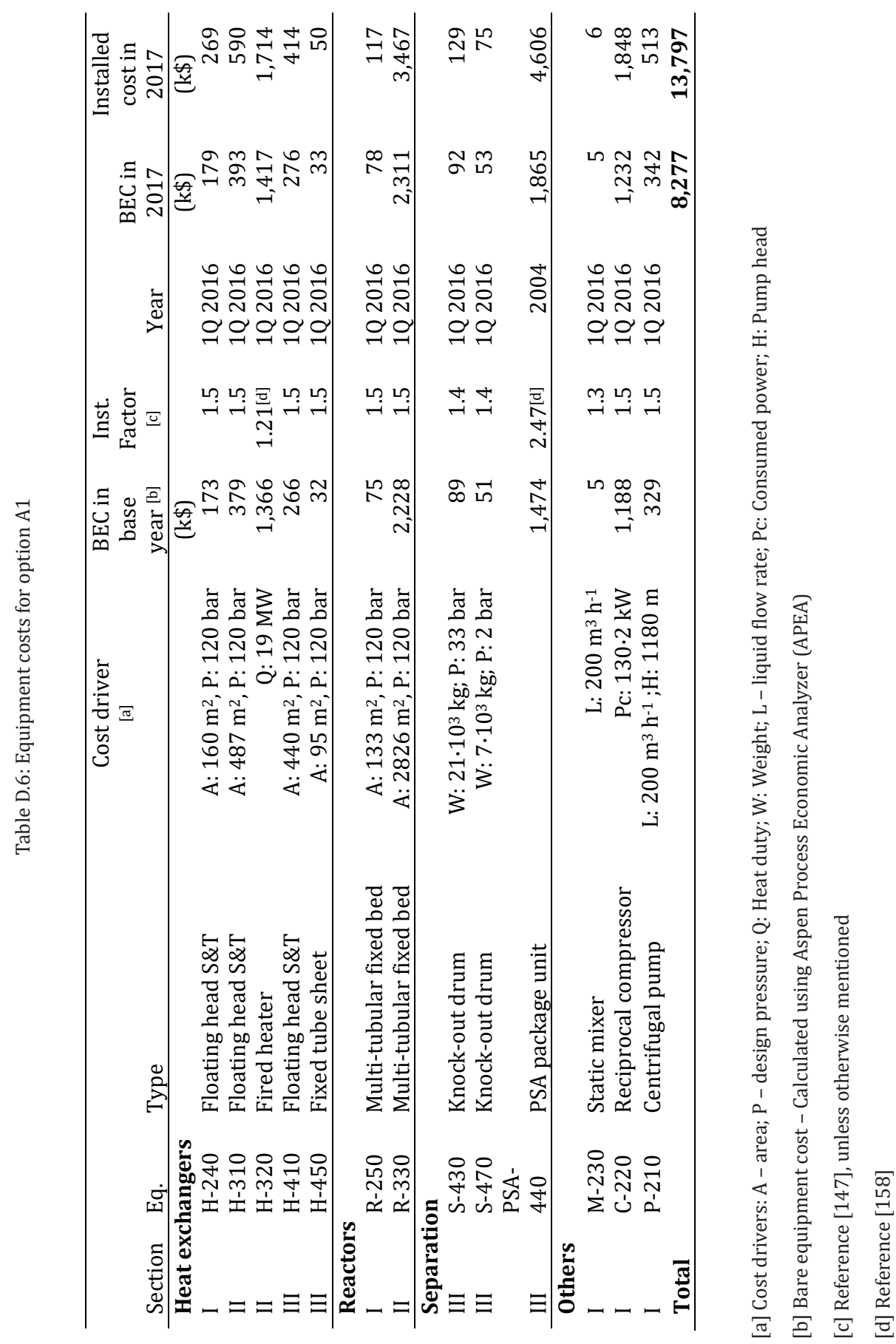




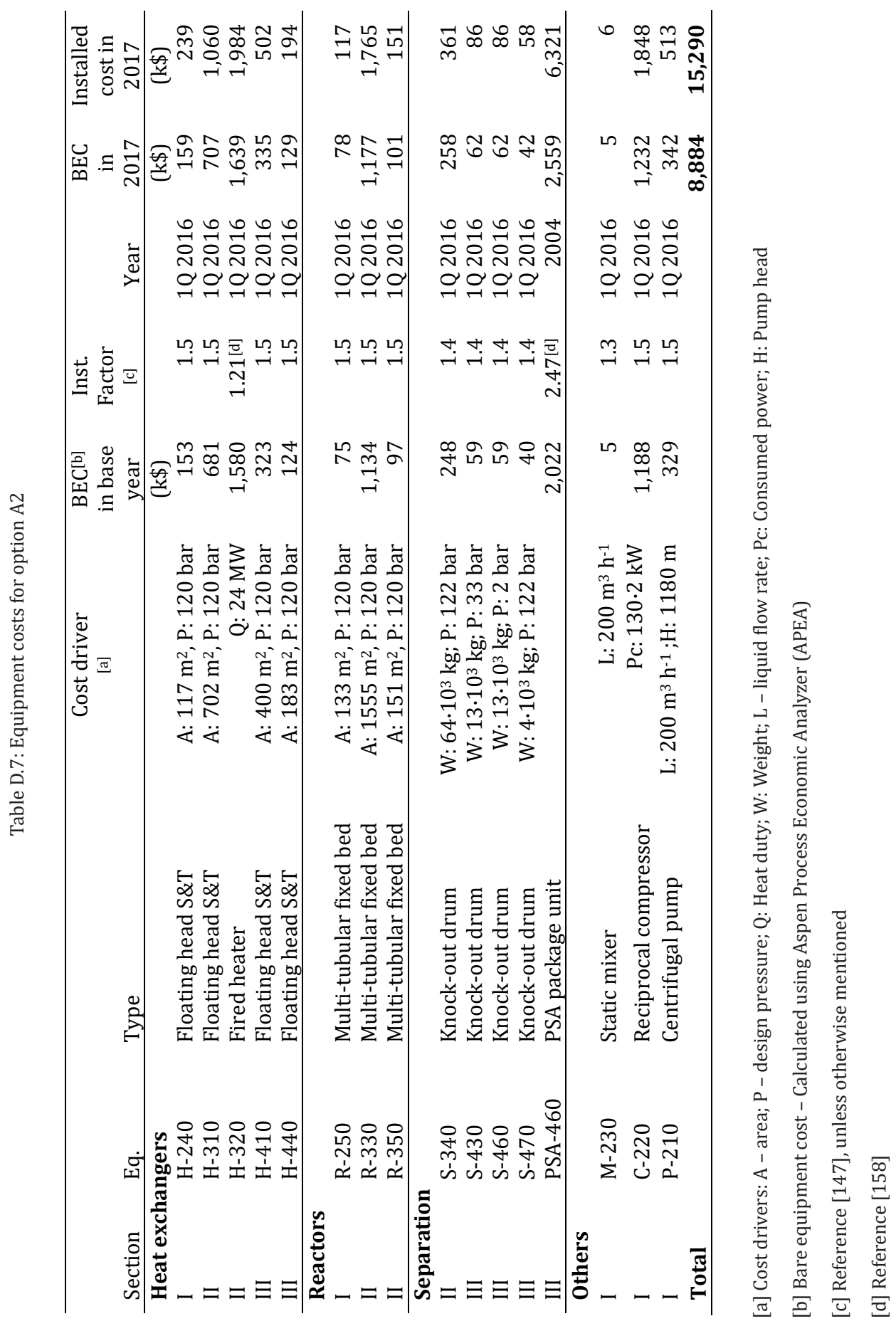




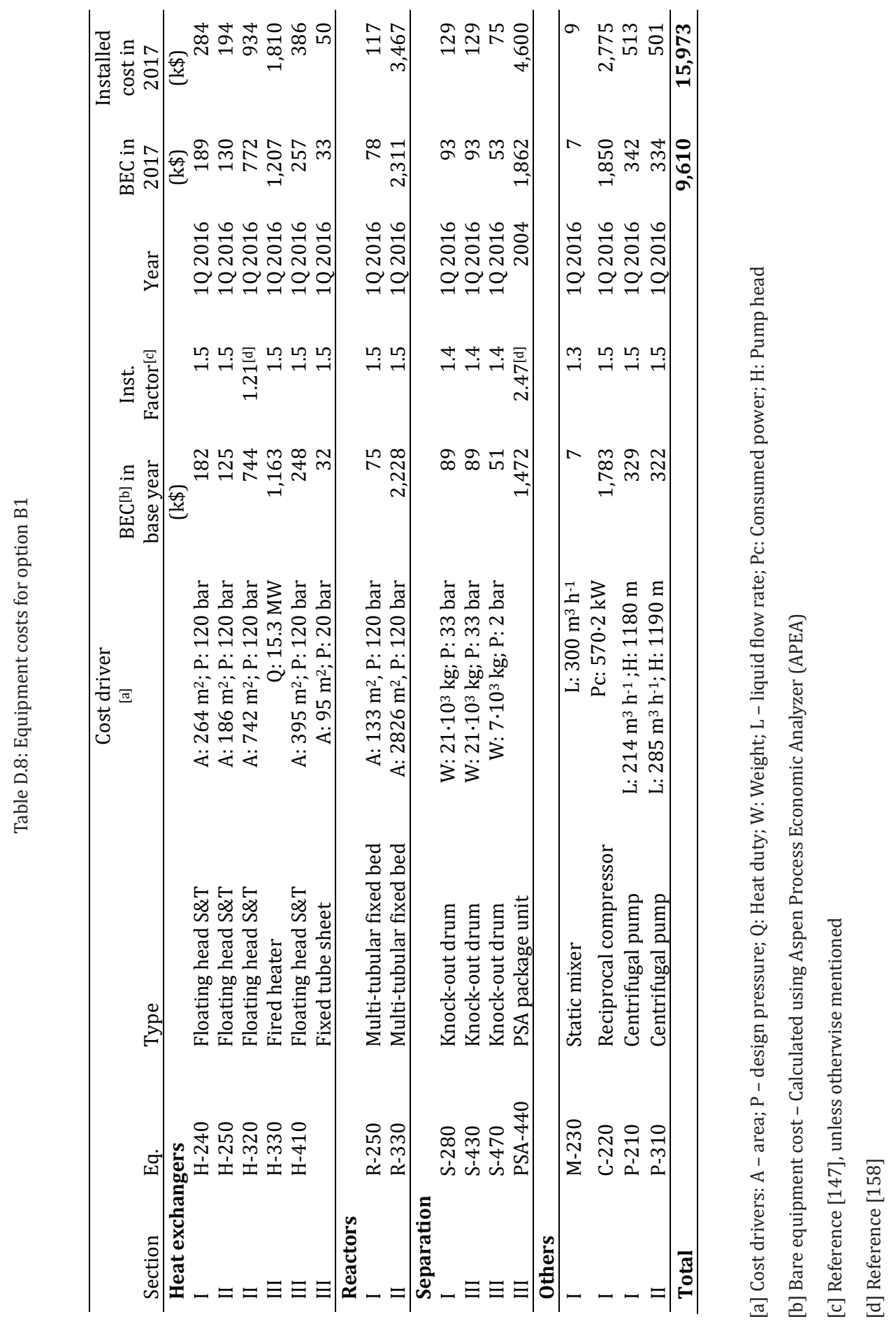




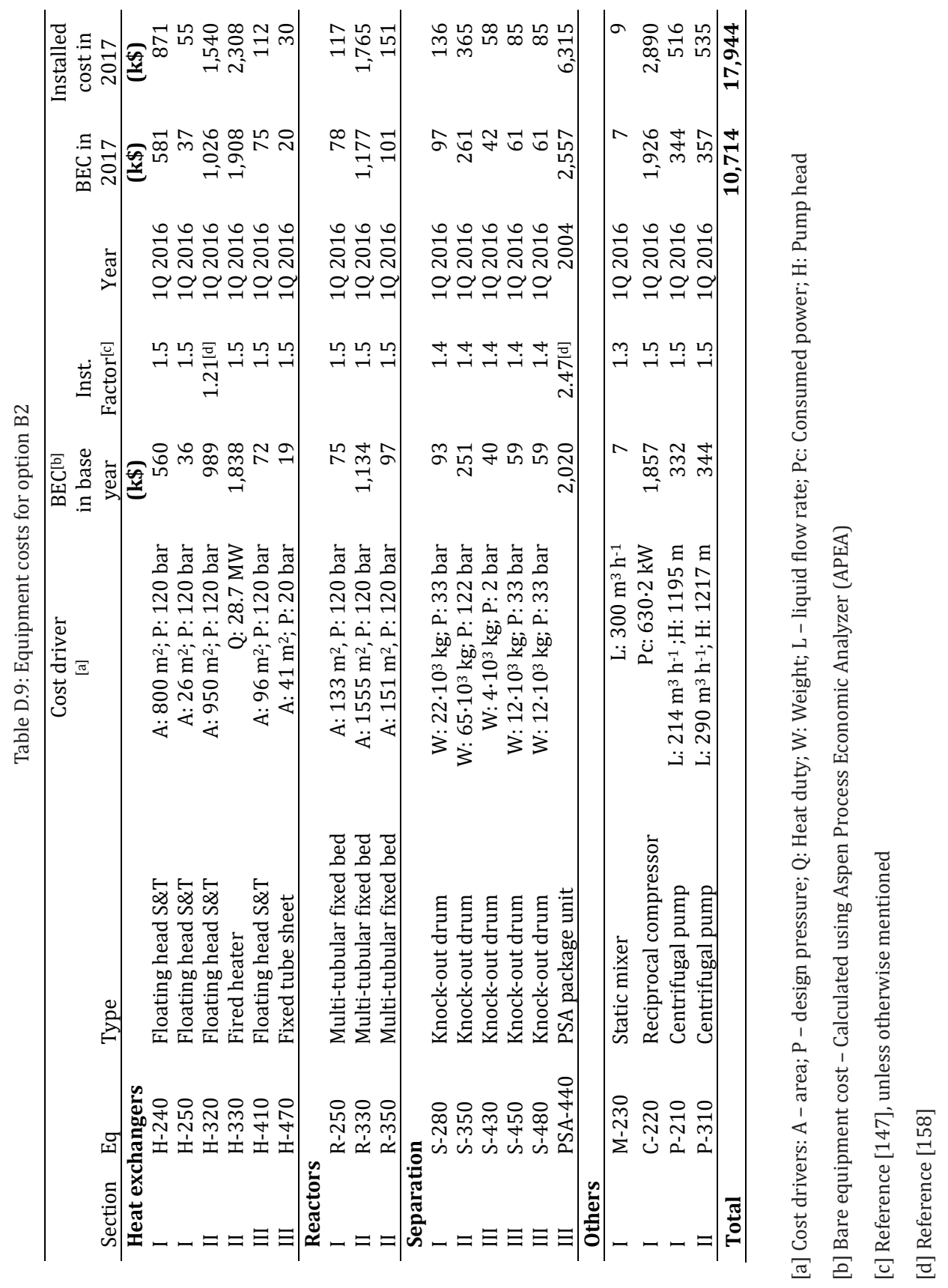




\section{D.4 Breakdown of TCI and TPC}

The TCI is calculated as the sum of the fixed-capital investment (FCI), which refers to the capital needed for manufacturing and plant facilities, as well as the working capital (WC), which is the capital required for plant operation. The FCI comprises of direct costs and indirect costs. Direct costs include the total equipment cost within battery limits (Section I, II and III), as well as additional direct costs for buildings, site development, service facilities and land. 


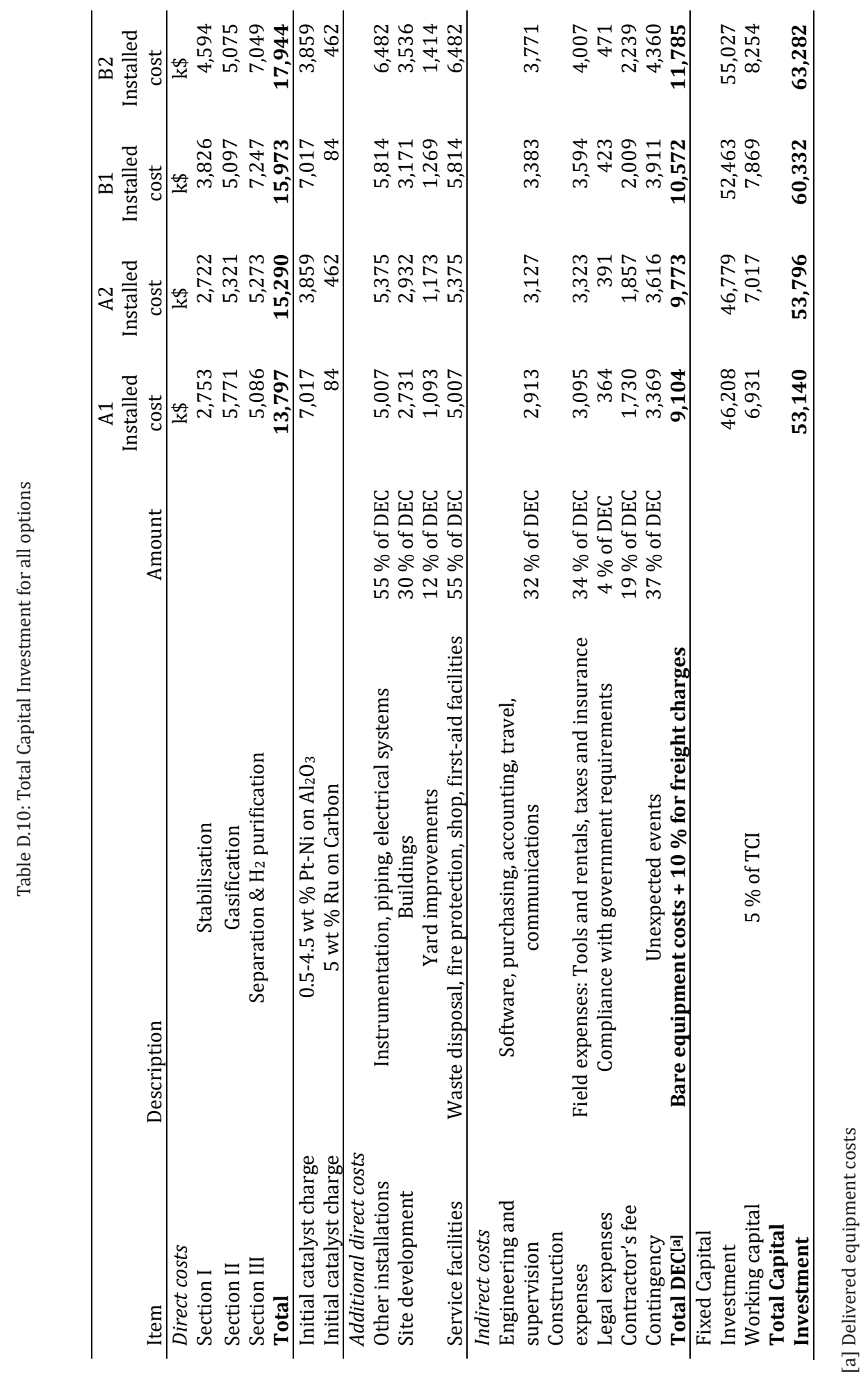


The TPC is calculated as a fraction of operating labour. Operating labour is calculated based on the number of workers required per equipment per shift based on Peters et al. [147], as shown in Table D.11.

Table D.11: Labour requirements for process equipment

\begin{tabular}{lr}
\hline Equipment & Workers per unit per shift \\
\hline Compressors & 0.15 \\
Heat exchangers & 0.1 \\
Continuous reactors & 0.5 \\
Knock-out drums & 0.1 \\
PSA package unit & 0.4 \\
Pumps & 0.1 \\
Mixers & 0.1 \\
Total number of workers: & \\
$\quad$ Option A1 & 2.45 \\
$\quad$ Option A2 & 3.15 \\
Option B1 & 2.75 \\
$\quad$ Option B2 & 3.35 \\
Number of shifts & $5148]$ \\
Cost of labour & $60 \mathrm{k} \$ \mathrm{yr}^{-1}[148]$ \\
\hline
\end{tabular}

The breakdown of the total production cost is tabulated in Table D.12. 


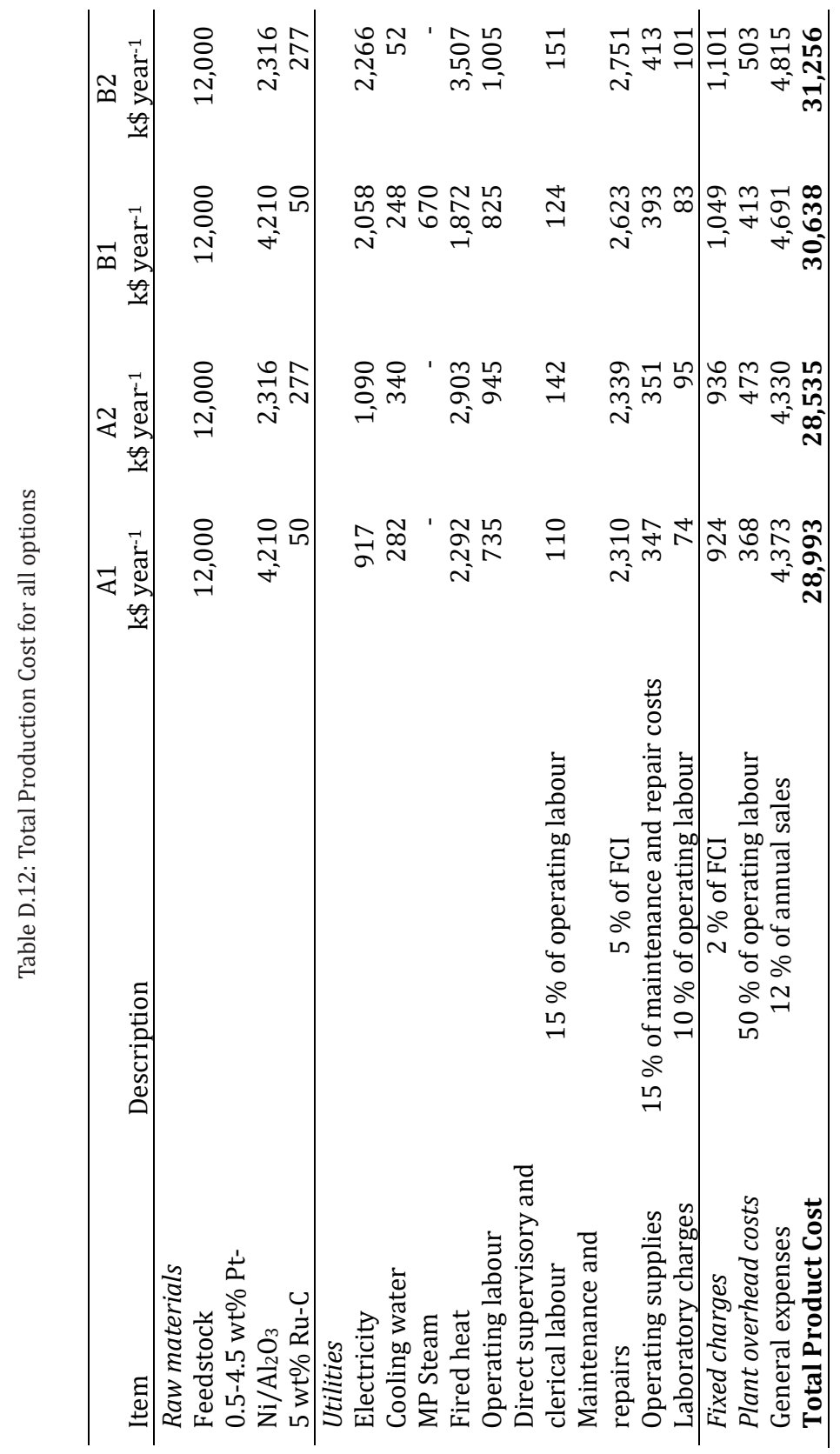




\section{D.5 Discounted Cash Flow Analysis}

A discounted cash flow analysis is used in order to calculate the minimum $\mathrm{H}_{2}$ selling price for all the options. This is done by calculating the net present value (NPV) and equalling it to zero. The NPV is calculated as the difference between the present worth of all cash flows and the present worth of capital investments, as shown in the following equation:

$$
N P V=\sum_{j=1}^{N} P W F_{c f, j}\left[\left(s_{j}-c_{j}-d_{j}\right)(1-\emptyset)+d_{j}\right]-\sum_{j=1}^{N} P W F_{T C I, j} \cdot I_{j}
$$

where $P W F_{c f, j}$ is the present worth factor for the cash flow in year $j$. Considering a discrete, year-end cash flow pattern with a discrete compounding interest rate, $P W F_{c f j}$ is represented by the formula $(1+i)^{-j}$, where $i$ is the discount rate and is considered to be $10 \%$, which is the DOE recommended value for renewable energy technologies [171]. The present worth factor for the total capital investment equals 1 because the total investment is made at time zero. $s_{j}$ is the annual sales revenue, $c_{j}$ is the total production cost, $d_{j}$ is the depreciation and is the income tax rate. Table D.13 presents the parameters used for the analysis. A 7 year depreciation recovery period is considered, according to the Modified Accelerated Cost Recovery System, suitable for a 'Waste reduction and resource recovery plant' [147]. The tax rate is only applied for the years in which the net profit is positive.

Table D.13: Discounted cash flow analysis parameters

\begin{tabular}{lr}
\hline Discount rate & $10 \%$ \\
Plant life & 30 years \\
Depreciation recovery period & 7 years \\
Tax rate & $35 \%$ \\
Working capital & $15 \%$ \\
\hline
\end{tabular}





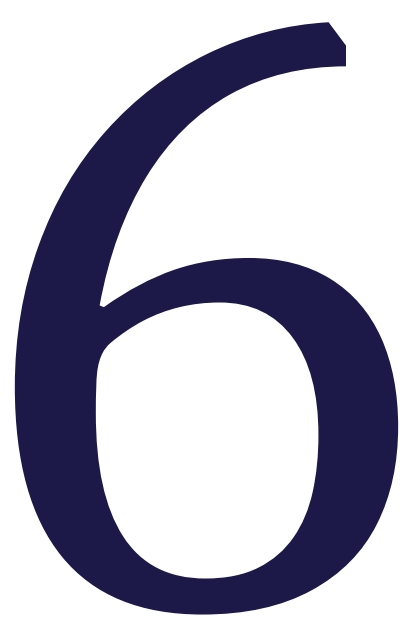

Conclusions 
144 | Chapter 6 


\subsection{Conclusions}

This thesis deals with the development and design of a process for the conversion of carbohydraterich aqueous wastes and wastewaters, primarily to $\mathrm{H}_{2}$. The work included in this thesis has been divided into two main parts. The first part (chapters 2 and 3) includes studies focussed on obtaining a more fundamental understanding of the two main catalytic processes under consideration: stabilisation and gasification.

The concept of stabilisation, described in Chapter 2, was applied to convert highly reactive aqueous carbohydrates to more stable molecules that would subsequently minimise, if not eliminate, coke production upon further processing. Stabilisation was conducted using 5 wt \% $\mathrm{Ru}-\mathrm{C}$ as a hydrogenation catalyst and under $\mathrm{H}_{2}$ pressure. It involves reactions including hydrolysis, hydrogenation and hydrogenolysis. Such reactions were found to convert carbohydrates to a mixture of polyols and alcohols. Stabilisation was tested on three different feedstock with increasing complexity: sucrose, starch and sugar beet pulp. Initial tests using sucrose as a model compound demonstrated its successful conversion to a mixture of C6 polyols, namely, sorbitol and mannitol. Kinetic studies between $100-140^{\circ} \mathrm{C}$ and at weight hourly space velocities (WHSV) of $20-80 \mathrm{~h}^{-1}$ showed that the rate of hydrolysis of sucrose to its monomeric sugars, glucose and fructose, was orders of magnitude slower than the rate of hydrogenation of the monomeric sugars to sugar alcohols. This is desirable, since the quick hydrogenation eliminates the possibility of monomeric sugar degradation in hot compressed water to by-products (5-HMF, furfural etc.) which are known precursors to coke formation. A kinetic model was developed that can be used to describe the complete conversion of sucrose to the polyol mixture with $>99 \%$ selectivity within the range of operating conditions considered.

Stabilisation studies with starch were conducted at higher temperatures $\left(200-240{ }^{\circ} \mathrm{C}\right)$ in order to obtain higher rates of hydrolysis. The use of high concentrations of the Ru-C catalyst were found to lead to $\mathrm{CH}_{4}$ production. This led to the unavoidable, but not necessarily undesired consumption of $\mathrm{H}_{2}$ in hydrogenolysis reactions, breaking down sorbitol, a C6 polyol, into smaller alcohols. The selectivity towards sorbitol production was therefore limited. Stabilised samples were gasified with negligible coke formation on the catalyst, producing similar carbon gasification efficiencies and $\mathrm{H}_{2}$ yields as the gasification of stabilised sucrose, or stabilised glucose. The success of stabilisation was based on the absence of oligosaccharides obtained from the incomplete or partial hydrolysis of starch detected using HPLC and was supported by the colouring tendency of the liquid product. While the stabilisation of sugar beet pulp was successful, owing to the large amount of water used to dissolve the pulp under experimental conditions, the resulting liquid stream contained 0.3 wt \% carbon. 
On an industrial scale, however, a more concentrated stream can be obtained by grinding the solid pulp to release bound moisture without the use of additional water.

In essence, the stabilisation of carbohydrates ranging from model sugars to realistic feedstock was achieved to produce alcohol mixtures that present negligible coking tendencies upon gasification.

The hydrothermal gasification of sorbitol, presented in Chapter 3, was studied using a 5 wt \% Pt on $\gamma-\mathrm{Al}_{2} \mathrm{O}_{3}$ catalyst. The main requisite of the process was to obtain high carbon gasification efficiencies. One of the key findings from experimental work was that, especially at higher temperatures, $\mathrm{H}_{2}$ produced from reforming is consumed in side reactions producing alkanes, unless it is separated from the reaction environment. In addition, the presence of $\mathrm{H}_{2}$ in the reacting environment inhibits further reforming. Therefore, it is imperative to separate $\mathrm{H}_{2}$ from the reaction zone as soon as it is produced. In experimental work, this separation was achieved using inert $\mathrm{N}_{2}$ as a sweep gas. The use of a sweep gas improved the $\mathrm{H}_{2}$ yield by decreasing the partial pressure of $\mathrm{H}_{2}$, therefore increasing the driving force for mass transfer from the liquid to gas phase. On an industrial scale, the increased yields of $\mathrm{H}_{2}$ could be achieved by considering reactors that show improved mass transfer (high $k_{L} a$ 's as in slurry reactors) in combination with the in-situ separation of $\mathrm{H}_{2}$ as soon as it's produced, through the use of a sweep gas, or a catalytic membrane reactor. At present, the use of a catalytic membrane reactor was found to be too expensive due to the large areas required for $\mathrm{H}_{2}$ transport.

The complex reaction mechanisms involved in the conversion of sorbitol to gaseous products were described by considering a path lumped kinetic model. Using experimental observations and statistical insights, the kinetic model was simplified to eventually be represented by three series reactions. This model was found to predict both total carbon gasification and $\mathrm{H}_{2}$ yields within the considered temperature range $\left(270-350^{\circ} \mathrm{C}\right)$.

The second part of this thesis (Chapters 4 and 5) includes work focussed on process development with an aim to identify whether the process is ready for implementation on an industrial scale. A sequential combination of the studied gasification catalysts ( $\mathrm{Pt}$ and $\mathrm{Ru}$ ) provided a two-fold advantage to the hydrothermal gasification process. The high selectivity for $\mathrm{H}_{2}$ production using $\mathrm{Pt}$, combined with the high reactivity of $\mathrm{Ru}$, was found to be promising at increased WHSVs. On an industrial scale, higher WHSVs translate to the requirement of smaller reactors with lower catalyst loadings. The Pt-Ru sequential combination, reported in Chapter 4, therefore presents an industrially attractive route for increased productivities of $\mathrm{H}_{2}$ and carbon gasification, introducing opportunities not only as a technology of $\mathrm{H}_{2}$ production from renewable feeds, but also as a technology for the treatment of wastewaters. 
The developed kinetic models for stabilisation and gasification were used to design the process for industrial scale. Most relevant wastes and wastewater streams were identified as ones that contained a large organic load, typically represented by the chemical oxygen demand (COD), such as those present in the food industry (sugar, potato, fruit and vegetable processing). A look at the energy balance demonstrated that the $\mathrm{H}_{2}$ product and off-gases each contained roughly 35 $\%$ of the energy of the feedstock. The rest of the energy produced $(\sim 30 \%)$ was used to meet the process demands of electricity, steam and fired heat, therefore giving the process an energy efficiency of $70 \%$.

An economic analysis, presented in Chapter 5, was conducted in order to determine the minimum $\mathrm{H}_{2}$ selling price from the process. The price of $\mathrm{H}_{2}$ obtained was comparable to $\mathrm{H}_{2}$ prices obtained from other renewable technologies. However, it was found to be significantly influenced by the concentration, quantity and price of feedstock. This implies that prior to selection of this process, the developed cost model should be used to evaluate the application and suitability of the technology for the feedstock considered. Further advancement in the areas of catalyst development (hydrothermal stability, affordability) as well as increased $\mathrm{H}_{2}$ yields are necessary in order to improve the economics of the process on an industrial scale.

\subsection{Potential applications}

Through the Energy Roadmap 2050 [2], the EU aims to reduce GHG emissions to 80 - 95 \% below 1990 levels by 2050. Scenarios presented in the Roadmap explore routes towards decarbonisation of the energy system. One of these scenarios is increasing the use of renewable energy sources, leading to a high share of such sources in the final energy consumption $75 \%$ in 2050). Hydrogen, an industrially important chemical and feedstock in industrial processes, will play a more prominent role in a decarbonised energy system, as a storage option, energy carrier option, and as feedstock for chemicals and fuels [172].

Presently, over $95 \%$ of the hydrogen produced worldwide is from fossil fuels [5]. Fossil $\mathrm{H}_{2}$ will however, soon be replaced with sustainable or green $\mathrm{H}_{2}$, produced from renewable sources. Electrolysis of water is currently regarded as the ideal technology for producing sustainable $\mathrm{H}_{2}$. However, the present electricity mix is still largely coal-based, making $\mathrm{H}_{2}$ production via electrolysis carbon intensive. Other alternatives with potential for sustainable $\mathrm{H}_{2}$ production include the use of biomass (pyrolysis, gasification, fermentation), photo-catalysis and thermochemical water splitting. Biomass, being the major renewable source of carbon, plays a crucial role as a renewable feedstock to replace fossil-based chemical products and fuels. The use of biomass for the production of sustainable $\mathrm{H}_{2}$ alone, is therefore questionable, and will not be a major production route in the years to come [173]. However, the conversion of waste biomass 
to energy presents a significant advantage to the circular economy. The Circular Economy Action Plan by the EU [160] presents long-term targets for waste management and recycling in Europe. By 2030, a landfill target of a maximum of $10 \%$ of municipal waste and a target to re-use and recycle $65 \%$ of municipal waste were set. The presence of these targets increased incentives for the recovery of energy and chemicals from solid municipal wastes. Bio-wastes, including food wastes, agricultural, forestry, marine and animal derived residues, characterise a large portion of municipal wastes [160]. Such wastes represent an untapped resource with potential to generate energy.

The main gaseous products released from treatment plants dealing with wastes and wastewaters from households and organic industrial processes are $\mathrm{CO}_{2}$ and $\mathrm{N}_{2}$. However, non- $\mathrm{CO}_{2}$ GHGs including $\mathrm{CH}_{4}$ and $\mathrm{N}_{2} \mathrm{O}$ are also produced, which represented a total of $40 \mathrm{Mt} \mathrm{CO}_{2}$ eq in 2005 [174]. The introduction of anaerobic digestion (AD) as a waste-to-energy technology for bio-wastes and wastewaters provided multiple environmental benefits including the reduction of waste volumes, GHG emissions and the possibility of nutrient recycling [175]. Biogas, produced from $\mathrm{AD}$, typically contains a $60-40 \mathrm{vol} \%$ mixture of $\mathrm{CH}_{4}$ and $\mathrm{CO}_{2}$ and is used as a source of heat and electricity. Its production in Europe has increased from $9.3 \cdot 10^{6} \mathrm{~m}^{3}$ in 2009 to $1.7 \cdot 10^{7} \mathrm{~m}^{3}$ in 2015 [169]. While AD provides numerous advantages to processing wastes and wastewaters, there is still scope for improvement including increasing efficiencies, biogas productivities, microbial activity and feedstock specificities [169]. One of the main challenges faced when waste-to-energy processes are selected is a need to ensure that the most efficient techniques are utilised in order to maximise the contribution to the EU's climate and energy objectives [176]. This has paved way for the collaborative use of multiple biodegradable feedstock, such as co-digestion within anaerobic digestion, or through the usage of combined technologies, such as co-incineration within an existing combustion plant, in order to achieve the required goals. Another challenge is dealing with expected changes in waste-to-energy feedstock. More rigid rules on improved separation and recycling will not just reduce the amount of waste potentially available for wasteto-energy processes, but will also make waste streams more specific in nature. There is then opportunity for technologies aimed at specific wastes as feedstock, that can be used in conjunction with existing plants and infrastructure that generate such waste streams. The studied technology of hydrothermal gasification presents a potential application to tackle the aforementioned challenges. Some examples of opportunities within relevant industries are discussed.

\section{Sugar industry}

In 2018, the global sugar production amounted to 185 million metric tons, with production in the EU at 20 million metric tons, third to India and Brazil [177]. The end of the sugar production quotas in the EU in September 2017 and the slight decline in EU sugar consumption [178] has 
caused large uncertainties in the sugar market scene. In the Netherlands alone, an increase in sugar production in the past year has already seen a decrease in price because of the lower demands of sugar in the food sector, lower exports, the need for a healthier diet by replacing sugars in foods with artificial sweeteners, etc. [179]. The reduction in the demand for sugar will leave larger quantities of white sugar or sugar beet crops that will not be needed for food purposes. Alternatives to their use, for example, as renewable feedstock for the production of energy or fuels, is a potential application.

The side products from the sugar beet industry (pulp, molasses, wastewater) have been studied as potential sources of fuel and energy for the past few decades [66,180-183], specifically in the field of biotechnology where processes such as anaerobic digestion, fermentation or enzymatic reactions are used to produce biogas, bioethanol, bio-butanol or lactic acid [184]. The utilisation of sugar beets themselves for the production of $\mathrm{H}_{2}$ has been much more limited $[185,186]$. Some of the main challenges in biological processes are the low $\mathrm{H}_{2}$ productivity $\left(7-15 \mathrm{~mol} \mathrm{H}_{2} \mathrm{~m}_{\mathrm{w}}^{-3} \mathrm{~h}^{-1}\right.$ ) obtained due to inhibitory effects of $\mathrm{H}_{2}$ on the microbes and the requirement of long residence times [185]. The use of sugar beets as starting material for hydrothermal gasification via the twostep process pose several advantages. Firstly, sugar beets contain about $75 \%$ water, 20\% sugar and 5\% pulp. In the sugar industry, sucrose is extracted from the carbohydrates of sugar beet with a yield of $0.45 \mathrm{~g}$ per g dry biomass, by using an extraction step [187]. Theoretically, this would lead to an aqueous sucrose stream with a concentration of $11-12 \mathrm{wt} \%$, ideal for the two-step approach. A quick calculation based on measured productivities shows that the production of $\mathrm{H}_{2}$ from sugar beets would be 25,000-50,000 $\mathrm{mol} \mathrm{H}_{2} \mathrm{~m}_{\mathrm{w}}^{-3} \mathrm{~h}^{-1}$, three orders of magnitude higher than the abovementioned biological processes.

\section{Potato processing industry}

The processing of potatoes requires copious amounts of water (roughly 17 liters per kg potatoes) [188], leading to starch-rich wastewaters from certain processing plants (COD: $5-12 \mathrm{~g} \mathrm{~L}^{-1}$ ). This translates to an aqueous stream with a $1-2 \mathrm{wt} \%$ organic load. Potato processing plants contain an integrated waste treatment system that usually consists of primary, secondary and advanced treatment. Secondary treatment systems include both anaerobic and aerobic systems where $70-80 \%$ of the COD is removed. Some of the disadvantages of the current treatment system are the space requirements (stabilisation ponds, lagoons etc.) and the long residence times required for the treatment. While the two-step approach might not be the obvious choice as a treatment method of $1-2$ wt \% starch-rich wastewaters, it still presents advantages in terms of improved productivity and less land requirements. However, concentrating the relevant wastewaters might be a necessary step prior to hydrothermal gasification in order for the technology to be energy efficient. This can be achieved by using evaporators, or reverse osmosis or nanofiltration 
membranes, or a combination of the two to increase energy efficiency [189]. Further work should focus on the energy and economic feasibility of such pre-treatment methods for dilute streams. In addition to wastewaters, opportunities also exist for by-products and solid wastes (peels, pulp) from the potato processing industry. Potato peels, for example, typically used as cattle feed, are a promising waste for the two-step approach because they contain $15 \%$ dry matter, roughly $70 \%$ of which is represented by carbohydrates [69]. Further work should also consider pre-treatment options for the removal of nutrients including nitrogen and phosphorous from potato wastes.

\section{Fruit and vegetable processing industries (FVPI)}

In the EU, roughly 88 million tonnes of food waste are generated annually, which alone generate 8 $\%$ of GHG emissions [190]. Based on the waste hierarchy, the priorities are for the prevention and reduction of food waste at all points of the food chain. However, inevitable during food processing are the generation of wastewaters and solid food wastes or by-products. In the FVPI, this includes pressed residues, or pomace, obtained from various fruits including apples, grapes, citrus, olives etc. [67]. Fruit solid wastes typically contain high moisture content (80 - 90 wt \%) and high concentration of sugars and carbohydrates, making these valuable feedstock for the two-step approach. Fruit wastewaters, like wastewaters from the potato processing industry, contain low organic loads (COD: $2-5 \mathrm{~g} \mathrm{~L}^{-1}$ ), but are produced in quantities of $50-300 \mathrm{~m}^{3} \mathrm{~h}^{-1}$ [72].

The suitability of the two-step approach applies, but is not limited, to the wastes and wastewaters discussed above. It is envisioned that the technology can also be adapted to treat agro-food industrial wastewaters such as those derived from distilleries, dairies, meat processing, pulp and paper mills, olive oil mills and other starch industries. Wastewaters from such industries also contain high organic loads and upon further evaluation, could be promising feedstock for the process.

Although not elaborated on, additional taxes, fees, incentives and benefits offered by the government keeping in mind carbon footprints, sustainability, the use of renewable feedstock, production of green energy and production of dischargeable water will enhance the viability of the two-step approach and make it more favourable economically. Additionally, this will provide incentive for producers to incorporate changes in existing facilities or invest in new infrastructure. That being said, the rationale for the choice of a technology, or combination of technologies, must not be economics alone. Other equally important drivers such as improved energy efficiencies, and long term sustainability benefits are necessary in order to reach the goal of a true circular economy. 


\section{Nomenclature}

\section{Chapter 2}

$a_{S}$

$C_{b}$

$C_{M n}$

$C_{s}$

$C_{S b}$

$C_{\text {Su }}$

D

$D_{e}$

$d_{p}$

$E_{a}$

$k_{S}$

$k_{S u}$

l

$m_{c a t}$

$m_{f}$

$N$

$n_{C, i}$

$n_{\text {C,in }}$

$n_{f}$

$n_{f, i n}$

$n i$

$r_{F}$

$r_{G}$

$\mathrm{rH}_{2} \mathrm{O}$

$r_{o b s}$

$r_{p}$

$r S$

$r_{S u}$

$S$
Specific surface area of particle

Bulk concentration of species

Mannitol concentration

Concentration at the catalyst surface

Sorbitol concentration

Sucrose concentration

Diffusion coefficient

Effective diffusivity

Diameter of particle

Activation energy

Liquid-solid mass transfer coefficient

Rate constant for sucrose hydrolysis

Stirrer diameter

Mass of catalyst

mass of feed

Stirrer speed

moles of carbon in species $\mathrm{i}$

Initial moles of carbon

Final moles of feed

Initial moles of feed

moles of species $i$

Rate of fructose hydrogenation

Rate of glucose hydrogenation

Rate of starch hydrolysis

Observed rate of reaction

Radius of particle

Rate of sorbitol hydrogenolysis

Rate of sucrose hydrolysis

Selectivity of mannitol over sorbitol

$$
\begin{aligned}
& \mathrm{m}_{\mathrm{p}}^{2} \mathrm{~m}_{\mathrm{p}}^{-3} \\
& \mathrm{~mol} \mathrm{~m}_{\mathrm{f}}^{-3} \\
& \mathrm{~mol} \mathrm{~m}_{\mathrm{f}}^{-3} \\
& \mathrm{~mol} \mathrm{~m}_{\mathrm{f}}^{-3} \\
& \mathrm{~mol} \mathrm{~m}_{\mathrm{f}}^{-3} \\
& \mathrm{~mol} \mathrm{~m}_{\mathrm{f}}^{-3} \\
& \mathrm{~m}^{2} \mathrm{~s}^{-1} \\
& \mathrm{~m}^{2} \mathrm{~s}^{-1} \\
& \mathrm{~m}
\end{aligned}
$$

$\mathrm{kJ} \mathrm{mol}{ }^{-1}$

$$
\mathrm{m}_{\mathrm{f}}^{3} \mathrm{~m}_{\mathrm{p}}^{2} \cdot \mathrm{s}
$$

$\mathrm{g}_{\text {cat }}^{-1} \mathrm{~s}^{-1}$

$\mathrm{m}$

g

g

$\mathrm{Hz}$

mol C

mol C

moles

moles

moles

$\mathrm{mol} \mathrm{m} \mathrm{f}^{-3} \mathrm{~s}^{-1}$

$\mathrm{mol} \mathrm{m} \mathrm{f}^{-3} \mathrm{~s}^{-1}$

$\mathrm{mol} \mathrm{m} \mathrm{f}^{-3} \mathrm{~s}^{-1}$

$\mathrm{mol} \mathrm{m} \mathrm{f}^{-3} \mathrm{~s}^{-1}$

$\mathrm{m}$

$\mathrm{mol} \mathrm{m} \mathrm{f}^{-3} \mathrm{~s}^{-1}$

$\mathrm{mol} \mathrm{m}_{\mathrm{f}}^{-3} \mathrm{~s}^{-1}$

mol Mn mol Sb-1 


\section{Chapter 3}

$a$

$a_{S}$

$C_{b}$

$c_{i}^{j}$

$C_{P t}$

$C_{\mathrm{s}}$

D

$D_{e}$

$d_{p}$

$E_{a}$

$F_{c, i}$

$F_{c, i n}$

$\mathrm{FH}_{2}$

$F_{i}^{j}$

$F_{s b}$

$F_{S b, \text { in }}$

$H_{a d s}$

$H_{i}$

$\mathrm{JH}_{2}$

$k_{0, i}$

$K_{\text {eq }}$

$k_{i}$

$k_{L}$
Specific surface area for G-L

Specific surface area of particle

Bulk concentration of species

concentration of species $i$ in phase $j$

concentration of platinum in reactor

Concentration at the catalyst surface

Diffusion coefficient

Effective diffusivity

Diameter of particle

Activation energy

Molar flow of carbon in species i

Initial molar flow of carbon in feed

Molar flow of hydrogen

Molar flow of species $i$ in phase $j$

Final molar flow of sorbitol

Initial molar flow of sorbitol

Heat of adsorption

Henry's coefficient for species $i$

Hydrogen flux

Pre-exponential factor for rate constant $\mathrm{i}$

adsorption equilibrium constant

Rate constant of reaction $i$

Gas-liquid mass transfer coefficient

$$
\begin{array}{r}
\mathrm{m}_{\mathrm{f}}{ }^{2} \mathrm{~m}_{\mathrm{f}}^{-2} \\
\mathrm{~m}_{\mathrm{p}}{ }^{2} \mathrm{~m}_{\mathrm{p}}^{-3} \\
\mathrm{~mol} \mathrm{~m}_{\mathrm{f}}^{-3} \\
\mathrm{~mol} \mathrm{~m}_{\mathrm{f}}^{-3} \\
\mathrm{~mol} \mathrm{Pt} \mathrm{m} \mathrm{r}^{-3} \\
\mathrm{~mol} \mathrm{~m}_{\mathrm{f}}^{-3} \\
\mathrm{~m}^{2} \mathrm{~s}^{-1} \\
\mathrm{~m}^{2} \mathrm{~s}^{-1} \\
\mathrm{~m}
\end{array}
$$

$\mathrm{kJ} \mathrm{mol}{ }^{-1}$

mol C s${ }^{-1}$

$\operatorname{mol~C~s}{ }^{-1}$

$\mathrm{mol} \mathrm{s}^{-1}$

mol s${ }^{-1}$

mol s-1

mol s-1

$\mathrm{kJ} \mathrm{mol}{ }^{-1}$

bar. $\mathrm{m}^{3} \mathrm{~mol}^{-1}$

$\mathrm{mol} \mathrm{m}^{-2} \mathrm{~s}^{-1}$

$\mathrm{m}_{\mathrm{f}}^{3} \mathrm{~mol} \mathrm{Pt}^{-1} \mathrm{~s}^{-1}$

$\mathrm{m}_{\mathrm{f}}^{3} \mathrm{~mol} \mathrm{Pt}^{-1} \mathrm{~s}^{-1}$

$\mathrm{m}_{\mathrm{f}}{ }^{3} \mathrm{~m}^{-2} \mathrm{~s}^{-1}$ 


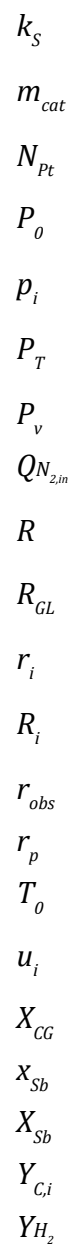

\section{Chapter 4}

$m_{C, i n}$
$m_{c a t}$
$n_{C, i}$
$n_{C, i n}$
$n_{i}$
$t$
$X_{C G}$
$Y_{C, i}$
$Y_{H_{2 c}}$

Liquid-solid mass transfer coefficient

Mass of catalyst

Moles of platinum

Normal pressure (= 1)

partial pressure of species $i$

Total pressure

Vapour pressure of water

Initial volumetric flow rate of $\mathrm{N}_{2}$ at NTP

Gas constant $(=8.314)$

Gas-liquid ratio at NTP

Intrinsic reaction rate of reaction $i$

Rate of reaction of species $i$

Observed rate of reaction

Radius of particle

Normal temperature $(=20)$

Superficial velocity of phase $j$

Carbon to gas conversion

Mass fraction of sorbitol

Conversion of sorbitol

Yield of species $i$ (carbon basis)

Hydrogen yield

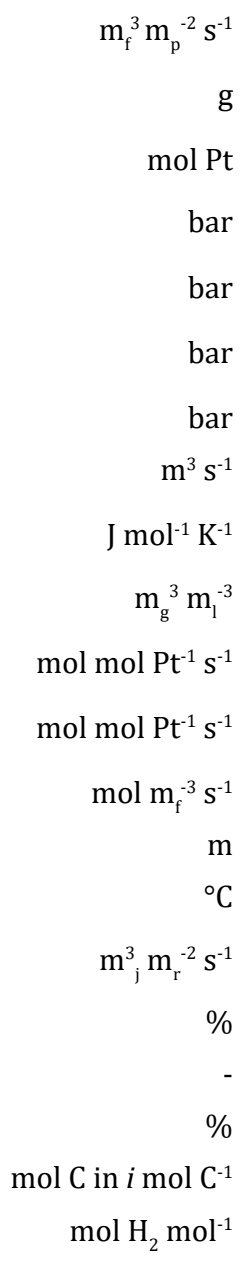

mol Pt

bar

bar

bar

bar

$\mathrm{m}^{3} \mathrm{~s}^{-1}$

$\mathrm{J} \mathrm{mol}^{-1} \mathrm{~K}^{-1}$$$
\mathrm{m}_{\mathrm{g}}^{3} \mathrm{~m}_{\mathrm{l}}^{-3}
$$

mol mol Pt ${ }^{-1} \mathrm{~s}^{-1}$

mol mol Pt-1 $\mathrm{s}^{-1}$

$\mathrm{mol} \mathrm{m} \mathrm{f}^{-3} \mathrm{~s}^{-1}$

$\mathrm{m}$

${ }^{\circ} \mathrm{C}$

$\mathrm{m}^{3}{ }_{\mathrm{j}} \mathrm{m}_{\mathrm{r}}^{-2} \mathrm{~s}^{-1}$

$\%$

$\%$

mol C in $i \mathrm{~mol} \mathrm{C}^{-1}$

$\mathrm{mol} \mathrm{H}_{2} \mathrm{~mol}^{-1}$

Initial mass of carbon

Mass of catalyst

g

Moles of carbon in species $i$

mol C

Initial moles of carbon

mol C

moles of species $i$

moles

Residence time in batch reactor

$\min$

Carbon to gas conversion

$\%$

Yield of species i (carbon basis)

mol C in $i \mathrm{~mol} \mathrm{C}^{-1}$

Yield of hydrogen (carbon basis)

mol mol C-1 


\section{Abbreviations}

APEA

APR

BEC

CCS

COD

DEC

EROEI

FCI

GHG

HHV

IRR

NPV

PSA

PWF

SBP

SCWG

TCI

TOC

TPC

WHSV

WHSV $_{c}$
Aspen Process Economic Analyser

Aqueous phase reforming

Bare equipment costs

Carbon capture and storage

Chemical oxygen demand

Delivered equipment costs

Energy return on energy investment

Fixed Capital Investment

Greenhouse gas

Higher Heating Value

Internal Rate of Return

Net present value

Pressure swing adsorption

Present worth factor

Sugar beet pulp

Super-critical water gasification

Total Capital Investment

Total organic carbon

Total Production Cost

Weight hourly space velocity

Weight hourly space velocity (carbon basis)

\section{Dimensionless numbers}

$C_{a, L S}$

$\mathrm{Np}$

$R e$

Sc

Sh

$\varphi \mathrm{w}$
Carberry number for L-S mass transfer Power number Reynolds number Schmidt number Sherwood number Weisz-Prater number 


\section{Greek letters}

$\alpha$

$\beta_{i}$

$\varepsilon$

$\eta$

$\mu$

v

$\rho$

$\tau$

$\varphi$
Molar deviation parameter

Hold-up of phase $i$

Energy dissipation

thermal efficiency

Dynamic viscosity of fluid

Kinematic viscosity of fluid

Density of fluid

Residence time

Income tax $\mathrm{m}_{\mathrm{i}}^{3} \mathrm{~m}_{\mathrm{r}}^{-3}$

$\mathrm{J} \mathrm{kg}^{-1} \mathrm{~s}^{-1}$

$\mathrm{Pa} \cdot \mathrm{s}$

$\mathrm{m}^{2} \mathrm{~s}^{-1}$

$\mathrm{kg} \mathrm{m}^{-3}$

$\mathrm{s} \cdot \mathrm{mol} \mathrm{Pt} \mathrm{mol}^{-1}$

$\$$ 


\section{References}

[1] BP Statistical Review of World Energy, BP, 2018.

[2] Energy Roadmap 2050, European Commission, 2011.

[3] J. Valentine, J. Clifton-Brown, A. Hastings, P. Robson, G. Allison, P. Smith, Food vs. fuel: The use of land for lignocellulosic 'next generation' energy crops that minimize competition with primary food production, GCB Bioenergy 4 (2012) 1-19.

[4] P. Bajpai, Structure of Lignocellulosic Biomass, Pretreatment of Lignocellulosic Biomass for Biofuel Production, Springer Briefs 2016.

[5] P. Nikolaidis, A. Poullikkas, A comparative overview of hydrogen production processes, Renewable and Sustainable Energy Reviews 67 (2017) 597-611.

[6] R.E.H. Sims, W. Mabee, J.N. Saddler, M. Taylor, An overview of second generation biofuel technologies, Bioresource Technology 101 (2010) 1570-1580.

[7] J. Fang, L. Zhan, Y.S. Ok, B. Gao, Minireview of potential applications of hydrochar derived from hydrothermal carbonization of biomass, Journal of Industrial and Engineering Chemistry 57 (2018) $15-21$

[8] A.R.K. Gollakota, N. Kishore, S. Gu, A review on hydrothermal liquefaction of biomass, Renewable and Sustainable Energy Reviews 81 (2018) 1378-1392.

[9] R.D. Cortright, R.R. Davda, J.A. Dumesic, Hydrogen from catalytic reforming of biomass-derived hydrocarbons in liquid water, Nature 418 (2002) 964.

[10] I. Coronado, M. Stekrova, M. Reinikainen, P. Simell, L. Lefferts, J. Lehtonen, A review of catalytic aqueous-phase reforming of oxygenated hydrocarbons derived from biorefinery water fractions, International Journal of Hydrogen Energy 41 (2016) 11003-11032.

[11] M.J. Antal, S.G. Allen, D. Schulman, X. Xu, R.J. Divilio, Biomass Gasification in Supercritical Water, Industrial \& Engineering Chemistry Research 39 (2000) 4040-4053.

[12] S.N. Reddy, S. Nanda, A.K. Dalai, J.A. Kozinski, Supercritical water gasification of biomass for hydrogen production, International Journal of Hydrogen Energy 39 (2014) 6912-6926.

[13] C. Rodriguez Correa, A. Kruse, Supercritical water gasification of biomass for hydrogen production - Review, The Journal of Supercritical Fluids 133 (2018) 573-590.

[14] O. Yakaboylu, J. Harinck, K.G. Smit, W. de Jong, Supercritical water gasification of biomass: A literature and technology overview, Energies 8 (2015) 859-894.

[15] D.J.M. de Vlieger, A.G. Chakinala, L. Lefferts, S.R.A. Kersten, K. Seshan, D.W.F. Brilman, Hydrogen from ethylene glycol by supercritical water reforming using noble and base metal catalysts, Applied Catalysis B: Environmental 111-112 (2012) 536-544.

[16] A.G. Chakinala, W.P.M. van Swaaij, S.R.A. Kersten, D. de Vlieger, K. Seshan, D.W.F. Brilman, Catalytic Reforming of Glycerol in Supercritical Water over Bimetallic Pt-Ni Catalyst, Industrial \& 
Engineering Chemistry Research 52 (2013) 5302-5312.

[17] M.H. Waldner, F. Vogel, Renewable Production of Methane from Woody Biomass by Catalytic Hydrothermal Gasification, Industrial \& Engineering Chemistry Research 44 (2005) 4543-4551.

[18] D.C. Elliott, L.J. Sealock, Jr., E.G. Baker, Chemical Processing in High-Pressure Aqueous Environments. 2. Development of Catalysts for Gasification, Industrial and Engineering Chemistry Research 32 (1993) 1542-1548.

[19] D.C. Elliott, Catalytic hydrothermal gasification of biomass, Biofuels, Bioproducts and Biorefining 2 (2008) 254-265.

[20] J.B. Müller, F. Vogel, Tar and coke formation during hydrothermal processing of glycerol and glucose. Influence of temperature, residence time and feed concentration, Journal of Supercritical Fluids 70 (2012) 126-136.

[21] T. Karayildirim, A. Sinağ, A. Kruse, Char and coke formation as unwanted side reaction of the hydrothermal biomass gasification, Chemical Engineering and Technology 31 (2008) 1561-1568.

[22] D. Knežević, W.P.M. Van Swaaij, S.R.A. Kersten, Hydrothermal conversion of biomass: I, glucose conversion in hot compressed water, Industrial and Engineering Chemistry Research 48 (2009) 4731-4743.

[23] K. Ehara, S. Saka, A comparative study on chemical conversion of cellulose between the batchtype and flow-type systems in supercritical water, Cellulose 9 (2002) 301-311.

[24] T. Bhaskar, A. Sera, A. Muto, Y. Sakata, Hydrothermal upgrading of wood biomass: Influence of the addition of $\mathrm{K}_{2} \mathrm{CO}_{3}$ and cellulose/lignin ratio, Fuel 87 (2008) 2236-2242.

[25] P.T. Williams, J. Onwudili, Subcritical and supercritical water gasification of cellulose, starch, glucose, and biomass waste, Energy and Fuels 20 (2006) 1259-1265.

[26] A. Chuntanapum, Y. Matsumura, Formation of tarry material from 5-HMF in subcritical and supercritical water, Industrial and Engineering Chemistry Research 48 (2009) 9837-9846.

[27] M.M. Titirici, M. Antonietti, N. Baccile, Hydrothermal carbon from biomass: A comparison of the local structure from poly- to monosaccharides and pentoses/hexoses, Green Chemistry 10 (2008) 1204-1212.

[28] A. Chuntanapum, Y. Matsumura, Char formation mechanism in supercritical water gasification process: A study of model compounds, Industrial and Engineering Chemistry Research 49 (2010) 4055-4062.

[29] M.L. Valderrama Rios, A.M. González, E.E.S. Lora, O.A. Almazán del Olmo, Reduction of tar generated during biomass gasification: A review, Biomass and Bioenergy 108 (2018) 345-370.

[30] Y. Matsumura, M. Harada, K. Nagata, Y. Kikuchi, Effect of heating rate of biomass feedstock on carbon gasification efficiency in supercritical water gasification, Chemical Engineering Communications 193 (2006) 649-659. 
[31] B.R. Pinkard, D.J. Gorman, K. Tiwari, E.G. Rasmussen, J.C. Kramlich, P.G. Reinhall, I.V. Novosselov, Supercritical water gasification: practical design strategies and operational challenges for labscale, continuous flow reactors, Heliyon 5 (2019) e01269.

[32] N. Boukis, U. Galla, H. Müller, E. Dinjus, Biomass gasification in supercritical water. Experimental progress achieved with the VERENA pilot plant., 15th European Biomass Conference and Exhibition Berlin, Germany, 2007.

[33] P.C. Dell'orco, L. Li, E.F. Gloyna, The Separation of Particulates from Supercritical Water Oxidation Processes, Separation Science and Technology 28 (1993) 625-642.

[34] A.A. Peterson, F. Vogel, R.P. Lachance, M. Fröling, M.J. Antal Jr, J.W. Tester, Thermochemical biofuel production in hydrothermal media: A review of sub- and supercritical water technologies, Energy and Environmental Science 1 (2008) 32-65.

[35] M. Osada, T. Sato, M. Watanabe, T. Adschiri, K. Arai, Low-Temperature Catalytic Gasification of Lignin and Cellulose with a Ruthenium Catalyst in Supercritical Water, Energy \& Fuels 18 (2004) 327-333.

[36] M. Waldner, Catalytic hydrothermal gasification of biomass for the production of synthetic natural gas, ETH Zurich, Zurich, 2007.

[37] R.R. Davda, J.W. Shabaker, G.W. Huber, R.D. Cortright, J.A. Dumesic, A review of catalytic issues and process conditions for renewable hydrogen and alkanes by aqueous-phase reforming of oxygenated hydrocarbons over supported metal catalysts, Applied Catalysis B: Environmental 56 (2005) 171-186.

[38] G.Y. Chen, W.Q. Li, H. Chen, B.B. Yan, Progress in the aqueous-phase reforming of different biomass-derived alcohols for hydrogen production, Journal of Zhejiang University: Science A 16 (2015) 491-506.

[39] H.D. Kim, H.J. Park, T.W. Kim, K.E. Jeong, H.J. Chae, S.Y. Jeong, C.H. Lee, C.U. Kim, Hydrogen production through the aqueous phase reforming of ethylene glycol over supported Pt-based bimetallic catalysts, International Journal of Hydrogen Energy 37 (2012) 8310-8317.

[40] G.W. Huber, J.W. Shabaker, J.A. Dumesic, Raney Ni-Sn Catalyst for $\mathrm{H}_{2}$ Production from BiomassDerived Hydrocarbons, Science 300 (2003) 2075.

[41] D.C. Elliott, T.R. Hart, G.G. Neuenschwander, Chemical processing in high-pressure aqueous environments. 8. Improved catalysts for hydrothermal gasification, Industrial and Engineering Chemistry Research 45 (2006) 3776-3781.

[42] D.C. Elliott, G.G. Neuenschwander, T.R. Hart, R.S. Butner, A.H. Zacher, M.H. Engelhard, J.S. Young, D.E. McCready, Chemical Processing in High-Pressure Aqueous Environments. 7. Process Development for Catalytic Gasification of Wet Biomass Feedstocks, Industrial and Engineering Chemistry Research 43 (2004) 1999-2004. 
[43] R.H. Venderbosch, A.R. Ardiyanti, J. Wildschut, A. Oasmaa, H.J. Heeres, Stabilization of biomassderived pyrolysis oils, Journal of Chemical Technology and Biotechnology 85 (2010) 674-686.

[44] A. Tanksale, Y. Wong, J.N. Beltramini, G.Q. Lu, Hydrogen generation from liquid phase catalytic reforming of sugar solutions using metal-supported catalysts, International Journal of Hydrogen Energy 32 (2007) 717-724.

[45] Z. Fang, T. Minowa, C. Fang, J.R.L. Smith, H. Inomata, J.A. Kozinski, Catalytic hydrothermal gasification of cellulose and glucose, International Journal of Hydrogen Energy 33 (2008) 981-990. [46] F.D.M. Mercader, P.J.J. Koehorst, H.J. Heeres, S.R.A. Kersten, J.A. Hogendoorn, Competition between hydrotreating and polymerization reactions during pyrolysis oil hydrodeoxygenation, AIChE Journal 57 (2011) 3160-3170.

[47] P.A. Lazaridis, S. Karakoulia, A. Delimitis, S.M. Coman, V.I. Parvulescu, K.S. Triantafyllidis, D-Glucose hydrogenation/hydrogenolysis reactions on noble metal (Ru, Pt)/activated carbon supported catalysts, Catalysis Today 257 (2015) 281-290.

[48] M. Makkee, A.P.G. Kieboom, H. van Bekkum, Hydrogenation of d-fructose and d-fructose/dglucose mixtures, Carbohydrate Research 138 (1985) 225-236.

[49] B. Kusserow, S. Schimpf, P. Claus, Hydrogenation of Glucose to Sorbitol over Nickel and Ruthenium Catalysts, Advanced Synthesis and Catalysis 345 (2003) 289-299.

[50] J. Wisnlak, R. Simon, Hydrogenation of Glucose, Fructose, and Their Mixtures, Industrial \& Engineering Chemistry Product Research and Development 18 (1979) 50-57.

[51] B.W. Hoffer, E. Crezee, F. Devred, P.R.M. Mooijman, W.G. Sloof, P.J. Kooyman, A.D. van Langeveld, F. Kapteijn, J.A. Moulijn, The role of the active phase of Raney-type Ni catalysts in the selective hydrogenation of d-glucose to d-sorbitol, Applied Catalysis A: General 253 (2003) 437-452.

[52] E. Crezee, B.W. Hoffer, R.J. Berger, M. Makkee, F. Kapteijn, J.A. Moulijn, Three-phase hydrogenation of D-glucose over a carbon supported ruthenium catalyst - Mass transfer and kinetics, Applied Catalysis A: General 251 (2003) 1-17.

[53] A.W. Heinen, J.A. Peters, H. Van Bekkum, Hydrogenation of fructose on Ru/C catalysts, Carbohydrate Research 328 (2000) 449-457.

[54] J.P. Mikkola, T. Salmi, R. Sjöholm, Modelling of kinetics and mass transfer in the hydrogenation of xylose over Raney nickel catalyst, Journal of Chemical Technology and Biotechnology 74 (1999) 655-662.

[55] D.K. Mishra, A.A. Dabbawala, J.-S. Hwang, Ruthenium nanoparticles supported on zeolite Y as an efficient catalyst for selective hydrogenation of xylose to xylitol, Journal of Molecular Catalysis A: Chemical 376 (2013) 63-70.

[56] K.L. Deutsch, D.G. Lahr, B.H. Shanks, Probing the ruthenium-catalyzed higher polyol hydrogenolysis reaction through the use of stereoisomers, Green Chemistry 14 (2012) 1635-1642. 
[57] K. Wang, M.C. Hawley, T.D. Furney, Mechanism Study of Sugar and Sugar Alcohol Hydrogenolysis Using 1,3-Diol Model Compounds, Industrial \& Engineering Chemistry Research 34 (1995) 37663770.

[58] D.G. Lahr, B.H. Shanks, Kinetic Analysis of the Hydrogenolysis of Lower Polyhydric Alcohols: Glycerol to Glycols, Industrial \& Engineering Chemistry Research 42 (2003) 5467-5472.

[59] X. Guo, X. Wang, J. Guan, X. Chen, Z. Qin, X. Mu, M. Xian, Selective hydrogenation of D-glucose to D-sorbitol over Ru/ZSM-5 catalysts, Cuihua Xuebao/Chinese Journal of Catalysis 35 (2014) 733-740. [60] P. Gallezot, N. Nicolaus, G. Flèche, P. Fuertes, A. Perrard, Glucose hydrogenation on ruthenium catalysts in a trickle-bed reactor, Journal of Catalysis 180 (1998) 51-55.

[61] R. Geyer, P. Kraak, A. Pachulski, R. Schödel, New catalysts for the hydrogenation of glucose to sorbitol, Chemie-Ingenieur-Technik 84 (2012) 513-516.

[62] P.H. Brahme, L.K. Doralswamy, Modelling of a Slurry Reaction. Hydrogenation of Glucose on Raney Nickel, Industrial and Engineering Chemistry Process Design and Development 15 (1976) 130-137.

[63] N. Déchamp, A. Gamez, A. Perrard, P. Gallezot, Kinetics of glucose hydrogenation in a trickle-bed reactor, Catalysis Today 24 (1995) 29-34.

[64] J. Wisniak, M. Hershkowitz, R. Leibowitz, S. Stein, Hydrogenation of Xylose to Xylitol, Industrial and Engineering Chemistry Product Research and Development 13 (1974) 75-79.

[65] A.M. Ruppert, K. Weinberg, R. Palkovits, Hydrogenolysis Goes Bio: From Carbohydrates and Sugar Alcohols to Platform Chemicals, Angewandte Chemie International Edition 51 (2012) 25642601.

[66] S. Kühnel, H.A. Schols, H. Gruppen, Aiming for the complete utilization of sugar-beet pulp: Examination of the effects of mild acid and hydrothermal pretreatment followed by enzymatic digestion, Biotechnology for biofuels 4 (2011) 14-14.

[67] M.R. Kosseva, Sources, characterization, and composition of food industry wastes, Food Industry Wastes 2013, pp. 37-60.

[68] G. Carucci, F. Carrasco, K. Trifoni, M. Majone, M. Beccari, Anaerobic digestion of food industry wastes: Effect of codigestion on methane yield, Journal of Environmental Engineering 131 (2005) 1037-1045

[69] D. Arapoglou, T. Varzakas, A. Vlyssides, C. Israilides, Ethanol production from potato peel waste (PPW), Waste Management 30 (2010) 1898-1902.

[70] B.K. Mishra, A. Arora, Lata, Optimization of a biological process for treating potato chips industry wastewater using a mixed culture of Aspergillus foetidus and Aspergillus niger, Bioresource Technology 94 (2004) 9-12.

[71] R. Rajagopal, N.M.C. Saady, M. Torrijos, J.V. Thanikal, Y.T. Hung, Sustainable agro-food industrial 
wastewater treatment using high rate anaerobic process, Water (Switzerland) 5 (2013) 292-311. [72] K. Valta, P. Damala, V. Panaretou, E. Orli, K. Moustakas, M. Loizidou, Review and Assessment of Waste and Wastewater Treatment from Fruits and Vegetables Processing Industries in Greece, Waste and Biomass Valorization 8 (2017) 1629-1648.

[73] C. Amor, M.S. Lucas, A.J. Pirra, J.A. Peres, Treatment of concentrated fruit juice wastewater by the combination of biological and chemical processes, Journal of Environmental Science and Health, Part A 47 (2012) 1809-1817.

[74] A. Tawfik, H. El-Kamah, Treatment of fruit-juice industry wastewater in a two-stage anaerobic hybrid $(A H)$ reactor system followed by a sequencing batch reactor (SBR), Environmental Technology 33 (2012) 429-436.

[75] E. Alkaya, G.N. Demirer, Anaerobic mesophilic co-digestion of sugar-beet processing wastewater and beet-pulp in batch reactors, Renewable Energy 36 (2011) 971-975.

[76] M.C.M. Castoldi, L.D.T. Câmara, D.A.G. Aranda, Kinetic modeling of sucrose hydrogenation in the production of sorbitol and mannitol with ruthenium and nickel-Raney catalysts, Reaction Kinetics and Catalysis Letters 98 (2009) 83-89.

[77] C.M.B.M. Barbosa, E. Falabella, M.J. Mendes, N.M. Lima, C.A.M. Abreu, Kinetic evaluation of hydrogenation of sucrose over ruthenium containing Y zeolites, Reaction Kinetics and Catalysis Letters 68 (1999) 291-298.

[78] L.C.A. Maranhã, F.G. Sales, J.A.F.R. Pereira, C.A.M. Abreu, Kinetic evaluation of polyol production by three-phase catalytic hydrogenation of saccharides, Reaction Kinetics and Catalysis Letters 81 (2004) 169-175.

[79] Y. Sano, N. Yamaguchi, T. Adachi, Mass transfer coefficients for suspended particles in agitated vessels and bubble columns, Journal of Chemical Engineering of Japan 7 (1974) 255-261.

[80] C.R. Wilke, P. Chang, Correlation of diffusion coefficients in dilute solutions, AIChE Journal 1 (1955) 264-270.

[81] H. Furukawa, Y. Kato, Y. Inoue, T. Kato, Y. Tada, S. Hashimoto, Correlation of power consumption for several kinds of mixing impellers, International Journal of Chemical Engineering (2012).

[82] E. Tombari, G. Salvetti, C. Ferrari, G.P. Johari, Kinetics and Thermodynamics of Sucrose Hydrolysis from Real-Time Enthalpy and Heat Capacity Measurements, The Journal of Physical Chemistry B 111 (2007) 496-501.

[83] C.A.M. Abreu, N.M. Lima, A. Zoulalian, Catalytic hydrogenolysis of starch: Kinetic evaluation of selectivity in polyol and monoalcohol formation, Biomass and Bioenergy 9 (1995) 487-492.

[84] B. Blanc, A. Bourrel, P. Gallezot, T. Haas, P. Taylor, Starch-derived polyols for polymer technologies: Preparation by hydrogenolysis on metal catalysts, Green Chemistry 2 (2000) 89-91.

[85] M. Nagamori, T. Funazukuri, Glucose production by hydrolysis of starch under hydrothermal 
conditions, Journal of Chemical Technology and Biotechnology 79 (2004) 229-233.

[86] T. Miyazawa, T. Funazukuri, Polysaccharide Hydrolysis Accelerated by Adding Carbon Dioxide under Hydrothermal Conditions, Biotechnology Progress 21 (2005) 1782-1785.

[87] R.L. Orozco, M.D. Redwood, G.A. Leeke, A. Bahari, R.C.D. Santos, L.E. Macaskie, Hydrothermal hydrolysis of starch with $\mathrm{CO}_{2}$ and detoxification of the hydrolysates with activated carbon for biohydrogen fermentation, International Journal of Hydrogen Energy 37 (2012) 6545-6553.

[88] L. Hartstra, L. Bakker, H.A. van Westen, Hydrogenation of carbohydrates, 1959.

[89] P. Jacobs, H. Hinnekens, Single-step catalytic process for the direct conversion of polysaccharides to polyhydric alcohols, 1989.

[90] X. Jin, P.S. Thapa, B. Subramaniam, R.V. Chaudhari, Kinetic Modeling of Sorbitol Hydrogenolysis over Bimetallic Ru-Re/C Catalyst, ACS Sustainable Chemistry \& Engineering 4 (2016) 6037-6047.

[91] A.L. Woiciechowski, S. Nitsche, A. Pandey, C.R. Soccol, Acid and enzymatic hydrolysis to recover reducing sugars from cassava bagasse: An economic study, Brazilian Archives of Biology and Technology 45 (2002) 393-400.

[92] P. Lenihan, A. Orozco, E. O'Neill, M.N.M. Ahmad, D.W. Rooney, G.M. Walker, Dilute acid hydrolysis of lignocellulosic biomass, Chemical Engineering Journal 156 (2010) 395-403.

[93] A.A. Modenbach, S.E. Nokes, Enzymatic hydrolysis of biomass at high-solids loadings - A review, Biomass and Bioenergy 56 (2013) 526-544.

[94] R. Chamy, A. Illanes, G. Aroca, L. Nuñez, Acid hydrolysis of sugar beet pulp as pretreatment for fermentation, Bioresource Technology 50 (1994) 149-152.

[95] N. Maravić, Z. Šereš, S. Vidović, A. Mišan, I. Milovanović, R. Radosavljević, B. Pavlić, Subcritical water hydrolysis of sugar beet pulp towards production of monosaccharide fraction, Industrial Crops and Products 115 (2018) 32-39.

[96] B.L. Foster, B.E. Dale, J.B. Doran-Peterson, Enzymatic hydrolysis of ammonia-treated sugar beet pulp, Applied Biochemistry and Biotechnology - Part A Enzyme Engineering and Biotechnology 9193 (2001) 269-282.

[97] Y. Zheng, Y.S. Cheng, C. Yu, R. Zhang, B.M. Jenkins, J.S. VanderGheynst, Improving the efficiency of enzyme utilization for sugar beet pulp hydrolysis, Bioprocess and Biosystems Engineering 35 (2012) 1531-1539.

[98] D. Lachos-Perez, A.B. Brown, A. Mudhoo, J. Martinez, M.T. Timko, M.A. Rostagno, T. ForsterCarneiro, Applications of subcritical and supercritical water conditions for extraction, hydrolysis, gasification, and carbonization of biomass: A critical review, Biofuel Research Journal 4 (2017) 611626.

[99] J.N. Chheda, G. Huber, J.A. Dumesic, Liquid-Phase Catalytic Processing of Biomass-Derived Oxygenated Hydrocarbons to Fuels and Chemicals, Angewandte Chemie International Edition 46 
(2007) 7164-7183.

[100] V. Dal Santo, A. Gallo, A. Naldoni, M. Guidotti, R. Psaro, Bimetallic heterogeneous catalysts for hydrogen production, Catalysis Today 197 (2012) 190-205.

[101] D. Castello, A. Kruse, L. Fiori, Biomass gasification in supercritical and subcritical water: The effect of the reactor material, Chemical Engineering Journal 228 (2013) 535-544.

[102] Y. Guo, S.Z. Wang, D.H. Xu, Y.M. Gong, H.H. Ma, X.Y. Tang, Review of catalytic supercritical water gasification for hydrogen production from biomass, Renewable and Sustainable Energy Reviews 14 (2010) 334-343.

[103] L.I. Godina, A.V. Kirilin, A.V. Tokarev, D.Y. Murzin, Aqueous Phase Reforming of Industrially Relevant Sugar Alcohols with Different Chiralities, ACS Catalysis 5 (2015) 2989-3005.

[104] A. Tanksale, J.N. Beltramini, G.Q. Lu, Reaction mechanisms for renewable hydrogen from liquid phase reforming of sugar compounds, Developments in Chemical Engineering and Mineral Processing 14 (2006) 9-18.

[105] B.M. Kabyemela, T. Adschiri, R.M. Malaluan, K. Arai, Glucose and Fructose Decomposition in Subcritical and Supercritical Water: Detailed Reaction Pathway, Mechanisms, and Kinetics, Industrial \& Engineering Chemistry Research 38 (1999) 2888-2895.

[106] T. Madenoglu, N. Cengiz, M. Saglam, M. Yüksel, L. Ballice, Catalytic Gasification of Mannose for Hydrogen Production in Near- and Super-Critical Water, 2016.

[107] R.R. Davda, J.A. Dumesic, Renewable hydrogen by aqueous-phase reforming of glucose, Chemical Communications 10 (2004) 36-37.

[108] A.V. Kirilin, A.V. Tokarev, E.V. Murzina, L.M. Kustov, J.-P. Mikkola, D.Y. Murzin, Reaction Products and Transformations of Intermediates in the Aqueous-Phase Reforming of Sorbitol, ChemSusChem 3 (2010) 708-718.

[109] G. Huber, R. D Cortright, J. A Dumesic, Renewable Alkanes by Aqueous-Phase Reforming of Biomass-Derived Oxygenates, 2004.

[110] L.L.L. Vilcocq, Transformation of sorbitol to biofuels by heterogeneous catalysis: Chemical and industrial considerations / Transformation du sorbitol en biocarburants par catalyse hétérogène: Considerations chimiques et industrielles, Oil and Gas Science and Technology 68 (2013) 841-860. [111] F. Aiouache, L. McAleer, Q. Gan, A.a.H. Al-Muhtaseb, M.N. Ahmad, Path lumping kinetic model for aqueous phase reforming of sorbitol, Applied Catalysis A: General 466 (2013) 240-255.

[112] A. Kirilin, J. Wärnå, A. Tokarev, D.Y. Murzin, Kinetic Modeling of Sorbitol Aqueous-Phase Reforming over Pt/Al203, Industrial \& Engineering Chemistry Research 53 (2014) 4580-4588.

[113] R.M. Ravenelle, J.R. Copeland, A.H. Van Pelt, J.C. Crittenden, C. Sievers, Stability of Pt/ $\gamma$-Al 203 catalysts in model biomass solutions, Topics in Catalysis 55 (2012) 162-174.

[114] D.M. Alonso, S.G. Wettstein, J.A. Dumesic, Bimetallic catalysts for upgrading of biomass to fuels 
and chemicals, Chemical Society Reviews 41 (2012) 8075-8098.

[115] M.F. Neira D'Angelo, V. Ordomsky, J.C. Schouten, J. van der Schaaf, T.A. Nijhuis, Carbon-Coated Ceramic Membrane Reactor for the Production of Hydrogen by Aqueous-Phase Reforming of Sorbitol, ChemSusChem 7 (2014) 2007-2015.

[116] M.F. Neira D'Angelo, V. Ordomsky, J. van der Schaaf, J.C. Schouten, T.A. Nijhuis, Aqueous phase reforming in a microchannel reactor: the effect of mass transfer on hydrogen selectivity, Catalysis Science \& Technology 3 (2013) 2834-2842.

[117] K. Koichumanova, A.K.K. Vikla, D.J.M. De Vlieger, K. Seshan, B.L. Mojet, L. Lefferts, Towards stable catalysts for aqueous phase conversion of ethylene glycol for renewable hydrogen, ChemSusChem 6 (2013) 1717-1723.

[118] J.W. Shabaker, R.R. Davda, G.W. Huber, R.D. Cortright, J.A. Dumesic, Aqueous-phase reforming of methanol and ethylene glycol over alumina-supported platinum catalysts, Journal of Catalysis 215 (2003) 344-352.

[119] R. Mohamad, T. Aki, Y. Nakashimada, Y. Okamura, T. Tajima, Y. Matsumura, Kinetics of Sorbitol Decomposition under Hydrothermal Condition, 2016.

[120] M.F. Neira D'Angelo, V. Ordomsky, J. van der Schaaf, J.C. Schouten, T.A. Nijhuis, Continuous hydrogen stripping during aqueous phase reforming of sorbitol in a washcoated microchannel reactor with a Pt-Ru bimetallic catalyst, International Journal of Hydrogen Energy 39 (2014) 18069-18076.

[121] J.A. Cusumano, G.W. Dembinski,J.H. Sinfelt, Chemisorption and catalytic properties of supported platinum, Journal of Catalysis 5 (1966) 471-475.

[122] V. Meille, N. Pestre, P. Fongarland, C. de Bellefon, Gas/Liquid Mass Transfer in Small Laboratory Batch Reactors: Comparison of Methods, Industrial \& Engineering Chemistry Research 43 (2004) 924-927.

[123] F. Larachi, L. Belfares, I. Iliuta, B.P.A. Grandjean, Heat and Mass Transfer in Cocurrent GasLiquid Packed Beds. Analysis, Recommendations, and New Correlations, Industrial \& Engineering Chemistry Research 42 (2003) 222-242.

[124] H.A. Duarte, M.E. Sad, C.R. Apesteguía, Aqueous phase reforming of sorbitol on Pt/Al $\mathrm{O}_{3}$ : Effect of metal loading and reaction conditions on $\mathrm{H}_{2}$ productivity, International Journal of Hydrogen Energy 41 (2016) 17290-17296.

[125] S.V. Jadhav, V.G. Pangarkar, Solid-liquid mass trasnfer in packed bubble columns, Chemical Engineering Science 45 (1990) 1139-1143.

[126] E.J. Molga, K.R. Westerterp, Gas-Liquid Interfacial Area and Holdup in a Cocurrent Upflow Packed Bed Bubble Column Reactor at Elevated Pressures, Industrial \& Engineering Chemistry Research 36 (1997) 622-631. 
[127] F. Larachi, A. Laurent, N. Midoux, G. Wild, Experimental study of a trickle-bed reactor operating at high pressure: two-phase pressure drop and liquid saturation, Chemical Engineering Science 46 (1991) 1233-1246.

[128] P.B. Weisz, C.D. Prater, Interpretation of Measurements in Experimental Catalysis, Advances in Catalysis, 1954, pp. 143-196.

[129] Hydrogen and Deuterium, in: C.L. Young (Ed.) Solubility Data Series, Pergamon Press, UK, 1981.

[130] Z. Duan, R. Sun, An improved model calculating CO2 solubility in pure water and aqueous NaCl solutions from 273 to 533 K and from 0 to 2000 bar, Chemical Geology 193 (2003) 257-271.

[131] Methane, in: H.L. Clever, C.L. Young (Eds.) Solubility Data Series, Pergamon Press, UK, 1987.

[132] C. He, C.-L. Chen, A. Giannis, Y. Yang, J.-Y. Wang, Hydrothermal gasification of sewage sludge and model compounds for renewable hydrogen production: A review, Renewable and Sustainable Energy Reviews 39 (2014) 1127-1142.

[133] R.D. Cortright, Synthesis of liquid fuels and chemicals from oxygenated hydrocarbons, United States Patent Application PublicationUSA, 2008.

[134] A.F.v. Nieuwenhuijzen, M. Havekes, B.A. Reitsma, P.d. Jong, Wastewater Treatment Plant Amsterdam West: New, Large, High-Tech and Sustainable, London, UK, 2006.

[135] P. Azadi, R. Farnood, Review of heterogeneous catalysts for sub- and supercritical water gasification of biomass and wastes, International Journal of Hydrogen Energy 36 (2011) 9529-9541. [136] M. Walker, Y. Zhang, S. Heaven, C. Banks, Potential errors in the quantitative evaluation of biogas production in anaerobic digestion processes, Bioresource Technology 100 (2009) 6339-6346. [137] E.L. Kunkes, D.A. Simonetti, J.A. Dumesic, W.D. Pyrz, L.E. Murillo, J.G. Chen, D.J. Buttrey, The role of rhenium in the conversion of glycerol to synthesis gas over carbon supported platinum-rhenium catalysts, Journal of Catalysis 260 (2008) 164-177.

[138] A.C.C. Chang, R.F. Louh, D. Wong, J. Tseng, Y.S. Lee, Hydrogen production by aqueous-phase biomass reforming over carbon textile supported Pt-Ru bimetallic catalysts, International Journal of Hydrogen Energy 36 (2011) 8794-8799.

[139] L.I. Godina, A.V. Kirilin, A.V. Tokarev, I.L. Simakova, D.Y. Murzin, Sibunit-Supported Mono- and Bimetallic Catalysts Used in Aqueous-Phase Reforming of Xylitol, Industrial \& Engineering Chemistry Research 57 (2018) 2050-2067.

[140] M.F. NeiraD'Angelo, V. Ordomsky, J. Van Der Schaaf, J.C. Schouten, T.A. Nijhuis, Selective production of methane from aqueous biocarbohydrate streams over a mixture of platinum and ruthenium catalysts, ChemSusChem 7 (2014) 627-630.

[141] V.R. Paida, D.W.F. Brilman, S.R.A. Kersten, Hydrothermal gasification of sorbitol: $\mathrm{H}_{2}$ optimisation at high carbon gasification efficiencies, Chemical Engineering Journal 358 (2019) 351-361. 
[142] D.C. Elliott, G.G. Neuenschwander, T.R. Hart, Combined hydrothermal liquefaction and catalytic hydrothermal gasification system and process for conversion of biomass feedstocks, Battelle Memorial Institute, USA, 2017.

[143] T.W. Kim, M.C. Kim, Y.C. Yang, J.R. Kim, S.Y. Jeong, C.U. Kim, Hydrogen production via the aqueous phase reforming of polyols over CMK-9 mesoporous carbon supported platinum catalysts, International Journal of Hydrogen Energy 40 (2015) 15236-15243.

[144] A. Tanksale, J.N. Beltramini, J.A. Dumesic, G.Q. Lu, Effect of Pt and Pd promoter on Ni supported catalysts-A TPR/TPO/TPD and microcalorimetry study, Journal of Catalysis 258 (2008) 366-377.

[145] D.C. Elliott, G.G. Neuenschwander, T.R. Hart, L.J. Rotness Jr, A.H. Zacher, D.M. Santosa, C. Valkenburg, S.B. Jones, S.A. Tjokro Rahardjo, Catalytic Hydrothermal Gasification of Lignin-Rich Biorefinery Residues and Algae, Pacific Northwest National Laboratory, 2009.

[146] A. Kruse, Hydrothermal biomass gasification, Journal of Supercritical Fluids 47 (2009) 391399.

[147] M.S. Peters, K.D. Timmerhaus, R.E. West, Plant Design and Economics for Chemical Engineers, Fifth ed., McGraw-Hill, New York, 1980.

[148] W.D. Seider, J.D. Seader, D.R. Lewin, S. Widagdo, Product and Process Design Principles: Synthesis, Analysis and Evaluation, Third ed., John Wiley \& Sons, Inc.2008.

[149] R. Davis, L. Tao, C. Scarlata, E.C.D. Tan, J. Ross, J. Lukas, D. Sexton, Process Design and Economics for the conversion of lignocellulosic biomass to hydrocarbons, National Renewable Energy Laboratory, 2015.

[150] J.A.M. Withag, J.R. Smeets, E.A. Bramer, G. Brem, System model for gasification of biomass model compounds in supercritical water - A thermodynamic analysis, The Journal of Supercritical Fluids 61 (2012) 157-166.

[151] K.R. Westerterp, E.J. Molga, K.B. van Gelder, Catalytic hydrogenation reactors for the fine chemicals industries. Their design and operation, Chemical Engineering and Processing: Process Intensification 36 (1997) 17-27.

[152] F. Gallucci, A. Basile, F.I. Hai, Introduction - A Review of Membrane Reactors, Membranes for Membrane Reactors: Preparation, Optimization and Selection (2011) 1-61.

[153] M.F.N. D'Angelo, V. Ordomsky, J.C. Schouten, J. Van Der Schaaf, T.A. Nijhuis, Carbon-coated ceramic membrane reactor for the production of hydrogen by aqueous-phase reforming of sorbitol, ChemSusChem 7 (2014) 2007-2015.

[154] R.M. Ripken, J. Meuldijk, J.G.E. Gardeniers, S. Le Gac, Influence of the Water Phase State on the Thermodynamics of Aqueous-Phase Reforming for Hydrogen Production, ChemSusChem 10 (2017) 4909-4913.

[155] A.A. Plazaola, D.A.P. Tanaka, M. Van Sint Annaland, F. Gallucci, Recent advances in Pd-based 
membranes for membrane reactors, Molecules 22 (2017).

[156] S. Adhikari, S. Fernando, Hydrogen membrane separation techniques, Industrial and Engineering Chemistry Research 45 (2006) 875-881.

[157] S. Peramanu, B.G. Cox, B.B. Pruden, Economics of hydrogen recovery processes for the purification of hydroprocessor purge and off-gases, International Journal of Hydrogen Energy 24 (1999) 405-424.

[158] S. Jones, Y. Zhu, D. Anderson, R. J. Hallen, D. Elliott, A. Schmidt, K. Albrecht, T. Hart, M. Butcher, C. Drennan, L. Snowden-Swan, R. Davis, C. Kinchin, Process Design and Economics for the Conversion of Algal Biomass to Hydrocarbons: Whole Algae Hydrothermal Liquefaction and Upgrading, Pacific Northwest National Laboratory, 2014.

[159] J. Matthey, Precious Metals Management, 2018.

[160] P. Lee, E. Sims, O. Bertham, H. Symington, N. Bell, L. Pfaltzgraff, P. Sjögren, H. Wilts, M. O'Brien, Towards a circular economy - Waste management in the EU, European Parliamentary Research Service, 2017.

[161] D. Hogg, Costs for Municipal Waste Management in the EU, Eunomia Research \& Consulting, 2002.

[162] D.J.M. De Vlieger, B.L. Mojet, L. Lefferts, K. Seshan, Aqueous Phase Reforming of ethylene glycol - Role of intermediates in catalyst performance, Journal of Catalysis 292 (2012) 239-245.

[163] InfoMine, Mining markets, 2018.

[164] L.K. Wang, Y.T. Hung, H.H. Lo, C. Yapijakis, Waste treatment in the food processing industry, CRC Press Inc., Boca Raton, 2005.

[165] R. Łukajtis, I. Hołowacz, K. Kucharska, M. Glinka, P. Rybarczyk, A. Przyjazny, M. Kamiński, Hydrogen production from biomass using dark fermentation, Renewable and Sustainable Energy Reviews 91 (2018) 665-694.

[166] K. Urbaniec, R.R. Bakker, Biomass residues as raw material for dark hydrogen fermentation - A review, International Journal of Hydrogen Energy 40 (2015) 3648-3658.

[167] J. Akinbomi, M.J. Taherzadeh, Evaluation of fermentative hydrogen production from single and mixed fruit wastes, Energies 8 (2015) 4253-4272.

[168] Y.K. Salkuyeh, B.A. Saville, H.L. MacLean, Techno-economic analysis and life cycle assessment of hydrogen production from different biomass gasification processes, International Journal of Hydrogen Energy 43 (2018) 9514-9528.

[169] S. Achinas, V. Achinas, G.J.W. Euverink, A Technological Overview of Biogas Production from Biowaste, Engineering 3 (2017) 299-307.

[170] T. Guo, J. Englehardt, T. Wu, Review of cost versus scale: Water and wastewater treatment and reuse processes, Water Science and Technology 69 (2014) 223-234. 
[171] W. Short, D.J. Packey, T. Holt, A Manual for the Economic Evaluation and Energy Efficiency and Renewable Energy Technologies, National Renewable Energy Laboratory, 1995.

[172] A Clean Planet for all: A European strategic long-term vision for a prosperous, modern, competitive and climate neutral economy, European Commission, 2018.

[173] J. Gigler, M. Weeda, Outlines of a hydrogen roadmap, TKI Nieuw Gas - TOpsector Energie, 2018. [174] EU Energy, transport and GHG emissions - Trends to 2050, European Commission, 2013.

[175] T.P.T. Pham, R. Kaushik, G.K. Parshetti, R. Mahmood, R. Balasubramanian, Food waste-toenergy conversion technologies: Current status and future directions, Waste Management 38 (2015) 399-408.

[176] The role of waste-to-energy in the circular economy, European Commission, 2017.

[177] Sugar: World Markets and Trade, United States Department of Agriculture, 2018.

[178] The end of the sugar production quotas in the EU, European Commission, 2017.

[179] Long-term stability of the European sugar sector after 2015, Suiker Unie, 2014.

[180] E. Içöz, K. Mehmet Tuğrul, A. Saral, E. Içöz, Research on ethanol production and use from sugar beet in Turkey, Biomass and Bioenergy 33 (2009) 1-7.

[181] T.A. Maung, C.R. Gustafson, The economic feasibility of sugar beet biofuel production in central North Dakota, Biomass and Bioenergy 35 (2011) 3737-3747.

[182] L. Panella, Sugar Beet as an Energy Crop, Sugar Tech 12 (2010) 288-293.

[183] G. Zhu, C. Liu, J. Li, N. Ren, L. Liu, X. Huang, Fermentative hydrogen production from beet sugar factory wastewater treatment in a continuous stirred tank reactor using anaerobic mixed consortia, Frontiers of Environmental Science and Engineering in China 7 (2013) 143-150.

[184] J. Tomaszewska, D. Bieliński, M. Binczarski, J. Berlowska, P. Dziugan, J. Piotrowski, A. Stanishevsky, I.A. Witońska, Products of sugar beet processing as raw materials for chemicals and biodegradable polymers, RSC Advances 8 (2018) 3161-3177.

[185] R. Grabarczyk, K. Urbaniec, E. Koukios, R. Bakker, G. Vaccari, Options of sugar beet pretreatment for hydrogen fermentation, Zuckerindustrie 136 (2011) 784-790.

[186] K. Urbaniec, R. Grabarczyk, Techno-economic assessment of the fermentative hydrogen production from sugar beet, CHISA 2012 - 20th International Congress of Chemical and Process Engineering and PRES 2012 - 15th Conference PRES, 2012.

[187] J.A. Panagiotopoulos, R.R. Bakker, T. De Vrije, K. Urbaniec, E.G. Koukios, P.A.M. Claassen, Prospects of utilization of sugar beet carbohydrates for biological hydrogen production in the EU, Journal of Cleaner Production 18 (2010) S9-S14.

[188] Y.-T. Hung, H.H. Lo, A. Awad, H. Salman, Potato Wastewater Treatment, Waste Treatment in the Food Processing Industry, CRC press - Taylor \& Francis Group2005.

[189] D.A. Sievers, J.J. Stickel, N.J. Grundl, L. Tao, Technical Performance and Economic Evaluation 
of Evaporative and Membrane-Based Concentration for Biomass-Derived Sugars, Industrial and Engineering Chemistry Research 56 (2017) 11584-11592.

[190] Estimates of European food waste levels, European Commission, 2016. 


\section{Publications}

Paida V.R., Brilman D.W.F., Kersten S.R.A., Hydrothermal gasification of sorbitol: $\mathrm{H}_{2}$ optimisation at high carbon gasification efficiencies. Chemical Engineering Journal. 2019;358:351-361. https:// doi.org/10.1016/j.cej.2018.10.008.

Paida V.R., Kersten S.R.A., Brilman D.W.F., Hydrothermal gasification of sucrose. Biomass and Bioenergy. 2019;126:130-141. https://doi.org/10.1016/j.biombioe.2019.05.013.

Paida V.R., Kersten S.R.A., van der Ham A.G.J., Brilman D.W.F., A two-step approach to the hydrothermal gasification of carbohydrate rich-wastes: Process design and Economic Evaluation. 2019; (submitted)

\section{Conference proceedings}

Paida V.R., Brilman D.W.F., A novel process for the complete gasification of sucrose. Proceedings of the 26th European Biomass Conference and Exhibition, 14th - 18th May 2018, Copenhagen, Denmark

\section{Conference oral presentations}

European Biomass Conference and Exhibition, 26th edition, 14th - 18th May 2018, Copenhagen, Denmark.

Netherlands Process Technology Symposium, 15th edition, 30th - 31st May 2018, Enschede, the Netherlands. 


\section{Acknowledgment}

This thesis describes the technical results of four years of research work. The path towards achieving these results has been one of the most trying and fulfilling life experiences; one that I could not have gone through alone.

Firstly, to my parents, for making numerous sacrifices in their lives to provide their children with the best opportunities. Ma, thank you for your idealistic faith in your children's abilities to change the world! These past four years, thank you for showing so much interest in my work. From reading my abstracts to following that up with innumerable questions, you helped put things in perspective and made me feel invaluable when I most needed it. Pa, thank you for your philosophical anecdotes, for making me laugh, for enjoying food as much as I do and thereby making me look like less of a glutton when you're around, for sharing great music and for reminding me in your own ways that there is more to life than work. It has been great comfort to me that you both could visit every year these past few years.

To my supervisors Sascha Kersten and Wim Brilman, for the opportunity to pursue my PhD in the SPT group. Sascha, thank you for your guidance and for helping me improve the quality of my work. I learnt a lot from you, particularly the importance of statistics in modelling. Wim, thank you for your creative ideas that have led to some very interesting graphs in this thesis, for always having your door open and for your support during the trials and tribulations involved in fixing the continuous experimental setup. You have always stressed the importance of me being my own supervisor. While that seemed daunting at first, it boosted my confidence and helped me become a more independent researcher.

Special thanks to Louis van der Ham for his guidance on the process design and economics, and to Boelo Schuur for introducing me to the SPT group.

To the dissertation committee, for accepting the invitation and reading my thesis. I look forward to having a fruitful discussion with you on the $12^{\text {th }}$ of July. Special thanks to Seshan for introducing me to catalysts in aqueous phase reforming and for his kindness and encouragement during the early stages of my PhD.

To the staff of the SPT group, for all the support these past few years. Benno, Johan and Karst, thank you for all your help with the setups, for frikandel Wednesdays, for helping me practice my Dutch and for making the high pressure lab a fun environment to work in. Erna, thank you for your help with the analytical equipment in Meander. Yvonne, thank you for all your help with the certificates and forms, and for chatting with me in Dutch even though it took twice as long! To my students Martijn, Sander, Stijn, Deden, Ruben and Hans, for their contributions. I enjoyed working with you and hope you did too!

To two of my dear friends and colleagues, Martin and Juraj, whom I'm honoured to have as 
paranymphs. Martin, thank you for spending hours getting the GC to work and even more hours maintaining or fixing it! I enjoyed travelling to Florence with you for the ISCRE conference and will not forget all the blunders on that trip (setting off the room's alarm by mistaking it for the bathroom light and losing the posters)! It was nice to share the experience of finishing a PhD with you. Thank you for the good conversations, for sharing my appetite for food, and for being someone I could depend on. Like you once said (perhaps joked), I'm still counting on you to convince Roger Federer to attend my defence party! Juraj, I'm so glad you joined the SPT group. You have a gift of being a great conversationalist, which made it so easy for us to talk about nearly everything under the sun. Our email exchanges with music recommendations during the last few months were a respite from the monotonous writing days. Thank you for being a good sport and for making me laugh. A big thanks to you and Miska for the fun board game evenings and dinners we've shared.

The biggest perks of working at SPT were my colleagues, some of whom have become good friends. Surika, I'm so grateful for our friendship. Our bi-weekly squash sessions were good fun, great exercise, and helped clear my mind. Thank you for being a listener when I needed to vent, and for making our trip to SA so special by welcoming us to your home. I thoroughly enjoyed carpooling with you and Vincent. Your fight or flight response to an elephant approaching us was to close your passenger seat window and that still makes me laugh! Vincent, I'm glad we got to share a thrilling experience as we jumped off the Bloukrans bridge one after another. Thanks for being a great driver and for being extremely calm when I reminded you that you were driving on the wrong side of the road! Pushkar and Prachi, thank you for being my reminder of home away from home, for inviting me to a very special wedding where everybody thought I was the travel agent for a group of Dutch people! Lisette, I admire your passion for running and wish you much success for your future marathon. Thanks for clearing all my Dutch grammar doubts! Rick, I respect how you're never afraid to speak your mind. That's one of the many qualities I have tried to learn from you. Thimo, it was nice to have a colleague to discuss both biomass research and Formula One with, thanks! To Thomas, Gerardo, Chiel, Dion and Fred, thanks for the enjoyable company that made the trips to India and SA worthwhile!

To my former colleagues and friends, who made life in Enschede enjoyable. Sam, you are one of the most open-minded people I know. I'm thankful that our friendship has lasted even after you left the group to one of the most remote places in the Netherlands! Ehsan, I'm excited that we will be living a lot closer and can continue our board game evenings, movies, dinners and my failed attempts at playing on the PS4. You were a great neighbour to have in the office. Maria, thank you for teaching me how to use the batch autoclave, the elemental analyser and the micro-GC. I wish you and Roger much happiness in Spain and success with the games. Stijn, for teaching me the 
tips and tricks of working with a bench-scale setup, for introducing me to kickboxing which was a great stress-reliever, for the amazing dinners and whiskeys, and for the good times at concerts, thank you! Marek, thank you for making me laugh with your sarcasm, and for introducing me to tatratea. Natalia and Maiju, thanks for making girls night so much fun. I look forward to our trip to Krakow, and based on past experience with you two, I hope to remember the trip as well! In the past few years I have met many wonderful people in the Netherlands who I'm honoured to now call my dear friends. Kaisa, I am so glad we met. Thank you for your kindness these past few years and for introducing me to your APR project when I started my PhD. Pavlina, you and Dmitris are always so much fun to be around. Thank you for inviting me to join your ECN group at the EUBCE conference, although I will never trust your hotel recommendations again! Adithya, it's not every day that I meet someone who I know instantly will be a great friend. Thank you for being a big comfort to me these past few years. I'm glad we got to go through our PhD experiences together. I hope you will take my suggestion of becoming a professional climber seriously. Bob, for being adventurous, loud, and obnoxious at times, thank you! I'm glad to have a friend like you in my life. Tomas, a big thanks to you for your creativity in designing the cover of my thesis. It is beautiful and I'm grateful that you chose to do it. Thank you for always being there and for your continuous faith and support these past few years. Diana, thank you for inviting us to your lovely Cretan wedding, for your humour and optimism.

To friendships that have lasted time and distance, I would like to thank Jack, Matthew, Roshni, Rukmani, Supriya, Priyanka and Adarsh.

To the rest of my family, Keshav \& Anu, Pranav \& Tanu, Thatha \& Nainamma and Paati, for their love and support all these years. Special thanks to my wonderful aunt, Krishna Aunty, for always considering Amsterdam as a stopover on her trips to India. You've always brought so much joy to Shriya and me.

Finally, to my two favourite people, Rens and Shriya. No words can do justice to all the things that I'm thankful for. Rens, thank you, for sticking this out with me and most of all, for going out of your way to make me laugh, especially after a bad day. Shriya, you've been my good luck in life and my rock these past four years. To me, calling you my twin, or sister, or best friend always falls short. Thank you for juggling the roles of a cheerleader, a philosopher and a comforter, depending on my mood. I am so grateful for both of you, and look forward to many more wonderful times together. 
$176 \mid$ 
Temperatures averaged across the globe are rising. They are driven prominently by increasing concentrations of greenhouse gases, that result from our continued use of fossil fuels. Therefore, there is a need for fossil fuels to be replaced by sustainable sources for the production of energy, chemicals and fuels. Biomass, being a renewable source, is a promising feedstock. The work presented in this book focusses on one of the numerous routes for the production of energy from waste biomasses. 